\title{
EDUCATION IN THEORY AND PRACTICE GILBERT H.JONES
}




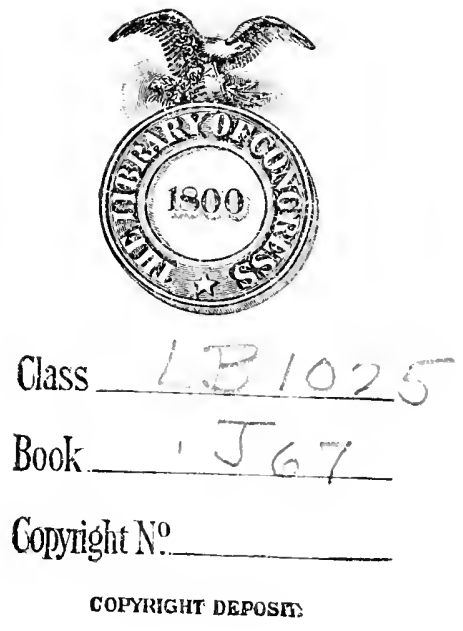





\section{EDUCATION IN THEORY AND PRACTICE}

BY

GILBERT H. JONES, A.M., Ph.D. (Jena)

Professor of Psychology and Education, Wilherforce University

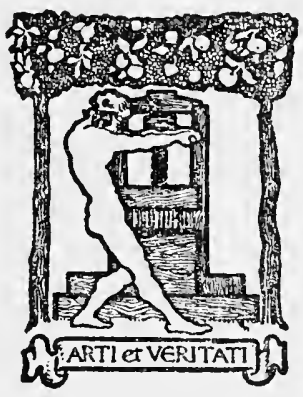

\section{BOSTON \\ RICHARD G. BADGER \\ THE GORHAM PRESS}


Copyright, 1919, by Richard G. Badger

All Rights Reserved
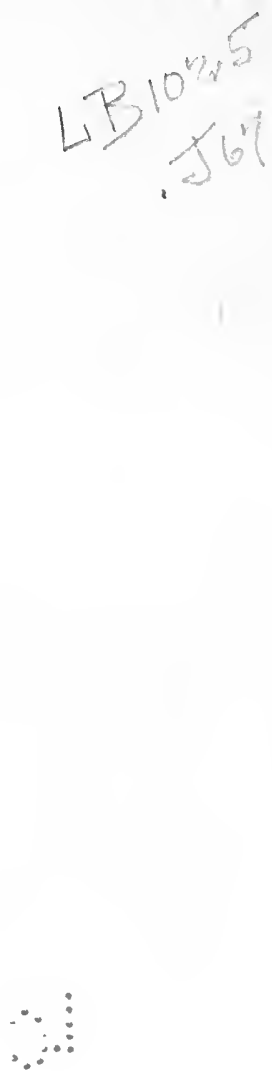

Made in the United States of America

The Gorham Press, Boston, U.S.A.

(3) 0.580083 
THIS BOOK IS DEDICATED

TO

MY BELOVED FATHER

WHOSE LOVE OF TRUTH, AND

UNREMITTING SEARCH FOR

IT, FIRST INSPIRED MY YOUNG

LIFE AND LED ME TO LOVE

STUDY 



\section{FOREWORD}

Books on the subject of Education abound. And because of the relative as well as actual value of the subject whose principles they attempt to expound it is necessary that they abound. It is only by having access to the various view points as advanced by the various authors in their texts that anything like a full understanding of the subject is to be gained. Again students of the subject of education come from every walk of life and prepare themselves for the work in varying degrees. While the author is not ready to assert that the field of education has more unprepared or partially prepared workers in it than other vocations, he knows it to be a fact that it has its full as well as relatively large quota of unprepared or partially prepared workers. For this reason books that would do the most good must be in thought, language, scope and manner of treatment so simple as to be easily within the reach of the less mature and more uninitiated of the group. Because of the slight acquaintance of these young students and workers with the nature and scope of the problems of this their basic science, in a treatise of this kind which is intended to be primary in the sense of introductory, it has been deemed both unnecessary and unwise to give many specific citations and quotations. Especially is this plan desirable since the text does not attempt to be argumentative or analytical but particularly descriptive and explanatory. It is the aim and hope of the author that this little effort to open the field of Education to the beginning and young student will be helpful to him in his struggle to solve the simpler problems of education. In particular does he desire that both the principles discussed and the statements made shall prove to be enlightening in themselves, and which is to him more important that they shall serve to inspire him and create within him a desire for a more advanced, complete and fundamental study of the subject of education 
which is by its nature in scope and relationship one of the grandest and most serviceable fields of human endeavor.

The Author wishes to thank at this time his associates in Educational work for their kindly suggestion and liberal criticism of the manuscripts. Prof. Youngblood and the assistants in the English Department, Prof. Henderson of the Normal Department, and the students of that department who by their work and cooperative study contributed so much to the solutions of various of the problems of education.

Instead of giving many quotations and citations, for reasons given above there have been given only a few chapters for collateral reading at the end of each chapter and a general and more extended bibliography at the end of the book. This it is agreed is more in keeping with the aim and scope of the work, by the reading of which the student will gain a larger insight into the content of the field and be better prepared later to take up a more extended and more thorough as well as more systematic study of the problems of education.

Wilberforce, Ohio, August, 1918. 


\section{CONTENTS}

CHAPTER PAGE

I The Definition, Nature, Scope and RelationShip of Education . . . . . . . . 11

II The Nature and Aim of Education . . . . 30

The Nature and Application of Education - 42

Education as Related to Governmental Insti-

Tutions . . . . . . . . . . . 51

III Kinds of Education . . . . . . . . . . 55

IV The Agencies in Education . . . . . . . 80

V The School . . . . . . . . . . . . 101

Its Location, Environment, Equipment, Heat-

ing, Lighting, Sanitation, Etc. . . . . 101

VI The Sсhоolroom . . . . . . . . . . 125

Its Supervision and Control . . . . . . . 125

VII Discipline . . . . . . . . . . . . 149

VIII Punishments in the School . . . . . . 171

IX Incentives and Stimulants in Education . . . 198

$\mathrm{X}$ Routine and Accessory Duties of the Teacher . 223

I Routine Duties . . . . . . . . 223

II Accessory Duties. . . . . . . . . . 235

XI Instruments of Progress in the Schoolroom . . 248

The Courses of Study and the Daily Program 248

XII Accessories of the Recitation . . . . . . 272

XIII The Hearing of the Recitation . . . . . 295

XIV Psychologic Processes in Education . . . . 318

XV Subsidiary Phases of Education . . . . . 341

XVI Play, Playgrounds, Athletics . . . . . . 367

BibLIOGRAPHY . . . . . . . . . . . 389

INDEX • • . . . . . . . . . . . 393 
; 


\title{
EDUCATION IN THEORY AND PRACTICE
}

\author{
CHAPTER I \\ THE DEFINITION, NATURE, SCOPE AND \\ RELATIONSHIP OF EDUCATION
}

The Nature of a Definition. A formal definition of education that will be acceptable to all or even to a majority of students of a given subject is hardly possible. Yet definitions of every subject abound. But not only do definitions abound, but there is something of the true nature of the subject to be found in each and every attempt at defining it. This is true also of education. A definition aims to mark out and clearly define conceptions of a given subject, individual definitions intending to represent more nearly individual conceptions. The nearer the individual concept approaches the general concept, the nearer will the individual definition be generally accepted and become the more generally used. The individual conception being made up in a way of the total experience of the individual is different for each and every member of the human species. Many definitions seemed to be opposed in the ideas which they convey and some even contradictory, yet they all have the same end in view. The cause of this variety is not difficult to find, nor is it to be deemed a fault or disadvantage but rather an advantage to the truly zealous student. It is traceable to the varied view points of the different authors. They are all looking at the same object from different view points, with minds of various degrees of power, variously cultivated and directed by moral and physical natures, which are themselves susceptible to the control of various interests. The description of the object 
which these definitions give us is without a doubt sincerely and honestly given even though they may seem to be widely divergent. Technically speaking, then, a true, all-comprehensive definition is practically impossible with us. A near approach to it is obtained by unbiasedly selecting from the whole group of given concepts, as found in definitions, that which is essentially true from the different view points and combining it into a harmonious whole, unified and consistent with itself.

What view point an author takes and consequently what he ultimately sees in a given subject is determined chiefly by what he wills to see in it, i.e. his purpose in desiring a definition and the use to which he intends to put that definition when known. For it goes without saying that no human mind is so broad in its grasp, so well balanced in and unyielding to the element of personal bias as to be able to form what to all others would be accepted as a perfect, or in many cases even as a satisfactory definition. The fact is, the moment you read an author's definition you can quite clearly tell the nature of his conception, the trend of his thought and those things in the given subject which he values and those things to which in his treatise he will give the most prominence.

The Definition of Education. Some definitions describe education as a process whether it be continuous throughout life as regarded by some, or as continuous only throughout the school career as such, as regarded by others. Still others limit their definitions of it to the purpose or end of the process as restricted in its application to the individual whether he is conscious of the purpose or end of this process or not. Some again make their definitions practical or utilitarian, while others still would define education in regard to its capacity for fitting the individual for a life with and among his fellows. Another class having the child rather than the matured individual in mind would shape their definitions to him, his particular needs and the processes in education by which these may be best discovered and attained.

a. For those definitions of education which regard education as a process we might quote the following: 
"Education is the process by which one mind forms another and one heart another heart."-Simon.

"Education is any act or process which results in knowledge, or power, or skill." - White.

"Education is the organization of acquired habits of conduct and tendencies to behavior" and "consists in the organizing of resources in the human being of powers of conduct, which shall fit him to his social and physical world." - William James.

"Education is the process of making individual men participants in the best attainments of the human mind, namely in that which is most rational, true, beautiful and good."Wherell.

b. For those definitions which regard education as a purpose or end we quote the following:

"The purpose of education is to give to the body and to the soul all of the beauty and all of the perfection of which they are capable."-Plato.

"The aim of education is the adjustment of the individual to the life in which he must participate."-Ruediger.

"The end of education is to render the individual as much as possible an instrument of happiness, first to himself and next to others."-James Mill.

"The end of education is to permit each individual to attain the most complete development of his body, mind and heart."-Laboulaye.

"A liberal education is an education in which the individual is cultivated not as an instrument toward some ulterior end, but as an end in and to himself alone."- Hamilton.

c. For those definitions which regard education as practical, and fitting a man for a life with his fellows we might quote the following:

"Education is to develop social efficiency in individuals, and this comes through the developing of individual power by means of work in cooperation."-Gilbert.

"Education in the last analysis is the influence of one person upon another."--Scudder.

"Education is the culture which each generation pur- 
posely gives to those who are to be its successors."-John Stuart Mill.

"Education is a preparation for complete living." - Herbert Spencer.

"Education is a living into better things."-Kerr.

"Education can only develop and unfold." - Rosen.kranz.

"The child is the center and end of Education."-Bryan.

"The proper education of to-day is a preparation for the duties and responsibilities of life."-Woodward.

The general view point, purpose and comprehension of these definitions of education are evident. The element of truth which they contain as well as the trend of thought which they convey is also clear. From the author's view point, Education is a process through which individuals go, or are taken (more often the latter) which is intended to fit them for social efficiency, i.c. for an active aggressive life of service among their fellows. It aims to remove from the individual defects with which they are born or through any cause have acquired, and supplant them with the capacity to live harmoniously with their fellows and to share equitably with them the duties and responsibilities as well as the material goods of this life. Its purpose or end is to create for mankind social advantages and opportunities in life by nurture which they could never hope to attain by nature.

Education in its Broad and Narrow Scnse. In the definitions quoted above it was clear that apart from the view points which those definitions represented the term education itself has a two-fold meaning. It has a broad, liberal usage, and a narrow restricted usage. In its broad sense it is applied to any and all experiences and processes by which the contents of the soul life is increased. Looked at from this view point the educational process begins with the earliest prenatal evidences of life and continues till the last signs of conscious life disappear in death. It is a process co-extensive with life itself, and, in the process, the regular routine of school plays as small a part as is the actual fractional portion of life that is spent in the schoolroom. In tho 
broad sense of education the world is the school, mankind the teacher, and life itself the school period.

b. In the narrow sense education applies to those special processes of soul enlargement and mental growth that are carried on under specialized conditions, during special periods of life and by special persons working along specially prescribed lines with a definite end in view. In other words in its narrow sense the term education is used as coextensive with the terms school training, school development and growth. This is the sense applied to the term when people ask the question "how much education have you?" This is also what is meant when one speaks of an educational career, or of an educational institution. Parents who wish their children to get a "good education" or who send them off to school to be "educated," use the term education in this narrow sense. In this sense education is synonymous with the process of school life and begins and ends with it.

Reason of Being of Education. But why do we possess such a concept as education, what has brought it into existence, how is it that it has assumed such colossal proportion in our thought and activity? These are to us potent questions. The reply is, life is one continuous struggle. If we would preserve ourselves, we nust produce and rear off spring, defend ourselves, against the ravages of the forces of the environment both natural and artificial, and against the aggression of our fellows. In order to live we must know both what forces of the environment are favorable, what ones are unfavorable, and how those that are unfavorable may be modified, or where this is not possible how they may be circumvented or destroyed. We must also know what portion of the aggression of our fellows may be overcome, what portion must be modified and what part of it may be successfully circumvented, and in each case how. That is to say we must know how to live in the social relation; how to govern our conduct under all conditions of the environment and under all circumstances arising out of our social relations so as to cause the least amount of friction in and restriction of our individual tendencies to action. This is the 
duty of education, and every system of education is worthy of the name only as it approaches this idea in the results which it achieves. Hence, education is a process of knowledge getting. The more liberal the education the more general and broad will be the knowledge gotten. Society demands of its members that they know and be able to do. It little cares nor long seeks to find out by what process you came to know or by what means you can do. It is content to abide in the fact that you possess the knowledge and along with the possession of it have the power to use it in doing things. Under this demand the modern conception of education has arisen and the new curriculum has been formed, together with the establishment of new systems of schools. To educate is to cause to know what is to be done and how it is to be done. Hence the effort in all systems is directed toward the end, to cause to know. Practical education is the kind of education that meets the popular demand; that kind of an education which shows by results how much it causes one to know and how much it shows one how to do. This is the conception which has created the modern trend toward that technical education, manual training, industrial education, and vocational and commercial education that has swept over those sections of the world peopled by the highly civilized and enlightened races. Schools of applied science, high schools, colleges and universities of technology, manual training and trade schools, agricultural and mechanical colleges and universities all have been instituted by the various state governments of this country and by the national government in other countries under this conception of the meaning and application of the term education and of the best methods of achieving this, in harmony with the aim and end of life, and the value of knowledge in life, and in an education system. The rapid rise and growth as well as the loyal support and large patronage of these schools testify only too clearly to the very unique demand they supply in popular education and how well they meet the present conception of the term. This brings us down to the peculiarity of American education.

The all absorbing demand in American education is results. 
What Americans wish they desire without delay. Parents in sending their children to school wish to see immediately the effects of money and time expended and inconveniences endured to educate their children. Any educational process that fails to show these results is quickly condemned. In order to survive the censure of public opinion and come into its own it must readjust itself to get results, a given system standing or falling by its success in meeting preconceived standards and producing for the state and society educated material of a certain quality and degree of efficiency.

Repetition in Education. However much educational processes may be improved, educational systems advanced, and however much greater efficiency it may attain, its progress and its achievements are limited, or perhaps better, conditioned by one serious but simple fact. Education is a repetitive process. When a highly educated man dies he can bequeath his knowledge by means of the printed page to those who come after him, but his education as a power of achievement to all intents and purposes dies with him. It canuot be passed bodily into the mind of his son or into the minds of succeeding generations. Each generation, both individually and collectively must obtain its education for itself, by the expenditure of its own time and energy. Its knowledge, it is true, does come primarily from that possessed by its ancestors, and indeed, consists chiefly of such knowledge. But whatever of this ancestral store of knowledge each individual gains for himself he must gain it by putting forth his own time and energy, the total amount of knowledge possessed by any people at a given time being made up of his ancestral knowledge aided by that small increment which each generation may wring out of the environing world during its own struggles for existence and during the stage of early life, preparatory for that struggle.

This knowledge which is the result of education is obtained through three sources: namely experience, observation and experiment. The educated must teach the uneducated, the old must teach the young. Socrates taught Plato and Plato in turn taught Aristotle. Herein lies both the fascination and the burden of education. If we could ac- 
quire an education once for all for ourselves and our posterity education as a process would be an easy one and we would all be no doubt highly educated and that too without anything like the waste of time, energy, money and personal application necessary under the present physical and mental structure and social order. But this is not the case, and education is never finished, but each individual is carried only so far. Then when he drops out of the world of life and action, his offspring is taken over the same ground, perhaps a little farther, perhaps not quite so far, each according to his circumstances or condition and according as his mental nature reacts upon and responds to the physical and mental stimuli of the school and of the world about him. Each generation receives its intellectual inheritance (merely a favorable or unfavorable physical basis possessing a potentiality for mind) from the preceding generation, labors to improve upon it, stamps it with the impress of its efforts and acquired knowledge and passes it on down the line to the succeeding generations by training them in its activities and secret intellectual lore. Nothing comes into this life in its finished and perfect form. Everything in the organic and inorganic world, the bee, the flower, the stone, has its moment of beginning, its period of growth and development, its season of flower and fruition, its hour of death and decay and finally its fateful process of dissipation and disintegration. The mental life so far as its earthly existence is concerned in its relations with body, undergoes apparently the same process. Its susceptibility to educational processes and educational influences lies in the fact that it is imperfect from the start in its power of manifestation, but from the beginning one possesses the power of taking on an enlarging form subject to the growth of its place of abode, the body, and to the influence of the environment.

Theory and Practice in Education. The individual who enters upon the task of controlling the manner of growth and lines of development of a living subject without an extended knowledge of the nature of the subject to be controlled and developed, is undoubtedly seriously handicapped at the outset. Whatever other resources either natural or artificial may 
be at hand to solve the difficulties, the problem will still present certain forms of difficulties otherwise practically unsolvable. The problem is very like one that for instance would confront a farmer who was trying to raise a certain kind of plant from the seed without knowing anything about the nature of the seed, what physical conditions are favorable to its germination and growth, into what kind of soil it should be planted or what kind of care and attention are necessary for its continued growth and final flowering and fruition. Perhaps a still better case for illustration would be that of a man attempting to feed, care for and raise animals without knowing what kind of food they may best eat, how the eating of various foods will effect them, in what quantities and after the lapse of what intervals of time the feeding should be repeated and how it should be " mixed" or "changed" so as to produce the best results in normal healthy growth and development. The same dire results that would arise in either of these cases to the object undergoing the experience will attend the like experience in the case of the object experiencing the mental process. Only with this noteworthy exception in the case of the supervision and care of the mind, namely that by its very nature and subtlety mind presents problems in and of itself that require a distinct and separate consideration and study. It is obvious, therefore, that to be able properly to control and direct the growth and development of the mind we must have an especially capable knowledge of it. That is, the teacher must have a special fitness for his work, which has been acquired by special preparation and training for it! This fact has just begun to be brought home to and impressed upon the workers in this field. This is seen by the strenuous efforts now put forth by them, though, in some cases, under statutory compulsion, to master the detailed knowledge of mind, bring it into the field of education and blend the principal of the two into a harmonious scheme that works out the laws of the activity of the mind and makes fitting application of them in the theory and practice of education. Education may be an art and some people may claim for it the advantage of being more inherited than acquired, but 
in the severe test of modern physiological and psychological research it nevertheless has been proved true that however adept one may be in any profession by the gift of nature, he or she is never so well adapted for a profession as to be incapable of some considerable improvement or of learning something of value from the accumulated experience of the world collected and classified in such a form as to constitute a science.

There are some things highly essential to a success in education and in educating. One of the chief of these is practice. While it is valuable as a means of attaining a high degree of perfection in any profession or along any line of activity, practice becomes capable of displaying its power to its greatest advantage only when supplemented by theory. By theory we reach out for results within the range of known and recognized possibilities, by practice we test these theories for whatever virtue they may contain in fact. In the great game of life these two ends meet and one acts as a kind of restraint upon the other.

Art and Science in Education. From the element of practice in the field of education we develop what is generally called the art of education. From the element of theory we develop what is commonly called the science of education. The teacher who in his daily contact with his pupils and students observes little generalities, or communities of action and thought, or devises methods of attaining a desired result, is acquiring the art of education. For example when either by accident or conscious experiment one learns, that, when students assemble in the morning for school boiling over with a life and enthusiasm that seriously threatens to make impossible the obtainment of the usual quiet and order in the school for the day, by merely having them sing, in the opening exercises or at any time a hymn that is of a soothing and quieting melody, their excitement cools down and their youthful exuberance subsides, he has, whether wittingly or no, reached a fundamental art of handling pupils. Again, when this same teacher or another discovers that by using illustrations from the daily life of the pupils he can arouse in them a distinct and peculiar interest in the work and hold their 
attention longer or until he has succeeded in impressing the facts that the pupil is required to learn on his mind, he is gaining ability in the art of teaching. Still, again, when he has learned that, by asking interesting and suggestive questions about a given lesson and then leaving the child's mind in a state of restless curiosity, he can arouse the young mind until it will of its own accord seek out answers to these questions for itself, he has acquired the essence of the art of education.

Now when the fact which aids the one teacher in this or that circumstance and that which aids in another or the same circumstances are brought together and this is repeated again and again until from many sources and conditions there are gathered together a number of isolated facts, and all are compared and a general principle common to all is deduced therefrom, one is moving into the field of education as a science. The art of education is the knowledge gained by immediate experiments here and there, spasmodic, accidental, unrelated experiments, and used in a general manner. The science is the knowledge gained when the experiment of many individuals are systematized and regulated and certain definite though perhaps general conditions and results formed and tabulated and the law or principle underlying these results as causes, formulated and given out. By collecting, comparing and classifying the facts of experience and experiment gained in the art of education it has been found that the mind has a power and shows a tendency to group and classify certain impressions of the senses together in certain ways under certain natural relations that they bear. It is in the understanding and expected validity of a law so deduced that the art of education and science of education blend. The science gives us the law, but the law being a generality in which the special cases of exceptions are ignored it remains for art in practice in the detailed processes of experiment and experience to test in each particular case and see just what part, if any, is valid in the particular case under consideration, and what not, and thereby clarify and purge the science.

Method in Education. The success of education as a proc- 
ess has been found to depend pretty much upon three equally important things. Knowledge of the individual with whom as an object education has to deal, knowledge of the subject matter which education is to impart to the individual and knowledge of the method by which education is to bring the mind of the individual into contact with the matter, the proper intaking of which constitutes education in this sense. Successful education is attained when between these the most cordial relations and agreeable association have been established and the most lasting as well as most beneficial effect produced both upon the subject as recipient and the subject matter as the thing received. But just how to do this is the problem. Because of the great diversity of homes and home surroundings from which the material to be educated in our schools comes, the variety of temperaments and general differences both physical and psychical, due to various normal and abnormal conditions, the human mind presents such a heterogeneous form as to complicate and make almost hopeless any attempt to reduce the chaotic mass of facts observed to anything like the definiteness that the term science would lead one ordinarily to expect, where that term is used. However, we do have method in the science of education, and this method is to-day reduced pretty much to a science. As such it has contributed much to the cause of education, and by advanced educators is considered practically indispensable to those who would succeed.

The Use of Terms. In attempting to discuss method in teaching it will be of value for clearness of treatment to state that the terms in general and ordinary use in education are not clearly defined. Each author uses the delegated freedom of authorship to bring into play his own ingenuity and power of thought to express his own conception of the meaning of terms in his own manner and language, limited only by the general laws of propriety and good usage. For that reason there are almost as many conceptions of the subject evident in the use of educational terms as there are respective authorities upon educational matters. However, several of the terms in general usage though technically they are differentiated and regarded as separate terms, in common usage 
they are regarded as synonyms and are so used. But as this is true in general of every field of science, the fact need not give any particular concern here. The terms most commonly occurring in education and which underlie all principles to be applied are instruction, teaching, training, and learning. By the popular mind teaching is generally regarded as the process of producing mental activity by presenting objects and subjects of thought to the pupil's mind that results in knowledge for him. With this general conception, however, already the difficulty of defining the others is clearly seen. For the benefit of the student, however, clearness will be served by giving definitions for the other terms in which the generally understood distinction and differences are reasonably clearly brought out. It may be said that teaching is what is carried on by the teacher in presentation with its accompanying explanation and other aids to clear understanding; instruction is the mental ac-tivity aroused in the pupil by and during the process of teaching; while education is the state of mind that results in the subject from this external and internal activity by means of which knowledge is gained and skill and power in mind and body acquired. But in each case it will be found that that which each shares in common with the other is that in each there are acts of presentation on the part of some one, say the teacher, mental activity on the part of some one, say the pupil. Knowledge, power and skill result in the psychic make up of the individual educated. Reduced to a nicety this difference is generally recognized. Teaching is carried on by other than the subject receiving the education, while learning represents the activity of the subject himself in his own behalf. Instruction is teaching limited to a narrow and more specialized field of knowledge and is often regarded as a phase secondary to teaching in the broader and more general sense. Training applies more directly to skill and power and dexterity in bodily movements, nerve control and muscular coordination. However, in each and every case in the narrow sense education as above understood is accomplished to a degree more or less extensive according as the system under which the process is carried out is efficient and 
thorough or not. In both the narrow and the broad meaning of the term all of these processes denoted by the words, teaching, instruction, training, are educational, and any and all methods employed in accomplishing them if successful will be received with more or less degree of satisfaction.

Much ado has been, and is still being made, over the matter of methods in education. This is undoubtedly justly so. For while method soon tells in any field of labor it is particularly effective in result-getting in the field of education. So well has the importance of methods in education been recognized that methods have developed to have subject matter of its own which it is now required generally that all who would aspire to teach should obtain some knowledge of its meaning and content in education. By method in the educational sense both as used narrowly and as used broadly is meant any series of acts of teaching arranged according to the art and science of education to attain a definite end in itself or in a definite and outlined series of processes.

Education and Psychology. In the study of the mind there are to be found two elements, the physical element and the psychical element. We have the former in the nature and condition of the mind itself, and the latter in the fact that the mental life is physiologically conditioned. The study of education proper will involve, therefore, a two-fold aspect, one, the psychological which considers the general mental nature and temperament of the individual, the other the physiological which considers the physical organism, its nature and its general adaptitude to its environment during the period of the educative process, also how the one may be used to stimulate and arouse, the other to an activity which will induce healthy growth and development as well as lead to an enlargement of the field of knowledge, and the laws by which it will act when properly aroused and stimulated. Every educator recognizes the fact that the child has a mind and that that mind is capable of receiving an impetus to growth and development through the medium of his physical organism. The problem of the best means available for stimulating this growth both in the field of psychology and education is just beginning to loom up. It also grows and takes on 
proportions not only as the fact that all minds appear to be different in their capacity of taking on development and of responding to different kinds of stimuli is realized, but also when it is observed that at different periods in its existence the mind responds in different degrees to the same kinds and forms of stimuli. To a certain limited degree mind seems to be independent of the body in some of its activities and forms of manifestations, but in the matter of education and educational processes mind is apparently almost completely dependent upon the body and its relation to other bodies. It is the aim of psychology to trace out the operation of mind, the bodily states by which these are induced, to discover how the one acts upon the other and how it is in its turn acted upon by it. Education seeks to embody the facts obtained about the mind in psychology in a code of principles, or perhaps better here, laws, whereby methods of applying the truths of psychology to education might be worked out into a fitting and successful scheme which will promote the largest and most complete form of mental, moral and physical growth and development. Here it is that education and pyschology strike common ground. Here it is that they begin to diverge. In education the mind is the thing to be treated, that is to undergo the effect of the molding influence of these active processes. The science through which we are to learn of mind is psychology. It tells of the natural growth, development and activity of the mind. If education is the result to be wrought on mind, if education is a result to be attained by mind, if the thing to be instructed developed and trained is mind and that which is controlled by mind, namely, the body, if the principles to be applied are to be applied to mind in its normal and incidentally to mind in its abnormal operations, then these operations can only be successfully performed, these resulting states can only be successfully produced by an adequate knowledge of mind, its nature and its laws of action growth and development and manner of manifestation in these operations. This is why a knowledge of psychology is so essential to a successful direction of the process of education, why education and psychology are correlative sciences, why an attempt at 
the effectual carrying out of the process of education is a failure where the basis of all methods and principles are not founded upon the science of mind, psychology. This is why to-day more than ever before psychology is made the starting point of all work in education and of all work in initiating and directing educational processes.

Education and Pedagogy. With most authors the idea of education and pedagogy are kept apart from each other. With them education is a result and pedagogy a group or a system of principles, by which the result is obtained. As was stated in the definitions above teaching is the methods by which the process of enlargement in education is accomplished. Pedagogy is the science which tells what the principles involved are and shows how they are applied to accomplish this end. Education is the process of teaching the instrument of guiding and directing the process throughout its course, while pedagogy is the principle or perhaps better the group of principles which tell us how the instrument is to be applied to the subject undergoing the treatment. However, while the above distinctions afford a definite kind of clearness that has its practical value in actual life it must be remembered that the term education in this sense has a two-fold neaning, which it will be well to understand here in order to avoid future misunderstanding. In one of these senses it means the processes by which certain predetermined ends are to be attained; in the other it denotes the end which these processes are supposed to attain in the individual and in individual capacity for activity. It is thus at one and the same time both an end and a means to an end. As a process it is a means to an end, as a result it is an end in itself.

Education as Related to the History of Education. In its general or broad sense education as a process is as old as man himself. At first it was unorganized and without system, being conducted spasmodically and as emergency demanded. Later on as the need for it spread it became more regular, more organized and systematized. At first there were no schools as such nor were there any set places or times for giving out instruction. Specially designated places gen- 
erally in the opening or under natural protection from the elements, followed later, as did specially built structures. Gradually system was introduced. With system came method under observation and experiment. At this advanced stage the need of keeping records showed itself. The beginning of keeping records in education marked the advent of the history of the development of education. The value of keeping records of the fruits of observation and experiment in education has long since been seen and appreciated. By this means all of the various vicissitudes through which education has passed together with its various outgrowths, all that have had any notable effect on education since the dawn of our western civilization in the Hebrew, Grecian and Roman cultures have been preserved for us of to-day. Through them we may learn the stages through which the process of education has passed and just how much each has meant to us and our present methods of conducting education. By means of the history of education those interested in education to-day can tell how certain things came to be in education and what effect their being has had upon those particular countries or localities in which this particular form of education has been fostered or allowed to develop. They can also see what particular phase of education has been developed in various sections, how these phases have modified or been modified by the manners, morals and institutions of various countries, as well as how they reflect the temperament of a people. Apart from this, by studying the history of education students can see what warrant certain methods and processes in education have and through what fluctuations they have passed before they reached their present stability. In this knowledge they can feel that these methods and processes have been purged of their dross by years, even centuries of test under every form of stress that a changing condition of living and thinking and a changing environment could force upon it. Thus, history of education shows many things in our systems to-day that have outlived centuries of criticisms and opposition. He who in the light of this hastily assails a system or a method, takes upon himself grave responsibility. However by this it is not meant to say 
that everything that has come down to us as relics of the past has not served its day of usefulness, and is therefore not worthy of further use. Nor is it intended to bind us in any set way to the past. There is much in education today which the history of education shows has held prominence in the past and which has the warrant of ages of experiment and test, but which has lived out its days of usefulness and because of which has been and should be discarded. It is only recently that a criticism of the present content of educational process and method has started a reform, the good of which all appreciate now fully. The wave of reform brought with it the reduction of the time devoted to a study of the classics, the removal or reduction of time devoted to rote and stereotyped teaching and the introduction of more science, history, and biography. It also led gradually to the introduction of modern language and professional, commercial, vocational and industrial phases of education.

Thus it is seen that education owes much to the history of education in more ways than one. So closely has the growth and development of education been associated with the history of education that no clear conception of the former can be had unless it be gotten in the light of the latter. The history of education is therefore a necessary adjunct of education and should go hand in hand with it. Knowledge of it means knowledge of education. Courses in education therefore cannot hope of much success unless they are given in connection with a course in the history of education.

From this brief discussion of things introductory, but at the same time of value for the light they throw upon the subject in general we pass to discussions more directly to the purpose of the work.

\section{REFERENCE READING}

Bain's "Education as a Science." Chap. I.

Barnard's "Journal." Vol. XI and Vol. XIII.

Compayre's "Lecture on 'Teaching." Chap. I.

White's " Elements of Pedagogy." Chapter Introduction.

Spencer's "Education." Chap. I. 
Butler's “The Meaning of Education." Lectures I and II. Compayre's "Psychology Applied to Education." Chaps. III and XI. McKeever's "Psychologic Method in Teaching." Cnap. I. Dewey's "The School and Society." Chap. II.

Roark's "Psychology in viducation." Introduction.

Bagley's "The Educative Process," Chap. II.

Ladd's "The Higher Education." Chap. IV. 


\section{CHAP'TER II}

\section{THE NATURE AND AIM OF EDUCATION}

A. The Aim of Education. As was seen by the various definitions quoted in the opening chapter, the aims of education were manifold. Indeed, in the aim of education as in the definitions of it, it takes but little observation either of the process of education or of its conception in advanced minds to discover that the aims of education are as varied as are the relations which individuals sustain to each other and to their local environment. A true education would aim to fit man for the proper fulfilling of all of the responsibilities of these relations; to prepare him for " complete living" in the Spencerian sense of the word. It aims to bring about harmonious development in the individual members of the human family. We are born into the world with certain defects, moral, mental and physical. Education as such aims to remove or modify these defects in such a way as to give us increased activity and increased participation in and enjoyment of the affairs of life. What we become in life is determined by two things, first, the natural tendency to action growing out of an inherited structure given us by the accumulated experience of the race in its life history which we call instinets, and, secondly, by the modifications which the forces of the environment work upon us in inhibiting or nurturing these tendencies to action. From this viewpoint the aim of education would be adjustment to any and all conditions required for or in any way contributing to life. The conditions requisite for and contributing to life to which education aims to adjust us when considered in detail are far too numerous to receive even the most brief consideration. However, we may mention some of the few more important. Among them are physical adjustment, mental adjustment, economic, civic and social 
adjustment. We take up first the adjustment to the physical environment.

The adjustment to the physical environment is primary, for without this form of adjustment life itself would scarcely be possible. Not only would it be difficult to begin life, but its maintenance would be an even greater difficulty. Physical adjustment consists of a serics of acts seeking to circumvent and overcome the bad effects of the play of the natural forces present in the environment. This circumvention and overcoming may be accomplished in many ways. Chief among them is the making of wearing apparel for overcoming or aiding the various climatic conditions, namely, the heat of summer and of the torrid zone, the cold of winter and of the frigid zones, and the effect of sunshine, rain and wind. The preparation and taking of medicine to check or repair waste brought on through the ravages of the elements of the environment and to thicken or thin the blood for heat or cold as the case may be, the building of houses for protection against heat and our fellow man, the manufacture of the material for artificial light in the home and business plant, the preparation of artificial foodstuffs that enable man to escape the environmental conditions, all of these constitute forms of physical adjustment which man must learn if he would successfully maintain himself against the forces of the world that play constantly about him. But these are only artificial means of adjustments. The natural forms of physical adjustment are only indirectly under the control of man. These are characterized by being much slower in the results they produce. They are not under control of the human will but spring involuntarily from the natural reaction of the life spirit in its struggles against the external forces of the environment. Such adjustments show themselves sooner or later generally as modified structure and in science are known as acquired cliaracteristics. These acquired characteristics may or may not become transmissible by heredity as they do or do not enter into the living and functional activity of the organism. The adjustments of the mind to its intellectual environment are secondary in their importance to life, but primary in their importance to happiness. The 
mental acquisition of the various racial groups of mankind is varied. That of the various individuals in the same racial group or subgroup varies also considerably, according to their circumstance or condition of living and the opportunity which it offers them of gaining mental advancement. The minds vary also in quality both among individuals and races so far as their capacity for gaining special knowledge and their fitness for special kinds or degrees of activity. This disparity in mental calibre (quality of mind) and intelligence (quality of mind and content of mind) is the source of much inconvenience and misunderstanding among men. Some men are so far in advance of their fellows in their possession of knowledge that they are and can be of little good to them. Consequently though possessing much knowledge their power for good among men practically is nil, because they have not enough in common in their thoughts and manner of action and reaction to effect a mutual regard and general consent for commingling, even if they really desired such. These cases are few it is true. But every once in a while the clash of such spirits with their fellows leads to some serious shock to the general social body. Often, too, the world loses what these would give, because they are out of harmony and touch with these spirits and it is thereby set back oftentimes many years in its progress by not being in a position mentally to appreciate the value of the contents of such advanced minds and therefore repudiates it often in its entirety. On the other hand there are men who are so far behind their fellows in their possession of knowledge that they are not so much a menace to civilization as they are an inert and sometimes stubborn load which contributes little except mere weight to racial advancement and adjustment through education. In fact they are mostly the mentally "unadjustables" and " uneducables." Between these two groups just mentioned as extremes there are to be found men of all degrees of adjustableness and of all capacities for education and modification through education. Among these might be found the supcr-adjustable as well as the sub-adjustable mentally, the various forms of maniacs, paranoiacs, inebriates, eccentrics and feeble-minded, with their corresponding states of mind 
and susceptibility to education, and educational effort. To the man therefore, who in this state of seeming intellectual instability and uncertainty must depend upon individual knowledge and ability to steer his intellectual ship safely through the disturbed group or period, there must come a mental adjustment that must be at once wide and general. If he would hold his own and make progress he must at the same time attain the mental equipoise and balance necessary for safe guidance in such an intellectual maze. He must be capable of taking on adjustment. The intellectual aberration (super-mental adjustment) to which mankind is subject and the misery and suffering which this entails upon men are too numerous to need mentioning.

False prophets abound everywhere as do false agitators and preachers of false creeds. All of these are mere cases of those unadjusted mentally to the environment. Where these are sufficiently in touch with the mental environment to readjust themselves through education and do so they may become of practical service to the world in aiding its progress.

Moral Adjustment. The term moral adjustment is used here in its primary and primitive sense. By moral adjustment is meant the adjustment of an individual to the habits and customs of his fellows as a race or type. The eccentric in dress, in manner of living and achieving all come under this head. These are they who are continuously "shocking" society by arbitrary and unusual habits and actions. We find them in the parlor, the library, the dining-room and hall as well as in the places of public assembly. Instead of being in harmony with the social order these men are decidedly out of harmony with it. Often they are so by choice and pride themselves in so being, in which case it is the more difficult to bring them under the adjusting influence of education. Still it must be admitted that they are out of adjustment with the social order and to the extent of their lack of adjustment retard if not seriously check, social movements and social progress. To this extent they are not harmoniously developed and are not prepared for complete living. For the most complete living is only to be had where there is the greatest harmony and accord among men. But 
this is not the most common nor the most serious form of lack of moral adjustment. This is to be found in the criminal. His is the most flagrant case of lack of adjustment. He it is that the mighty forces of society bend their efforts to reform. One of the chief burdens of the public school is to educate in such manner as to protect society against the vicious and the criminal tendencies in society. While many of the evil and criminal tendencies in men are created outside of, away from, and despite the efforts of the school much of it is fostered there. Some is brought on by laxity of methods, some by severity of methods, but all of it education should overcome.

Religious Adjustment. Nowhere is adjustment more necessary than in matters of religion. Religion is very intolerant and very impatient in her intolerance. Those who are unadjusted here have generally paid for their lack of adjustment in most countries by considerable suffering and at times even by the loss of their lives. Throughout all ages religion has generally demanded and does now frequently demand the freedom, the life and limb of those unajusted. Here persecution is rampant and the suffering inflicted is almost indescribable even if not almost unbelievable. In religious adjustment education as conducted in the schools can accomplish little chiefly because no religious education is taught in the schools. The church originally controlled all forms of education and in the separation between church and state she lias held tenaciously to religious education, losing in the fight all other forms of education except perhaps some right to continue moral education. Now the church is mostly stultified and wedded to the past. It is also to a considerable extent dogmatic and empirical. Being these it accepts change slowly, consequently with it, adjustment is but a small possibility. It opposes adjustment through the channel of the school and initiates but little within itself. And yet how much has this lack of adjustment not cost the clureh, the state, and society? And yet, if the church is to keep its hold on the people, it must accept education and make within itself those adjustments which education brings in order that religious adjustment may keep pace 
with the other forms of adjustment which education aims to bring to men.

Economic Adjustment. Indigence, poverty and pauperism are the lot of those unadjusted to the economic environment. The multimillionaire represents the highest stages of economic adjustment. Morally he may be completely out of order, unadjusted and he may suffer certain inconveniences, therefor, but the degree of economic adjustment must have been for him high. Much of his adjustment if we are to believe the facts printed about them has been gained not so much through the education of the school as through that gained by contact with the world, its men and its affairs. Of course much of the wealth in the possession of the millionaire class does not represent the real fruits of economic adjustment. Especially does it not represent adjustment during the life of one individual. Then, too, much of that wealth that has been accumulated by one individual represents sometimes extortion, robbery and "graft," unscrupulous and unprincipled plunder of the public goods and utilities that have been made possible by the general faults of governmental agencies, and the general social disorder, which prevails to more or less extent. Without this fact before us it would appear from the few rich that there are but few highly adjusted to the economic order. However, there are many who are highly adjusted to the economic order, but who do not stand out as do these mentioned here because they have not invoked the secondary means to advance the natural results of their economic adjustment. So that while the various stages of material progress and material accumulation represent the various degrees of adjustment, it does so fully, only where the fruits of this adjustment are allowed to flow freely but unabated by accessory conditions unto those so adjusted. Thus the day laborer, the mechanic, artisan and farmer as a class seem to be at the lower base of the scale of economic adjustment. But where there is natural want or suffering here the cause or causes will be found to be less elsewhere than in mere lack of adjustment in this particular field, that is in the economic field. Education both moral and mental will do much to effect a more general 
economic adjustment, that is, will do much equally to distribute the per capita wealth of the world, though because of other forms that combine to produce results economically this will never be fully attained even under imperfect economic adjustment.

Civil Adjustment. In civil adjustment the danger is from the demagogue and the professional politician. To avoid the sweet antidotes of the one and the panaceas for all political ills of the other, is the aim of education in seeking to accomplish adjustment to the civic environment. The true statesman represents the man most perfectly adjusted to the civil environment. Here as elsewhere are the dangers of lack of adjustment present. The pillars of free government, freedom of life, freedom of property, rights and justice, all are to be safe guarded if government is to be maintained. To bring this about the fullest harmony in adjustment must prevail. Of all governments popular governments are the most constantly in danger from the evil consequences of lack of adjustment. It was in this necessity that public or state education was undertaken. The hope of the state lies in popular education, to teach individuals their civic duties and responsibilities and to give them a full appreciation of their seriousness. It was in the realization of this burden encumbent upon it that the state first saw the need of controlling and directing certain forms of education and seeing to it that certain conceptions of the state and its duties and relationship be given to the citizenship. It was in realizing how vitally such education affected its own existence and wellbeing that it consented to grapple with the church over this form of education.

Social Adjustment. Adjustment to the social environment is both varied and intricate. Because of the ramifications of the general social problems, social adjustment involves all that has already been said and more too. The social environment is in a state of unstable equilibrium. It is always active and we believe always progressive. Here adjustment is paramount. We must be adjusted to every relation into which we come in association with our fellows. Adjustment there must be, to our political institutions, our 
ecclesiastical institutions and our educational institutions. Those unadjusted to the social environment are sometimes ignored, sometimes ostracized, sometimes banished and at other times imprisoned and even whether legally or illegally, deprived of life. Full adjustment here means social contentment, social happiness. It means complete living. If education could bring about complete adjustment here all other forms of adjustment would have been achieved. All that is evil and corrupt in society, all that makes for social disorder would have been removed. The golden rule would be in vogue working smoothly. The day of the millennium would be at hand. Of course this will hardly be possible in the actual and yet education can and will accomplish slowly a general social adjustment.

Equal Opportunity. Besides these various forms of adjustment which education aims to effect, there are other aims in education that are as far reaching in their results as adjustment and perhaps even more fundamental. One of these aims is to create equal power over circumstances. Since no two men are alike either physically or mentally and since no two of them react alike against natural forces their opportunity and their power over circumstance are limited in various degress at the very outset by nature. It is without this realm of natural difference, in opportunity and power over circumstance, that education aims to be effective. It is a fact that education can overcome the limitations of nature. And it is in giving to all the same or equal opportunity to improve and use what they have by nature that education is to give equal opportunity and equal power over circumstance. All human institutions teem with the human element. This human element is selfishness. All governments are built mostly upon clannishness, caste and favoritism. This is true even in a republic, though least of all there. In giving equal opportunity and equal power over circumstance, education aims to place all as nearly as possible on a basis of individual merit. In doing this education has had to combat the idea that all men are created equal. But while in government this tenet is necessary for justice to prevail and is absolutely true before the law, as a 
prineiple of psychology it is hardly tenable. The minds and bodies of men differ infinitely. This difference however, we hold is not so great as we are inelined to grant nor does it count for the great differences in quality in individual minds. There is a great disparity mentally between men and also between their achievements. But is there " a divinity in some of us that makes us great whether we will it or no" which the others of us do not possess? If there is such a divinity there it certainly does not do much for us apart from opportunity and circumstance. The real fact is that though the intellect may be better in some than in others from its dependence upon the physical organism or even if we assume that it is an entity capable of independent existence yet when through education equal opportunity and equal power over circumstance is given, efforts to prove this difference in mental quality show very varying and uncertain results. Not that there is any reason to claim that the intelligence of all is equal. The difference in intelligence is too great to be for a moment called into question. But this difference is not traceable so much to the differences in the mind itself as to its access to, acquaintance with, and ability to use the materials of civilization in the acquisition of knowledge. Locke was undoubtedly within the range of truth when he compared the mind to a sheet of paper on which everything that it was to contain had yet to be written. But Ward who went him one step further and eompared the mind to soil into which seed was to be planted and eultivated struck at the fundamental verity of the problem. Great minds, "men of genius," are not so much born so (by nature) as they are made so (by nurture). Many men have no access to and skill in the accumulated knowledge of their day. Many of those who have such access lose their opportunity for superiority by default in time and energy. They waste their opportunity by not taking the best advantage of it whether through ignorance or inability. Throughout the entire strata of society those members of society who have acquired varying elevations among their fellows are those who have been able to possess in correspondingly varying degrees the intelleetual and material "heritage of the past" 
and used their possessions to the best of their " knowledge and ability." Of course, most of them possess this heritage in varying degrees, but wherever they have gained the ascendency they have been found to have possessed certain amounts of the heritage and to have used it. The fact that there have been so few great minds is due to the meager transmission and slight diffusion of the accumulated knowledge, to the poor organization of society and to the comparatively small number who have gained access to the stored experience of the human race. But this is the aim of education, namely, to equalize the opportunity of all in their access to the accumulated knowledge of the race and to give to one and all alike equal opportunity to acquire skill in the use of its material achievement.

It was stated above under the head of economic adjustment that some men through the control of large influences obtain adjustments that are not rightly theirs and because of this unfair advantage and profit would seek to thwart the aim of education in bringing about adjustment. This constitutes the chief objection to popular education in certain minds. The principal reason for the argument of the difference in the capacity of individuals is that there is present in such minds a tacit knowledge that the equal opportunity which education gives will rob them of their advantage and prevent the further exploitation of the ignorant by the intelligent, of the socially low by the socially high. But this is and must be the fundamental aim of education. Herein lies one of its chief virtues. Especially should it serve this end in republics where the laws are made by the popular will as expressed in the casting of the ballot and where an equal opportunity in life and its good is vouchsafed to all.

From the foregoing it would follow that since men are born into the world under the present regime in all strata of society and in all social conditions and must struggle from under the burdens and hindrances of these conditions it must follow that if education accomplishes its aim of equalizing opportunity and of giving access to and skill in the use of the intellectual and material accumulations circumstances of race it must also give them power over the circumstances 
of life. 'That we are all "creatures of circumstance" is a truth that man has had forced upon him by the ravaging experience of countless ages. Many experiments have been made to show the effect of circumstance upon the human mind. The most noted of such experiments are those of Psammetichus with the two new born babies, of Kasper Hauser, Rauber and Father Xavier, the Indian Missionary. Besides the experiments here referred to there are any number of authors who have become acquainted with these effects. In this regard Confucius wrote, "We very nearly resemble each other by nature; condition separates us very far." Adam Smith in his "Wealth of Nations" said "The differences between the most dissimilar characters, between a philosopher and a common street porter for example, seem to arise not so much from nature as from habit, custom and education." Helvetius gives us the same thought, "We see in the same way that their (the citizens') elevation or their decline, their good fortune or misfortune are the products of a combination of circumstances." To all of this Henry George adds "The influence of heredity, which it is now the fashion to rate so highly is as nothing compared with the influences which mould the man after he comes into the world." Give, then, the fact that circumstances are a power in determining the success or failure of an individual his achievement or non-achievement, how is education to give man influence over this circumstance? The aim of education, that of giving man power over circumstance, may be accomplished in any one of the four different ways. First it will show him the achievements of men during the past and tell him how these were accomplished. Secondly, it will show him what the achievements of the immediate future will probably be by showing him the most pressing human needs. Thirdly it may by proper guidance through a series of protectionary and experimental activities discover and develop his peculiar fitness for ccrtain kinds of achievement. Last, but not least, education may show him how to acquire skill in the methods of endeavor and in the use of instruments so that he may achieve.

While it is true that there are not a few achievements that 
have brought much good to mankind and unlimited prominence to the individual who has been accredited with the achievement, still we do not hold that such men are truly great nor that their accidental discoveries are achievements in the true sense of the word. What is meant by achievements are the accomplishments preconceived and sought by means fully known to the subject. In this sense, no mind, it matters not how potent the capacities are that are latent within it can either know the avenues of achievements, the value of it to himself or to his fellows, nor how he may get into the proper channel of activity without having a definite knowledge of what he wishes to do and how he may set to work to do it. For it is obvious that no man can intelligently set to work to pursue a given line of endeavor or research, much less can he decide to employ certain means in a given way when he does not know that the work is to be done, nor how he is to set out to do it. For as Leslie Ward well says, "There has been no discoverer so great in the world as to owe nothing to this circumstance (initial acquaintance with the given field of labor), none who might not have lived and died in the profoundest obscurity had not some external force first lifted him to the height, however humble, from which he was able more or less clearly to overlook the field of his future labors; none who had he chanced to live in another land or a prior age could have achieved results which he was enabled to achieve under the actual circumstances." But education aims to give all an equal chance to see what things in life have been done, what are to be done, how they have been and may be done and to arouse the proper feeling necessary to enter upon them and push them on to their successful conclusion. After this the individual must act for himself. But this is just what, according to the premises that he is educated, he is both capable and desirous of doing.

These then are some of the aims of education. It will be many a day before they will be attained. But they can constitute the goal toward which educational endeavor may be directed. Progress toward it will be slow and at times almost imperceptible. Still there must be no faltering. The 
great forces of nature in mind and body never grow weary, never grow less. They issue constantly in action. Education must direct and control the progress of the human family. The aims for review we may sum up briefly here. They are:

To prepare for self-preservation.

To prepare for self-maintenance - gaining a livelihood.

To prepare for self-recreation - reproduction parenthood.

To prepare for civic and social relationship.

To prepare for cultured and refined living.

To give equal opportunity to all to acquire knowledge and skill in the use of the material of the world.

To give equal power over the circumstances of life and living.

Many other aims of education might be mentioned here, but these are considered primary and as such sufficient here. With this we pass on to the nature and application of education.

THE NATURE AND APPLICATION OF EDUCATION

(B) THE NATURE OF EDUCATION

In treating of the "Aim of Education" we saw certain phases of the problem of education that are to be traced directly to the nature of the thing to be dealt with in education, namely, the humian mind. In the various forms of adjustments to be attempted and made, in equalizing the opportunity of all and in giving to all equal power of control over circumstances in all things in which education has to be attained, the question of its nature plays a prominent part. In education as understood here, we deal with the human mind and body, man as an organization. In the first place the mind comes into the world, limited in regard to the kind of education which it can take in, but besides being limited in the way it comes into the world, it is limited both in capacity and the nature of its "educability" by the instincts and tendencies which is its by inheritance from the ancestral relic of racial experience now recorded in the structure of the descendants as racial history. 'The sense media of the 
mind through which education is accomplished for example, are all predetermined and arranged and to a certain extent have their natural capacities in educational activity already limited. In like manner the bodily energy is restricted in quantity and its sources of supply between which and the power of action of the mind there is close and acute relation are likewise limited. The mind itself is restricted in its activity to material furnished by the senses and though it be granted that given this sense material as a basis, the distance to which the mind may go is only distantly restricted, still all will admit that in its action it is limited and strictly so, to the material of the senses. By the nature of the mind, then, the nature of the adjustments, their limitations and possibilities, in education are definitely determined. Certain extraneous elements and changed conditions enter at various times to change and check the process of education, others enter again to modify and increase it. Too, in the natural order of things mind bears a static as well as dynamic relation to mind. When either of these relations between minds change the process of education undergoes a change that retards it or advances it. We have just referred to static and dynamic states of mind, without destroying the correspondence we might also mention the inertia of mind. The inertia of mind affects the process of education everywhere. All reformers and agitators among men will attest freely to the inertia of mind. In education we find it presented chiefly in adherence to the old and the established order. The greatest problem of education is to arrest the direction and rate of motion in education and modify and change it into other directions. Minds like bodies tend to take the line of least resistance. Only in the case of mind this line of least resistance mostly becomes the line of greatest pleasure. It is strange sometimes to see what some minds call pleasure, but their lines of action in education is the line of greatest pleasure, either immediate pleasure or remote pleasure anticipated in the present. In the inertia of mind, however, we have an element, the element of choice, which does not enter, at least as intelligence, into the inertia of matter. Education would not have such a problem in the 
inertia of mind if it were not that it had to overcome the element of choice in arresting and changing the line and rate of motion. Fear, love, hate, envy, jealousy, etc., all enter to affect and either stay or deflect the mind. All of these education must overcome, if it is to achieve its end. Some show up at one place, time and under one circumstance, others at and under another, all of them however, are innately a part of education and its problems, all of them as such must be accepted and dealt with either individually or collectively, or both, by education. Because, then, of the nature of education, of the nature of the mind in education, there is much that it will have to overcome. In and through it all patience, love, perseverance and effort must control if anything is to be accomplished. Some of the things which arise in education through its nature are the hindrances to which it is subject, its limits, the sources from which educational opportunity must come, both direct and contributory and its relation to them.

Hindrances to Education. Apart from the fact that education as a process must be repeated in the life history of each individual there are other influences that materially retard education either by misapplying the knowledge gotten or restricting the quantity and despoiling the quality of it. Because of such effects these are known as hindrances to education. Chief among these hindrances are tradition, superstition and prejudice.

Tradition has always been a bane to advance thought and to progress in general. Its chief characteristic is that it lives exultingly but reverently in the past. Everything that looks to the future with its ceaseless changes tending to growth and progress is of necessity to be condemned. The dictum that the education of the fathers is ideal and all disposition to turn from it or reach beyond it is wrong and should be assiduously crushed as leading to woe and destruction, is its stronghold. It throttles individuality and chokes the spirit of investigation and research. How long tradition held China and Japan in bondage is a fact of history too well known to all students to need mentioning here. Our own Southland is just beginning to overcome the retarding 
effects of a tradition which it holds dear but which has for several decades held it bound to a past that was and is destructive of much of the best that is in her and stifles all attempts to move upward in progress. The tradition of which many old families are proud and to some extent perhaps justly so is still a hindrance to advancement. Traditions are relics mostly of a neglected and forgotten past and out of time with the demands of the new and progressing present. Traditions are either negative or positive. Positive traditions possess in them almost the sum total of that which is good in tradition. Negative traditions are generally harmful especially where they prevent the individual from meeting the legitimate demands made upon him by his day and generation. Most traditions are met in education as negative effects either retarding the work of the school, modifying and changing it or in some rare cases successfully opposing it. Sometimes they are met openly, sometimes they constitute a silent and secret but strong undercurrent reactive against education and educative progress. Positively they serve to bind us to the past and thereby prevent the future from running away with things. To this extent they are meritorious. Negatively they exclude change and thereby prevent progress. Their danger lies in their negative attitude wherein is mental stagnation and death.

Superstition. There are certain things demanded in our thought and action that are fundamental and that are demanded by our very nature. If they are not given us through one source we create them for ourselves through other sources. Chief among these are the thought and action that cluster in and around the idea of causation. Next to the disposition to find a cause is the problem of finding out how these causes operate.

In the discovery of these two things lies the beginning of all superstition. A cause for all manifestations the mind is under compulsion by nature to seek. If the legitimate, sufficient and final cause cannot be found, in its place will be substituted any cause which to that stage of development of the mind will be accepted as sufficient. The lower down the scale of intelligence we are the less do we know of real and 
efficient cause and the more are we compelled to accept substitutes for them. But it is this tendency to accept substitutes for real but unknown causes that constitutes superstition par excellence. The less we know of the true natural cause the more are we prone to offer instead causes that while artificial scem to us sufficient. The more superstitious we are, the more are we inclined to link phenomena with crude and insufficient causes. Not knowing the fundamental nature of things nor their laws of action we accept plausible explanations of causes without being able to detect their actual untenability. The earlicst evidences of mind seem already to have ideas of world order regulated either by man, subman or superman. Where man does not appear as a sufficient cause the sub- or superman is accepted. With mind and superstition has come religion. The more superstitious man is the more religious is he. The more superstitious he is the more readily does he accept the superficial causes as explanation for the observed order. But if this were all, the problem of education would not be so difficult. The difficulty of the problem lies in the fact that superstitions soon become sacred, are absorbed in public morals and develop for themselves a strange zeal that not only antagonizes but often successfully defies education. To root out superstition is always an early but sometimes slow and tedious process of education. For much that is sometimes called education is training in the nature of justification in tradition.

The subject matter given under hindrances to education would not be complete without including the mental state known as prejudice in them. In the light of education as a process tradition is bad, superstition worse, but prejudice is the worst of all of these especially in that it offers opposition to the advance of knowledge through education. Prejudice has little psychological justification and perhaps less psychological explanation. Few of us can account for its presence in our mental make up, we have it all of us who have mind, but just why or how, none can tell. It just seems to be a kind of natural bend in mind, now inclining to this line of thought and action, now to that. It is just a mental 
bias that seems to be present simply by the nature of our entire mental content, makes us think, feel and act in a certain way without our learning why. In some it manifests itself in one way and in others in other ways. Its explanation lies probably in the fact that our mental life is influenced by our past experiences, the kind of habits of thought and action we have formed and the relating of our present thoughts and actions to our general well being. That is, what we think, how we think it and what we do is to a considerable extent determined by our past experience and our habits. This is negative prejudice. This is not the difficult side of prejudice to education. In fact education can only succeed slowly with it in as much as it is also passive. It is the prejudice that is active that is difficult but with which education must deal, the kind that is willful. Where one wills to take a certain view and hold it against opposition, decide that something is so and then rule out all evidence that would convince one to the contrary that is the attitude of mind that is dangerous. Here the problem of education is particularly difficult. Such people are prejudiced to knowledge because they don't know and do not wish to know, in fact refuse to know.

In education we have to do with all three, tradition, superstition and prejudice and nust seek to overcome them. Parents teeming with race and family tradition, resent any attempt on the part of the teacher to remove the idea from the child's mind. Being superstitious no one not one of them or not one who can win their confidence can successfully appeal to them. While on the other hand one who is of them will probably feel and think as they do about them and have little or no disposition to attempt their removal. If all such could maintain an open mind the education of them would be an easy matter. But first the wrong conception must be removed and the right one substituted. This is both a difficult and delicate task. Sometimes it is impossible to accomplish anything with the minds which entertain these thoughts. Then education can only succeed by working upon those minds into which they have not entered or having entered have little or no hold. In either case the task lies in so performing 
the operation as to retain the confidence of the subject. Each is married to his idol and clings tenaciously to it. The burden of education is to remove the old, win over to the new and give instruction in it.

The Limits of Education. While education must begin anew with each individual the extent to which a person can be educated has never been determined. No person has ever been educated to the limit. Though if the mind is mortal there must be a limit to its capacity to those who hold the mind as immortal there will of necessity be no limit in this world to its capacity for knowledge. Knowledge when condensed may be easily imparted. That which it has taken decades to discover or work out, the merest youth of to-day may learn fully and generally does learn in a few hours. Besides that knowledge is not spatial, nor is it restricted within spatial limits. Though the brain and body which contain the mind and furnish it with the media for gaining knowledge are spatial as well as temporal the mind itself is not by all so regarded, and hence cannot necessarily be said to be limited in this way. Though since its media and abode are so limited it might be concluded that as far as this world is concerned the mind is limited likewise in its capacity for knowledge getting. From this view point, however, it can still be truthfully said that no one has yet been educated to the fullest extent of his capacity. From this view point then at least theoretically, though every person has a limit in obtaining education, no such limit in practice has ever been reached. However, every person's capacity for education is limited only by the field of knowledge itself, the physical endurance of the individual in pursuing knowledge and his intellectual capacity for imbibing it coupled with the years he spends in the process or the number of years in his normal waking life. The entire known field of knowledge has never been acquired by any human being to date, consequently the intellectual capacity of man has never been fully attained though in many cases the physical limitations by strain and excess has often been reached and passed. No teacher, therefore, need 
fear that he will carry an individual beyond his capacity for knowledge. The danger lies more in the opposite direction - that the individual will not be educated at all up to the limits of his capacity. Too, there is some danger in extensive education in one field to the neglect of it in other fields. Oftentimes in cases where practical knowledge is most necessary, because of fake standards and ideas of living, the practical is neglected for the liberal, the luxurious and the theoretical in education. Care should, however, be exercised always that the physical endurance of the individual which even in the strongest, is limited, be not over reached. Every now and then through this source local and general school processes come in for severe and oftentimes just criticism. The limitation of individuals in this capacity is always a matter of serious concern to educators.

Sources of Educational Opportunity. Opportunity for education is given through three chief sources namely, the church, the state and society. Education looks to the uplift of humanity. That is originally and primarily the Church. Long before government as such was a clearly established institution and the state itself as such had existence, the church as an ecclesiastical institution held sway over human destinies. What little systematic education there was existing among early people was under the control and direction of the church and generally offered exclusively to the officers of the church. All education then consisted of instructions in church lore and church literature. Even to-day among the savage and barbarous peoples and in some cases among civilized people the church through the clergy is the chief possessor and disseminator of extant knowledge. Not only has the church always possessed itself of all extant knowledge, but when the intellectual advancement of man seemed threatened with destruction and all forms of knowledge seemed abandoned to itself to perish the church gathered unto itself the precious truths of humanity and treasured them away, perpetuating them within itself until it could safely give them out again to the world. In this way in the troubled middle ages the church was exclusively the educational in- 
stitution and remained so for centuries. Finally as church and state separated, the state took on a certain phase of education and disseminated it, until to-day the phases of education given out by the church are in many instances at variance with that of the state. 'Too, most of the educational institutions to which the state had access were under the direct control of the church. The oldest schools in this country were established by denominations and many of our present colleges and universities owe their origin and present support to ecclesiastical organizations. However, the tendency at present is toward educational opportunity furnished by the state and state institutions are already eclipsing so-called church schools in size, support and patronage.

'The church's real interest in education and its chief claim to prominence in education is because of the moral influence it wields thereby. In periods of unrest and disturbance the church has always acted as a bulwark of human rights and liberties, however crudely conceived. By its possession of knowledge it has served to direct, guide and hold in check rebellious natures. This is the church's justification in offering to the world opportunity for education.

As the state advanced in civilization (knowledge) and the church and state grew apart, in the resulting conflict of authority and rights the state was forced to provide an education of its own for itself. At first the education differed but slightly from that offered by the church and statesmen were chiefly churchmen. Gradually the breach between church and state in political education widened. In this condition defense from foreign and domestic enemies caused the state to feel keenly the need of supervising the education of its citizens. The value of this was exemplified by Sparta, Athens and Rome. When in the Middle Ages the power of the papal See spread over nearly all christendom, state education fell somewhat into disuse. But with the break between church and state during the Revival of Learning in the 15th century state education came again gradually into use. Today state institutions of learning greatly predominate in Australia, Asia, Africa, Europe and America. 
EDUCATION AS RELATED TO GOVERNMENTAI,

INSTITUTIONS

The state is dependent for its existence upon the quality and nature of its citizenship. Consequently the question of education and educational opportunity is with the state a serious one. Each state offers the kind of educational opportunity that will best serve its existing political institutions. Hence the educational opportunity offered by the various states will vary as their political institutions and the civic responsibilities they imply, vary. In absolute monarchies education will differ from that offered by a limited monarchy and both of these will differ in many essential details from that offered by various republics. 'The less the civic responsibility and participation in government allowed under a given form of government the less is the demand for general or popular education. Conversely, the greater the civic responsibility and participation in government granted a people under a given form of government the greater is the demand for a citizenship enlightened through education. Especially is this true in republics where the successful maintenance of stable government and the perpetuation of its various institutions of the state devolves directly upon its citizenship. So that while the tendency to-day is toward state fostered schools, this tendency is greatest among republics and decreases proportionately as the form of government diverges or perhaps better recedes in form from that of a republic. In monarchies whether limited or unlimited state education is not extensive where the reins of government are under the control of certain groups of citizens by heredity and the masses though in the majority are delegated but little participation in the government. In those governments where the masses are intended for service, their education is correspondingly an education for service and indeed for that kind of service which the governing wish the governed to render. Our education is an education for service too but unlike the service referred to above, our education prepares for voluntary service with opportunity given to all for complete freedom of action and achievement. What 
servier ons remders to the body us a whole is determined by romdition mol the use of opportumity and not hy the selfish

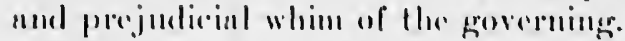

lidacalion b!y social c'omtare. 'The educatiomal opportumily which sociely olliers is clithorent frome cither of the

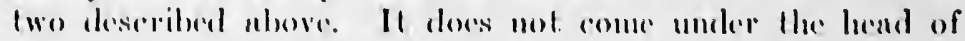

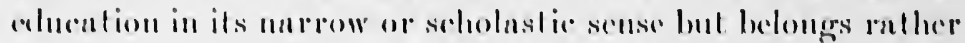
to celucation in its broml sense. Since socidy rame before

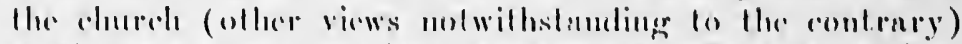

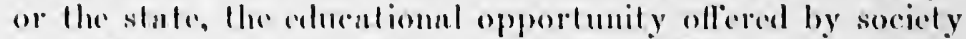
in itself is primary mul fumbumental. Other edurentional

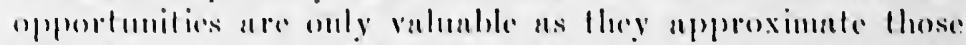
ollered hy socioly. lifo is inlended lo be lived with our follows and we enu ouly live wilh them suceessfully by knowing

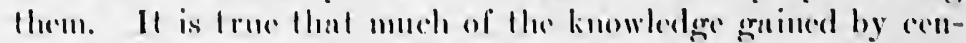
turies of experienes is now habulnted nod presereved in book form to be lemened in solocols, but. Here is also moch that,

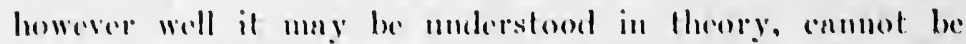

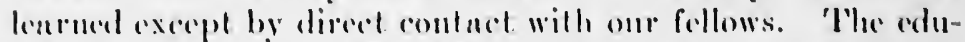

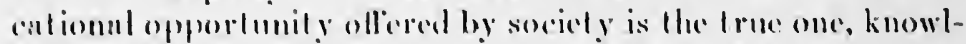

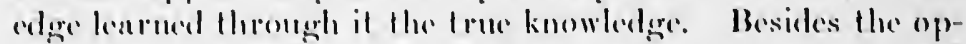
porfunity lhus oflerent is with us durimg all of our nomme waking hours. It is lla roul and true colucational opporhinily.

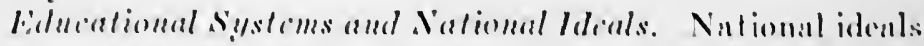

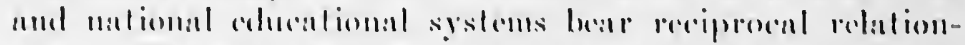
ships. 'The one determines the othere not the other renels

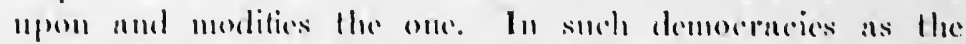

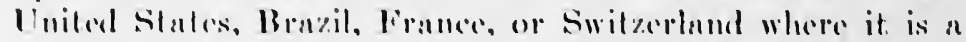

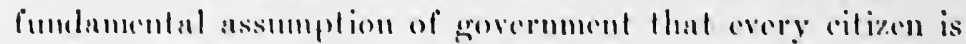

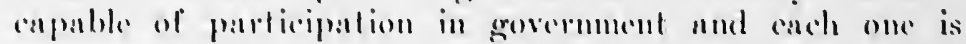
frumantred equal rights umber the law in atministering the

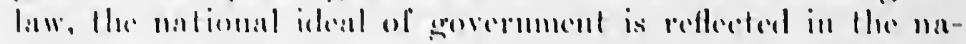

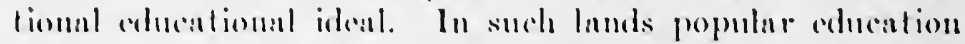

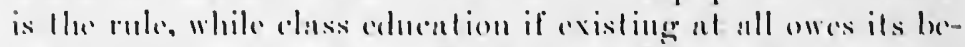
ing to privale andeavor. ('ivic dutios demund enlightment.

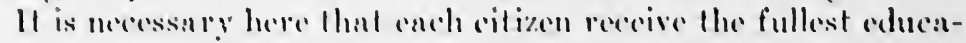

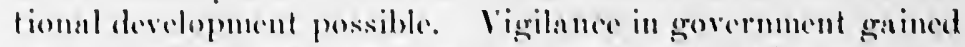
through proper aluention is the surest means of perpetunt- 
ing democracies. Limited and unlimited monarchies in the: hands of an electorate are under like necessity to supply full opportunity for cducation to those excercising such rights of govermocnt. In absolute monarchies where the nutional idcals cluster around a $\mathrm{f}: \mathrm{w}$, the ruling class, and where they depend for their successful perpetuation upon this class, class colucation in general is limited and addapted chicfly to them, while the masses are cither poorly taught or untaught. in the dusties involved in civice redalionships. For to tench them freely in government in any form would destrony the mational ideal, thess involving cither the destruction or modification of the various institutions of the state. Roussia and 'Turkey would well represent commtrias where national ideals ure clesarly opposed to popular education with the frecedom of life and action that accompanies. While: Norway, Sweden, Italy, Corminy and England are representatives of constitutional limited monarchies, where popular education is general and highly disseminated. Apart from these general rolations of national ideals in government, and socicty which are roffectad in the coducational ideals of a country the mational ideals are in others even more explicitly represented in the: educational ideals. In America, for instance, civic and social service is the national ideal to the successful attainment. of which all of our educutional forces are most intensely bent. With us the educational systrom in its contirety is devoted to teaching the members of the body politic and of society bow best to ad just themselves to their environment and how best. to serve their fellows even in the broadest and most general relationships. 'The: linglish ideal loosks Jess to social relationship and the responsibilitics of government and more to the creation of certain national types and characteristics of the people, so much so as to be easily noticed even to the point of making them apposar clannish, and to the cestablishing of constant, adjustment and resedjustment to the existing social order. Among the Germans the social order and charneteristic: type is foreed even further into the background and the chief stress of German education is placed upon the attaiment of commercial advantage. 'T'o this cond the (ierman youth even before maturity is laught the laws of com- 
merce and sent to spread German wares in the distant parts of the earth. Another form of German education fostered by the national ideal and now become traditional is its education for specialization and research. This ideal has so absorbed the minds of educators and so worked the ideal to the exclusion of all else that is vital in education that it has considerably weakened its force. Specialization in education has been carried almost to excess. The German parent chooses the career for his son, which is to a considerable extent determined by his social caste, and sends him along this line of special education long before the American youth is even told of the divergence in work that is to come and his mind prepared to accept the specialized education that he or his parents will choose for him to pursue some six or eight or even ten years after the German youth is into his course.

In France the educational ideal is for specialization and research, but not to the extent that it is among the Germans, while the ideal of commercialism is supplanted by the ideal of social and political supremacy. Turning from here to the ancients, the Jews, a religious people, fostered an educational ideal that was a religion, to the working out and perpetuation of which all of their social, political and educational institutions were devoted. The Chinese education was a blind worship of the past and their social, political and educational institutions allied them with this past until stagnation set in putting China centuries behind the countries of to-day in practical and material advancement.

\section{REFERENCE READING}

Bain's "Education as a Science." Chap. I.

W'hite's " Elements of Pedagogy." Introduction.

Compayre's "Psychology Applied to Education." Chap. I.

Mcheever's "Psychologic Method in Teaching." Chap. I.

Roark's "Psychology in Education." Introduction.

Keith's "Flementary Education.” Chap. II.

Putnam's "A Manial of Pedagogics." Chap. I. 


\section{CHAPTER III}

\section{KINDS OF EDUCATION}

According to the traditional view there are fundamentally three kinds of education. This division has arisen from the time worn custom of dividing the mind into the two faculties of knowing and feeling (this latter including within itself what we know as willing), and the habit of treating the body as essentially related to mind because of which relation mind is dependent upon body in such a manner that the education of one involves the training and control of the other. Hence two of these kinds of education deal with the development of the mind, the other with that of the body. This method of classification gives us intellectual education, moral education and physical education. Intellectual education aims to develop and strengthen the mind, and to exercise the intellectual faculties in acquiring, using and adding to the various forms of extant positive knowledge. Moral education aims to develop and strengthen the will and through it the heart (the natural capacity for feeling in its various forms) and to exercise and develop the will in controlling the bodily and mental activities and to conform them to the demands of the individual life and of the social life. Physical education aims on the other hand to prepare us to develop and strengthen the body.

Apart from these traditional divisions of education the march of modern science and the increased acuteness of modern thought and reflective processes, together with the development of the new science of physiological psychology has led to a more detailed division of the phases or kinds of education. To these three original kinds of education the changes of educational forms and systems have added still others. To physical education there has been added physiological education more as a coordinate than as a sub- 
ordinate field to physical education. In like manner but as involving a separate field from moral education, esthetical and religious education have appeared. While the general tendency to popularize education now prevalent in all of the advanced and liberal countries from a governmental viewpoint and to make it democratic (useful to all classes) has led to the introduction of those forms of education known as industrial education, vocational and commercial education. Somewhat overlapping these and yet sufficiently distinct from them to permit of consideration here there might be added to the list already given to make the above analysis more complete, practical and theoretical education.

We find, then, upon detailed analysis that we have ten different kinds of education, to each of which we will devote a few brief paragraphs by way of explanation and discussion.

1. Physiological Education. In the reaction against the asceticism of medieval times, the body instead of being as heretofore despised as the seat of evil and the source of sin and corruption in man and an unfit temple for the indwelling of the immortal spirit of man and accordingly mutilated, maltreated, scourged and its normal functions with its appetites suppressed that the soul might be freed as soon as possible from its earthly home of clay, became a source of respectful consideration and consequent study until in the eyes of all it grew into an object of pride and lofty regard. This feeling grew apace until it was given new life by the educational theories of the eighteenth, nineteenth and twentieth centuries, wherein the true relation of body and mind was first seen and appreciated, though even then but dimly. Since Herbert Spencer turned his trenchant pen upon the subject of education physiological education has been a prominent part of all educational systems and the subject has been a prominent part of the curricula of all educational institutions. The "don'ts" of the nursery and kindergarten followed later by the effective prohibition of the tendency to abuse and overtax the stomach resulting from the insatiable desires of distorted appetites are all forms of physiological education. Most of these have been embodied in book forms and are now taught in the school as regular part of the curriculum. In 
the lower grade schools this takes the forms of talks on "the care of the Body," "How to obtain and maintain a healthy Body," "the Vital organs and their functions," "The value of food and exercise," etc., accompanied later on in the higher grades by the use of distinctive texts on $\mathrm{Hy}$ giene and Physiology. In the higher grades of the public schools this is followed by a more minute and analytical study of the organs of the body, the nature of their functions, their relations to health and growth and how they may be properly cared for. In the secondary and higher institutions of learning physiological education is gained through the study of anatomy and its many related subjects - the so-called physiological sciences. Though in these latter there is much less of hygiene than is learned in the more elementary forms of the physiological sciences. Physiological education includes the teaching of how to prepare food and balanced rations, how to chew and masticate food, how and in what quantities to take food and exercise, when to rest, etc. By this the value of it as a form of education is at once seen and appreciated.

Apart from this form of physiological education, in the higher courses in advanced institutions of learning is to be found as a practically newcomer in the field of the natural sciences, the science of physiological psychology - the relation of the bodily processes to the functioning of the brain. This form of physiological education is very valuable to the study of the processes of mental education and has given much needed explanations of conditions and problems that were a source of inconvenience and obstruction to educational processes in general, but for which no sufficient remedy had thus far been found. When physiological psychology made its advent upon the scene it gave new facts and added new zest to physiological education in general and showed in a way never before known what proper physiological education means to the bodily and mental welfare of a people. The value of certain food values as shown by dietetics have all given increased impetus and strength to physiological education.

The importance of physiological education forms a marked contrast to the astonishing neglect of it by many schools 
and most parents. In the case of the human body a few ounces of prevention is indeed better than many pounds of cure. Intemperance in physiological habits and ignorance of the simplest laws of health combined with indifference toward and neglect of the few laws of health that we may happen to have learned is the sorrowful explanation of most human ills. The fearful percentage of infant mortality and the alarming presence of such bodily ailments as constipation, and dyspepsia with their hosts of related ailments, colds, consumption, catarrh, fevers and the other myriads of human maladies are chiefly traceable either to a lack of or general disinterest in, the dissemination of physiological education. Here ignorance is a withering curse that spreads misery and woe everywhere, which like a blighting frost in the night falls upon the innocent and unoffending and nips off the young buds long before they have approached the season of flower and fruit. The burden that present day economic problems force upon the successful man necessitates care of the body as never before. With this burden upon him he can little afford the physiological handicap of overfeeding, underfeeding or irregular feeding and in fact he can afford no kind of irregularity in habits. In the time of epidemics, pestilences and scourges proper habits of bathing and of resting are of as much importance as physicians' medicines and druggists' disinfectants. 'To be fully effective then, physiological education would involve a training in the feeding, cleansing and clothing of the body together with a knowledge of the proper care of the internal organs assisting in the vital processes and their relations to and dependence one upon the other. In formal educational processes this is attained by instructions in physiology, hygiene, anatomy and its allied natural sciences, and still more recently by the introduction of courses in domestic economy, domestic science and household arts, but more especially through the domestic science courses.

Physical Education. Physical education and physiological education have much in common. The fact that generally what little writers have to say about physiological education they include under physical education will serve 
to show that the conception of them as identical or nearly so is quite common. Hence the lines drawn here may not seem justifiable, nor even acceptable, to all. However, granting all or even part of what is said under the one may be included under the other, there are still good reasons based on fact for separating them, and the conception of them as distinet is both clear and logical. For at bottom all of the forms of education are closely inter-related and consequently much of what is said under one head might oftentimes with reasonable clearness be included under the other. However there is a justifiable distinction as the facts present will show.

The current dictum that each generation grows weaker and wiser seems to bear the test of scientific analysis. Scientific study has disclosed the fact that the life span is steadily growing less than the accepted thirty-three years and also that in stature and endurance man is smaller and weaker than even his near ancestors. While this is partly explained by the demands that the strenuous life of to-day is making upon our bodies, it is also partly due to the fact that physical education is not keeping pace with intellectual education. In ancient times physical education was a prominent part, indeed the most prominent part with some countries, of all education. Oftentimes as among the Greeks (especially among the men of Sparta and Lacedemonia) and the Romans it became the all absorbing part. Later under the stress of other social and civic problems it was gradually neglected until under the influence of the stoic and later the ascetic of medieval times it was entirely lost sight of or neglected in matters of education, and only comparatively recently did it appear again and gradually assume a place of steadily increasing prominence in the modern schemes of education.

The need of the body for exercise as well as rest, food, cleansing and clothing has always been more or less tacitly implied when not indeed overtly stated. The general assumption however, has been that this demand was not as imperative as others and could be supplied without any special provision for it in school systems and educational institutions. For this reason while nearly every school has been indis- 
criminately provided with playgrounds, comparatively few schools have provided themselves with the means of systematic physical instruction. The fact that we are born with physical defects as well as mental, and that we cannot " just grow up" physically any more so than mentally is being finally though tardily appreciated by those who are clothed with the authority and charged with the responsibility of looking after and providing for matters educational. Even after much discussion and agitation the best that has been attained along these lines in formal education is generally physical training, carried on by means of gymnastics and calisthenics in rather restricted quarters, and during very limited periods of time. In higher institutions of learning it is somewhat better. For example, in this country practically every college and university of any consequence has its gymnasium, which is in charge of a physical director, wherein the students are given physical entrance examinations and classified according to their various physical abilities and shortcomings and these either developed or overcome and removed. To what extent and on what scale physical education is being conducted in these institutions one can only know by either visiting one of them or by reading carefully prepared illustrated descriptions of the courses outlined and the work done. There are classes in physical education organized with practical exercises for the development of the eye, ear, nose, throat, lungs, stomach, the back, kidneys, neck, chin, face, limbs (arms, hands, fingers, legs, feet, toes). Also courses for the development of the body as a whole such as exercises to produce symmetry in form, beauty of figure and grace in movement, are offered to all who need them as the regular accompaniment of the other regular courses, literary, technical, professional and vocational. In the public school, of course, not so much has been done or can be done both on account of the general purpose of the public school and the nature of the duty which it aims to perform for the citizenship as a whole.

However, in the public schools of those cities where the problem of physical education has been given an attempted solution the issue is met sometimes in pretty much the same 
manner as is done in the colleges and universities. But more often it only approaches it as nearly as the means at hand will permit. Where means for physical education are wanting the problem is met as best it can be. In those places where the presence of funds permit there are physical directors and assistants provided by the authorities, who visit the schools, and give exercises in calisthenics calculated to remove the strain of the mental educational processes and at the same time to improve the body. Because of the relation which this kind of education is seen to bear to the other forms of education, and in the important place which it has come to occupy in our educational processes, many school boards are requiring the teachers to prepare themselves to teach some form of physical education in their schools, indoors when necessary and out of doors when the weather will permit, offering this as the nearest and best substitute for a physical education which their limited means will allow them to furnish. In those cases in which the physical education is conducted on a technical scale, the physical directors are assisted in their work by examining physicians whose duties it is to visit the various schools and examine the students for evident physical defects and recommend for them the appropriate forms of physical training. In many cases here, too, the work has been carried sufficiently far to be graded and to extend with the grades throughout the school course.

But physical education par excellence is carried on in American Schools by that system of training provided for now by all secondary schools and schools of higher learning under the name of athletics. This form of physical education has become a fine art in many American institutions, so much so that it has called the attention of the world to that particular phase of our work and in many instances national governments abroad are sending representatives to us to study and master our athletic systems for the purpose of having them introduced and taught in their respective countries. In many cases athletics like many other popular things have been carried to excess soon thereafter to fall into disfavor and in a few cases even into disuse. Here 
oftentimes the claim is justly made that the process is carried to too great a degree of specialization and this also at too great a sacrifice of time and money. Another strong objection to the American method of athletic training as a fitting substitute for physical education is that the former system is too highly selective and, as such, benefits only those few who possess rare ability and power of endurance in a given line, these being used for purposes of inter-scholastic competitive tests and exhibitions, to the neglect and even complete exclusion of the remaining major part of the student body. Apart from these objections however, which have some foundation in truth, it must be said that much of the sturdy American manhood and power for strenuous activity which has become a national characteristic and an international social asset and which is a joy to every true hearted American may be traced directly to our competitive system of school, college and university athletics, - football in the fall, basket ball, indoor baseball and hocky in the winter, with baseball, handball, rowing, golf and tennis in the spring, which with a host of minor games added to the group and strung out through the school and calendar year make up the whole. On the other hand the gymnasium and every form of athletic sport as fostered and supported by the school authorities are absent from the systems of Europe, though calisthenics and other forms of physical education in the public schools of Europe are much the same as in America. In fact in some cases, especially in the public schools, much of the European method has been adopted in the larger American city schools. The gymnastics and calisthenics systems are developed to their best in some of the countries of Europe for mass training in the open air. At the head of such countries perhaps stands Switzerland where in some of the cantons the whole able bodied male population having been trained in the schools during their school days join on festal occasions in physical drills in groups of a thousand or more. Closely following the lead of Switzerland in this kind of physical education come Norway and Sweden. In America the college hero is " the mighty athletic warrior," the champion of his school in many "gory" contests. In 
Germany he is a great beer drinker and saber fighter (duellist). In France he is a great wine "bibber" and saber fighter, while in England he wins his right to the title by his prowess in cricket, football (association) and tennis.

The demand for a physical education is quite generally recognized and in most cases proper provision made for it by those charged with the responsibility in such matters. In only a few cases, however, is the real need of physical education for the growing child fully understood by the masses of the people. The physical strain upon the ordinary child in performing the duties of the daily school routine is severe. Much more severe than many teachers and parents realize. Occasionally this fact is brought forcibly to our notice by an extreme case of suffering, sickness and even rarely by a death. But we pass even these flagrant cases by without more than a passing thought, little imagining that the situation may be brought home to us at any time by a similar case. The strenuous activity necessary for success in modern life puts an ever increasing strain upon men of the world. The growing intensity of competition taxes the energies of both young and old to an ever increasing degree. Indeed so great has this strain become that its weakening and destructive effects are now traceable into the life and powers of the younger generation. The children of today are born weaker, more nervous and emaciated than those of former generations. On the other hand this weaker constitution received through heredity is called upon to bear even greater strain than that of the older generation. The curriculum of the school is steadily increasing both in the number of subjects and in the degree of complexity of the treatment in the texts used. Under this strain the youthful body unprepared at the start and with poor and meager opportunities for physical education must of necessity weaken and in time break down under the strain. One need but visit the schools of the congested districts of our large cities to see the effect of this neglect of physical training upon the youth. Pale and worn faces everywhere meet the gaze and investigation shows the fearful prevalence of headaches, constipation and dyspepsia. In boarding schools this condition 
is generally intensified. In both of these there are occasional breakdowns, nervous prostration and sometimes fevers. Mind and body are so related that this fearful strain on mind soon shows on the body and the bodily functions, resulting ultimately in producing a weaker and in every way physically an inferior generation. The law of Lamarck that use of organs strengthens, disuse impairs, and abuse destroys, certainly holds good here. The only remedy for this condition of strain and over exertion is to balance it by proper physical development induced through a proper physical education.

Most of what has been said about the provisions for physical education, especially athletics and gymnastics applies chiefly to physical education for boys. Strange to say that those who are most in need of physical education by their very nature and social responsibility - girls - are given the least consideration and opportunity to obtain this kind of education. One of the most serious traditions inherited from the past and most obstructive to progress in this matter is the idea that girls should be brought up delicate and weak. Though much has been accomplished in overcoming this traditional idea and much is still being done to break the fetters of this dangerous tradition, the girls and women of the race still suffer woefully from the restraint upon them in indulging in the various forms of physical and bodily exercise, a restraint maintained almost solely through an unjustifiable and even maudlin sentiment. It is surprising to see how strong and widespread is this sentiment. Women and men otherwise advanced and liberal in thought are narrow and biased in this one particular. Mothers and teachers who will witness with deep pleasure the health and vigor of a growing boy, obtained through unrestrained indulgence in play, will throw up their hands in horror at the very thought of a daughter indulging in any kind of active physical exercise in any way so violent or intense. Still, let it be said with pleasant and cheerful expectation of its constant extension that a counter sentiment has been awakened and has already done much for the benefit of our girls. Many schools for girls nowadays are equipped with gymnasiums and physical directors and in many co-educational 
institutions the girls share the gymnasiums equally with the boys, generally having access to its equipment during certain parts of the day or on certain days during the week, at which time under the watchful care of a properly trained attendant their physical education is looked after. The physical education of women is however chiefly cultural, consisting of gymnastics, calisthenics and exercise in dancing, walking and sometimes in advanced courses in rowing and fencing. More recently many out door games have been opened to them such as basket-ball, tennis, golf, etc. in which in some cases they have gained prowess equal to men and compete with them ably in open contests. A very recent custom to open to them in many sections interscholastic competitive contests has been inaugurated, thus adding a purpose, zest and spirit to their efforts in gaining physical power through physical education. Where gymnasiums could not be had open air gymnastics and calisthenics have been provided for the girls until to-day the sentiment is pretty strong for a physically well developed womanhood to keep pace with our sturdy manhood.

Industrial Education. In the trend toward popular government, popular education and democratic institutions, new forms of education have been introduced to meet the new responsibilities of new civic and social relations and to create new opportunity for the masses. To meet these new demands manual training schools, vocational schools, industrial schools and agricultural and mechanical colleges have been established. In America the industrial school is a popular form of the technical school which has become general in the public school systems of Europe as trade schools. In many European countries the system of apprentices is still in vogue where the youth are bound out as artisans under stipulated conditions that they may learn the given trade or profession. With us the technical school was the first to appear. Later in reaction against the theoretical and abstract education of our public schools and institutions of higher learning there was created after considerable agitation a demand for a more practical education. The Sloyd system of manual training was first introduced from Scan- 
dinavia and later on this movement was extended to include various trades. A particularly strong demand for this kind of education was created by the emancipation of the Negro slaves of the South. To meet this demand Hampton Institute was started as an experiment by Major Armstrong. Out of it grew Tuskegee. Both of these proved their practical value and usefulness until to-day there are many such schools throughout the country, but chicfly in the South daily proving their worth by the kind of training they give and the product they put out. The aim of this work was originally for the Negro. But in the agitation and spread of it among them the general value of such education to the entire American citizenship was soon seen and the agitation for such schools increased in scope until it included a scheme for schools of this kind for whites as well as for blacks until now opportunities for industrial and vocational education is offered almost everywhere in the larger cities of the country. In many cities such as Philadelphia, Boston, Pittsburg, St. Louis, these manual training schools are the pride of the school system and the attendance at North East Manual Training High School, Philadelphia, is greater than quarters will allow for accommodation. Maryland has taken the lead among the states in this movement and has a state educational fund available for the conducting of such work in all of the public schools of the states. The providing of means of the teaching of this kind of work is made compulsory on the part of school authorities, the failure to provide such opportunity being penalized by the loss of the pro rata portion of the state fund for such work. On the other hand attempts to introduce such work in the schools have in many places met with serious and successful opposition. Buildings put up and equipped and teachers employed have often been idle and attendance poor until in some cases the movenment had to be abandoned through lack of popular support. In Harrisburg, Pennsylvania, such conditions existed. The custom has been introduced in most sections of exhibiting at the close of each school year the work done by the pupils in the public schools under the head of manual training. These exhibitions have always proved interesting 
and instructive. Besides serving to win over the opponents of this kind of education to its cause, the exhibition itself is generally a source of agreeable surprise at the degree of efficiency and skill which the students show that they have gained during the brief hours of training and the meager opportunity and equipment for the work. It seems to fall short of the work of the commercial world only in point of speed in production. Some of it is so fine in its evidence of workmanship, mastery of detail and evidence of skill in tool manipulation that we can hardly believe that the objects made were the work of boys in their early "teens." In the manual training schools the work is never pursued to the points of a finished course, but merely offers a kind of introduction to the work and this only in its lighter and simpler forms. In the industrial and vocational schools the aim is to put out a finished mechanic who in speed and skill is able to compete successfully with the practical artisans in the various fields of labor. Hence in these schools more time is spent in the work with better equipment and the working conditions are more conducive to the results desired. Many industrial and vocational schools endeavor in their trades offered to cover much of the field of the general trades and handicrafts.

As a result of this same demand for industrial and vocational education, engineering and mining schools, where electrical, mechanical and civil engineering and courses in mining and metallurgy are taught, have been established in various places (instance the Roller School of Mines in Missouri, and the State Schools of Mines in Oklahoma and Colorado). In supplying this same demand agricultural schools, the present agricultural and mechanical colleges, have been started in nearly every state in the union. How large a gap this form of education fills in our educational systems and how strong the tendency toward it is, is shown by the wonderful popularity, magnificent financial support and large attcndance which these institutions enjoy. 'The agricultural and mechanical colleges hare become even more popular since to break up the constantly increasing congestion in cities with its disease, poverty and crime, "back to the 
farm" movements have been inaugurated both by private individuals and by the local, county, state and national governments. To work up interest and enthusiasm along this line where opportunities to go to school cannot be accepted, government experts go conducting " moving schools." Railroads have recently joined this form of educational work and "agricultural trains" manned with expert instructors by the state and supplied with large exhibits make annual tours from city to city, also to town and hamlet and give expert instruction as a supplement to the agricultural education of the public school and the more especially equipped ligher institutions for such training. All of these schools and movements represent one more step in the present day trend from the abstract, impractical and valueless in education to the concrete, practical and valuable. They fulfill a demand only recently realized and appreciated but which has proved to be amazing in scope and relation. It is a welcome sight under the near democratic education to walk into a school, where alongside of the much decried but still valuable Latin and Greek and abstract sciences and the less objectionable but still highly cultural French and German, one may gaze upon the happily engaged classes in domestic science, household arts and home cconomics; or in the more remote parts of perhaps the same building amid the whirr and buzz of machinery, that give the school the air of the busy industrial world, to see the classes in woodwork, machine work and smithwork all alive and with a step and bodily movements keyed to the rush of machincry, is equally pleasing. Each speaks volumes. The future of any nation with such a coming citizenship is easily safe. The educational effect of this kind of education for the weal of the masses can hardly be estimated. From these schools the boys and girls go into the home and the world of business and industry, carrying with them an enthusiasm and a knowledge of new values and relations that broaden conception of human life as a whole and add much to human happiness.

Moral Education. Moral education may be defined as that kind of education which teaches us the habits of action and thought of our fellows and our relations to them in 
regulating our own habits of action and thought. As such it has always been given a prominent place even in the earliest types of formal education. At first it consisted merely of a training in the national habits and customs and the general manners of action of the people, as well as training in the written and expressed laws of the land. Though later separated much of early moral education was a training in religion and religious rites and customs. As mankind advanced in the scale of culture and refinement the moral code became more extensive and began to take on its more modern form until finally moral education as conceived of to-day and as taught in our schools partook more of what we might for clearness define as social usage. To-day moral education is not given a very prominent place in our school curriculum. Indeed it seems chiefly to serve the purpose of "chinking in gaps" in our regular weekly or monthly program. It is limited chiefly to instruction in social usage, such as the value of the simple virtues and courtesies and talks on patriotism in the attempt to arouse national pride and a respect for our civil institutions. Often and with credit it takes up such subjects as respect for the aged, the sick and afflicted, the poor and the weak and helpless. Sometimes again it branches off quite distinctly into manners proper. In a broader sense moral education deals with tendencies, instincts and habits and the formation of what we call good character attained through an effective training of the will. In this scnse in a general way by monthly, bi-weekly or weekly talks and by such opportune additions as the teacher may perhaps find time and occasion to give instruction, a moral education is provided for by the schools. In this harum-scarum way but little effective education along moral lines is done. When, however, we stop to think of the moral imperfections in ourselves and our fellows and how much human suffering is caused thereby, we marvel at the little provision that is made for this kind of education in the schools. When, again, we think of the moral pitfalls, that we must pass from day to day and what effective willing it requires even in the minds of highest balance for it to weather safely the storms that assail on every side and how compara- 
tively few men and women there are who are well educated morally, the absence of well regulated moral training becomes even a greater mystery. That such training is needed one need only gaze in the daily newspaper and the current magazines at the stories of graft and political and business corruption throughout the country to see plenty of evidence. It goes without saying that a neglect of this side of our education will cast a shadow on our educational institutions and their product that no amount of mental brilliancy and an otherwise successful achievement will be able to hide or remove. In national ideals, in political life and in governmental methods we will be as a ship at sea without a rudder exposed to the merciless force of the raging billows, helpless beforc our own depravity and weakness.

There is a still broader sense in which moral education is used, - that of procreation and the rearing of children and teaching them conformity to the laws of nature and man as established in both the natural and artificial system of rewards and punishments. The duties of parenthood are the most serious that human beings are called on to perform, in that all neglect, impropriety or ignorance in performing them is more fatal to mankind than in the case of any others. And yet this form of education is almost entirely neglected despite the fact that it is a very complex problem and cxperiment in it most costly. By reason of this neglect human children are very poorly born. But if this were all and the problem ended here things would not look so bad. For owing to the general pliantness and plasticity of the infant and child together with the high degree of impressibility of the growing mind of youth, proper nurture could easily undo much of that which an iniproperly aided and controlled nature had done. While the birth of children is bad, their rearing is generally infinitely worse. The liome is the first place where the awakening mind comes into contact with restraint under law. Upon the nature of these first lessons, their consistency and justification in reason depends the attitude of the child in the future toward all forms of restraint and law during his entire life. Here above all other cases a moral education on the part of the governing is very neces- 
sary. Will power and character must show themselves. A broad understanding of cause and effect as well as of moral law as manifested in the play of forces in the physical world is necessary - especially that form of it which shows the severity and sureness of punishment consequent upon wrong doing. Feeling and passion are absolutely incompatible with a successful system of moral education. In the home and in the state much more uniformity in human conduct both in action and reaction would prevail if there were more extensive and more effective moral education, especially in this last broad sense.

Esthetic Education. There is no phase of education that brings as much direct pleasure to man, that affords him more simple joy in living than esthetic education. Esthetic education is based upon the natural and instinctive capacity which all men have for desiring the beautiful, the sublime and humorous in life. It is the training and developing of this power to further perceive, appreciate and enjoy the beautiful, sublime and humorous in the environment. Its greatest possibility of exercise and development as well as of enjoyment lies in the field of nature, art and literature. 'The services which esthetic education renders to humanity are many. Turned into the physical nature they exalt and refine, turned into the intellectual, they increase human happiness by making mental processes appreciative, while turned into the moral nature they serve as a powerful check on all tendencies to evil deeds and on all that is vicious and degrading in human conduct.

Genetically, while the faculty of esthetic perception (the esthetic sense) appears quite early in life, it is at its highest power of fuctioning during the early years of puberty, appearing usually at about the age of fourteen or fifteen years and maintaining a maximal degree of activity until the age of nineteen or twenty where it maintains itself for a while and then begins slowly to wane, the process of waning differing in different temperaments. The aim of esthetic education is to create in man high ideals. When he is esthetically educated he becomes able to appreciate the world about him as made visible in color, form, motion, sound, etc. 
Practically, esthetic education is offered more exclusively in such arts as painting, molding, sculpturing, in such sciences as music, clocution, poetry, fiction, ethics, astronomy, philosophy and religion.

Historically because of the low cultural position of man, his proximity in the way of living to the lower animals and the fact that the struggle for existence which was made severe by his political status caused him to spend most of his time in "earning a living" prevented in the past and still prevents to-day the masses from enjoying esthetic education. Again esthetic education has been and still is confined chiefly to the leisure class. This being a fact, since they could create the opportunity for such education in their own way and since the remaining groups of men had all they could do to agitate for and demand other phases of education, esthetic education has received but little special attention and as a branch of general education has yet to come fully into its own. The public educational systems of the country are beginning to increase the opportunity which they offer for esthetic education. In all cities of any size in the country there are specially provided courses in drawing, music and elementary clay modeling and molding. In most of such cases there are specially prepared supervisors who map out courses and keep the system graded and harmonious. The introduction of folk dances in the school tends to contribute in a general way to esthetic education. However, esthetic education in its entirety is still regarded to a great extent as cultural and a luxury fit only for pursuit by the leisure class. Even the higher schools and colleges where distinct courses in esthetic education are offered show their attitude towards it by imposing upon those who seek training in such courses high duties in the forms of excessive fees. Many such schools offer extensive courses in rhetoric, elocution, music, drawing and painting, but few of these offer as yet extended courses in sculpturing. Education in sculpturing is chiefly restricted to apprenticing and private tutoring. In fact much of all forms of esthetic education is in the hands of private individuals, who pursue it chiefly for financial gain without any thought of fitness or the capacity to 
give value for value. Just a few higher schools supported by public funds either in this country or Europe offer courses in painting, sculpture and are in general patronized. Private schools for it abound everywhere. There are art studios of considerable note in such cities as Philadelphia, New York, Boston, in this country and in such cities as Paris, Berlin, Rome, Venice, Milan and Edinburgh, in Europe. Many schools in this country offer well elaborated courses in art and architecture. However, despite all that is being done along these lines for esthetic education, because these efforts are chiefly private, and because private efforts are always ill-organized and often at loggerheads with itself, esthetic education will not come fully into its own until it is taken over more extensively by the systems of public education where the chief problems of education are and must of necessity be solved. That the opportunity for good which esthetic education offers to society and the state would justify such an undertaking few will dispute, nor will they deny that esthetic education as a creator of high ideals, lofty emotions and a love of the good, the pure and the refined in life, and hence as a regulator of human conduct for good, can not be surpassed by any other phase of education. Here, then, in esthetic education is a virgin and fertile field for expansion in educational endeavor.

Religious Education. In contra-distinction to moral education, religious education aims to fit man for the fulfilment of the duty and responsibility devolving upon him out of the relation he bears to his Maker, God. It aims to acquaint him with the truths of nature and of the revealed word, with the varied creeds and canonical laws, and with the teachings, dogmas and tenets of the church catholic and of the various denominations in particular. Much of this kind of education we have inherited from medieval times when the church and state were not separate and each had a coordinate sphere of influence. In most of the countries of Europe the state has not successfully alienated the masses from the church and therefore often yields to the pressure from ecclesiastical bodies that they be allowed to teach religion as a regular subject in the public schools. In France this is true, though 
the separation is of more recent date. In Protestant Germany however, by a compromise effected under pressure of the church by the commissioner of Education, though religion is taught as a regular subject in the public schools it is optional with all and parents may at will either keep their children at home or send them to school during the period for religious instruction (die Religionstunde). In America because of the desire for freedom in such matters no religious education is offered in higher institutions of learning or schools supported by public taxes, though they all hold some form of devotional exercises each day and in some cases talks upon God and a future life and the benefits of right living are given from time to time as occasion may permit or demand. In denominational schools the various religious services of the respective denominations are used, bible classes held, courses in various subjects in theology offered and denominational religious literature is taught. The effect of this neglect of religious education in protestant and democratic countries is easily apparent in the lowered religious standards, the falling off in voluntary church support and regular attendance and in general in a lighter regard for matters religious. This, because of its general tendency to foster atheism and infidelity, has become a source of alarm to the church. As a result some agitation is starting up to turn the tide of affairs in the direction of the church and religious education. That is, realizing what this neglect in religion means to its future growth, the church is seeking the cooperation of the state in pushing religious education. In this matter, however, the state having at the imperative demand of the church turned over to her the responsibility and right to control and direct religious education does not feel that it is in any way to blame for the dilemma of the church and responds sluggishly to the appeal of the church for a provision in state systems of education for a place for formal religious education. It has been proved that religious education left entirely to the church does not grow apace with state education. In the several centuries of the experiment, the church has been unable to maintain the religious education of the masses in competition with the education offered 
by the state. The education of the state has begotten freedom and an advance in thought with which the religious education of the cliurch has not kept pace. 'This the church shows that it knows in its very appeal to the state for aid by requesting that it put a course for religious education in its regular courses and maintain it on a par with the other subjects of the courses.

The Christian Associations, both the Young Men's and Young Women's associations have become a powerful educational force in American life. They are prominent in educational work in other countries, but nowhere have they risen to the prominence in such work as in the United States. These associations were originally church organizations but in time outgrew the church and sought their own quarters. They have not broken their original affiliations however, nor have they deserted their original purpose. But they have extended their sphere of operation and influence. The original purpose of the association was to bring within its doors and influence that element of the citizenship that the church could not attract. To do this it attempted to attract to itself by methods common to the world, but under an influence purged of the sin and corruption of the world. It afforded a place of amusements in a pure social atmosphere. It advocated a practical religion. To those who sought evening entertainment and reading it furnished it but under elevating conditions. Cleanliness was advocated and provided for. Association quarters were provided with sanitary baths and a swimming tank. As the attendance grew and support increased, more attention was given to physical education along with the religious. It took up social work, and looked up and found quarters for strangers in towns to keep them from falling into bad hands and in with evil associates. Gradually literary courses were offered, also vocational and industrial courses until to-day the educational work of the association is in many localities equal to similar work offered by some of our best educational institutions proper. The courses offered are generally simple, brief and practical and at times that will accommodate those whose work hours for self-maintenance will only permit them 
to give the hours of freedom from work to this kind of effort for education and mental, moral and physical enjoyment and growth. So rapidly has this work grown that in less than a quarter of a century it has grown from a few scattered organizations to thousands of branches with several million members. They own millions of dollars' worth of property. At present the parent organization is seeking a four million dollar endowment for use in meeting an immediate demand for housing quarters. While the young men's branch is the older, the young women's branch keeps up with it both in membership and field of usefulness. To-day the organization maintains branches in all of the higher institutions of learning with a large student enrollment. The future of this movement cannot be predicted. Its present usefulness as an educational force in society cannot be overestimated. In most of its local branches it is rapidly becoming a real educational institution, offering as was said all of the more important forms of education, reaching an element of society that circumstances will not allow to take advantage of the schools maintained by public and private funds under a different regime and for other classes.

Intellcctual Education. Intellectual education is education par excellence. All other forms of education are but variations of it. Formal intellectual education is as old as civilization itself. Since the separation of church and state it has become chiefly the burden of the state. Each state in accordance with the civic responsibilities devolving upon its citizens has offered them intellectual education. In democratic countries for all alike educational opportunities are free and equal. In limited monarchies where the " chosen few" hold the reins of government by right of inheritance educational opportunities are restricted correspondingly. The chief test of intellectual education seems to be on a basis of illiteracy statistics. Figures gathered during the decade 1890-1900 showed the United States to have onetenth of its population illiterate, England one-twentieth of its population so and Russia more than one-half of hers illiterate. The Negro is the chief cause of the high illiteracy in America. But white the Indian is more illiterate than 
the Negro his small numbers prevent him from affecting the general illiteracy average of the country to such an extent as that of the Negro. Next to these (the Negro and Indian) in illiteracy come the lower class of immigrants whose numbers cause them to affect decidedly the illiteracy percentage. In New York Mennsylvania twenty-five percent of the immigrants during 1900-1910 according to the national commissioner of education were illiterate. But in most states the number is about 5 percent. In the period 19001910 the Negro illiteracy clecreased about thirty percent, while that of the immigrant because of the constant influx of illiterates from Russia and the countries of southern Europe remained about stationary. The Negro illiteracy and the Indian illiteracy constitute a serious problem in education, but from the evidence of decrease in illiteracy among Negroes in the last decade it would seem that education is doing its work well with them. The immigrant presents a different and even more difficult problem in a way. For while the immigrant authorities and the United States Commissioners of Education claim that the immigrants and their children become rapidly educated the constant influx of illiterates among them makes the problem a never ending and almost hopeless one. This conglomerate citizenship places a severe tax on education and educational systems. Upon the success of the education given to all must depend the future of the country. The Indian is too few to endanger the national institutions of government and the Negro is so restricted in political power and the use of the elective franchise as to be of little danger. But the immigrants are large in numbers and eligible almost immediately to citizenship. They know little of our political and civic life. They are unused to our social ideals. Strangers to each, different in speech and creed, crowded together in poverty and filth they are an easy prey to political demagogues. Education here must deal with both old and young. All alike must be prepared for American citizenship and for free and full participation in our democratic industrial, social and religious life. Here education both of the school and of forces outside of the school has a very definite and delicate 
work to perform. Here adjustment must be swift and sure if the opportunities offered and responsibilities accepted are to redound to the perpetuation of our government and the. perfecting of our national ideals. Opportunity for education must be constantly brought within the reach of all. This is being done. Herein is the glory of our education. Intellectual cducation is being reduced more and more to a science. Realizing its burdens intellectual education is responding nobly. Special schools of education for teachers are being opened daily. State, County and City Superintendents are demanding higher grades of teachers and higher standards of efficiency in professional training are in vogue. School journals and educational magazines as helps for teachers abound. Everywhere intellectual education atuned fully to the spirit of the occasion is making fitting advance along the lines necessary for the future welfare of the nation.

Practical, Theoretical and Cultural Education. Besides the kinds of education discussed in the foregoing we mentioned also practical, theoretical and cultural education. While these are distinct kinds of education and obtained by a different viewpoint they do not require separate treatment as such. The terms explain themselves and since in the actual work no stress is laid upon them only a word need be added here in regard to their meaning and application in education. Wost of our education to-day is practical in aim, especially the lower grade work. Such of it that is not is rapidly becoming so because of the current demand for that kind of education. By practical education is meant utilitarian education, that kind of education that is useful in " baking bread." Of course all education has a theoretical side, the former is a necessary complement of the latter. The theoretical and abstract in education is the forerunner of the practical and useful. Theoretical education as such while it has its reason of being is only for the few and much of it has little value at least for the masses, outside of the historic walls of the classic college halls. As an advance agent of practical education it is indispensable.

In contradistinction to practical, theoretical education is 
not intended to be of any practical utility. Those who obtain it were not originally supposed to have any needs in this world's goods. For them it filled an intellectual and esthetic need. In this sense all education which we know now as a formal education was in its early history cultural, a luxury, which only the rich and leisure class had time to pursue. To-day though much of the originally cultural education is still regarded as such and in this light desired and sought, it has not escaped the sordid commercialism of the present. By many cultural education is made to " earn bread." Cultural education is to be found in the study of the romance and classic languages, music, art, poctry, sculpture, painting, drawing and stencil work. While cultural education has not the place in our educational systems that it formerly had, it should be said in all justice that no form of education has contributed more to the sum total of human enjoyment and to expand the soul life of man than cultural education.

\section{REFERENCE READING}

Putnam's "Manual of Pedlagogy." Chars. II, XI.

Compayre"s "Psychology Applied to Education." Chaps. I, III, XI.

Compayre's "Lectures on 'Teaching." Chaps. II, III.

Spencer's “Education." II, III, IY.

Huxley's "Science and Education." IV, XVI.

Putnain's "Elementary Psychology." Chaps. XIV, XIII.

Parker's "Talks on Pedagogy." Chap. XIV.

Morgan's "Studies in Pedagogy." Chaps. VI, VIII.

White's "School Management." Pages 105, 218, 239, 295.

Horne's "The Philosophy of Education." Chaps. III, VI.

Welch's “'Teachers' Psychology." Chaps. XV, XVI.

Roark's "Psychology in Education." XIV, XX.

Baldwin's "Psychology Applied to Art of Teaching." XXI, XXII.

Hughes' "Dickens as an Educator." Chaps. IV, XIV.

King's "Social Aspects of Education." Chaps. IX, X.

Sharpless's "English Education." Chap. VI.

MacArthur's "Education in its Relation to Manual Industry." Chaps. I, II, III, and XVII.

Dutton's "Social Phases of Education." Page 143.

Fitch's "Educational Aims and Nethods." Chaps. III, V.

King's "Education for Social Efficiency," XII, XIII.

Hanus' "Beginnings in Industrial Education." Chaps. II, III, IV, V.

Snedden's "Problems of Educational Readjustment." Chaps. I, VIII, IX.

Adler's "Moral Instruction of Children." Chaps. I-V. 


\section{CHAPTER IV}

\section{THE AGENCIES IN EDUCATION}

In the opening chapter of the text it was stated that the term education had a broad and a narrow use. In its broad sense it includes all of the influences which combine to modify our mental structure and give it increased activity. These influences begin their work imperceptibly in the embryonic stage which later become perceptible at birth and continue so until death. In its narrow sense education includes those influences which are restricted in their effects to certain life periods, certain periods of the day and of the calendar month and year and which are given over to the direction and control of certain idividuals who labor at certain specifically provided places and under certain given conditions of restriction and confinement. In its broad sense these influences of education are limited only by the life history of the individual and the forces of the universal environment, and include all of those influences which tend to modify one's life, mode of living and form of conduct. In its narrow sense education is usually intended to carry with it conceptions implied in the terms instruction and training which we get in school and which are planned directly, of ten laboriously and after much experimentation with an intent that is purely educational. It is in this latter sense that the term education is most generally used. However, since the influences of education cannot all be brought under the head of education in the narrow sense and also in order to obtain a broad conception of education and educational factors we will pass in this chapter from what we distinguish as scholastic education to what we have earlier defined as education in general. The factors of education regarded from the viewpoint of convenience of treatment and for reason of the natural sub- 
divisions into which they fall are in the order of their ascendant powers over the individual, the home, the school, the church, the state and society. A careful study of these factors will show that they are not all planned equally with a view to the attainment of educational ends. Some are planned purely for this purpose, others only partly for it, while the others scem apparently not planned at all for this end. Hence as directly educational in intent these factors are either regulated or unregulated. Though it is plain that we can establish no division of these factors with a strict line of demareation between them such as the nature of the treatment and conception here would demand, yet on the contrary they will overlap each in many ways, and each in the distinctive subject matter, will extend to some extent into the field to be delegated to the others. This is only as the agents themselves run each one into the other. The home, the school, the church, the state and society, each has some things in common and some phases that are peculiar to itself and that serve to differentiate it from the other. The factors or agents in cducation may be in general, despite the general points of likeness and overlapping in conception, divided into two groups, this division being upon their original educational intent, and agreed upon as adequate for the purpose here intended. They are the agents that are definite and regulated and those that are indefinite and unregulated in their educational intent. Those factors definitely organized for and immediately directed toward the accomplishment of educational ends are, the school in its entirety, the church in certain of its functions, the home in most of its functions, and the state in some few of its. Society is so only in a general but to a very extensive and effective degree. Those factors most indefinitely organized and unregulated as to their educational intent but tending at the same time to disseminate knowledge or bring about knowledge giving experience and to direct human activity include society almost in its entirety and the state to quite an extent. On the other hand, the church and the home have functions that are not intentionally educational in their effect but which must be conserved in order not only that 
educational ends may be achieved but even that social ends and life itself may be achieved.

The Home. The home broadly speaking is the chief as well as the oldest institution either social or non-social possessed by man. If understood in all of its relations and properly administered in them it becomes also the most powerful factor for good to which man has access. The reason of being of the home lies at the bottom of the procreative instincts, and is necessary for their full exercise. As an institution the home is primarily for producing and preserving life. All of its other functions are second to this great one. Education itself was and still is mostly a secondary, though, in the earlier stages of home life, a no less important function of the home and as such is and has always been an unregulated and unorganized factor to this end. As civilization has advanced and the civil and social life with its increased duties and responsibilities has become more involved and complex, educational demands became greater as did many other demands upon the normal forms of human existence. Many of the functions of the home earlier regarded as secondary became primary and to-day remain coordinate with the reproductive and preservative functions of the home. Apart from furnishing food, clothing, shelter and protection to the young lives that come into it, and creating and maintaining normal and wholesome conditions for the full growth and development of this life, a very explicit duty of the home is in a manner especially fitted and properly regulated to educate its inmates in a way to promote human welfare and to produce happy and healthy members of society.

The chief cause of the failure and inefficiency of the educational processes of the world to-day is that the unregulated processes of the school is not properly supplemented by that of the home. If we were to have regard for the most important factors in education, time, physical and moral control, mental responsiveness and community of interest all well tempered with love and sympathy and a disposition to self-effacement in sacrifice, we would make school education supplementary to the home instead of the reverse as it mostly 
is to-day. It is one of the most serious misfortunes of mankind that its members are permitted to become parents without any care being exercised to sec that they either possess a definite or a correlated knowledge of the duties of parenthood or that they possess any trained fitness for the performance of these duties even should they become in any way known. By the order of things all education of necessity begins in the home. All parents both civilized and uncivilized know that this education of the home nust and will be supplemented by an education received in the school or from other sources later in life. All home education should be regulated, systematized and graded to such an extent that it will be available in the educational processes of the school and of life. They should not, howerer, be so regulated as to become a strain or source of worry to the young child and thereby either dull his faculties of knowledge or produce bad effects upon any part of the growing and expanding organism. For education in the achievement of its ideal should aim at the formation of a being as well made physically as mentally and morally.

The first duty of parents with children is to start the physical organism of the child off properly in life. The beginning of this should be in themselves. They themselves should cultivate a soundness of body and mind and vigor in their bodily functions together with a high degree of development of their esthetic nature. They should surround themselves in the home with a pure intellectual atmosphere. Having made these a part of themselves either by nature or nurture, the laws of heredity will bring them into effect upon the child even in the earliest embryonic period of the prenatal life. After birth these elements now grounded in the organic structure of the child they endeavor to follow up and expand by guiding and directing through the knowledge which they have gained and the tendencies which the child has inherited into a wholesome application and use with an especial view to the relation and association which will be the child's in his present and future experience and contact. There is a natural unfolding both of mind and body accompanying a natural organic activity. Though this 
tendency to organic activity may seem at times overly strong and the energy which it presupposes superfluous, it should not be inhibited, but controlled and directed constantly toward a goal to be found in the type of civilization and government into which the child is born, and sooner or later is to take his place as a self-directing responsible moral agent and who as a factor in it is to exercise force. But here the duties of home do not stop. They extend beyond the immediate bounds of the home. This those at the head of the home and responsible for the proper direction of its affairs should not fail to recognize. But having thus controlled and direeted the forces which have been by nature instituted in the home, parents should interest themselves actively in the manner in which the other agencies of education perform their functions. Failure on the part of any of these agencies the school, the state, the church, society, will ultimately return with power and evil effect upon the home and either destroy its effectiveness for educational ends or destroy it entirely. How the educational ends of the state, the church and society are administered is vital to the home and in their administration, must, if for no other reason than that of self-preservation, be influenced and to some extent shaped by home influences if the home itself is to be able to pursue its own educational ends satisfactorily. In particular must the home see to it that the school performs its functions and the general and special values of those functions in the general life and the relation of those functions to the corresponding functions of the home. Were this practice commonly followed, much of the useless in the school as well as much of the evil could be and would be quickly removed. A watehful, sympathetic and reasonable parentpatronage is always conducive of good results in a school. But apart from the intelligent agitation and reform that could be thus effected, the home knowing by close contact and association what the school is aiming to do and how well it is succeeding in accomplishing its aims could easily and with great benefit to all education and all educational agencies intelligently supplement school education with home education. Especially would this be possible where there is 
for any cause, justifiable or not, remedial or not, serious neglect in the work which the school purports to do or only partially does. Again, on the other hand, the home could inform the school of what it aims to do and how it is attempting to accomplish its aims and in turn what it wishes done, and thus produce a kind of mutually reciprocal cooperation which if undertaken intelligently and in the proper spirit is teeming with large possibilities of good. Of course all of this does not mean that the home must meddle with the affairs of the school in the detail of its working. No one could safely advise that. But what is meant is that the representatives of the home should have a definite idea of what it wishes accomplished by the school and opportunity should be given for those charged with administering the affairs of the schools, namely superintendents, boards, principles and teachers should have opportunity for coming together and counseling over such matters and in a general way of agreeing upon the things that the school should aim to accomplish in order to facilitate and supplement the educational efforts of the home. Public sentiment is a controlling force in developing the growth and development of democratic institutions in a democratic country. Schools, superintendents, boards of education and others in authority in school matters could not long successfully withstand an intelligent, consistent, as well as insistent demand from its patrons in regard to the work which they authorize and direct. Whatever public sentiment demanded in education either as supplementary to the education that is attempted in the home, or as corrective of such conditions in education which the home found it impossible for any reason to control, would be almost immediately forthcoming. Thus there would be produced an effective progressive education both in the home and in the school, resulting in a brief period in a like improvement in the kind of education obtainable from the church, the state and society.

Some of the things in which the home could educate and be ably aided by the school are a rational care of the body and mind, due regard for law, extending from the simple rules and regulations of the home to the relatively more 
complex and comprehensive ones of the school, the state, the church and society, morals, manners and the various forms of etiquette and conventional usages, courage, and manly integrity, social diversions, and social rights and privileges. Also in a way the home can regulate the school curriculum and maintain therein a happy normal. Because of a lack of proper adjustment and coordination in the educational work of the home and the school much confusion results in our domestic, civil, political and social life and habits. There is between them not a sufficiently definite understanding, simply because the teachings in the one did not properly accord and harmonize with the other and those conceptions gained in the one as proper were more or less out of harmony in the other, the breach of law being therefore more a mistake attributable to the flaws of the methods and agencies of our general educational methods than to a wilful act of misdemeanor on the part of the individual. However, let it be said in all justice and with open pleasure that this does not occur nearly so often as do the more innocent but no less painful and humiliating transgression of the social laws by individuals uneducated by the home, the school and the church. Whatever of blame for inefficiency and failure may rest upon the other agencies in education the home must bear its part. Parents are only too prone to shirk their duty and then blame the school for the deficiencies and shortcomings of their children. At best the work of the school can only be narrowly restricted. It is left to the home and the other living agencies of the world at large to magnify and intensify that which the school has done. In order to do this I repeat from above each must know what the other aims to do, and how well each aims to do its part, and also how well each succeeds in the attempt. In this way then, each can know what to expect of the other and see to it that each, at least to some extent, does what it pretends to do, in the manner in which it pretends to do it and to the degree of its pretentions. Whereupon the home, the church, the state, society each can lend its efforts to enlarge, intensify and supplement the work which the home has done.

The School. Genetically, the time was when all of the 
functions of the school were carried on in and by the home. Since then by a natural process of evolution, the school has become divorced from the home and now occupies a place and performs a function as vital and necessary in the economy of life as that of the home. As mankind progressed in civilization his duties and responsibilities as well as his relations in life became more and more complex. Consequently, the preparations for life necessitated thereby became more extended and increasingly comprehensive, and the home becoming gradually overburdened through this natural expansion delegated much of its responsibility in education to the school. Inasmuch as educational methods kept pace with growing and spreading civilization the school found that it had its hands full merely to master and apply them, to say nothing of the burden of assimilating and disseminating the knowledge now so rapidly accumulating, as a result of the highly developed mind and constantly growing intelligence of man. Besides this, apart from all that has been said and written about heredity and the transmission of acquired capacities, knowledge has been found to be impossible of transmission either by laws known to man or by chance, but must be gained if possessed at all during a period especially provided for by nature and if we are to judge by its apparent fitness it is to be gained chiefly during the periods of infancy, childhood and youth when the human body is by nature in its stage of greatest pliantness, plasticity and physical and mental impressibility. The demands upon man which the school aims to meet are two-fold. They are those demands which must be satisfied if the physical life is to be properly maintained and those which must be satisfied if his spiritual life is to be properly maintained. The last of these - the demands of the spiritual life fall into the demands of the moral, religious and of the intellectual life strictly so-called, whose demands were no less distinct and imperative though by nature immeasurably interrelated.

In the wild and nomadic life of primitive man whose demands in life were simple and few and whose activities were of a correspondingly simple nature, there was no demand for a school, neither was one such as we know possible for 
them nor did such exist. Through the members of the family or tribe the child was taught by precept and example, but chiefly by example. He learned to do by doing. His doing was necessary to his living. The parents and the tribes were responsible for his learning how to do and directed, therefore, both the means and methods of his knowing and doing. As conditions became more acute and resultingly more conplex and his manner of living changed, the struggle for existence grew, knowledge spread and tradition became more firmly entrenched, the training necessary for such life became more diversified. As physical needs became more varied, customs, manners and morals became more complete and as the religious life spread from fetichism to animism and other varieties of cults, the demands upon the intellectual life became intensified. Gradually these duties because of their number and complexity were delegated to other agencies. They were placed in the hands of those evidencing special fitness and aptitude in accomplishing desired results in others. Fathers wishing their sons to acquire practical skill in hunting or fishing, tending the flocks and herds of the family, in tilling the soil, or in driving out or away evil spirits, in healing the wounded or sick placed them under the immediate care and direction of those whom because of their fame in these things they believed possessed much skill and knowledge in some one of these special fields. This was the initiative stage of the school as an institution of civilization. The first of such schools were crude and hardly worthy of the name in the sense of its modern application. Assuming that there are to-day tribes of people in various parts of the earth who are not far removed from the primitive and aboriginal in habits and progress, we have learned from them that the earliest organized or systematic attempts grew out of and took the form of efforts to "educate" "medicine men" and the priesthood. These attempts at education or forms of education were directed toward training and instructing in the healing art and the manner of performing and holding the ceremonial observances. Here is one reason why all of the learning was chiefly in possession of the church and that the first schools were chiefly ecclesiastical schools, for at that 
stage of development, the healing power was believed to be a supernatural power and diseases due to the presence in the body of evil and malignant spirits present therein for the purpose of plaguing and punishing the individual. This belief continued for many centuries and inasmuch as the medicine men and the priesthood exercised much arbitrary power and were generally in cooperation one with the other they became more or less strongly united and grew into power together down through the ages. During this time the church gradually assumed the chief part of the burden of education and what little education there was for the state was given chiefly in conjuction with church education. Later the separation between state education and church education began. Church schools have had their heyday of pomp, glory and power. At present both in Europe and America they are falling into the background and state schools are occupying the front of the stage. But not only are the state schools historically of later origin and development but they are the direct outgrowths of the church schools. In fact all ancient and medieval intellectual activity was fostered by and owes its very survival to the church. For during the great stress and storm periods that at times swept over christendom and civilization and threatened the complete overthrow and destruction of all intellectual institutions and consequent intellectual activity, and the written accumulated knowledge and verbal traditions of men, the church not only collected, protected and preserved these tools of progress but it also offered an asylum to the persecuted among the learned of the laity and clergy and not only permitted but encouraged their continued activity, giving to the world again in times of peace the stored up and treasured culture and accumulated knowledge. In the schools for the priesthood, as formal knowledge accumulated formal instruction by those specially acquainted with it became necessary. But the popularizing of the school did not become a fact until the industrial arts were well advanced. For while they made formal education more necessary they also gave more leisure for the pursuit of it by creating a larger leisure class. 
From this meager beginning the function of the school has grown steadily until to-day it covers every possible form of human endeavor. Apart from intellectual and moral education which the sehool originally undertook, there is to be obtained through the school to-day physical education for which as we have shown above elaborate preparation for both boys and girls have been made. Religious educational opportunities still exist as provided for by the church in church schools. In some sections as in Germany and some parts of France, as has been said, even in the state schools (public schools) religion because of the agitation of the clergy, especially the catholic clergy has been made a regular subject in the curriculum, though it is left optional with parents to have their children attend upon the religious instruction or not, or as they wish to, to have them excused from school during this hour. Much of the industrial training formerly given the young through the work of guilds and other such industrial organizations and by the apprentice system is now turned over to the industrial school, which because of the effectiveness as well as practicalness of their work has become quite popular. Vocational and professional education which in the eariler centuries were maintained chiefly through a system of apprenticeship is now also in the hands of the school. Even so practical a field of activity as agriculture including all of its more prominent phases such as farming, dairying, poultry culture, animal husbandry, and horticulture is now receiving educational attention from the school and courses under the direction and management of experts are being offered by it.

Nor has the home lost any opportunity of pushing its burdens off upon the school, until to-day that work which has always been considered par excellence the work of the home - giving training in the household arts, domestic economy and domestic science have finally been pushed off by the home and found their way into the scliool room revised and adapted to the methods of the school and reduced to a science, until now our girls may learn in the scliool how best, most easily, and most speedily to perform all of the duties of the home, from the very important latest methods 
and means of fumigation to avoid and overcome infection and preventing common diseases, to cooking a meal of a very simple or elaborate fare and serving it in a most wholesome and appetizing manner. This is the scope of the work done educationally by the modern school. Truly it is great. Its power for good to humanity is unlimited. All the more then should we see to it that it performs its functions well. The school is a necessity with us to-day. It would seem that outside of the reproductive function the school has by absorbing nearly all of the regulated and directed forms of education of the home almost put it out of the educational business. Though there is a part of educational work that devolves upon the home that the school can never entirely absorb. Just how the home stands in relation to the school, has already been shown. The one is a supplement to the other. The best school can only be obtainable through close contact with and full understanding of the home and its explicit educational functions. Likewise the best in the home educationally is only attainable where there is close association with the school and through a full knowledge and understanding of the function and processes of the school together with a friendly and reciprocal relation which produces a wholesome harmonious cooperation in the training of the young body in the way it should grow, the young intellect in the way it should think, the young soul in the way it should feel and react upon feeling issuing in action, and the young hands in the way they should manipulate. Thus we see that the home, though primarily and primitively a factor in regulated education has been and is being displaced in performing this function by the school whose formal educational functions the school already had almost entirely absorbed.

The Church. The history of the church as an agency in formal education is very much the same as that of the home. Here, too, the school has to quite an extent absorbed the function of an ancient informal education. Since the church evolved historically from the home and in time before the school, and historically the school as an institution is almost in its entirety an evolved product of the church the treatment of these two in preceding paragraphs has to a great 
extent involved the discussion of the function and evolution of the church and its relation to both formal and informal education. The church, as we saw, grew out of the imperative demand everywhere present in the mind of man for some means of placating the forces of nature and controlling the phenomena of mind as exhibited in the living and from these inferred as a power present in the dead. The earliest historical evidence of social evolution is found in the ceremonial rites and religious observances at the head of which stood the priesthood and the medicine man. Each was learned and excelling in his art; the former in placating the forces of nature and both the friendly and unfriendly spirits of the dead and sometimes of the living; the latter in healing the sick and administering to the diseased. Closely allied to and in function associated with the priesthood were the sorcerer, the wizard and the shaman. With man in this state of development everything was anthropocentric, that is everything by the men of this stage of development was likened unto them in their modes of acting and manner of thinking and feeling.

From this early and crude beginning the church grew into a powerful institution with intricate institutional rites and observances which she maintained successfully against all external attack and became in every way " a very present help in trouble" to mankind in the period of stress and dire trouble, until corruption from within sapped its vitality and ate out its core leaving it in many instances but a mere wreck of its former self, a victim to the reconstructive forces of an outraged and revolting public sentiment from which it will probably never succeed in wresting its former power and in becoming its former self.

In the great division of labor that came on with the revival of learning, the advance in science and philosophy and the creation of new industrial institutions and new forms of education, at a time when the church was weak and had as a result little influence in temporal affairs much of its educational functions were passed over to the school some voluntarily and some under legal compulsion or under the stress of a powerful public opinion. These have been re- 
tained by the school and been embodied regularly in its processes. However, in all catholic countries and in some protestant countries the church still has much of its formal educational functions remaining with it. In protestant countries where state and church are distinctly divorced there is a strong sentiment against the school, which is maintained by the state through public taxation attempting to carry on in its regular educational work any formal religious education, a sentiment which is due in all probabilities to the fact that science is at times at variance with religious dogma, whereupon the church attempts to control and direct the movements of science which science resents, and to the fact that science has become more popularized, liberal and rational while religion has remained stolid and dogmatic and is as a consequence less fully rationalized and opposed to much in science which is advanced and of aid to the world's material progress. Dogmatic religious education and liberal secular education do not go well together. Hence has come their separation and by the very nature of the case the omission of formal religious education in the scientific processes of the school. This has been done upon the demand of the church and with the expressed understanding that she be left with a free hand to administer religious education. Now when it is appearing that the church is not holding the citizenship like the school, she is seeking the aid of school by asking that certain forms of religious education be looked after by the school. However, as far as the real work of education is concerned the church quite unlike the home has left for it still considerable of formal education to do. The branches of education in which the church instructs are religious histories and literature and certain special theological sciences. In Christian lands it is the history and literature of the life and acts of Christ and the Christian church and the geography and history of Christ's native land or country, Palestine and of its chief cities such as Jerusalem, Jericho, Tyre, Sodom and Gomorrha. In pagan countries it may be either Buddha, Mohammed, Zoroaster, etc., as the case may be. Outside of theological scminaries and religious schools, but little is done by the school to propagate 
and study religion and religious literature either Christian or pagan. The church preserves and propagates this as her own specific right and duty. The Sunday school was organized as an adjunct to the church for the purpose of properly instructing the young in Christian tenets and teachings and Christian history and literature. The church through its ministry in the synagogue, monastery, abbey, convent, and other church buildings such as schools, seminaries, colleges and universities is supposed to perform a function like that of the Sunday School for its more matured membership. The work of the Sunday School is poorly organized, without method and system, the teachers arc poorly instructed from the viewpoint of intelligence and in most cases ill-fitted for their work. Of necessity, then, formal education in religion will be of little value to christendom until it realizes the importance of its mission, the value of the material it offers to mankind and bring into use in the instruction in and dissemination of it the most advanced methods employed by the secular schools, and employs a teaching force in a like manner specially prepared and equipped with the proper tools for its work. The church takes much for granted when it enters into its formal educational work with the lack of any thorough system of gradation, and method in the spreading of a knowledge so foreign to the present thought and activities of men, but so potent for the general uplift and betterment of humanity.

In the church services thenselves, there is even a greater lack of systematic formal education. Instead of systematic instruction, in the comparatively few pulpits where sermons are prepared and delivered in a manner calculated to conform to the degree of mental development of the hearers there is no collective system of such methods in any church, or churches, denominations or cities. So, with all of its earnestness and effort the church almost completely nullifies its capacity for good in an educational way, by the disregard or ignorance of all formal educational processes and methods. With this state of affairs it can be and is easily secn why the church has fallen far short of its real possibilities in formal education, and has thus lost much of its power 
for usefulness and consequently its hold upon the people. Few people go to church to-day in a spirit of real search for knowledge either sacred or secular, but more for a general social contact, to be aroused in sentiment and emotion by the music and prayer and by these edified and nourished in an indefinite way rather than for any definite, concrete, clearly preconceived line of reflection, or for the purpose of being given any particular subject matter either in quality or quantity for progressive thought that has any particular rank or position in a line or system of thought, for which the listening mind has been prepared and put into a state of expectancy either by that which has preceded or which by announcement he knows is to come. Most people go to church only out of a morbid custom for whose continuance there is for them no rational ground. Many others go to church because during that time there is no other place so appropriate or convenient, though it is a reflection on the church to acknowledge it. While others go there merely as a meeting place for a higher form of social contact and enjoyment. Besides this there is a floating, curious element in the church nembership who attend any church which at the moment happens to be popular. It may have a new minister, an excellent choir or a fine church structure or it may be in a convenient locality. It may be a fashionable church or may have in its membership certain ones whose social station we emulate or whose recognition or contact we desire for wordly or even sordid ends. With an attending membership thus irregularly and loosely attending and having such superficial reasons for attending services, the meager and limited education which the church can give through its forms of assemblage and worship is of necessity slight and inconsiderate. Then, too, the church membership is as a whole an adult membership whose opinions are pretty well formed and whose store of religious knowledge is pretty well what it will ever be. To these the educational grounds for attendance upon cliurch worship are not so much for the purpose of their religious education as for the strengthening and renewing of that religious education which they already have. But from an educational view- 
point this can be of little value to the church. From another viewpoint by its regular church services the church offers an asylum to its own membership and to the world at large who desire it from the attacks of the non-churchgoing public. While this is of but little educational value in itself, through this fact it is one of the church's ehief sources of influence upon the people both in its membership and non-membership, secondarily by bringing these people within its reach this then becomes a means of exercising an educational influence on the part of the church of no inconsiderable power. In the world about us we see and hear much that is contrary to the teachings of the church, and to Christian dogma, oftentimes the cluurch is fiercely assailed and even in some of its strongholds seriously imperiled. For those whose faith is small and thus easily shaken, the church services offer an opportunity for gathering and communion, furnishes a means of stimulation and encouragement for them in their beliefs and thus aids them in maintaining and continuing their Christian life. In this besides being disciplinary the church is educative.

The State. The state as an educational factor belongs to the group of unregulated agencies regarded from the viewpoint of its educational intent. However the state is educative in many ways that are decisive and pronounced. Through its legal processes, its penitentiary and other punitive institutions, reform schools and reformatories it teaches rebellious spirits lessons that they have obstinately refused to learn elsewhere and previously to coming to these. The understanding of the legislative machinery, its methods of operation and the effects of these upon the citizenship in general; the function and flaws of the judicial machinery, the administration of justice, both successfully and unsuccessfully applied, the executive of the state as a check upon the other two departments and upon individual work all teach the citizenship lessons in civic duties and responsibilities to an extent and in a way that neither the home, the school nor the church could succeed in doing. In regulating commerce, travel, maintaining public highways, museums and libraries and institutions for the deaf and blind and feeble 
minded and insane (that is the partially demented patients of whom all such institutions contain a large number) the state performs a function that is highly though only specially educative. In maintaining a library for shelving and exlibiting for use state records and other official reading matter, in creating opportunity of learning trades for the inmates of the penitentiary, reform schools and the various asylums, in supporting agricultural experimental stations, weather bureaus and experts in farm and other kindred form of demonstration work such as that carried on in general by the department of health and in particular when contagion and epidemics threaten, by the fire commissioner, etc., and in sceing to the publication and distribution of the literature instructing in such work, the state becomes formally educative in its intent. By the holding of expositions and congresses both national and international, the holding of fairs both county and provincial, the state exercises again a function that is particularly educational, attendance upon which is often worth more educationally than whole periods of regulated study in college or university, by promulgating laws against vagrancy and laws for compulsory education, laws raising the standard of educational qualifications and laws establishing minimum school terms, the state is exercising a function that makes it in intent an educational agency or factor.

Society. The chief source of man's education both in quality and quantity is obtained through social contact and free access to social institution, though they are merely incidentally so. The functions of society are unregulated for the attainment of educational ends. Under the head of social education come all individual and collective effort which aims to further individual or collective self expression. In a certain sense everything which man does is in a way educative and life is the one great school. All forms of social intercourse while a pleasurable one, is a very prominent source of education, both in knowledge of conduct and knowledge of fact. Under social intercourse comes travel. Travel is a most highly educational process. Through it we learn of both people and places, and the products both of man and 
nature. The education gained is also both liberal and varied. It gives a fulness to the concepts of reading and study that could not be obtained in any other way. So highly has the educational value of travel been rated that many institutions of learning require stipulated amounts of travel either domestic or foreign or both as a condition of graduation in certain courses of study which they offer. This is especially true in the ease of contiguous countries of Europe. Students for example in German, French or English Universities having as their major subject any of the Romance or Teutonic languages are required to live in that country at least six months and learn first hand the customs of the people, their language and institutions, before admission to the work immediatcly preparatory to the taking of the examination leading to the degrees. Daily papers, all periodical literature and libraries are educational in their influence. Hence their presence in so many homes. Much educational work is donc to-day by the lecture courses of the cities during the winter season and the chautauquas of the summer. Though these lyccums and lecture burcaus have become highly popular chiefly as a source of entertainment, much of their patronage is undoubtedly due to the educational value of the entertainment which they offer. The theater, too, is a potent cducational factor maintained for social intercourse and entertaimment. Here while there is much to be condemned there is also much that is beneficial and of high educational value. The playground in its mighty lessons of cooperation, self-subjugation and self-denial, courage, endurance and self-control, apart from being a potent force for socialization is also a powerful educational factor. When the playground is under direct skillful supervision and the child activity directed along lines preconceived and chosen for their ability to develop power, skill and endurance as well as fainess and fellowship, it lays the basis of a character and teaches a lesson that the school could never in its most visionary dreams hope to teach. But nowhere does one learn the rastness of human endeavor and the intricate interdependence of all industrial and vocational activity and their educational value until he enters into the ficld itself. 
Here one soon loses any original ideas that he may have had of his independence and irresponsibility. He learns his real insignificance as well as true worth and real importance in the world, which serves decidedly to sober and temper him. Contact with the ponderous machinery of these large industrial plants and the workings of the vast systems of hire, directing labor and discharging it is a great and valuable lesson. Society is indeed a great educational agency. It is this from our first to our last contact with it. Many of the lessons which it teaches are hard and bitter, and the cost of its teachings are sometimes high, especially to the fractious and the rebellious ones. But no agency in education is as effective in the power to impress its facts upon us as is socicty. It is too busy working out the progress and development of the whole to give much time and consideration to the individual. A blind, insensate mechanical monster, one who cannot fall in with it, soon uses up his meager supply of energy in fruitless resistance or efforts at change and is crushed out and covered up by the dust of those ground up and shaken off from its ever moving machinery. We learn of it by being part and parcel of it. In no other way could we so effectually be taught by it. Its methods are infinitely varied and many, but they are not those either of the home, the school, the church, the state, but all of these and more too. Society has educational methods and processes of its own. But however mighty an educational factor it is, it must be classed as an unregulated and undirected educational agency.

\section{REFERENCE READING}

Rosenkranz's "Philosophy of Education." Part II, Chap. I. Scott's "Social Education." Chap. V, I.

O'Shea's "Social Development and Education." Chaps. XI, XII.

King's "Social Aspects of Education." Chaps. I, II, III, IV, XV, XIX.

Horne's "Psychological Principles of Education." Part II, Chaps. XXXI, XXXII, XXXIII.

Gillette's "Vocational Education." Chaps. III, IV, IX, VIII.

Gesell's "The Normal Child and Primary Education." Chap. XxII.

Blair's "Mottoes and Commentaries of Froebel's Mother-play." Pp. $42-49$.

Parker's "History of Modern Elementary Education." Chap. III. 
Blow's "Educational Issues in the Kindergarten." Chap. X. De Garmo's "Principles of Secondary Education." Vol. I, Chap. III. Harris' "Psychologic Foundations of Education." Chaps. XXI, XXXII.

Scott's "Social Education." Chap. XII.

Pickard's "School Supervison." Appendix A. 


\section{CHAPTER V}

\section{THE SCHOOL}

Its Location, Environment, Equipment, Heating, Lighting, Sanitation, Etc.

Its Location. As the term is here used the school refers to the building or structure in which the pupils or students are wont to gather for their daily routine exercises of reciting their lessons and receiving the guidance and help of the teacher in explaining to them that in their lessons which they do not understand, directing them in the preparation of their future lessons and conducting other exercises considered as adjuncts to these. The school as here used may be a building of one room or many rooms. It should be located in such a place of convenience as will afford the greatest ease of approach to the greatest number of pupils. This of course, is merely a proposition in abstract justice and as an idea will be agreed to by all. In the actual work of practice many reasons mostly local will arise to cause variation from this general principle. On general principles, also it is generally intended that a school should be located as near the center of population of the school district as possible, all other things being equal. In practice again this proposition will meet with various forms of modification according as various circumstances and conditions enter to induce change. For example inasmuch as land near the center of population is in greater demand than land off the center of population the cost of the land at the center of population may be considered as unreasonably high or it may even be beyond the financial means of the school authorities. Besides these, other conditions of cost price may serve to thwart the putting into practice of this principle. Again means of travel are not always best in the 
center of population, though it is generally expected that they should be. Consequently oftentimes points more or less off of the center of population may be in the end actually nearer in the reduction of the amount of time consumed by the pupils in getting to and from school. In our own civilization the chief aids to attendance on school are good roads in the country and paved streets in the city. To these in more recent years have been added interurban cars and regular service in street cars. For the well situated in life, materially, horses and buggies or carriages, bicycles and even automobiles serve also to bring schools and school opportunity within easy reach. In this way schools though spatially more distant from pupils may by the various means of travel becone relatively nearer, and vice versa. In cities with all of the modern means of travel and conveyance the particular advantage to be gained would be perhaps best conserved by locations of school buildings near one or more street car lines through the district, or perhaps better, if these two or more lines crossed each other, at or near the junction of such lines. In rural and country districts this advantage would perhaps be best conserved by locating at or near the junction of two or more roads, these being picked for the amount of travel which they facilitate, the maxim being, the better the road the greater is the ease of travel along it. As to the grounds themselves modern science gained through almost unlimited experience and experiment, has proved that the question of their character, location, size (amount of play space afforded each pupil), slope, drainage and general healthfulness is a very important question. Especially is this the case when these are considered from the viewpoint of general service schools shall render their patrons and the degree of physical wellbeing they are intended to furnish for the school children. From the facts taught us by the science of medicine and the facts and results brought to our notice by physical education it has been shown that these things seriously affect the health of the child. And the health of the child is worth more to it, to its family, the state and society than any mere bit of learning that it gains in the school at the 
hands of the teacher. Because of the advantages indicated, above all, ground chosen for school building and play ground purposes should be by nature high and well drained. Lowlands are damp and more or less impervious to water and are a harbor for all kinds of insects, which breed there and nurse and spread all manners of diseases and pestilences. Besides this the bacteria of many diseases such as catarrh in its various forms and affections of the bronchia, lungs, pleura and mucous membranes are said to have their "hang out" in these places, from which as a result of constant exposure infection would be correspondingly easy. Modern agriculture has taught us much as to the nature and contents of various soils and subsoils. Geology has given us still more. From these sources we learn that clay soils and subsoils are particularly to be avoided as sites for the school and grounds. Clay soils are moist, cold and clammy and send off moist vapor constantly. Many subsoils while apparently dry and well drained on the surface carry what is known commonly as free or ground water. In sections where such subsoils are present and ground water abounds cellars oftentimes become filled with water and when not thus filled with water they are cold, damp and unhealthy. Oftentimes, too, a few feet below the surface of the ground rocky ledges become pockets acting as reservoirs for the water which percolates through the interstices of the soil. This ground water is not the same as the so-called subterranean water which comes from greater depths and differs from this chiefly in being surcharged with various mineral elements that make it very healthy and as such not a menace but a strong contributor to health. Land used, therefore, not only for school sites, but for any kind of building purposes should be thoroughly drained of all forms of water, both surface water and ground water. It is better that it be so drained by nature, but if nature is against the proper drainage then artifice should step in and do what nature has not done. If a subsoil carries ground water it can be discovered by tests being made through boring or digging of holes into the soil or subsoil and leaving these exposed for a few days when the ground water will show its presence by gathering in these 
holes, whereupon it may be at one's convenience pumped out or drained off. The land itself should be as nearly as possible free from organic matter. For organic matter in the first place tends to hold water and thereby prevents drainage and in the second when exposed to the air and the actinic force of the sun's rays decomposes and putrefies, robbing the air of its health giving oxygen and surcharging it with all manner of odoriferous and disease bearing impurities, which by means of various physical agencies, such as warm air or hydrostatic pressure, raises the ground water to the surface and the heat causing evaporation fills the adjacent air with impurities which in time gain entrance to and fill the building with impure if not contaminated and disease laden air. All of these things mean much to the general good of the school and should be carefully studied by those interested in or charged with the responsibility of finding proper location for a school.

Its Environment. It goes without the saying that from the very mission that the school is charged to perform, namely to produce normal, healthy, wholesome beings in mind, soul and body, and to develop and train them for the greatest amount of productive activity, it must have the very best physical, mental and moral environment. To begin with these ends in general can be best conserved by the school being well away from all noise and such disturbing agencies of the city, town, village and rural community as contribute thereto. It should be far away from the industrial sections with their massive buildings of rough ungainly architecture, the machine shops with their distracting whirr and buzz, the foundries with their huge smoke stacks from which day and night leap lurid flames, dense smoke and gases polluted with every kind of mineral poison which both worry and exhaust with their noise, dim or shut out the light and either contaminate or keep away entirely all draughts of fresh air. It should be away from the main streets and thoroughfares of the business sections with their din of traffic, the rattle and prattle of horse and wheel, the clang of bell and the ceaseless patter of hurrying feet, together with the general but ever present danger to life and limb to be found in 
these sections both for young and old, but especially for the young and unwary. It must also be away from the unsightly houses and buildings of the poor sections and the rickety and dilapidated houses of the redlight districts with unhealthy congestion and open and unrestrained immorality and degradation. The importance of keeping the school in the more beautiful, sanitary and wholesome sections is obvious. The dwellers in and frequenters of the redlight districts are not accustomed to show consideration in modesty to those older people who know the nature and purpose of their acts and will resent it by appealing to the law, much less are they disposed to consider children in the mere passing. And yet these children do not know the import of things seen and heard while passing and will take on pollution unwittingly as if it were the best in our eivilization. The school needs the aid of all good forces in society to attain its best results and certainly whatever of aid can be given in environment should be seriously considered and eagerly sought in locating a school.

Along with environment of the school come the subjects of the size of the grounds and their arrangement. The size of the plot of ground from the theoretical viewpoint is determined by the number of students the school is intended to accommodate. From the practical side the question of economy plays a prominent part especially in city schools where ground is rented, leased or sold at so much per square foot. There is much difference to authorities limited in finances between ground that cost oftentimes hundreds of dollars per square foot and land which costs less than a hundred dollars an acre - a fact that is oftentimes a matter of serious consideration. At present, however, under the stress of a demand for physical education a play ground allowing ample room for healthy exercise is of paramount consideration. This it is a pleasure to say is generally appreciated and grounds are provided everywhere though sometimes at great financial cost to the taxpayers. In Germany a square meter of playing room is considered necessary for each child. In America the norm is placed by most authorities at about thirty square feet of playing space 
per child. At this rate a school in order to accommodate five hundred pupils at play would require play ground space about the size of a quarter of a city block or a space about the size of six city lots. Other schools would require play grounds in corresponding proportions as they were intended to accommodate less or more pupils. However, such other conditions as the means on hand and the ground in the particular locality available for such purposes would enter as incidental factors to determine the size of play grounds furnished any school. Besides for esthetic reasons wherever and whenever possible the grounds should be large enough to admit of beautifying. In such cases it could hardly be deemed advisable to sacrifice space really needed for child activity for giving mere beauty to grounds. In beautifying grasses, flowers and shrubbery artistically arranged with shade trees set out in corresponding symmetry and all well set off with settees and swings may be found sufficient to produce the desired esthetic effect. Where possible fences surrounding the premises might be of hedge instead of being of the ordinary iron, rail or pale fence. None of these esthetic ends are however of sufficient value to warrant their being sought at the sacrifice of adequate play ground space. Though unjustifiable in the nature of things, if either sex should be forced to sacrifice either ornamentation or playgrounds the present social sentiment would give the boys the playground and the girls the ornamented grounds. Inasmuch as sunlight is desirable as well as exercise and pure air, all playgrounds should where possible be on the sunny side of the building and have the benefit of whatever protection is available from the chilly winds and be equipped with buildings for shelter during storms and bad weather. Trees when present should be if possible of the evergreen variety in order to soften the otherwise barrenness of the cold and bleak winter days. These besides being systematically arranged should be far enough away from the building in order not to be light obstructing by casting their darkening shadows through the windows of the school room during the regular school periods. Should there be both the evergreen and deciduous trees the deciduous trees should be placed 
near the building so that in the winter when they cast their longest shadows they will be devoid of leaves to offer obstruction to the entrance of light through the windows. For drainage cleanliness and healthful activity grounds covered with natural sand and medium sized gravel have been found to give the best results. Boarded floors, asphalt, macadam, cement or other hard composition floors, besides being more or less slippery and dangerous in case of any form of violent activity are unyielding and painful by the resistance they offer and the consequent jars they cause to the joints of the body in the springing and jumping in which all children are wont to indulge at play. For moral purposes and sex hygiene as well as good manners all playgrounds however small should be separate for boys and girls and should have separate entrances.

Its Construction and Equipment. The school as here used we have said would be either a room or group of rooms. But if it should happen to be the latter both experience and experiment have shown that it should be the rooms put together to make the building and not the building made into the rooms if in the structure the best ends are to be conserved for the general health of the pupils and the quality and efficiency of the work. The best shape for room or building is a rectangle, with the second choice for a square building. The average life of a school building is about a generation and a half: while many of them do duty for several generations and there are some few over two hundred years old and still in service. From the length of service demanded of a school building and the part it plays in the life and health of those who attend it - both pupil and teacher - a school building should be of the very best material and should represent the best skill and workmanship obtainable and should as nearly as is practical under local conditions be of brick, stone or concrete. Brick, stone and concrete structures have the advantage of being more endurable, warmer in winter and cooler in summer, offer less danger in the case of fire than wooden buildings. In order to reduce the disturbances of the school and to gain order and quietude from the outside, the building should be as far back from the street 
as is possible without cutting off the supply of light and air, by its resulting enforced proximity to adjoining buildings. In order to overcome noise from the street produced by the passing wagon and horse, substances, that tend to deaden sound, such as sawdust and other forms of wood pulp and sand may be spread on the street pavement immediately surrounding the school. For continued use the best results will be found to obtain when this surface covering is either sprinkled with water or oiled frequently. If the school must be near other buildings they should be sufficiently far off to admit of a maximum amount of light. The ideal condition is the one where a line drawn from the base of the school building to the top of the neighboring building makes an angle with the earth's surface of between twenty-five and forty degrees, the nearer the angle is to twenty-five degrees the better. Light as we can all tell by our bodily feeling on sunshiny and cloudy days, is not only good for the eyes but is also a powerful motor for dispelling gloom from the soul and inducing good cheer and happiness. This power is possessed particularly by rays from the sun that fall directly upon the subject. Modern bacteriology has proved that the sun is a powerful disinfectant - nature's physician - and offers a serious check to the breeding of infectious germs and the spread of infectious diseases.

The consensus of opinion is that buildings should not be more than two stories high. In such buildings the minimum of fatigue in climbing stairs prevails and the mininum danger to injury in case of fire exists, with a maximum seating and recitation capacity. The strain in climbing stairs is not noticeable in the ordinary graded school, but where there is departmental work and every thirty to forty-five minutes for four, five and even six hours pupils must pace up and down long flights of stairs, the strain is sufficiently taxing to tell on the energy of even the stronger pupils and thereby materially affect the quality of mental work done. When it comes to the dangers from fire the question is one of even more seriousness and fraught with immediate danger to life and limb. For many reasons given above and others equally weighty entranceways to all school buildings should be as 
numerous as possible and as wide as possible with risers between five and a half and six and a half inches high and treads from ten to twelve inches wide. Stairways also will meet both normal and emergency conditions best if they are numerous. Under no conditions should there be less than two and these should be at the ends of the buildings and never in the center. For rapid exit doors should be from three to four feet wide and all rooms should open into two or more corridors from ten to sixteen inches wide. Fire-drill should be constantly practiced under compulsion of statutory law, so that order and self control may prevail. When these have reached such precision that the school building can be emptied in three minutes or less, the dangers from fire and panic in schools will be reduced to a minimum. The signals for fire should be distinct and easily intelligible to teachers and pupils alike.

For the purpose of light, health and cheerfulness of the school, the walls should be white, the ceilings high and concave and painted not plastered. All ledges, cornices, corners and other places where dust might collect should be avoided. Wainscoting where present is best either glazed or of a highly polished surface. Cloak rooms for reasons chiefly sanitary should be large enough to accommodate all wraps without crowding them together. They should also for similar reasons be well heated, well lighted and ventilated thereby reducing the possibilities of the spread of various contagions to a minimum. All schools need basements and wherever funds will permit authorities should be persuaded to provide them. But many dangers may lurk in basements unless the proper precautions are taken in their construction. Every possible precaution known to science should be taken to insure that they shall be dry and well lighted and ventilated. The walls of cellars and buildings should be impervious to water, especially if the subsoil carries ground water. A good wall that will insure a dry basement may be made out of asphalt laid between a brick or stone wall and tar on the outside with a floor of cement. Basements are a prominent utility for a school and if properly built may become a healthy place for play in inclement weather, but if 
unhealthy it may and generally does become a serious danger to the health of the pupils. Its practical utility is chiefly as a place for the furnaces and air passages for ventilation, coal-storage and as a place for the location of toilets, lavatories and baths, where such is furnished, and for a swimming pool. However, swimming pools are luxuries comparatively few schools can afford, but which are more common in the schools of the larger cities of England and Continental Europe.

Its Equipment. The equipment of the school should be simple, healthful, cheerful and practical. It may vary from a single array of desks seats, recitation benches, teachers desk, chairs and window shades, to a room with painted walls, highly colored wall maps, globes, pictures, library tables, blackboards, drawing and music charts and other objects for decoration, and plants for ornamentation or nature study, or both. A school overcrowded with equipment besides being deleterious to the health of the pupils through the opportunities the objects offer for the collection of dust with its tendency to support infectious germs, entails much work upon the teacher or janitor to keep them in order. Out of order they are a severe strain to highstrung nervous temperament accustomed to tidy and orderly homes and in this way as a result tend to have a demoralizing effect upon the school, it being claimed and generally conceded that the work of a school will more than likely take on the same general tone as is afforded by the physical environment of the pupil. Thus it is seen that equipment should be reduced to a minimum for maximum efficiency in teaching and maximum effect in decoration without becoming a source of strain and worry or demoralization upon pupils and teacher. A few educational instruments practical and in good working order with a potted plant or two to break the monotony of the view and bring eheer and happiness, and a lively progressive teacher have been found to be about the best equipment for a successful school. The rather recent arousal of sentiment for and interest in physical education has stirred educators to an investigation of the effects of the school life and surroundings upon the health of the pupils. This investiga- 
tion has led to a wonderful improvement in the physical conditions furnished the pupils by the school. Physiology and hygiene brought to light many glaring defects in the methods of seating pupils and the direful results that this works upon the young plastic bodies of school children. It was found out that many serious deformities possessed by people might be traced directly to vicious methods in the physical habits formed by the school many of which were caused by the school equipment. Many of these were found to have followed individuals throughout life. Investigation showed that there was more than one important side to the problem. Not only was it necessary that desks be strong, occupy a minimum amount of space for service rendered, but for the physical comfort and health of the pupil as well as for his working efficiency they should possess glazed or highly polished surfaces with as few crevices for the collection of dust and germs as possible. They should also be constructed according to the natural form of the body and permit the maintaining of normal postures without strain or fatigue. Like school buildings the school equipment is intended to last for a long time. Very often it is made to do duty for several generations. It is necessary, then, that it be of the best workmanship and material and also of the newest model, made according to the results of the most recent investigation of hygiene and physiology.

The subject matter of desks, seats, and order and methods of seating pupils both from the viewpoint of health, economy of time in school work and working efficiency of the pupil, have been pretty well investigated and some pretty definite conclusions reached as to the nceds of schools along these particular lines. The chief physical defects created by desks that are faulty in pattern or ill-adapted to the size of the pupil and the general shape of his body are curvature of the spine, bending posture, round shoulders, various affections of the eyes, impaired action of the lungs and viscera, along with repeated instances of bowed legs. The greatest problem in this connection has been to have desks that would accommodate properly all of the pupils of the various sizes. Examinations conducted by competent authorities interested 
in these matters showed that in boys six years of age, the difference in height varied as much as six and a half inches; at eleven this disparity in difference of height had reached about eight and a half inches and at fifteen it had risen to eleven and a third inches. These relative differences would vary slightly in the different localities and schools and in the same locality and schools during different years, because it is a fact of commonplace intelligence that scarcely any two children grow continually at the same rate, nor resultingly would they grow the same amount in the same given period of a year or school term. Besides this demand for desks and scats necessary to accommodate pupils of various sizes and rate of growth during the same age and grade, there are exercises that are conducted on the tops of the desks themselves which require that in order that they may be properly adopted to the various positions of the body in these exercises and thereby avoid strain on the body and that the object be at the proper distance from the eye and may rest at the proper angle of vision to avoid strain and the counteracting and sometimes harmful effects of light reflected by polished surfaces about the room at various angles. The proper distance of a book from the eye is said to be about twelve inches, while the line of vision should be at right angle to the angle of tilt of the book in order to produce the least strain and fatigue on the eyes during that exercise. Objects presented to the eyes for any length of time too far away, or too near, or while tilted at too great or too small an angle tend to produce myopia, hyperopia and various other afflictions of the eye. It used to be contended that an angle of from thirty to forty-five degrees was the proper slope of the eyes, and for mere reading this is probably true. But experiment has shown that at this angle drawing becomes difficult, and writing with ink practically impossible. For in the position of the pen in vertical writing ink will not flow at so great an angle of slope, at least ink of normal thickness will not, while all objects left loose on the desk lid when it is tilted at that angle even though they be relatively heavy, will overcome the surface resistance readily and if left alone will slide off the desk!id and fall to the floor. Now then, having found 
the relatively perfect condition for normal, natural bodily posture and movements, how to get a desk that would meet these conditions was the next great problem. With the constant variation in height and growth in the same grade in different pupils and in the same pupil during his stay in the same room and a demand for desks for different exercises during the various recitation periods of the same day by the same group of pupils, it was quite evident that the desk now commonly in use unadapted to a variety of heights and adjusted to no variation in growth and set at one angle, was not very appropriate for the task which these conditions set before it. An economic demand soon creates its own supply. Science ever responsive to the offers of finance soon responded and gave us an adjustable desk that in many ways accommodates the needs specified above as to height, growth and angle of slope for the top of the desk as required by the various exercises of the school. These desks are not perfect but are a step in the right direction. With time they will no doubt be improved to meet more nearly the demand in its entirety. The Heusinger desk at present seems to be the best on the market for these conditions. To help meet these demands for adjustment the Heusinger is fitted up with an adjustable seat that accompanies the chair. These seats may be raised and lowered at will so as to permit the feet of any pupil to rest squarely on the floor. They may be slid toward or away from the desk lid. They are fitted also with concave backs, curved in correspondence to the natural curvature of the spine, with a chair that is doubly concave rising in the middle in front so as to keep the thighs level and the pelvic girdle or seat bone in a healthy normal position. The depth of concavity of the chair seat should be about three-eighths of an inch, that of the back about one and a half inches. The curvature in the back, on the other hand, should be about three fourths of an inch. The seats themselves should also not be too narrow nor too wide as either one enforces a sitting posture that is harmful. For matters of health, discipline and a high working efficiency in the pupil all such desks and in fact all desks of any type should be single. 
Its Ventilation and Warming. If we are to accept the data of previous investigation by experiment the best results in health and working efficiency will obtain in the school when each pupil has sufficient warmth and fresh air. Careful calculation has shown that the normal pupil can be reasonably well supplied with fifteen square feet of floor space and 200 cubic feet of air space. A school fifteen feet wide, twenty-five feet in length and thirteen feet in height will hold as its maximum capacity for ventilation and floor space twenty-four pupils. With only twenty pupils the same size school would furnish to each one eighteen and seventy-five hundredths square feet of floor space and two hundred and forty-three and seventy-five hundredths cubic feet of air. While this is a general demand, the more fresh air per pupil and the larger amount of floor space a school furnishes, the better will be the health and working conditions of the pupils. In this condition many states have laws requiring that schools furnish more than the amount specified above. The laws of Massachuetts for example demand 30 cubic feet of pure air every minute according to which it would require a complete change of air every eight minutes for a school with twenty pupils or a complete change of air every six and nine-tenths minutes for a school of 24 pupils. It is to be remembered that floor space and fresh air are very essential prerequisites for health and work in routine school processes. In primary grades plenty of floor space for movements and an abundance of fresh air for breathing are more imperative than later in the grades, because here, child activity is greatest and vital functions generally more intense. Hence any check in these is especially to be avoided as the surplus energy created by air and room for movements goes into growth and development. The chief cause of bad posture while sitting is fatigue and sometimes exhaustion brought on to a great extent by an insufficient amount of air per capita. The habit of crowding primary grades though quite common is to be severely condemned as a vicious practice. The little folks above all others should have the maximum amount of air space for breathing per capita. The problem presented here is really the one as to how the air in a school 
may be changed. For, given the maximum amount of floor space, air enclosed in a room unless constantly renewed with fresh draughts becomes polluted and unfit for use even though there be no living being in it to draw off the oxygen of the air and charge it in turn with carbonic acid gas and putrefying animal matter. Hence in all of this the problem is one of procuring constantly fresh air and removing the "stale" air of the room. In schools where modern scientific methods and instruments are in use there are two generally accepted methods of accomplishing this. One of these methods because of its dependence upon the principle of gravity is known as the gravity method. This is based on the difference of the specific gravity or density between cold air and hot air. The cold air being more dense has greater molecular weight for a given amount hence is heavier than a like amount of warm air whose specific density and molecular weight is less, and as a result of this where cold air and warm air are brought together the warm air tends to and will actually rise while the heavier cold air tends to and will actually fall. Thus where heat is brought into a school room there immediately is created by this mechanical process a motion of air particles which results in the gradual warming of all the air in the room, the warm air rising in the process and the cold air falling to the floor. In this motion of air mechanically set up means of exit of the air being properly provided, the air generally finds its way, the warm air is admitted on one side up near the ceiling and the cold air is given exit somewhere opposite near the floor. This system is at its best for service in still cold weather. The other method is a mechanical system whereby the motion of the air is controlled by a fan and forced through conduits in or out as the temperature desired may require. The fan may also exhaust the air in a room by means of suction, but the results by this method are not as satisfactory as by pressure. The motion of the air should be slow and diagonally across one side of the room. It should enter about two thirds of the way up the side of the wall and leave at a distance from the floor opposite not more than one foot above it if the best results are to prevail. In a room with a ceiling thir- 
teen feet from the floor it will be found best to have an air passage inward about nine feet up the wall. The air should of course be the purest obtainable and where practicable it would furnish the best results if its humidity were guaranteed by its being drawn in over a constantly moistened gauze netting, which would extract from the air all dust with its possibility of contagion bearing germs and other forms of air polluting impurities. Even when well ventilated schools are unhealthy and the students sluggish because of the air being too warm. From sixty-eight to seventy degrees Fahrenheit is considered a good lively working temperature by most sehool authorities. However, on this point there is considerable difference of opinion, while also the heating conditions of the home to which the child has been accustomed will enter in each particular individual and class of individuals as well as the conditions of health, feeding and elothing, to determine which is really the best working temperature for a child and for a school. Many eminent authorities both in Europe and America advocate temperatures as low as 65 degrees and 66 degrees Fahrenheit for schools as the best for health and work. Some few authorities on the other hand advocate temperatures for comfort, health, work, as high as 72 degrees to 75 degrees Fahrenheit, the difference being explained by the personal equation element. Another element that enters to determine how warm air shall be is its humidity. For best results air must not be too dry. It must have a certain amount of moisture and if it is not there by nature it must be supplied by artifice. The presence or absence of moisture in air determines its effect upon the body and the bodily functions to quite an extent as all of us have no doubt noticed in the difference of penetration in damp cold days and dry cold days or in the difference in effect between damp hot (sultry) days and dry hot days. Cooks soon learn that you can steam a thing done before you can merely " cook" it done, the difference being due to the presence or absence of moisture in the air. The air we breathe in "dry" weather possesses generally between $50 \%$ and $75 \%$ of humidity. During "wet" weather it may range in humidity up to one hundred percent, which is the point 
of saturation, beyond which point the moisture descends as rain or snow. The air of a school room unaided mechanically will possess between $30 \%$ and $45 \%$ of humidity and may at times fall as low as $25 \%$ or even $20 \%$. This difference in amount of humidity between the air of the school room and that of the open air makes imperative the need of adding to the humidity of the school room by various mechanical devices. This may be done by the simple method of keeping earthen jars of water in appropriate warm places. Dry air has been found to be favorable to taking coughs and colds and various forms of throat affections and bronchial troubles, the nightmare of singers and public speakers. Teachers grown old in the cause find the first signs of age and wearing down generally in failing voice such as a "rattling" in the throat and coughs brought on by the constant inhaling of the dry air of the school room. Besides this, air robbed of its humidity enervates and when very dry absorbs moisture from the pores of the skin and various exposed and accessible membranes of the body, causing irritation and inflammation to delicate surfaces and dryness and roughness to the more hardened surfaces of the body. For heating purposes the need of storm doors for the entrances to all buildings is obvious. They not only offer double protection but they prevent drafts and make the heat of the building more uniform.

The means employed for heating schools are generally hot air, hot water, vapor and steam. Coal stoves are used in the less modern and less well equipped schools. Each has its advantage, hot air, hot water and steam are all popular now. Those heating systems that are fitted with self adjusting machinery are, of course, the best. Stoves, where in use, will be found to give the greatest satisfaction in a general way when they are located in a corner of the room and near the chimney. Their naturally small radiating surface often requires supplementing by additional means. The chief objection to stoves is that they require too much attention on the part of the teacher, that their heat is too varying and the burning fuel pollutes the air. It is difficult to place a stove so as to give perfect heat satisfaction. In 
real cold weather as in mild weather those near the stove are over-heated and suffer oftentimes physically and always in their working efficiency, while those farther away never get enough warmth and suffer correspondingly in health and working efficiency. Steam and hot water seem to offer least objections to health and working efficiency of all the methods of heating. They are both economical. Steam requires smaller radiators and is more easily regulated. Hot water seems to be more cconomical in material, but on the other hand requires more apparatus to furnish a greater radiating surface. Returning to stoves, stove heat is always dry heat whose harmful tendencies and means of overcoming them by giving to it the proper amount of humidity we have already mentioned. The cleaning of the stove and caring for the fire produces much dust however careful one may be. This dust from the stove combined with the dust from shoes, clothes and crayon in board work surcharges the air, which becomes laden with decayed animal matter, carbonic acid gas and other cutaneous excretions breathed from the lungs and thrown off from the bodies of the pupils and other foreign bodies present, thereby keeping the air of the room constantly polluted if not actually poisoned with contagious germs. If gas jets are present they will add to these animal poisons mineral poisons such as nitrous, carbonic, ammoniac and sulphurous gases. To offset and overcome these gases dust laden and germ bearing air ventilation must be constantly looked after, as must be the system and apparatus for ventilation and the whole kept always in perfect trim in order that this poisoned and poisoning air be constantly and fully removed.

Its Lighting. Much was said about lighting schools under the discussions of the grounds and environment. However some things more peculiar to the subject matter of lighting schools omitted there will be mentioned here. To begin with the problem of lighting is a vital problem both to eyes and body and consequently to the kind and amount of effective work done in the school. Light is a subtle phenomenon and its measurment is difficult and complicated besides requiring very delicate if not indeed costly apparatus. 
Again light measurements are too often entrusted to practical judgments which because of the nature of the problem make them untrustworthy. Where the light is unobstructed by objects near windows on clear days it is very easy to light most rooms sufficiently. It is on dark and rainy days or in the early morning hours and late in the afternoon of the short winter days that the amount of light available in the darkest parts of the room requires augmentation and additional artificial or natural increase. Here the eyes should not be trusted. The amount of transparent glass surface advocated by specialists in this subject is from $25 \%$ to $16 \%$ of the floor space on a general average. On clear days glass surface of $12 \%$ of the floor space would do, while on dark dreary days $25 \%$ is hardly sufficient to furnish the required light. The amount of light actually furnished and consequently the amount of glass surface necessary will vary in northern and southern exposures, and eastern and western exposures, being greater in northern and eastern exposures than in southern and western exposures. According to the figures given above the amount of glass surface required to furnish the requisite amount of light for a room $40 \times 25$ feet would average from 160 to 250 feet. On dark days the amount of light required by a child with eyes of normal strength is said by one authority, Cohn, to be about fifty candle power (fifty standard candles burnt at the distance of one meter from the eye). Where the light available under natural diffusion is insufficient additional light may be procured by artificially gathering it on surfaces and reflecting it therefrom into those parts where and when desired. For this purpose glass plates ribbed after the pattern of the Luxfer prism may be used to the best advantage. When arranged in the sash or outside this ribbed glass or Luxfer prism can gather light from the windows or other sources of exposure, refract it and by casting it upon proper receiving plates reflect it into the insufficiently lighted portions of the room.

The light itself, it is agreed, is most satisfactory when entering from the left. Light from the front is straining on the eyes, besides throwing shadows on the work on the 
desk. From the rear the body casts shadows on the work, thereby causing strain on the part of the pupil and is also a serious source of danger to the teacher's eyes, as it forms a constant glare to her front view. If more powerful than light from the left it is doubly objectionable. The light from the left is most free from any of these objections. Windows if located on an objectionable side of the room may have their harmful effects successfully counteracted by being eight or ten feet up from the floor, care being exercised to have the light thus obtained weaker than light from the left. The windows themselves, it is agreed, in order to be most favorable to light should be as near together as possible, extend as near to the ceiling as possible (within six inches), the light being reflected from the ceiling but absorbed by the floor, desks and furnishings. The higher the sources of light, the greater the lighting effect, a fact which offers serious objections to arched windows. Window sills should in general be on a level with the eye. Some authorities advocate five feet, some four and some as low as three and a half feet, the aim being to avoid the light from the lower part of the window producing reflections from the tops of the desks or being on the eye line when the pupils are seated. This aim would probably explain partly the differences in height advocated by various authorities. For primary grades the desks would be lower and the eye line correspondingly lower, while the desks would be higher as we pass from the lower to the higher grades and the eye line would rise accordingly. Hence, it is clear that window sills of rooms are to a great extent determined by the height of the pupils the room is intended to accommodate. If the demand for sufficient light on dark days is fully met, the light becomes too intense on bright, clear, sunshiny days, especially for those pupils near the windows. This inconvenience, however, may be overcome by the use of proper colored window shades adjusted to unfold and roll up from the proper place of attachment, the window sill. The windows, from what has been said above, should be toward the rear and left side of the room to admit light over the shoulders and from the left. The walls and their color play a prominent part in 
the light effects of a room. To produce the best effects in color blend, the walls of the room should be of a greenish gray, the ceiling white and the window shades a tint but slightly darker than the walls. Tests have shown that this combination is the least objectionable of the colors of the spectrum from a general standpoint, inasmuch as the colors of the spectrum produce some violent nervous reaction wholly out of proportion to their capacity for absorbing light. This is the case with yellow which though it absorbs a minimum amount of light is fatiguing and induces to a marked degree nervousness and irritability. All walls in a school room should be painted instead of white washed, but not polished or glossed, because they then become dangerous reflectors of light.

Its Sanitation. A few words might be added here about the general sanitation of the school. To begin with health is preserved only by the utmost care and watchfulness. In the case of children this care and watchfulness must be furnished for them chiefly by the school and the home. Both teacher and parents should know the symptoms of the various children's diseases and the physical signs of the changes due to mere growth and development. Health and exercise go hand in hand as do health and wholesome conditions of rest and labor. "Cleanliness is next to godliness." Not only must the decaying matter and residue from eating be removed from the teeth, but the hair must be kept clean and skin and nails also. Many contagious diseases are spread by the scales of the skin which the body throws off in its normal processes of waste and repair in growth. The nails in particular offer fit collecting places for all kinds of germs and many a case of serious even fatal blood poisoning has been started by scratching or picking an injured and perhaps itching part of the body with the finger nails, thus infecting it. Dust and disease are twin sisters. Where there is one the other may be expected to be also. Where through any cause a contagious disease breaks out there should be at once isolation, a physician called and the parents notified. Of the contagious diseases common to children and schools, diphtheria, scarlet fever, measles, whooping cough, 
mumps and chicken pox are the most common and most dangerous. Chorea is common in some schools. It is a nervous affection and its presence is made manifest by the twitching of the hand, fingers or eyes and a general lack of muscular control especially in walking. The symptoms of these diseases together with other common forms of children's complaints should be familiarly known to all teachers and the fact remembered that infection long after the cure of the patient is apparently accomplished, and therefore, by oversight or neglect of the proper steps of isolation a new epidemic may break out. This may be brought on if the convalescing child or his clothes is allowed to come into contact with other pupils. Contagions may be started by breathing polluted air from the lungs or thrown off by other parts of the body under diseased conditions. To promote fully the general health of students and pupils the utmost cleanliness must be observed. The buildings should be swept daily and the rooms and furnishings cleaned thoroughly. If books or pencils are used in common they should be disinfected each time before redistribution for use or over night after use. This is especially desirable in cases of contagion or known exposures. For this purpose commercial formalin sprayed in enclosures for books, if air tight, in the proportion of one unit (c.c.) of formalin to 300 units (c.c.) of air space makes a good disinfectant. The sources of water supply should be kept pure and the students should be encouraged, if not compelled, to use separate drinking cups. Where this cannot be controlled the drinking cups if possible should be left in running water. Many cases of consumption, bronchial troubles, throat affections and catarrh are contracted by pupils and persons drinking from cups where the germs have clung from the lips of infected persons. Water standing even though provided with movable lids is to be avoided for fear of contagion. Barrels or kegs with faucets are much to be preferred. In many modern schools contagion is to be avoided by drinking fountains. But while the one danger of contagion is probably overcome, another perhaps equally great danger is risked. For drinking fountains deny the opportunity of examining the water 
that is being drunk which for all one may know contains other germs and bacilli equally dangerous as well as other small animals none of which can be seen and their intaking into the system avoided, as well as their deleterious effects from the diseases which they cause.

Apart from the water and its dangers another set of evils beset the school in the form of closets. All toilets, closets and urinals are breeding places of disease producing germs and air polluting gases. They should therefore be kept clean and free from arising odors and have separate means of ventilation. By all means they should be kept dry and well lighted. Toilets automatically cleaned and flooded are the best, those regularly and frequently cleaned are not dangerous. In modern times various forms of disinfectants and deodorizers are much in use. But while they have their value they generally hide many dangers most of which they are powerless to cure. It would be better for the general health of pupils and teacher if instead of commercial deodorizers thorough cleaning should be more frequently resorted to. These points to health are simple but should be carefully read and employed wherever possible by all teachers as precautions and preventatives. They will easily repay their cost in money, time and labor by their contribution in health and working efficiency.

Its Purpose in the Community. From what has already been said in this chapter it is readily seen that the school besides dispensing knowledge has a large field of usefulness in the community. Everything connected with the school should be orderly and well regulated both as to grounds, building and school exercises. This kind of a lesson is of great value to the school children and the community. Nothing should be allowed to go forth from the school that is not of good quality, wholesome and elevating. Its every form and place should be in and of itself educative. There should be public gatherings both for pupils and patrons created and offered on the part of the school for all within its reach. Besides this the school is often and rightly so a place of assemblage for promulgating and transacting community business. In such cases the teacher should see 
to it that the commissioners or board through the janitors have the grounds and building well cared for, properly lighted and cleaned before and after use. The teacher himself should see to it that the building in such cases is in trim order, bespeaking cleanliness, if not refinement and culture, however simple the furnishings, and then he should insist to the proper authorities upon its being kept and left as found. By these simple acts both teacher and school will grow in respect, force and influence in the community. The immediate purpose of the school in a community is to educate for service and to render service. The sum total capacity for happiness of any community should be increased by the school. The desire for happiness should be elevated and purified. The health of many living and working together and the power of thinking of the community all should respond to the kindly but intelligent touch of the properly organized and operated school.

\section{REFERENCE READING}

Bagley's “The Educative Process." Chap. XXIII.

Sharpless' “English Education.” Appendix 3.

Bolton's "Principles of Education." Chaps. XI, XII.

Colgrave's "The Teacher and the School." Chap. XIII.

Johonnot's “Principles and Practice of 'Teaching." Chap. XI.

Fitch's "Lectures on Teaching." Chap. III.

Baldwin's "School Management and School Methods." IV, VI, VII. Perry's "The Management of a City School." Chap. VI.

Collar \& Crook's "School Management and Methods of Instruction." Chap. II.

Garlick's "A New Manual of Methods." Chap. I.

Bailey \& Burrage's "School Sanitation and Decoration." Chaps. III, V, VI, X. 


\section{CHAPTER VI}

\section{THE SCHOOLROOM}

\section{Its Supervision and Control}

All of the formal educational agencies center around the schoolroom. It is preeminently the school. Here it is that the chief functions of the school are carried on, here the problems of character formation and knowledge imparting present themselves in all of their varieties and stubbornness day in and day out, month in and month out, for a solution both adequate and appropriate for the demands of this particular day and generation; here all of the forces of formal education must be controlled, diligently directed and unceasingly applied upon the crude working material as presented, if the educational ideal of the country is to be even partly realized. The classroom is the ideal unit in all educational systems. It presents every form and phase of problems known to formal education. This was true of the schoolroom even in its early history when education as formally outlined and conducted was a luxury afforded only by the rich and the school consisted of a few or even a single pupil and a single teacher. With us to-day, when popular or mass education is the order of the day and the schoolroom contains anywhere from a few students selected for their special abilities and special material means of developing these abilities to nearly a hundred miscellaneously gathered and with various capacities for taking on education either in the groups in our rural schools or those in our highly congested urban schools the problems of education as known to the ancients, have changed but little in form and essence except perhaps in so far forth as to become infinitely more complicated and difficult of solution. The question of the size of the schoolroom and the number of 
pupils and grades it should contain has always been a problem. Various authorities place the ideal number of students for work and supervision at from twenty to thirty-five, twenty-three being accepted by a majority as the ideal class. But whatever the number of pupils, conditions of congestion or lack of funds may force into the schoolroom, its problems arising therefrom must be met and solved, if the educational work devolving upon it is to be in any way carried on successfully. The real problem of the schoolroom is that of time, closely followed by that of energy. Both must be used freely and yet conserved judiciously. The great question in school economy is the economy of time and energy. So important have these problems been realized to be that the "National Education Association" has had a sub-committee at work to investigate how the time in the school is used and how economy in its use might be affected. A similar investigation has been carried on by the present U. S. Commissioner of Education. ${ }^{1}$ From both of these sources valuable suggestions have come, which, however, cannot be embodicd here. How therefore, to control and direct the activity of all of the pupils in a schoolroom in such a way as to get the best possible results in imparting knowledge and forming character obtainable, in the least time and with the least expenditure of effort in pupil and teacher is the paramount problem of the schoolroom. This makes two things in school processes necessary, order first and then precision in all school movements and exercises, that is, economy of time and energy in the performance of all school duties.

The Supervision of the Schoolroom. Much has been written in treatises on school economy concerning the use and direction of time and effort in school. In it all there have been a variety of opinions, but all agree that proper supervision of the school on the part of the teacher is the primary requisite. This supervision is to begin at the beginning of school on the first day and to extend throughout that day and on through that year and on through all of the years of the entire educational process. It is to extend from the playground to the recitation seat. It is to be less direct and 1 See U. S. Bureau of Education, 1913, Bulletin No. 38. 
special as age and experience in school routine and school work bring power of self direction, of control and of individuality. That is to say, school supervision must be always and everywhere in evidence both to prohibit and inhibit, passing from the former to the latter as with age and experience self direction grows upon the pupils. The teacher must always be on the alert. His eyes must be "all seeing" and his ears "all hearing." From the first hour of school every pupil should be taught to feel that the teacher can both see and know all that goes on in a room and even much that is only about to go on in it. He must be able, if he would control all situations, to detect mischief even in the making and to tell the trend of conduct almost before it actually issues into conduct. The aim of supervision in education is the production of good moral character and intellectual activitiy. If it fails to do this it has failed in its first and most elementary function. According as it succeeds or fails in these regards school government is either good government or bad government. But there are many reasons why school governments above all forms of government should be good government. To begin with this is the first contact of the child outside of the home with tangible rules and regulations arbitrarily administered by unrelated agents. If here he is allowed to learn that laws are lax and their enforcement intermittent and uncertain he has learned a very harmful lesson, one that may turn out to be the first lesson in the disregard for and transgression of law, the first step perhaps toward the jail, the penitentiary and even the hangman's post or electric chair. The result of any such failure on the part of the school, is especially injurious to pupils being prepared for citizenship in democratic countries - republics where the meaning and force of law and the results of their breaking need be so well impressed upon the growing child as a direct and important part of the preparation for the assumption of the coming duties of good citizenship.

The Nature of Supervision. All teachers have seen cases of successful supervision and cases of unsuccessful supervision. The causes of the success or failure have in most 
cases been quite evident. We have said that a teacher must be all seeing and all hearing. This by no means makes it necessary that the teacher call the attention of the pupil or pupils to every little disorder in the room. Much in the schoolroom may be passed over as of no importance in supervision. Many pupils will deliberately do things to attract the attention of the teacher or to disturb other pupils about them. To follow such pupils up in their little acts is often to do just what they desire, namely to call attention to them, magnify their acts and let them know that they are a source of annoyance to the school in which instance socalled "bad cases" may result. It is much better that these should be treated either indifferently or quietly directed to some sort of activity in harmony with the activity of the other pupils. There is, however, a certain kind and amount of noise and disorder necessary in every schoolroom. It is the noise and disorder of work. While this kind of noise and disorder should be invited, it should also be controlled and reduced to a minimum. Such noise and disorder is a joy to the teacher. He knows then that everybody is at his or her work. It may be the movements in the seat, that from seat to seat or that from seat to blackboard, to the teacher's desk or to some remote part of the room for some tool or instrument of labor, that causes disorder or noise, but in it all there is that conscious satisfaction so utterly wanting when there is noise and disorder without resulting work or results from work. Children come to school to work, to be taught and to be trained. It is to attain this end that supervision is necessary and is prevalent in schoolrooms. It aims to give the best possible working conditions for study and learning. In the schoolroom where we have to deal with the variety of individuals present in mass education, it is necessary that in the mass the individual be not neglected, but that he be given at times special consideration. Supervision is high class only when it enables each pupil to receive special bits of attention without the work of the class as a whole suffering thereby. Unfortunately in our wellfilled, if not crowded schoolrooms we are to too great an extent compelled to neglect the individual pupil. Individual train- 
ing is lost sight of in the effort to attain group training. Our school plans are laid out for an ideal "average pupil", who does not exist and all of our efforts are directed toward his education. Such a method of education is and must bc on the whole fruitless of results as most teachers have found out by practice. Life is an individual affair. And so must the best forms of education be individual education if it is to fit one for life. Where an overcrowded curriculum or an overfilled schoolroom will not permit individual education the teacher must approximate the work of the school to the needs of all and still endeavor to satisfy the needs of this average pupil in order that he may do lasting and fruitful work. School work fails chicfly in that it is not individualistic but general. If we educated a general or average ideal pupil then education might well be general or ideal. But what we labor with in the schoolroom is not an average, general or ideal pupil, but a special, concrete individual pupil or groups of pupils as individuals and as such we must endeavor to educate him or them specifically and in detail.

Time and Energy in School Processes. The chief problems of the schoolroom revolve as was said upon the questions of time and energy. The energy naturally in the child is sufficient (often more than sufficient) for the ordinary routine of school without any special attempt at conservation on the part of the teacher. With time it is different. There is generally too little time rather than enough or too much of it. Time conservation then becomes the greater of the two problems in the schoolroom. Especially is this true in the graded school or where there is more than one grade in a room to be handled by one teacher. While, therefore, all school supervision has for its main purpose the conservation of time, in the rural ungraded school especially the question of time conservation easily takes first place. Much, almost too much has to be crowded into the brief school day with its still briefer recitation periods. On the problem of time conservation in the schoolroom much thought and experimentation have been spent. Further, it is agreed by all who have given study to the question that the teacher can do much toward this end by applying method and devising 
routine to save time for study and learning and thereby reduce the waste of time in the performance of the necessary schoolroom functions to a minimum. These methods and devices are either physical or spiritual. The physical aids to the supervision of the schoolroom are the proper seating of the pupil based on a study of their temperament and social compatibility, the proper seating of pupils based on a study of the fitness of the seats in size, in their proximity to the light and heat, and in their access to ventilation (fresh air supply), in the general attractiveness of the schoolroom and in the general movements in and about the room. The spiritual method or devices for good supervision are tact, common sense, discretion, sympathy, pleasantness of manner, skill in handling pupil and subject matter, scholarship, enthusiasm, and a general high tension with quickened sense activity.

Physical Aids to Successful Supervision. Proper seating. The bodily comfort of a pupil has much to do with his mental energy and will power. The problem of seats has already been discussed in the previous chapter and a little was said incidentally about seating. Seating of pupils can add or detract much from the general student habits and abilities of a pupil. Bodily discomforts besides fretting a pupil and making him peevish and irritable exhaust the bodily energy, use up energy that should be available for effort in the mastery of lessons and in the movements required for the recitation proper. The pupil worn out by the restless turning, because of the pain in the pelvic region, brought on by improper curvature in the desk seat, or legs tired from dangling in the air, or from faulty support for the back from the desk chair, is in no way mentally fit, either to receive or retain the subject matter presented in the lesson or appreciate the general manner of the teacher or the attitude of his fellows. Many a pupil otherwise bright and easily controlled loses hold upon himself and his lessons because of the exhaustion brought on by sitting in a desk seat which is not properly adjusted to his height nor to the general contour of the body in its natural positions when seated. In the cases of highly sensitive temperaments the effect from 
the strain produced by improper seat adjustment and seat accommodation is quickly noticeable. There is a like response to light, heat and ventilation. Children with poor or defective eyes when seated at a distance from the lighting surface, because of the strain caused by working in poor light soon become fatigued and before long the exhausted energies and lagging movements will show themselves in the form of indisposition to do, and other forms of reaction that make for poor school work. Under the influence of certain stimuli, such as promise of reward, desire for high grades, love of emulation, or fear of rebuke, or punishment, the will may revive or spur on the flagging energies, but soon they will fail to respond to the will and the usefulness of the school processes at least for the time being, are at an end. This is one explanation of the poor work of students on cloudy days, another being that the absence of sunlight produces retardation in all of the bodily functions, thereby making the vital functions low and the energy generated small in quantity in comparison with that produced on bright sunshining days.

Fresh Air. The action of fresh air obtained in a schoolroom through ventilation is similar to that of light. Fresh air increases the vital functions and the number of red corpuscles in the blood. The bodily processes thereby are quickened and deoxidation with its consequent generation of heat and the production of waste material is aided by fresh air. Thus in the normal schoolroom good ventilation is necessary, not alone for the general health of all, but is necessary also for the energy made available thercby for the schoolroom work and activity. Now it is a fact that deoxidation goes on normally more rapidly in some pupils than in others and in the case of disease and sickness the same is true. This means that it requires more fresh air for the same results in some pupils than in others, and that some pupils may with benefit have more ventilation in a room than others. Where this is impossible the best results can be obtained by falling back on the proposition of seating. Such pupils may be seated nearer the source of the fresh air supply than others. This will be found to give more 
nearly the desired results. The same is true in the case of the heat produced by deoxidation and functional activity. These generate the bodily heat and maintain the bodily temperature and are affected noticcably by the temperature and ventilation of the room. Since these processes vary in strength in different individuals it obviously follows that some pupils will not only be able to stand more heat than others, but some will actually require more heat for their bodily comfort than others. All teachers have met in their experiences with the pupil who is eternally annoying them because always too warm as well as he who is doing the same because eternally too cold. They have also had them exhibiting all of the intervening stages of bodily temperature requirements. But not only can these circumstances not be avoided, but they are vital in the schoolroom. Their careful observance means first of all much in health to the pupil, and not only this but that which is of equal concern to know here, they mean much to the working efficiency of the pupil and successful supervision on the part of the teacher. Pupils whose energies are taxed unduly to furnish the required amount of heat for the body, whether because the temperature of the room is unduly low or because the air does not furnish the amount of oxygen necessary for vigorous vital function as well as those whose energies are exhausted by overcoming strain produced by an overdemand on the part of the body to accommodate itself to any normal condition in the environment of the schoolroom, are in a corresponding degree disabled and their power for work decreased, whereupon time not only is not conserved but all of the school processes suffer accordingly. The true import of these questions to the pupil cannot be overestimated. Anything in the schoolroom which tends to bodily comfort or mental case and satisfaction raises the working efficiency of the school and conserves time in a way little realized by most teachers. School esthetics such as pictures and paintings on the wall, everything of a decorative or artistic nature indirectly affects the attitude and manner of pupil and teacher and reacts upon their work.

Mechanism in the Schoolroom. In reducing the super- 
vision of the schoolroom to a minimum and raising the working efficiency to a maximum, much can be done by mechanizing the school movements. There is, however, serious opposition among modern and advanced educators to reducing school movements to a mechanism. The modern tendency in education is toward individualism, with all of the freedom of development and independence of action which the word implies. Consequently it is not surprising to see the most penetrative minds and trenchant pens directed against the introduction of mechanism into the movements of the schoolroom. However, in our schoolrooms which are crowded with pupils and with the curriculum too large for both pupils and teacher, a demand for time conservation and a high working efficiency is bound to creep in and make itself felt imperatively. For the benefit of these it will be well to discuss the problem of mechanism in the schoolroom, and see its good points as well as its bad points and leave its application and uses in the schoolroom to the intelligence and discretion of the individual teacher. Education as promulgated and fostered by the state is for the purpose of producing a good citizenship. As governments change the type of citizenship will change and the forms of education fostered by the state will soon be so modified as to produce a modified citizenship in accordance with the changing political views and duties. It might with more trutl be said that one is reciprocally reactive upon the other, the institutions of government and the institutions of education change together. In the past when governments ruled by mere force and citizens were the mechanical cogs in the machinery of government who followed law in a blind mechanical way, the pupil was prepared for this kind of citizenship by a school routine that reduced all of his movements to a mechanism, and by force (corporal punishment) compelled him without explanation or enlightment to follow the arbitrary instruction and will of the teacher. With the rise of government from this level to a higher one of freedom processes have looked more to a development of freedom of action and individualism in thought. This advanced method in education has gained a powerful hold in the schoolroom. But the old school of educators 
are not going to give up without a struggle. There is to be sure much of merit in the claims of each. It is true that the niceties of mechanism are used by many a poor teacher as a ready cover for many of his faults in teaching that would otherwise stand out glaringly. In fact the chief complaint against mechanism in school routine is that it is the harbor too often sought by the incompetent teacher. The teacher confident in his ability, full of enthusiasm and winning in manner frets under the strain and restraint of a stolid mechanism. He is desirous of freedom both in himself and in the pupil under his supervision. The opponents of mechanical routine believe that conduct should come from within and not be forced upon the pupil from without. With these all pupils should be self-governed. In fact so thoroughly has this idea of education dominated our present day educational methods that the hands of government of some schools of higher learning are left almost entirely to the students themselves. While under the same idea in the public schools of many cities the inhibition of self-activity by corporal punishment has been forbidden under the plea that child activity should not be crushed but rather be persuaded and guided into a strong individuality by the rational method of being told the whys and wherefors of everything required of him. On the other hand the advocates of the mechanical routine argue that the child of the graded school and especially of the lower grades is not prepared for selfgovernment and cannot therefore successfully govern himself. Hence their claim that he should be forced to do some things recognized to be for his own good whether he wishes to or not without being told the whys and wherefors, and this too even if corporal punishment is necessary to accomplish the desired end. All of the intermediate stages between mechanism of routine and freedom in school process have their advocates. Experiment and experience, however, have proved that some children require more mechanical movements in school while others require less, and that the higher the grade of pupils the more in each will be found who can be trusted to govern themselves. So that at bottom the question is not as to whether or not there should be mech- 
anism in sehoolroom movements, but how much is required to get the desired results of conservation of time and working efficiency with the least loss of individual activity on the part of the pupil. This must be left to the teacher and his judgment of the needs of his pupils and the work required of him. The value of mechanical movements in the schoolroom no one of any experience will deny. Lessons in law, order, regularity and concerted action are of inestimable value to the young growing mind. What kind of characters would otherwise evolve from the home and the school, we can all picture quite vividly in the imagination. No parent desires a child nor does the state a citizen, that has no sense of concerted action or cooperation, as it is sometimes called, while one who has no conception of regularity and precision of group consciousness and orderly action, is equally undesirable both as a companion in the home, in society and in the state. However, there are cogent reasons against the mechanizing of school movements, many of which are decidedly opposed to the modern educational tendency toward individualism, self-activity and selfgovernment. In group activity the individual is too prone to lose self-consciousness in the presence of group consciousness. This tendency needs to be corrected rather than encouraged. Again, however, it might be added that there are some spirits which are sufficiently self-assertive and free to overcome all influences directed toward mechanical action and group consciousness and press toward self expression, and individual thought and action. For those less strongly impelled in the direction by nature the presence of mechanical movements in the schoolroom can hardly be said to be a benefit.

The opposition to the reduction of the schoolroom movements to a mechanical routine has justification that is fundamental and which lies at the bottom of our physical and mental structure. The school aims to fit one for the activities of life. Now for success in life we need the power and the desire to take the initiative, that is, the ability to meet and cope successfully with the emergencies, the crises of life. Mechanism deadens if it does not destroy the tendency to 
initiative action. In life we need a high power of reflection for the solution of novel experiences, thought compelling surprises and the intricate problems of life. Mechanical routine in school movements tends to weaken both reason and judgment. In life we need independence of action and selfassertiveness in thought to lead us to discovery and invention and the consequent material advance which they afford us in life and habits of living. Mechanical routine stifles both independence of action and self-assertiveness in thought. Self-government and individualism are the under-lying principles in all forms of democratic government in fact are a necessity for its very existence and perpetuation. The arbitrary and despotic rule blindly initiated and more blindly enforced destroys both the nascent power for self-government and the innate tendency to individualism. The mind to be at its best must have freedom of action. Minds restricted in action tend to become weaker. The body to be developed to its fullest capacity must have full and free play for the exercise of every normal function. Hence any system of training and education which has as its basis restriction and curtailment of action is at best faulty and vicious. Consequently the only justification that restriction in action and mechanization of routine can possibly have is that it conserves time and raises the working coefficient of the schoolroom. This is its sole reason of being, its only justification. To make it serve any other purpose in the schoolroom is to vitiate the purpose of the schoolroom processes and to rob mechanization of all usefulness as a school method.

The mechanization of schoolroom routine should be begun on the school grounds with some agreed upon signal as a warning signal of the approach of the opening hour. Following this in order of time at least slould come those for forming lines, followed at the proper interval by those to "mark time" and "march." Orderly lines with good posture and carriage and even step leave a pleasing effect upon the visitor and has a tendency to inspire respect and obedience on the part of the pupil. These mechanical processes of entering and leaving and proceeding to and from the rooms should be succeeded by like ones in the schoolroom itself, 
if mechanical routine is to be of greatest service in the school work. This routine process should also extend throughout the school year. Demand for such mechanical movements is presented in class movements to and from the blackboards and recitation benches and in the passing and collecting of the various working material of the pupils, such as maps, books, papers, pencils, etc., and even in the distributing and collecting of wraps. By having a place for everybody and everything connected with the school and school routine, and by having things taken from their places and returned to them in order and with regularity much time is saved, to say nothing of the wholesome and salutary effect of such conditions upon the mind of the pupil. Too, efforts to obtain neatness and uniformity in work should not be omitted from the mechanical movements of the schoolroom, if they are to bring out most that is good in them. The detail for such mechanical movements cannot be gone into here. The teacher must devise his own scheme and code of signals as the equipment of the schoolroom and the age of the pupils in the schoolroom make necessary. These matters can be worked out in detail to suit the wishes of the individual teachers, care being exercised always to regard these matters not as an end in itself in schoolroom supervision but only as a means to the conservation of time and the increase of the working efficiency of the pupil. Put to any other purpose mechanical routine has little place in the schoolroom processes and little or no justification in educational systems.

Mechanical routine in the schoolroom even when used judiciously and sparingly creates much extra work for the teacher. This work it is customary to detail upon monitors. The habit of selecting monitors is a matter fraught with considerable danger to the general wellbeing of the school and the pupil unless much care is exercised in employing the right to select pupils for such work. All pupils, the good and the bad alike like to be monitors. On a principle of absolute justice all alike have an equal right to be chosen for monitor duty. In order therefore that all be given an equal chance at the opportunity, on a basis of merit that is openly fair to 
all, some method of selecting them should be adopted and made known to all before hand. By no means is it a good method to let the selection of monitors be known to be a matter of personal preference of the teacher, or that it is used to pay for special personal favors. Monitorships bestowed for excellence in deportment or any line of work cannot but have a good effect on the morals of the school and call forth a responsive cord among the pupils. Nothing breaks in upon the order of the school, affects for worse its working capacity, and lowers the esteem of the teacher in the eyes of the pupils than a system of petty favoritism. Of course, some pupils will do our work better than others, but be that as it may in general the best results in the schoolroom will obtain if we pick our pupils for their various services upon a common basis of merit, so determined that all will know that they have an equal chance in the struggle. For matters of supervision and govermment it will pay, once we have through the announced process chosen a pupil as monitor and he prove unsatisfactory to have patience and train him rather than to pass him by or dismiss him (unless in cases of punishment for acts of willful carelessness or other faults which he exhibits as willful) and thereby let him know that he has no chance to become a monitor whatever might be his general virtues in the school processes and the school routine. The force of this suggestion cannot be overestimated. Here is a stumbling block for many a teacher who finds that his pupils dislike him and cannot tell why. Teachers often fail from causes arising out of such errors of judgment of real fairness. A safe way always is to dispense favors generally. In this connection too it may be added incidentally that many a time a notoriously bad pupil may be won over for his everlasting good by a well bestowed favor at the hands of a discreet teacher.

Social Surrounding as an Aid to Supervision. As important as are the questions of mechanical routine and physical confort of the pupil from the viewpoint of their access to the necessary amount of light, heat and ventilation they are perhaps secondary in inportance to their access to favorable and comfortable social surroundings. The most 
inexperienced teacher soon becomes aware of the fact that certain pupils are more or less susceptible to certain social influences of the schoolroom. In general the social compatibility of pupils varies. Some pupils are at home anywhere in the schoolroom, while others have few friends and gain these few slowly and are content to sit only in that immediate neighborhood. When seated in one section of the room in the midst of one group of pupils, a pupil may be very talkative and disorderly, or on the other hand silent and industrious. Then again a new social environment in the schoolroom may have one effect upon a given pupil for a while, but as the surrounding pupils become known to the pupil newly come into their midst, these previous attitudes may change and show themselves in his conduct for better or for worse. Boys and girls much given to disturbing the quiet of the room by their talk or play may be successfully quieted by being placed among pupils who will not talk with them and who will resent being disturbed in their quiet and work. Misbehaved pupils may often with advantage be disposed of in like manner. Lazy pupils too may at times be aroused to work by being moved into the midst of a group of industrious pupils and their ambitions thereby aroused to the extent where it will arouse them to action. These statements are not only based upon a wide and varied experience and experiment but are based upon fundamental qualities in human nature. In a like manner it is known that some pupils do well nearer the teacher's desk, the source of power, control and the exercise of arbitrary authority. Such pupils soon become conscious of any distance between them, and the source of control and feeling that they are to more extent out of reach of such power, and can therefore do certain things without being detected and punished will attempt many more things that tend to upset the order of the room. There are also in every room pupils who will be well behaved in any part of the room far from the teacher's desk or near it. There are also in some rooms at times pupils who will hardly behave in any part of it, at least not until a great effort is brought to bear to force good behavior. The former the teacher can use as a leavening power to raise the 
order and working efficiency of the room by use of good judgment in their seating. The latter must either be conquered by some harsh or diplomatic measures or if despaired of he may be removed by suspension or expulsion or as is done in some city schools, he may be sent to the school for incorrigibles. With these facts before him the judicious teacher can so seat his pupils from the viewpoint of social compatibility that his supervision necessary for control will be reduced to a minimum.

In the seating of pupils, however, the bad or unruly pupil is not the only one to be considered. If we did this we would place a premium upon badness or unruliness. In general we seat pupils in the schoolroom according to their size and age and sometimes in ungraded schools or in schools where more than one class is in one room we seat them by classes. Attention has already been called to the method of seating to satisfy the individual demands for light, heat and ventilation as well as to satisfy the demand for certain sizes of desk, height of desk tops and seat and seat backs. Apart from these considerations the well behaved pupil is due some consideration if for no other reason than that he is well behaved. It is very often a punishment to annoy well behaved hard-working students by putting into their midst ill behaved, lazy ones. And the practice is above all other things to be strongly condemned on general principles. Besides making the good, industrious student suffer for being such it is making him carry the burden of discipline and government when it should rest in reality upon the teacher. This side of the question should be well weighed by every teacher before going into the proposition of seating for conduct and work only. Besides that, there is always present the danger of having the good pupil corrupted by the bad one. In all cases of seating for ease and facility of supervision then, the good pupil should not be hampered to any great extent in his work or his habits otherwise of good work and conduct endangered. Where he is used as a means of tempering the conduct of another pupil, the moment the social contact is found to have a harmful effect upon him either in weakening his power of moral restraint or in fretting him 
and decreasing his working efficiency, the annoying presence should be removed. With this care, though that method of checkmating bad children in their acts by removing them to different and often better social environment is often seriously condemned, it is I think safe to say that it may be practiced discrectly for ends of minimum supervision and maximum working efficiency. In the case of putting lazy and indolent pupils in the midst of bright industrious ones the danger of tempting the lazy ones to prey upon and copy off of the smart, as well as having the tendency to become lazy, spread and infect the others, must be carefully watched for and guarded against and a change of scat arrangement made at the first signs of contamination.

Psychical Aids to Supervision. Besides these physical means of stimulating the child to work and giving him certain physical aids in his environment in pursuing his work and thereby conserving both his time and energy and raising the working efficiency of the school, there are certain mental attitudes which when possessed by the teacher do much toward promoting the facility and the rapidity of the work. By the judicious exercise of good common sense (a word which all know and understand, but which few if any can satisfactorily define), the school processes can be developed to a high degree of efficiency. Comnon sense has been wittingly defined as sense in common things. Accepting this definition of the word it is evident that common sense is what every teacher needs who would be a success in the work of the schoolroom. This provides a cure for every ill, whether it be due to light, heat, ventilation, seating, scats, laziness of pupil, social compatibility or what not, a resourceful common sense will adjust it satisfactorily to all and to the best good of the schoolroom and its processes. Some author's recently have named this quality of mind "tact." But whether we know it by the name of tact or common sense it is that quality of mind that enables one to meet successfully the emergencies in the affairs of life and which must be constantly in evidence in the schoolroom for the best good of all concerned. In its finest and most practical form it enables one almost instinctively to do the right thing in the right way and at 
the right time. The greatest problem of a teacher is to think and feel with the pupils, to put himself in the pupil's place mentally. Unless this can be done successfully the teacher often falls into the serious error of inferring wrong motives in child action. The fact is much of the action of children is unmotivated (without conscious motive, but rather impulsive and unreflective). In such cases any motive inferred or ascribed to an act would of course be the wrong motive. Teachers inclined to attribute motives to child action soon get the reputation among the pupils of being unfair and unreasonable and immediately fall heir to the entire train of consequent ills of bad supervision with its resulting dissipation of time and energy and low working efficiency. Out of common sense discretion and sympathy come. No one can put themselves into the place of children and not sympatize with them. The fact is a truism. Sympathy with a child means of necessity a complete understanding of child nature even down to its emotions, impulses and strong tendencies to action. Sympathy soon touches a responsive cord in all but the morally depraved and sonetimes even he can be finally reached by persistence. Stability in character, evenness in temper and consistency in using and enforcing rules all are strong guarantees of success for the teacher.

Next in importance to these as aids in raising the working efficiency of the schoolroom are a pleasant manner, skill in handling subject matter of the lesson, general evidences of scholarship and a high moral conception, with a daily evidence of exemplary conduct. It has been said that in the economy of life pleasures tend to increase life's activitiss, while pain tends to decrease these. The organism in its efforts to live, sceks to gain and retain pleasurable states of mind and body, while it seeks on the other hand to overcome and avoid painful states. It is also a fact obtained through the same processes of reasoning that we tend to retain well the conceptions of pleasures and tend to forget quickly the conceptions of pain. But whether there be any claims in truth in these conclusions or not, certain it is, that a pleasant mannered teacher working in a pleasantly arranged and 
equipped schoolroom under pleasant mental conditions does by far the most effective, rapid and lasting work. The brain and bodily organs function better under such an environment and the mind operates better. The children themselves soon notice the difference and learn to anticipate the pleasant teacher and the pleasant comfortable schoolroom, while the effects produced upon them are easily more lasting. The cross, scowling unreasonable and inconsistent teacher in the uninviting schoolroom soon finds an uninviting group of pupils in the room doing uninviting work. A pleasant manner on the part of the teacher is of great value in the schoolroom but is only at its best when coupled with skill in handling the subjects tauglit and other evidences of scliolarship in general. Pupils like to feel that their teacher possesses knowledge, that kind of knowledge which is power. Indeed, we are all admirers of people who possess such knowedge. Children in particular are worshippers of this kind of "heroes." Many a poor teacher, unpopular and ineffective has suddenly found himself successful, because of some accidental evidence of skill and power. This docs not. mean, however, that teachers are to make "exhibit bees" of themselves before the pupils, nor boast to them of their unexhibited prowess. It is always safe and becoming though for teachers to do whatever it becomes their manifest duty to do and to do that not only well but with excellence. Unpreparedness in any emergency is a serious situation for any teacher to meet, who would maintain a high regard and consequent control over his students. Modern pedagogics since the rise of physical education advocates the presence at, supervision of, and participation in, the games of the pupils on the playgrounds by the teacher. Here discretion is always necessary that he not enter into those games in which he is not apt or in which he has only poor execution. The moral effect of the effort to do what others do without effort or failure in the attenpt is far reaching in its effect upon the hold the teacher may have upon the pupils and will detract materially from his future supervision over and control of them. Pupils are all quick to make comparisons and suggest criticisms. The teacher cannot long successfully 
endure either the comparison if unfavorable or the criticism if adverse. We have in another place touched upon the hygiene of the school and grounds and much was said there that might have come liere.

The Effect of Health and Hygienic Conditions upon Supervision. In the earlier parts of this chapter we discussed the effect of proper lieating, lighting and ventilation, seating, seats and scliool novements upon time conservation in the schoolroom and upon the working efficiency of the pupils. The subject matter of this chapter would not be complete without a word or two about the effect of the general healthfulness of the pupils and the hygienic conditions of the schoolroom and school processes upon the conservation of time and the working efficiency of the pupils. 'The immediate responsiveness of the mind to ravages of sickness and disease is a matter too well known to need comment here. It follows as an obvious fact that the slightest evidence of unhygienic conditions in the schoolroom makes its presence felt immediately in the capacity of the pupil for work. Only, therefore, when the pupil is in good health and the schoolroom is in prime condition is it possible to secure the highest degree of efficiency in the play of educative forces. The general health of the pupil can to but little extent be regulated by the school. We therefore pass it by for the hygienic condition of the schoolroom which the tescher can control and which she is expected to regulate and control, at least in the essential things pertaining to health. Much has been done in the past quarter of a century along this line and the underlying principles for promoting the health and healthy working conditions in the schoolroom are pretty well established now. As usual Germany moved out into this field of inquiry and America soon followed. Kotelman in Germany and Shaw in America are both well recognized authorities in this field. Experience has proved and teachers if observing will find that erect postures in sitting and standing will serve to keep the pupils attentive and steadily at work. Attempts to "slide down" in the seats and stretch out the legs soon bring about a general relaxation in mind and body and invite laziness and indolence. If 
this were the only harm the habit could be passed by with little comment. But this is the least of the evil. Such a position forces the shoulders forward, presses the chest in and prevents full and deep breathing. Besides this it tends to producc spinal curvature bringing on oftentimes later in life deformities which often last until death. It also enforces improper breathing, short compressed inspirations which by bringing small quantities of air into the lungs and not completely filling them causes the remote parts of the lungs to dry up, make poor blood, impoverishes the whole body and thereby reduces the bodily power of resistance to the attack of discase. It also reduces the bodily energics required by the pupil for the performance of his daily schoolroom duties. Slothfulness and sluggishness of body thus produced react to produce a like state of mind. Pupils should, therefore, at all times be forced to sit straight and erect, with heads up, shoulders back and chests out. Constant drills in deep breathing if made to accompany these postures will add much to the general good effect. Their feet should be flat on the floor and the body back so as to be supported by the back of the seat. The pupils should be constantly drilled in all of these matters until they become matters of habit with them. Also in such schoolroom exercises as drawing, writing and desk work these details should be insisted upon. Every routine of the schoolroom should be done in that way which will produce the least strain upon the pupil for the amount of labor demanded. But these very practices themselves become a source of fatigue and in time will bring on exhaustion. To overcome them a brief recess period should be instituted to give change of bodily posture and reinvigoration by motion and fresh air. Where a recess cannot be taken, a few moments of gymnastics in the room with windows open, or any form of rest and relaxation with some means of invigoration included will serve to bring out a state of rest with a recharge of the storage cells of bodily energy for the remaining time of the session. There should not only be a stated time for these periods of relaxation, but there should be sufficient laxity in the schoolroom routine as to allow the teacher at any time at his own dis- 
cretion to break in on the day's routine, when deemed necessary, to take sufficient time to relieve any apparent strain or exhaustion manifest in the children. The time thus lost. may be easily made up by the increased power for work gained thereby. However, of all forms of relaxation and recuperation free play in the open air is preferable to any form of activity indoors.

Personal Cleanliness. Because of the close relation between matters of personal cleanliness and matters of health and rentilation as well as the problems of seating and the problem of supervision of the schoolroom a word or two about personal cleanliness among pupils will not be amiss here. Personal cleanliness is always essential both in the schoolroom and out of it. It contributes much to the personal pride and resulting ambition of pupils. It is also a very prominent phase of education for daily practice in life. However, it is made a matter of secondary consideration because experience has shown that it is more or less a delicate matter for teachers to take up such matters with pupils, but because of the gravity of the situation teachers should have no fear in taking up such matters when the situation demands. They should be handled discreetly and tactfully but handled without delay. General talks are best in the beginning followed by personal talks with the pupils and attempts made to arouse their personal pride; this failing, it is imperative that the matter be taken up in consultation with parents. If still there is no response the only course open then is the school lavatory or wash basin. If the case reaches this stage it will probably be one of discipline and should be carefully weighed by the teacher before launching into it. Cleanliness however, in the schoolroom must be had almost at any cost. Beside being unsightly the odor arising from the clothes of such pupils is often disgusting and even sickening. They also make the problem of ventilation difficult and complicate the matter of seating for ends of better supervision. The relation of dirt to disease is very well known. All forms of disease bearing germs and infecting bacteria and bacilli breed lively and thrive in dirt. From this viewpoint cleanliness is a necessity for pupils in the 
schoolroom. In all such matters the teacher should lead off. His example both in dress and habits in this matter can be a potent one. Bodily odors of the home, sick room, or kitchen besides being germ laden are offensive and both contaminate the air of the schoolroom, and besides complicating the problems of ventilation and robbing the pupils of the fresh air needed for work, overtax the organs of respiration and produce enervation thereby noticeably reducing the working coefficient of the school. One of the chief dangers arising from the lack of personal cleanliness is infection from contagious diseases. The laws of the health authorities in dealing with such matters should be strictly enforced by the teacher and in conjunction with the strict enforcement there should be liberal cooperation between the school authorities and the health department. As has been said above it would be well for teachers to acquaint themselves with the general symptoms of the more common contagions, especially of those of the so-called "children's diseases." Whenever in doubt as to symptoms of contagious diseases or even suspicious of their presence among their pupils strict adherence to the spirit of the law will require that these pupils be sent home and a medical examination advised. Where cases of quarantine have existed the children from these homes according to the best expert medical advice should be excluded from school until the full period of germ incubation has passed and there is no longer danger of infection. If exposures to contagions have accidently occurred it will be safe to take the necessary precautions to avoid infection at once. In many cases due to the opposition and relation of the parents of a child it is difficult for the teacher to do his whole duty. But suffice it to say that here as in all such cases the general good must be primary and the teacher should unflinchingly follow the rules and regulations laid down in such niatters by the school authorities and the health department. The pride and wishes of the few should not under any consideration be allowed to endanger the liealth of the school and the community.

The question of school supervision, the conservation of time and energy in it and the maintenance of a high standard 
of excellence in its working efficiency are very important and may contribute much to his success or failure in his work. Prowess and ability there mean his ultimate success or failure in school work when judged by true standards. Much has been written and spoken upon it. It is still a live subject. Nor can we hope to say much upon it here. What has been said is and can only be suggestive. The teacher may take these few hints and supplement them out of his own experience. For after all it is out of resourcefulness gained through experience that makes a successful teacher.

\section{REFERENCE READING}

O'Shea's "Social Development of Education." Chap. XIV.

Arnold's "School and Class Management." Chaps. IV, V, XI, VI, Sect. V.

Colgrove's "The Teacher and the School."

Baldwin's "School Management and School Methods." Chaps. X, XI, XII, XIII, XIV, XV.

White's "School Management." P. 48, 19.

See also references to Chapter on Discipline. 


\section{CHAPTER VII}

\section{DISCIPLINE}

In the economy of educational processes the problems of supervision, government and discipline are very closely related. Because of this relation in treaties on education usually the discussion of government and discipline follow closely on that of supervision. There are, however, from the viewpoint of education some points of difference that it is very essential that we note and establish clearly here. For confusion in the meaning of these terms in education often leads to serious errors in government and in discipline that brings about misunderstandings between pupils and teachers which sometimes a whole lifetime does not succeed in straightening out. Webster says the aim of government is " to direct and control the actions or conduct of one, either by established laws or by arbitrary will." Discipline he says aims " to develop by instruction, and exercise; to bring one under control so as to have him act systematically, to train one so as to have him act under orders." There are here you see so far as school processes are concerned fundamental differences. Government in its primary sense is incidental to discipline. It is a means to an end, while discipline is an end in itself. Government is constraint upon individual actions, while discipline is conducive to freedom of individual actions. Government in and for itself exists everywhere only for the purpose of discipline. Its aim therefore is purcly and simply to control the action and conduct of the governed. Government in the schoolroom aims to maintain order and quiet in the school, to enforce respect and to act as a check upon rebellious and recalcitrant spirits until they can be brought under the influence and control of the forces of discipline.

There will be, then, if these basic differences between gov- 
ernment and discipline are fully comprehended an elemental difference between the punishments inflicted for the purpose of government, and those inflicted for the purpose of discipline. They provoke very different attitudes of response on the part of the pupil. The former he accepts as a necessity under the existing order of things, the other as something due in consequence of certain acts of commission and omission. Government considers merely the overt act as a breach of the school order, while discipline goes behind the act and considers the kind and quality of the intent. Government is temporary in the check it offers but final in the acts it considers. Discipline, on the other hand, is gradual and continuous growing in strength in its effectiveness as a spirit for it is engendered and fostered in the recipient mind. Thus one can readily see that while there is but little place in the modern conception of education and educational processes for government, there is infinite room in them for discipline. The old education was for the most part governmental in nature. The new education being essentially an education of frecdom and individualism is a reaction against so much of government in the schoolroom in favor of more disciplinc. At bottom the basis of the argument against the mechanization of school routine and the enforcing of government from without in favor of self government, that kind of government which is characterized as being voluntary and from within, lies in the opposition which is fundamental between government and discipline. In the present content of the concept government robs the individual of freedom of thought and individuality of action, makes of the pupil a blind automaton, following without question or after-thought the arbitrary rule of those in authority. Such a one, as he grows into manhood, is but little fit for the complex duties of a responsible citizen under democratic forms of government and of a member of an advanced or enlightened social group. It is discipline and not government that makes the highest form of instruction possible, though the contrary opinion attributing such power to government is the prevailing one. In effect government aims at temporary reform and control, while discipline ains 
at the permanent effects necessary in the making of the free and independent man. Government aims to produce a reaction that is temporary; while discipline aims to produce a relaxation whose effects are lasting and for the individual's improvement in moral and mental good. Whenever punishment is temporarily cocrcive, which at times it is highly essential that it be, it is a measure of government and not one of discipline. As such the punishment will not generally go dcep enough to do the desired good. It will only reach the feeling of the individual when it should reach his thought. As long as punishment does not get into the thought life of a pupil its reformative as well as its formative effects are at low ebb, sometimes practically nil. In such cases it is often better if dispensed with entirely, or employed only as a means to secure a foothold on the pupil for the application of measures of discipline. Much of the punishment of the schoolroom falls upon the child as water upon a duck's back, simply because it is not rational punishment. For the child, unless special efforts are made to show him, there is neither understanding as to the reason of the existence of the rule, nor explanation as to wherein a breach of the rule should be followed by this or that particular kind of punishment. Not only is there need for the grounds of punishment to be made known to the pupil, but there must also be seen by him justification of it in his action, if the punishment is to have any disciplinary value to the pupil at all. Punishment is intended to react upon the sphere of thought action of the pupil, to affect the form and content of his mental life. In order to do this it should get into the midst of the elements which determine human action, namely, into his interests, emotions and desires. When it does not do this there is a ready return to former mental attitudes and dispositions and the same forms of punishment must be meted out over again. This repetition in time brings about what is known as "callousness" in the attitude of the pupil and the result is, that by such a method of punishment one soon has on his hands a pupil incapable of government or of discipline. Misguided parents and teachers hammer at children in whom these false standards and methods of punish- 
ment have set up this attitude of sullen indifference determined to "conquer" them, when in reality there is nothing in the child to be conquered. By such methods not only is conquest an absurdity, but it is an actual impossibility. What is possible, what is necessary and desirable is, a mutual understanding between child and parent or between pupil and teacher, merely a mutual understanding of each other's attitude and motive. Once this is known, it is not conquest which is never necessary or desirable but discipline which will follow with ease and mutual benefit to each.

An appeal to the feelings, a mere stimulation of the emotions to more intense action, which is what arbitrary govermment and irrational punishment are, has two tendencies. These above all things are to be avoided in the case of the young and growing. In the first place they both tend to deaden aspiration and ambition by creating loss of respect in the subject for himself and a belittled conception of self, coupled with a belief that there is something decidedly wrong in limself that seems to make him so out of harmony with the established order of things. In the second place, if he finally energes from the difficulty and despair into which he has been driven, it is either with a morbid conception of his fellows and the world at large, or else he has imbibed false ideas of the real essence and trend of human action and government. In either case he is probably lost to all usefulness to his fellows immediately and more remotely to society at large. Sometimes again the individual mind because of this manner of handling it, may react in sullen determination not to be restrained and with silence and cold indifference forge on in his blind reactionary career with utter disregard for custom, law and government until by the aid of lucky chance he may stumble again back into the true paths of government and discipline. There is every evidence in experience that an appeal to feeling is but little affective except as a means of governing temporarily. Feelings, psychologically considered, are evanescent and the moment the stimulus that aroused them is lost or removed, the mental equilibrium returns to its old state of action or inaction un- 
less there is something in its nature or method of action to get within the sphere of mental action and produce thought activity - reflection and meditation upon the whole matter, the whys and wherefors of it. How readily even parental control loses hold and how quickly the force of parental government dissipates when within the home the recipient of the punishment is without the immediate range of parental supervision, goes only too clearly to show how little enduring effectiveness is inherent in government in and of itself, and how long youth can be subject to government that is not disciplinary with its being of little or no practical effect upon him, even when there is every evidence that there is the best of intent toward him on the part of the governing and where also there is a good attitude toward the governing on the part of the governed. The evident cause of all of this is that the motive for individual action has not been developed by those in authority in the child and in the pupil. That is to say, such punishments have been merely restrictive of individual action, governmental in nature, while the best results in attitude and motive would have followed such punishments had they been more directive of this tendency to individual action, that is, if they had been disciplinary in nature. In the same way and for the same reason incentives, however strong they may otherwise be, when applied to individuals to bring forth certain lines of conduct or beget certain kinds of action, fail. Not having gotten into the thought life of the individual, because they have been principally restricted in his affective life, their efforts die as soon as the state of feeling they aroused in consciousness or accompanied into consciousness passes away.

The great problem of the schoolroom is the "bad" boy, the "unruly" boy. And yet if properly as well as carefully handled he will be found not to offer such formidable resistance to the forces of government and discipline. The first step in the process of control and discipline is to learn what, if any, are the motives for his attitude and action. Youth, we all know, is an experimental age. The boy and the girl find within themselves daily newly awakened ideas, newly created desires and newly manifested powers. All of these 
constantly and irrepressibly seek realization, satisfaction and expression. Some of them, of course, are of themselves worthy and should be allowed continuation, others of them, however, will need some slight degree of modification or perhaps even redirection into new channels before they will become so in the life and actions of the child and pupil. Oftentimes what we see in the schoolroom is merely the child testing his newly found ideas, following his desires to their natural satisfaction or his powers to their natural expression. He is merely seeing what he can do with you or with the school and its routine. This the teacher must decide. In such a case proper government will restrict him to what consistent with the rules and regulations of the school, he may be allowed to do, while discipline will win him over to the mental attitude, by punishment, if necessary, to do in all of this irrepressible new mental life what he is allowed to do in the way prescribed and to restrain the rest of his soul life for expression elsewhere and under different conditions. The road to such a one's good will is manifestly not through curbing and arbitrary restraint as through intelligent and sympathetic redirection. The desires may be controlled and redirected to objects or processes in the schoolroom, while his powers may be developed by being applied to the performance of the various schoolroom functions. Strive to recall his desire from the things foreign and perhaps antagonistic to the processes of the school and concentrate them on the things in harmony with the schoolroom processes. Do this in the first place by putting in the schoolroom the means of satisfying as many of his natural desires as are possible, as well as, as many objects for expression of his powers as are possible. This done, all impulses away from the school such as result in absence, truancy and tardiness may be easily controlled. This done, whenever punishment is found to be necessary, the child can be readily brought into a state of mind where he will recognize the necessity or justification of the punishment to be inflicted. In such a school discipline will place teacher and pupil on better terms. A different conception of the teacher and of all school methods will take place. The schoolroom will have a 
new meaning. Instead of being a place where all forms of activity are inhibited or prohibited, it will be a place where desire for activity will find myriads of new ways of expression and of the realization of the ideals of child life. Thoughts of it will be filled with joy, pleasant memories and happy anticipations. Here the relation between pupil and teacher takes on more nearly the form of intercourse between individuals in daily life. The teacher instead of being an unwelcome task master and ruler, becomes an acquaintance, a friend, a desired companion. From this point on the teacher easily has the reins of control entirely in his hand. He may discipline by personal power and magnetism or by punishment. But if success is to come out of all of this the teacher must be of model conduct himself and of high moral stanina. Not only this, but the best that is in him must be always on the surface. In other words discipline should mould by its influence those who fall under its sway. The teacher should not only have high standards of personal conduct but these must show themselves in the reason and justification of his government and discipline, if the work of the school is to run smoothly and a high degree of working efficiency is to be maintained. His should be a life of stability and constancy in word and deed. His conduct should be at all times an arbitrary and fixed constant, wherein the pupil may have a known quantity to study, emulate and strive to attain in his own life. When there is a fixed standard of conduct, approximation toward it may well receive approval and retrogression from it disapproval on the part of the teacher. All pupils desire to please, and most especially do they desire to please their teacher. That much in them is human. Desire for approbation is in fact common to all men. It is a basic principle in regulating social conduct to-day. But when and where there is no consistency in the conduct which is to serve as a model, when there is a demand for a constant readjusting and reshaping of methods of behavior on the part of the pupil, it soon causes confusion in standards and disappointment leading in time to the ultimate conclusion that after all conformity to any such inconstant and inconsistent model of conduct is impossible of 
attainment. Whereupon the child soon ceases his attempts to please and win approval and thereafter the means and end of discipline are lost upon him.

The Nature of Discipline. Many teachers find it impossible to govern, and hence to discipline, because they are too far off from the pupil. They do not know them. They have too little in common with the thought realm of their pupils to get next to them. But this is the very thing that is essential to successful discipline. A common ground must exist between pupil and teacher whereon they can "get together." This, it is always well for a teacher to cultivate. No opportunity however simple or insignificant should be lost which may form a basis for the beginning of such understanding and resultingly the institution of discipline. Love of approbation of our fellows is one of the greatest social and socializing forces known to man. In the hands of a resourceful teacher it can be of inestimable value as a means of discipline. There are some natures in the schoolroom whom only strong forms of approbation or disapprobation will reach. For these cases the teacher must prepare himself through a long gradual process of study and analysis of the pupil. The best means to this end is a conversant knowledge of the emotions and wishes of the pupil. To be properly and fairly dealt with the pupil must be thoroughly understood. The next step to understanding a pupil is to have the disposition to respect carefully all of his wishes and where possible to satisfy those of his desires that are consistent with good order and work in the schoolroom. Prohibitions to childish requests and expressed desires should be the rarity instead of the commonplace. All childish tendencies, wishes and desires if necessary to be denied can be best handled if the reason for the refusal be freely, fully and candidly given. It is best always to let the pupils know you understand both what they wish and why they wish it, and assure them that you would, if it were possible or best, be glad to see them attain their desire. Candor in such matters is always appreciated. There may, of course, at any time in administration of such matters arise justifiable reasons for withholding this explanation, or even peremp- 
torily refusing it. This much the situation and the teacher must determine. In all of this true standards as has been said should be established, punishment meted out accordingly, government instituted and discipline introduced on this basis.

Because of the need of simplicity in all things for the child mind, all systems of discipline intended should be reduced to their simplest form. As the child mind grows in power of thought and comprehension these systems may become more extended. But under all conditions and for all classes the simpler they are the better. Again methods of discipline should neither be mechanical nor " ironclad." Discipline as has been said appeals to the mind and secks the consent of the mind; it is evident then from this that no mechanism in discipline can be effective. Individual cases must be handled as such. What the child needs in matters of discipline is to learn the natural relation he bears to his physical environment and to the state and society. Those of the school should be in harmony with all of these. Every act of the teacher must show evidence of justification in this general system if it is to carry with it weight with even moderate hope of success in application and then every move that the teacher makes of disciplinary nature should be intelligently directed toward the accomplishment of the purpose of the general scheme of his discipline. To do this will require on his part at all times a judicious exercise of much patience, gentleness and care. $\mathrm{He}$ who would be a good disciplinarian must not allow himself to be rash. Patience is a prime requisite in the attainment of discipline in the schoolroom. The new pupil is oftentimes a mystery to the teacher both in the matter of physical habits and mental moods and consequently in the kind of treatment to which he will best respond. This, the teacher can learn only after a more or less long period of study and observation in all of the various relations of the schoolroom routine. With the teacher and the pupil each is an experiment with the other, who must be carefully tried out. The teacher to discover what are the best and most available means of reaching the pupil and successfully disciplining him and preparing him 
for his experiences in life; the pupil to find what the teacher expects of him and how best he may do what is expected, or in some few cases how he may resist or avoid doing what is expected of him. Thus we see that to every act of the teacher there is a full reaction. Now teachers often notice only the action leaving the reaction to take care of itself. In which case the reaction sometimes returns to overwhelm the teacher and may prove his entire undoing. In matters of discipline it often takes a veritable genius and even at that some classes of pupils will tax a teacher's powers to the utmost. To be successful in both action and reaction the resources of the disciplinarian must flow from a perennial fountain, namely, a wide-awake sympatletic mind. Schoolroom discipline will brook no repetition of methods in its system of application, the spring must bring forth ever fresh and living methods. The very fact that punishments or methods of discipline can be anticipated robs them of their force. Here truly variety will be the spice of life.

Character and Discipline. Another thing that must be considered in administering discipline is the kind of character with which one is dealing or is to deal. From this viewpoint of discipline, the characters met are either stable or unstable. Character may have become stable either from earlier training, or age, or both. Characters that are stable present much the more difficult problem in cases of discipline. Yet when understood the stable charactered pupil is much more susceptible to discipline than the unstable charactered. You can know him. There is a constancy and consistency in his actions and reactions that may be expected at all times in the application of disciplinary methods to him. While with the pupil of unstable character there is never anything definite to be expected in his reactions, to-day it may be in one way and to-morrow in another. But the most serious side of the problem with the unstable character is that he is never even constant and consistent in the instability. Even his instability cannot be depended on to be lasting. To-day you get him just so far in discipline and begin to hope that you are accomplishing something and to-morrow when your hopes are highest and you begin to feel assured of results, 
the relaxation comes, all that was gained is lost and you must begin all over again with him. All of this is different with the stable in character. Whenever you do get the desired reactions they are lasting and you can always notice progress and have the satisfaction of knowing with what degrees of success your efforts are attended.

Conditions Incidental to Discipline. Looking at discipline from another viewpoint it is evident that it must change with the age, home training and environment of the pupils. Disciplinary methods that are successful at one time will utterly fail if applied at another time to the same pupil. Pupils of different classes and ages require different methods to reach them, while their locality, home surroundings and social station, etc. will also make a difference in the kinds of methods that will bring about effective results. For that reason the teacher in a city who met with great success as a disciplinarian in a city school may fail completely in a country school and in a mining or oil country; he may succeed with the pupils of one social class or home surrounding and training and fail with those of another. Too, fundamental differences in racial temperaments come in for consideration in discipline and disciplinary methods. The Italian, the German, the Russian, the Jew, etc., all will come in for consideration peculiar to their nationality and general national habits and traits traceable to their nervous structure and mental attitude. This point is worthy of consideration in the schools in the foreign and congested sections of our large cities.

The health of pupils, too, is a very essential consideration in administering discipline. In sickness and disease more so than at any other time patience and gentleness are required as well as attention to the nature of the method employed. The nervous tension of children is very different in health from that in disease. In general the reaction to disciplinary stimuli in sickness is greater than in health and the states produced thereby are more lasting. The feeling aroused during the one is more intense than that aroused during the other and the time of their endurance is longer. Because of this high tension nervously the possiblity of striking the wrong 
cord is greater as is the resulting attitude induced. The thought activity is more intense and the emotion, desires and wishes more fickle. That there is need here of care and patience as well as kindliness and gentleness even more than at any other time goes without saying. It follows, therefore, that mistakes at such times in matters of discipline will be more costly than at any other time. The remedying and removal of their effects is also more difficult. Many a teacher has lost complete disciplinary and resultingly complete governmental control of a pupil during some period of illness or physical derangement, which they have never succeded in regaining. The kind of treatment needed during the period because of the new kind of reactions was not forthcoming because the methods necessary to produce them were not applied. Very often, too, under like conditions the effects produced in a pupil are lasting and the individual persists in the new attitude, new reactions being heaped upon the old until all hope of again returning to the old relation is lost and we have a new example of the bad or unruly pupil.

The Aim of Discipline. From an educational viewpoint the purpose of government is to make possible discipline. In general discipline aims to form character,- here student character. In the first place it should place the student in the proper frame of mind to receive knowledge. This knowledge should be presented in such a way as to create an interest in the knowledge either for a near or remote end, that should have been conceived vividly and should have awakened an intense desire in the pupil for its attainment. In cases where the ends in life for which this knowledge is desired are more or less remote the intermediate means by which the more distant end is reached must change from time to time to keep up interest. Here lies the difficulty. of the task. But if it is successfully done, discipline will be maintained throughout all of the mental and physical changes in life incident to growth and development. As this goes on the demand for the open application of discipline to the subject will steadily grow less. Finally the great end of education will be established. The pupil will have become a well developed character with good powers of self direction along lines where there are well- 
formed desires. At the same time understanding the nature of processes in the activities of life and the tendencies of the various means as well as their efficiency for attaining results, he will be able to develop any new desire and judge of its value in the general system of desires. At this point he will have attained the height at which school processes and school discipline aim and may be safely trusted in the world to push out along any line of endeavor that may have appealed to him, competent to direct his action and restrain his desires within the range of the best judgments of the conservative members of the state and of society. The aim of the disciplinary processes of the schoolroom and of the school is successfully at end.

Discipline in Practice. Apart from this theory of discipline and government in the schoolroom there is a practical side which must be carefully considered and used under the guiding theory of the principle, if the school routine itself is to be successful and the primary ends for which it exists are to be conserved. Comparatively speaking government aims to maintain order in a schoolroom, discipline to bring about successful work. They are mutually effective and reactive. Group action in school routine has its advantages as well as its disadvantages, though the latter are necessary in our system of education. The chief demand of advanced civilization and democratic governmental institutions is self-assertiveness and individualism. Both of these must of necessity suffer in mass education. For the welfare and progress of the class as a whole must be made superior to that of the individual. The result is that discipline will tend to inhibit those individualistic impulses, and to subordinate the egoistic activities to the preservation of conditions favorable to the needed concentration of attention by the class in its entirety which endangers one of the chief mental attitudes which the discipline of the school is supposed to foster. However, this is only one of the draw-backs of group life and aggregate action. It is the basic principle of civilized society and must be accepted as necessary in the school that the best attempt be made to foster individualism which these more imperative demands on group life will permit. Group education is at its best only 
when it is acquired through the maintenance of the highest degree of working efficiency and the greatest possible conservation of time and energy. 'These are presumed to be attained through discipline and government in the school. Favorable working conditions to these ends must be preserved at all times. This is of the highest import in large classes, where daily accumulated waste of time may seriously hamper the work of the class room.

The Opening Day. The time to begin government and discipline in the schoolroom is on the first day of school and at the very opening. This is the psychological moment in the process of discipline. At this time everything is strategic and favors good discipline. The teacher is fresh and vigorous, full of plans and hopes and ready to tackle any problem of school discipline that may arise. On the other hand the pupils are there full of good intentions and good resolves, all determined to behave, study and do well in their schoolwork. Besides this the teacher is probably new to them and the work also, each carrying with it all of the native attraction attendant upon that which is novel. For a good measure of success it is only necessary that the teacher make full capital out of these natural conditions favorable to good government from the beginning. From the very first the teacher should insist upon all work being carried out in detail and all of the routine work of opening should be gotten out of the way as speedily as possible and the whole school started out upon the regular routine of the year's work. The attitude of the pupil is one of high tension and very unstable equilibrium, but it tends easily to become stable, care must be exercised only to the end that it settle in the right direction. If the work of classifying and grading and other preliminary work is extended over too much time and the pupils allowed to play and waste the school time, the equilibrium will settle in that direction and may remain there the balance of the school year, or if changed at all for the better it will only be done by the greatest labor and effort on the part of the teacher, and only then by gaining the ill-will or loss of respect of some of the pupils, or perhaps in both. Rigorous work should be the order from the moment of opening. The teacher should, on previous 
occasions, have acquainted himself with all of the routine necessary and should determine his method of conducting his preliminary exercises beforehand, having everything previously in readiness for them. From the first the teacher should show that he has anticipated and is prepared for every possible demand and at all times is complete master of the situation and of himself. Any cvidence of unpreparedness or inability to meet any emergency incident to the opening of school or thereafter is likely to have serious effects upon the relation of the teacher with his pupils and resultingly of his governmental and disciplinary powers. There should be no confusion in issuing orders, nor should there be too frequent need of retracting orders when once given, because they are wrong or incapable of successful accomplishment as physically impossible or impracticable. All of this should as far as possible be determined before the order is issued. He should understand the arrangement of the room and the control of its equipment and appurtenances and those of the building and grounds. Especially should he have mastered the methods of operating the system of heating and ventilation, both for reasons of health as well as for those of discipline. It is always unfortunate for a teacher new or old to be forced in the presence of the school to admit inability to perform any given act and be compelled to request the help of a pupil, send for the janitor or call in the aid of the principal, the school commissioner or one of the directors. 'This applies chiefly to those who would be expected naturally to possess the physical strength to do these things. In the case of women teachers, however, the cautions necessary for one who knows well the limits of her strength is always better followed. For even with them evidences of failure have their effects in matters of discipline even though they be less than in the case of men.

Whatever of mechanical routine it is expected to employ in school processes such as movements about the room, to and from the board and recitation seats, collecting and distributing wraps, and marching to and from the room, it is better to have them carefully thought out and instituted from the start. Once instituted they should be changed as 
little as possible, except where there is evident some glaring defect in them. In this case it will be justifiable to change them immediately. Under ordinary circumstances it will be found to be best to let plans once promulgated even though not entirely satisfactory run for a reasonable length of time or until a convenient opportunity offers itself for instituting a change in the order that the teacher may not put himself in a position of not knowing what is best or of not understanding himself, or, what is immeasurably worse, of being unstable in his views and methods.

As for the work of the first day outside of the duty of enrolling and classifying, which should be done as rapidly as due regard for accuracy will permit, the regular work of the school day when the school is fully under way should be done from the first. Here too, full possession of all information necessary to the proper and complete performance of this duty will be found to give the best results from the viewpoint of work and discipline. Ease and rapidity of work will be sceured from the outset if the teacher is also advised as to the relation of the work required in the room whether there be several or only one grade in the room and the relation of this work to the grade or grades immediately below it and those immediately above it. The basis of passing pupils and if possible the record of the pupils in the preceding year's work would greatly aid in this work. Where these are impossible the local course of study or the general county or state course of study should be available and should be used as a basis of outlining the work and classifying the various pupils. Apart from this every teacher would find it of great help to aequaint himself with graded courses of study for various states and be able to model for himself a complete course, not only through the grade school, but through the high school as well. This will place the individual teacher in his work upon an independent basis that will give him advantages in emergencies or difficulties hardly to be appreciated by the norice and unprepared. The attendance of teachers should be prompt at all times, and constant. Nothing has the demoralizing effects upon a school as do habits of tardiness or inconstancy in attend- 
ance upon the part of the teacher. Fortunately most of these things are controlled financially by the school commissioners and directors, but in country districts where supervision is only occasional the habit is often formed of being late and runs often for a considerable time doing its demoralizing work before it becomes known and is stopped. The teacher should endeavor to precede the children to the school and have everything in readiness for their reception when they arrive. In city schools and sometimes elsewhere it is impossible for the pupils to assemble in the assembly room and later pass to the school rooms. Where possible this is best. When the weather permits the pupils should be left out to play until the proper time for them to assemble, at which time they should assemble according to prescribed routine and in order. The teacher should by all means be in his position and receive the pupils. Greet them pleasantly but do not assume any manners with them that you do not intend always to maintain. Friendly but respectful regard is always best. Nothing that will not be tolerated later in the line of conduct or attitude should be tolerated the first day and very little before or after school, that will not be tolerated during school. Everything in the school should have an air of business and work from the start. An understanding that is to be maintained throughout is to be had at once upon the pupil filing into the schoolroom.

The Attitude of Outsiders in Discipline. In effectively applying these external or mechanical methods there are certain favorable conditions which may at times prove to be almost necessary. Chief of these is that there must be practical working relations existing between the teacher and those charged by law or by nature with the responsibility of the proper rearing, training and education of the pupils. I mean here the parents or guardian of the children on the one side and the school commissioners, school board, principal and superintendent, both county and city, on the other. Between these, for the sake of good work, genial relations are ever a prime requisite. Little as these may think, especially the parents, they can ruin the fitness of 
their children for the schoolroom and instill into them lessons of disrespect for law and order and those charged with the responsibility of administering it that may sometimes follow them throughout life, and in some cases bring them behind the prison walls or even down to the hangman's noose. Certain it is that the respect and confidence of the pupil for the teacher are readily destroyed by an attitude discountenancing or discrediting the acts of teachers before children. To begin with there should under all circumstances always be perfect confidence and good will existing between parents and teachers. But since both are human and filled each with his share of human weakness, and imperfections, this is ostensibly impossible at all times. This fact, however, may be reduced to a minimum of evil effects, if both teacher and parents will endeaver to make consideration for the other. Parents should never by word or manner let the child know that there is the least lack of confidence or ill-will existing between them and the teacher. Nor should the teacher criticize the parents before the pupil or pupils. The child is quick to detect any evidence of lack of friendly relations or lack of confidence and equally quick to take advantage of it for personal ends. Should the existence of bad feeling or a feeling of incompetence become known to the pupils, both the teacher, his power of government and discipline will be seriously disabled thereby, if not entirely broken down, and the amount and quality of instruction under such conditions fall to a minimum.

Teachers should be appointed purely for fitness and competency. The community should know that no other motive existed in the appointment. They should also know that there is no method, that they can employ that will enable them to retain or obtain their friends or relations as teachers. Much discontent and open effort to break down the power and influence a teacher both in the community and schoolroom is engendered and willfully nourished with the hope that a friend or relative may profit by the removal of the teacher. If perfect candor and honesty is employed in obtaining a teacher and he is elected and retained on a basis of merit much of the evils of lack of cooperation on the 
part of the parents and community will disappear of their own accord. This situation is bad enough, but becomes worse when the knowledge that other forces than competeney and fitness may be used to make vacant and fill the positions of teachers is employed by some, either to bully or eoerce or wreak vengeance upon a teacher for private or personal reasons, which are often low and degrading to say nothing of the selfishness that generally is in them. When this state of things arises the school is better abolished if the condition is not removed. It is a source of regret to admit that often such situations as these do arise and the innocent as well as the guilty suffer together, while the children whose ideas and standards are not fully formed get perverted ideas that make of them unfit citizens and unfit members of society. Let it be said, however, in this same connection that no teacher should at any time allow such a state of things to cause him to desert his high standard of living and acting, nor in any way to yield to any attempted pressure that is either belittling or compromising. Fortunately in such matters things have improved considerably and are continuing to improve and the teachers are mostly given hearty cooperation by the superintendent, boards, and commissioners of education. Too, the dissemination of literature upon the relation of the teacher to those in authority over him has caused a more perfect understanding of the rights and privileges of each and the bad effects resulting from an infringement of either upon the rights of the other. In some cases however the local rights of school boards and superintendents are overestimated and then the wrong kind of interference follows. The right to employ teachers, to prescribe courses of study and instruction and exercise supervisory authority over schools does not mean that those so charged with responsibility are either to so circumscribe or hamper teachers that their freedom of action is impaired or their power of instruction and administering government and proper discipline curtailed. The teaching powers and functions as well as those of government and discipline must of necessity belong to the teacher. To deprive him of them or interfere with him in exercising them is to do untold harm 
to the processes of the school. Prohibitive rules and restrictive or regulative advice should only be in a general manner and according to principles well known and well established. The details of these in the practical working of the schoolroom routine, experience has taught, are infinitely better if left with the teacher. Of course, supervision is for the purpose of preventing and overcoming flagrant abuses or degrading and damaging practices, and where found in use they should be corrected unhesitatingly, keeping in mind always the proper place and time for such things. It is a human error common to many not to know how to use vested authority. In school matters this fault is not absent from men. But whenever those in authority correct a teacher before his class, or show by any outward sign that there is fault or dissatisfaction found with a teacher's work or methods, trouble has been started that may cause untold difficulties for the teacher in government and discipline, that may eventually drive him from the community and the profession and may ruin the school for years to come.

Where the views of those in authority as to methods differ, or where there is evidence of ignorance of, or disregard for, the commonest principles of teaching and discipline the best results are known to follow always where the facts are presented to the teacher in private, kindly, clearly and thoroughly and where possible with references to current literature on the subject. Teachers are responsible moral agents and above all responsible physical agents, and are controlled chiefly in the proposition of their school work through material sources. Common justice and equity demands therefore that those charged with responsibilities be given the right of freedom of action and the right to follow their own judgments, at least in the employment of details in schoolroom operations. Methods that one can successfully use to secure results may not bring them when used by another. Now since what the American system demands is results, since every week, every month, every term, the teacher must be able to show in results what has been attained, would it not be fair to allow him at least freedom of individual action in his work? Give him this, give him some right to exercise 
undisturbed and unrestricted his individuality and inventive genius without fear of molestation and interference and the constant fear of public humiliation and perhaps the loss of his job.

Given these rights and privileges and freedom of action and supported in the rightful and conscientious pursuit of his work by those in authority the path to successful government, discipline and consequent instruction is comparatively easy. 'To these, however, the teacher must add, to further promote his success those personal virtues which we enumerated above under the head of the psychic forces of government and discipline. These are scholarship, a high sense of duty and right, courage and determination, tact, indefatigableness, good nature, good manners and an air of authority and business both in manner and voice coupled with an evident desire to be fair and just to all. Armed with these virtues in the schoolroom and supported by the good will and authority of those without the schoolroom the teacher is pretty well assured of success in almost any school and in almost any community. Goverment and discipline will be natural and easy, instruction will fall upon kindly ears and the whole being of the child can drink in of his surroundings as the teacher lights up the whole with his personality, his enthusiasm and his love for both his pupils and his work. Here it will follow as a natural consequence that rules will be few and fully understood and accepted as necessary. Only such rules will be made as will not tend to confusion and consequent misunderstanding, changes in them will seldom occur and when they do become necessary they will be anticipated, made known and justified to the pupil. As a result there will be a disposition for full and free obedience among the pupils. The pupils will know that obedience will be expected and rigidly demanded, and that the punishment in case of disobedience will be natural, fitted to the degree of transgression and administered kindly and with tenderness. The teacher will understand child nature and the pupil more of the nature of the matured. For each in every case there will be due consideration. Instruction and the imparting of knowledge will be easy and 
the intellect of the child will grow apace until we have a developed being capable of self direction in the affairs of life and of moral conduct toward his fellows, asserting itself along the lines of his chosen field of endeavor.

\section{REFERENCE READING}

Bagley's “The Educative Process." Chap. XIII.

Bolton's "Principles of Education." Chap. XXVIII.

Compayre's "Psychology Applied to Education." Chap. XIV.

O'Shea's "Social Development and Education." Chap. XV.

Arnold's "School and Class Management." Chaps. IV, V, VI, VII. Perry's "Management of a City School." Chap. IX.

Dinsmore's "Teaching a District School." Chap. X.

Gillette's "Vocational Education." Chap. VIII.

Collar \& Crook's "School Management and Method of Instruction." Chap. IV.

Pechard's "School Supervision." Chap. XV.

Fitch's "Lectures on Teaching." Chap. IV.

DeGarmo's "Principles of Secondary Education." Vol. I, Chap. III (2).

See also references to Chapter on Punishments. 


\section{CHAP'TER VIII}

\section{PUNISHMENTS IN THE SCHOOL}

The Nature and Justification of Punishments. No form of school routine and school method has received as much study and consideration, nothing connected with school life has been so written upon and discussed as the questions of the method, demand and justification of various forms of punishments for the school. This is a "progressive age." In everything there is a reaction against old methods and old institutions, both social, civil, ecclesiastical and educational. The reaction as to methods of punishments both in the state, the home and the school seems to be here to stay. This age is an age of encouragement of activity, better, of course, if directed, but desired even when uncontrolled or undirected by external forces. The wave of reaction tended to carry, and appears in some cases to have carried us almost to the other extreme. But sober judgment and wise discretion have brought us back to a more immediate middle ground. Punishment, if we are to accept the inherited practices of the ages as sufficient reason, are a necessity in all forms of group life and the control of group activity. In all forms of social life the will and best good of the majority whether conceived as such consciously or instinctively are vouchsafed for by some form of punitive systems. So well established has been the proof that punitive systems are necessary for community life and government that the demand is everywhere acknowledged and practiced by all. The very fundaments of biological principle rest upon a pleasurepain basis, that is a readjustment of habits of action to seek and maintain states of pleasure and avoid and overcome those of pain. So that the question involved to-day in educational processes is not so much as to the efficiency or need of punishment, but rather as to the need or efficiency of cer- 
tain kinds of punishments. No theorists, however idealistic they may be in their conception of education and the processes of education have ever presumed to advocate the abandonment of all forms of punishments in the schoolroom. With primitive man when might was right and little was known of the efficacy as well as benevolence of mental punishment all forms of punishments were chiefly physical. With these same types of men both then and now the life they lived is chiefly a physical life. Life was a hard and severe struggle and breaches of social conduct fraught mostly with much inconvenience to society. Consequently these breaches of conduct were restrained by severe physical punishments. During medieval times the struggle for existence was severe and the means of governing because the means of communication and movements were slow, were poor. Stringent measures were necessary to control rebellious and restless spirits and all breaches of conduct were severely and summarily dealt with. It is this relic of medieval government as found both in the home, the state and the school that we have inherited against which we are reacting to-day in an endeavor to throw it off. The danger lies in going too far. Where shall we stop? While the reaction all along the line in home, state and school is toward less physical punishment and more of an appeal to the spiritual side of man and the application of mental punishments it would, from the very nature of the subject to be treated in the case, be unwise to jump too hastily to the other extreme. Despite the agitation to the contrary both in general and in special cases the use of physical punishments has been found to be warranted in some cases. Mental punishments since first agitated and practiced have never met with serious opposition. To-day the most serious attitude toward them is seen in the desire to control and prescribe the manner, time and cause of them as based upon a study of the nature of the individual upon whom they are to be inflicted. This is in general now the attitude toward physical punishments.

School Punishments. We are concerned in our discussion here only with the matter of punishment as employed in and applicable to the school. Here is where the chief conflicts 
over the questions of the nature, kind, manner and occasion of the various forms of punishments both physical and mental rage. The home uses both kinds of punishments without arousing serious opposition oi discussion except perhaps in a few isolated and rare cases. The state does the same and there is likewise almost total acquiescence on the part of the citizenship in it. Society does too and here too resistence or objection is never strongly evident. But when the school attempts such there is no end to the discussion, agitation and opposition which it occasions. Is not the teacher in loco parcintis? Does the school not undertake with and for the child some of the specific duties of the state, society and the home? The answer in each case is in the affirmative. But even in the face of this, opposition to the school adopting the various means of punishment continues and the agitation about it and discussion of it goes on anon. In all of this there are at least two fundamental reasons for this attitude toward the administering of the various forms of punishment on the part of the school. The first one of these is that there is a basic relation existing between the child and the home and home government that is deeper and more lasting both in its nature and the duties and responsibilities which it bears, and though in a sense the school is in place of the home and the teacher in the place of the parent he can never think nor feel toward and for the child as the parent would and does do, nor can the school assume the basic responsibilities which the home must and does assume. These elements of difference in relation and responsibility will always be a source of inconvenience and hindrance to the school and the teacher in carrying on their delegated functions and will always tend to provoke criticism against them to more or less extent in these matters, even though at bottom there be little or nothing wrong with what they advocate and do. The other source of this attitude towards the administration of punishment on the part of the school is probably due to the lack of method and moderation in the administration of it and the absence oftentimes of the controlling element of love and sympathy. Along with these goes the further consideration that not 
only are these oftentimes wanting in the school while they are almost always present in the home, but even where present in the school they cannot be formally aroused in the teacher to the extent and in the manner in which they exist by nature in the parent, a fact for which the world in the formation and expression of its judgments is willing and wont to make such elaborate allowance for the shortcomings of the one which are entirely wanting in consideration of the failures and shortcomings of the other. In some cases it must be admitted that the school has at times because unprompted in its methods and feelings by the deeper emotions of love and sympathy been guilty of flagrant abuses of the rights to inflict punishments. However, there are imperative demands upon the school which if they are to be met must be met through the right and privilege of punishments. Further, if the school would succeed and have the approval of society it must make up by nurture whatever it lacks by nature along these lines and whatever the pupils in the school lack in ability. Method must be studied, moderation practiced and sympathy, care and gentleness cultivated. 'The day when 's readin' and 'ritin' and 'rithmetic" were "taught to the tune of a hickory stick" are chicfly past, as is the time when brute strength in the school on the part of the teacher compelled blind mechanical submission on the part of the pupil to arbitrary rules still more arbitrarily enforced, with the complete suppression, if not entire destruction of, all tendencies towards self activity and individualism. Investigation of the past methods of inflicting punishments and the causes for which punishments were inflicted shows that the penal code of the schoolroom was severe and impractical, and even at times, brutal. For the making of the modern man as conceived by our present standard of education it was sadly misapplied. Especially was this true of physical punishments. Mental punishments were little known it seems, but sure, we are that it was practiced but little. It was also the rigid and unregulated application of the system that caused the agitation and reaction Punishments were inflicted for almost 
any cause, trivial or grave and upon any part of the body, whether pupil were delicate or robust and the particular locality well or ill-adapted by nature to the kind of punishment inflicted. The result was that observation soon showed physical evil flowing from school punishment entirely out of proportion to the good which the school inflicted punishment was intended to accomplish. This called not only the school methods into question but also the very existence of the school itself.

What was there which the school gave that could compensate for nervous prostration brought on by super excitement from a whipping, deafness from a blow over the ear, blindness from one over the eye, or idiocy or insanity by one on the head? What had the school to give that could adequately compensate for genital or intestinal trouble induced by blows on the buttocks, or constipation, indigestion and other functional disorders produced by physical punishments inaptly applied to various parts of the body? 'That school punishments have been known at times to have produced all of these troubles is a fact well established by investigation. The case cited by G. Stanley Hall from Richter of the record of an old Swabian school teacher by name Haberle, is a good instance of the morbid use of physical punishments mostly in a manner strictly forbidden by pedagogical principles, if not by public sentiment. These punishments were inflicted during a period of service extending over fifty-one years and seven months of service. Because of their enormity and the fact that they were carefully compiled by the teacher himself, I present them here. They are: 911,527 blows with a cane; 124,010 with a rod; 20,989 with a ruler; 136,715 with the hand; 60,295 over the mouth; 7,905 boxes on the ear; 1,115,800 snaps on the head (with the tips of fingers and knuckles); 22,763 nota benes, with bible, catechism, hymn book and grammar; 777 times boys liad to kneel on peas: 613 times on triangular blocks of wood; 500 had to carry a timber mare and 1,701 had to hold the rod high the last two being punishments of his own invention. Of the blows with the cane 800,000 were for Latin rowels and 
76,000 of those with the rod for bible verses and hymns. He used a scolding vocabulary of over 3,000 terms of which one third were of his own creation.

This was undoubtedly an unusual case. One, perhaps, in need of pathological treatment. But in the earlier days, before the reaction set in, it had many counterparts throughout the civilized world though perhaps they were somewhat less severe. Is it any wonder then that there was an energetic reaction against this method of punishment in the school? Is it any wonder that it spread rapidly far and wide? France under the influence that produced Rousseau and Montaigne went to the other extreme and forbade corporal punishment in her schools, having now all of her disciplinary and governmental school measures free from all advocacy of it. In Germany and most other countries of Continental Europe, though allowed, physical punishment is strictly limited and prescribed as to kind, method of administering, parts of the body fit for receiving various kinds of punishments and the causes for which certain punishments may be aftlicted. In this country we have in general followed in the wake of England, Germany and the other countries of Continental Europe. There are a few men in this country among them educators of considerable influence and recognition who adrocate the French pedagogical practice of no physical punishments in the school. Too, many sections and even states in the eastern part of the country led on by the earnest adrocacy of one or more theorist and idealist have legislated many forms of physical punishments out of the school. Some of the teachers in the schools have succeeded in keeping school evidently successfully without the aid of these forms of physical punishments. Others, however, have apparently fared worse with the experiment and have because the experiment failed returned to the old method. One such city is New York. In most cases thongh the reaction from the prohibition of all corporal punishment did not return us to the old regime, it did not allow the use of physical punishment under certain specific restrictions. Under the general scheme of local rights and individualism in our American system of education such an 
intermediate (compromise) ground seems to have been the best obtainable. Even to-day such cities as Baltimore, MId., West Chester, and Harriburg, Pa., strictly forbid all forms of physical punishment.

The Purpose of Punishments. The purpose of punishments is to curb infractious and rebellious spirits and vouchsafe to society a maximum amount of freedom of action with a minimum amount of restriction and thereby increase the sum total of human happiness. In the school its purpose is to reform the wrong doer, to deter others from wrong doing and to give to school processes opportunity for the maximum working efficiency and conservation of time. Until man reaches a state of absolute perfection, mentally, morally and physically, until human knowledge shall be complete and all individual feelings, emotions, desires and impulses melt away into group consciousness and become identical with it and all human standards one, until all human action becomes absolutely free and all human imperfections gone there will be need of punishments, mental for some, corporal for others and both for still others to deter, reform and hold in eheck those who either ignorantly ignore or willfully transgress upon the rights of others and restrict them in the full and proper exercise of their individual rights and privileges. The basis of all punishments are the rights and best good of the majority. They are to repress in the individual all unsocial tendencies and make of him a fit member of the social group. In our modern conception which we have inherited probably from the views propagated by Hume the individual is secondary and the group primary. This is true in the school. While the individual has rights as such and apart from the group, the interests of all the pupils separately are subordinated to the interests of the class as a whole. Whenever one of the school would override the best good of the school he is brought back to that kind of conduct that is in harmony with the group (school) interests.

The Demand for Punishments. The school exists for the purpose of fitting individuals for the lives they are to lead among their fellows, equip them with and show them the use 
of such tools as they need to maintain themselves and help others to self maintenance. This duty of the school is imperative. To perform it, it has access to the whole category of penalties for application when it is found to be necessary to appeal to them. The cases that arise for management run the whole gamut of individualities. There are some who seem to have no social tendencies as far as their school mates are concerned. In them there is no love, no affection. Not caring particularly for the society of their fellows nor that of the teacher they neither desire their approbations and its effects nor do they fear their disapprobation. This may be easily seen by the conduct of such pupils toward their fellows. For those there is no hope except through the infliction of physical pain. Such pupils generally have peculiar moods and temperaments and due regard must always be had for such in administering punishments. Bodily pain when inflicted must be recognized by the sufferer as a natural and necessary consequence of his act. The administerer must have before-hand fully impressed upon him his good will toward him and have shown him the demand in the act for punishment to come. On the other hand there are natures timorous and easily intimidated. Care must be exercised not to destroy self assertiveness and the natural tendencies to action in such pupils.

The Reason of Being of Punishments. Since the dawn of the reaction against the severity of the various forms of physical punishments, much has been written about the nature and forms of punishments. In this connection the theories of Rousseau as brought out most clearly in his "Emile," and of Spencer as set forth in his essay on "Education" are basic and to-day quite popular. Both write from practically the same viewpoint and in general advocate the same nature and form of punishments. Spencer's principles have a biological basis while Rousseau's rests perhaps more on a physiological basis. Both of their theories have had far reaching effects upon all educational theories and practice. His plea is for "natural punishments." He bases his arguments on the theory of the pleasure-pain economy in nature. According to it all of those adjustments and activi- 
ties are harmful which bring pain to the organism; beneficial all of those which bring pleasure. In the moral world he makes things biologically liarmful wrong and those biologically beneficial he makes right. "That conduct, then, whose total moral results, immediate and remote, are beneficial is good conduct; while conduct whose total results, immediate and remote are injurious is bad conduct." Spencer's philosophy here as elsewhere is a sort of natural materialism that is mechanically self-operative and self-perpetuative. Here he would have acts and their effects mechanically react one upon the other. Here the bodily pain or pleasure that would follow any act would be the inevitable result issuing forth as a reward or punishment of such act. All acts that bring pleasure to the individual he would class as morally right and those that bring pain as morally wrong. All the teacher is to do is to stand aside and let nature take its course. Where the teacher deigns to enter and interpose he must not depart from the methods of nature. This theory has its good points as well as its bad ones. In favor of it, it might be argued that the punishments are unavoidable and inevitable. They also have an advantage in being free from many of the flagrant abuses of all artificial punishments. Being " constant, direct, unhesitating and not to be escaped" they remove the confusion and misunderstanding arising from moods and temperaments and other external circumstances attendant upon the infliction of punishments. They are proportionate to the degree of the offense, " a slight accident (wrong) brings a slight pain (punishment), a more scrious one a greater pain." There is no room manifestly for such things as malice, revenge or passion. No double punishments will occur here and no promise will be made only to be forgotten later. All will be a silent, rigorous performance where all are treated alike on sunshiny days and cloudy days, when the digestion is good and when it is bad, when there is sickness and when there is health on the part of the teacher. The child in his daily life is subject to a system of order that persists in unerring and unswerving force from life to death. "If the child runs a pin into its finger pain follows. If it does it 
again, there is again the same result and so on perpetually." It "listens to no excuse and from it there is no appeal; it is the order not only of school but also of life."

Spencer's theory of natural punishments is practicable, easily understood and capable of ready application in the schoolroom, besides possessing the merit of being a system for conduct in life. While there is much in nature that man imitates and the injunction everywhere a common place "be natural" has its virtues, there are times and places where not only do we not wish to be natural but in fact desire to be everything else except natural. Art has shown that it can make decided improvements on nature. The fact is that the very purpose of the school and school processes, the state and society, is to overcome and improve upon nature; to make us not natural but artificial. Culture for which we all struggle is directly away from nature. Validity is claimed for this theory of Spencer's on the basis that it is a biological principle and therefore fundamental. While this is true it also is a fact that it has value chiefly in biological matters. Applied to the realm of reason, feeling and emotion it falls far short of what its promulgator and devotees had hoped for it. Besides it is contrary to the modern social order. The tendency to-day is to alleviate pain and to save from the physiological effects of natural law. Legislation both in school and state and common usage in society all are directed to that end. In the home there is mitigation of transgression and oftentimes successful appeal from it; in the state so common has this become that legal procedure has been robbed almost entirely of its effectiveness as a deterrent from crime by the elaborate system of mitigation and appeal now a part of it. Since the school is a preparation for life in the state and society why may this not prevail in it also? Again the theory is certainly foreign to present pedagogical principles which claim for themselves grounding in extensive scientific investigation. The very thing we seek for in punishment, namely, reformation and the good will of the child is here impossible. All natures suffer alike whether through ignorance, evil intention, accident or even good intention. The sick and 
afflicted with the well and hearty, equally if not more intensely because of their increased nervous tension, the low and brutish natures alike with the high and ephemeral, the highly sentimental and responsive temperaments equally with the less sentimental and less responsive temperaments. Misunderstanding and ignorance have the same punishments as knowledge and willfulness. Its most flagrant and glaring fault, however, is that it makes no allowance whatever for the element of intent in the agent, a principle that is universally in practice in all penal codes and legal procedure in Christendom and which is the basis of modern pedagogy. Besides with nature there is neither gentleness, love nor sympathy, by which the school is expected to bring out that which is best in the pupil and arouse him to higher and nobler ambitions. But even to consider this theory in the field of biology which is its stronghold, here also the practices of men are in favor of mitigating and alleviating punishments for the transgression of natural law.

The theory attacked in its stronghold totters and falls. If the child pricks his finger with a pin, medicinal application reduces materially if it does not remove entirely the ensuing pain. We daily transgress both biological and physiological laws and either escape the penalties or materially mitigate them. In fact the entire science of medicine owes its very existence to the full knowledge that the effects of the transgression of biological laws can be more or less escaped by the cunning application on the part of the physician of various healing and remedial agents in the physical world about us. Other transgressions committed may be delayed and by living "model lives" for a while or for the rest of one's life the effects of these biological sins of either omission or commission become lost on us in the general tone of health that follows. Many wrongs biologically are thus committed and the organism never knowingly suffers for them. Furthermore in the cases of indifference to knowledge and neglect of it during the school age the penalty, if allowed to come by nature, would be delayed until the child grows to maturity before its full effects would be felt by him. At the time when he neither knows the value of knowl- 
edge, nor what the effects of the lack of it will be on his future, natural punishment would let him go free and later when it is too late to check one's self in the loss of given opportunity, where the power, at least to a full degree, of association of the cause of the punishment with its effect is gone, and when there is no opportunity to benefit by the punishment and consequently it can do no good, it comes with all of its train of suffering and misery.

One of the chief elements in the effectiveness of artificial punishments as advocated by modern pedagogy is that it should not be delayed long after the act for which it is to be inflicted has been committed, so that in the mind of the miscreant there may be a full association of the act as a cause with the punishment as an effect. In the cases of many persons punishments (as effects) both natural and artificial when delayed are seldom if ever fully associated with their canses. IVith children in whom the chain of cause and effect is but poorly established in thought, the danger of failing to grasp this relation in penalties is great enough when the wrong and the penalty for it follow each closely in time, but immeasurably greater becomes the likelihood of the absence of this association when punishments for acts are delayed for a greater or less length of time.

Natural punishments are to be condemned further because in many cases in them the "sins of the fathers are often visited upon the children unto the third and forth generation." A fact undoubtedly at odds with the present practical even if to some extent materialistic conception both of morality and justice. Another point worthy of consideration here is that the senses may become so distorted as to make pleasurable feelings that would undoubtedly be harmful to the organism. Then, too, many bodily states naturally pleasurable are harmful and many things naturally pleasant of themselves are biologically harmful and even deadly. So that from the viewpoint of modern pedagogy the theories of Spencer are not very applicable in the penal code of the schoolroom. 'The whole system of penalties as practiced to-day is one of reformation sought to be brought about by temporizing with the individual will. A compromise, as it 
has well been called, between the abstract method of nature and the concrete relative method of mind.

The Value of Justification of Punishment. German pedagogy advocates physical punishments because they are effective, require little time and are particularly adopted to children of low intellectual and moral natures. Children who fail to yield to all of the mental means of approach to their inner life of thought and action must be appealed to through sense, especially through the sense of feeling. This appeal to the senses should be made only when the gravity of the situation demands it. Oftentimes some acts have more serious consequences at one time than at another. Sometimes again they upset or undo things of greater import than others and sometimes they create situations that may even affect the life or success of the school. When for such cases punishments are inflicted they should be carefully adopted to the sensibility of the child in the first place and to his sense of responsibility in the second. Some children are highly sensitive and light blows cause great pain while on the other hand there are many children with dull and deadened sensibilities upon whom even vigorous blows have only slightly painful effects. Blows that bring great pain to the one may hardly arouse the deadened periphery of the other. In the other case young children and children who have had slight moral or intellectual training have not a highly developed sense of responsibility. The child who does something and knows beforehand that it will be held as a serious crime and will lead to various results that are serious in the hindrance of the attainment of individual or group ends and still persists in doing it, obviously requires greater punishment than he who has little knowledge of the far reaching effects of his deeds, or who was by reason of age or training vaguely aware of their consequence.

Punishments tend again by too frequent repetition to become ineffective. The moral nature becomes callous and there is thereafter no response to the punitive stimuli when applied. There is danger in such cases of producing the hardened criminal. Other means should be employed as a deterrent. For here the very end of punishment - reforma- 
tion - is being destroyed. Sometimes there is a frequent repetition of the act, not so much because the punishment was not severe enough, but chiefly because the punishment was not of the right kind, or perhaps too long delayed. There is always danger from delayed punishments which may lead as said above to the improper association of cause and which therefore may lead to a misunderstanding bctween teacher and pupil resulting in resentment on the part of the pupil toward the teacher. When not thus created hardness of feeling and indifference to punishments may arise when they are too severe and injurious. School punishments should produce no more pain than is required to inhibit the apparent tendency to the forbidden form of activity and bring about the ends necessary to promote successful class work. Punishments have a two fold end in view; they aim to promote the welfare of the class and to effect the reform of the individual. Justice must be done to both. Punitive systems that would neglect either principle would fall short of their mission in the schoolroom. In both cases the effects of the penalties should be enforced as quickly as possible. Hence any and all forms of punishments that involve functional or bodily injuries are to be condemned most severely.

The Effect of Punishment on the Teacher. One of the strongest arguments against the use of physical punishments in the schoolroom by those opposed to it, is, that besides the effects it has upon the child, some good, some questionable as to their good effects and some decidedly harmful, it is filled with certain very undesirable effects upon the teacher himself. The first of these deleterious effects is that it lowers the self-respect of the teacher and robs him of the finer feelings of kindliness and sympathetic care. Indeed it is claimed that it dissipates all of the finer qualities and ennobling social traits and characteristics. The next step in the process is the reduction of him to the plane of the brute. This is at once a very serious charge against the administering of punishments. In this connection it might be added that it is a fact that once the finer feclings are deadened, the brute in man, always near the surface very easily and quickly gains the ascendency. Still it is an ob- 
vious fact that teachers who allow themselves to see in the acts of children elements demanding physical punishments and who can bring themselves readily to believe that an appeal to physical pain is the only means of deterring them from the transgression of rules sometines misunderstand child psychic life and attribute the wrong motive to many a well intending act and to many an act that was thoughtless and consequently without real motive. So they can gradually bring themselves to believe that children are evil at heart and either need to be harshly governed, or else have no means of appeal by which they can be reached except through the physical medium of the body. When teachers have reached this state of mind in regard to child life and action their best days of usefulness in the schoolroom are rapidly approaching an end if not already there. For either they ruin the nature of the child and make of him a hardened malefactor, give him a perverted idea of the world's standard, beget in him disrespect for the teacher or an attitude of rebellion. In either of which cases the end of the school, the proper education and training of the youth is lost.

The next step, of antagonism to the child and childish activity, is easily reached. For when the teacher has brought himself to believe that the child is wrong at heart and believes that there is an evil motive in all or most all that he does that is a transgression of rules, he begins to think it necessary to anticipate the child and to cross him in his acts with prohibitions that restrain him in his every activity, which is his only way of self expression. Too, he thinks it both best and necessary to deny the child every request, both the innocent and the evil intending. The result upon the child is a reaction in which the teacher appears not as his friend but as his ever watchful enemy who constantly stands between him and any and all forms of pleasurable activity. It is easily seen that no teacher so regarded by a pupil can gain from him the amount of attention and good will necessary for him to impart knowledge or even arouse in him the interest necessary for the proper performance of the minor details in the educative schoolroom processes. Resentment into which this state of things sooner or later drifts, 
more often sooner than later, leads to results for the child which culminate in the putting of an early end to the school life of the child. This is a most serious result, yet how of ten is it the history of a boy or a girl. Oftentimes the brightest is thus early cut off from the advantages of the school. Parents signally disappointed in the failure of their children to make progress in school and be contented there, many of whom had their hearts gladdened by the successes of their children in earlier grades and under other teachers, but ignorant of the true cause, or, if aware of it, ignorant of the means whereby they may overcome it, or, if acquainted with the means, unable to bring them to effective use, finally give their reluctant consent for their children to stop school. Oftentimes, also, too proud to admit of friction or trouble with their children at school, they pass off the incident by the statement that their child has quit school to go to work, adding oftentimes by way of explanation that he prefers this particular kind of work to that of school work or has no taste for book knowledge.

Thus the young life is blighted or thrown out into the world of action with a serious handicap. Thousands of children, many of whom are fine specimens of humanity with promising futures, some of them a delicate, sensitive nature, each year pass out of the public schools into the great business of life simply because they were not understood, because of which the determined but well intending teacher, an ardent advocate of the use of the rod, drove them away and forever spoiled them for school life by an unfortunate appeal to the rod, when a word or a look from the teacher with a private talk or something of the sort would have saved the teacher and saved the pupil to the parents and to the world at large. These are potent arguments against the use of physical punishments by the teacher, arguments that should appeal to the innocent and guilty alike. But it does not mean that we should go to the other extreme and banish by statutory enactment physical punishments from the school entirely. What the situation demands is an appeal to the highest judgments and deepest sympathy of the teacher and a careful study of each individual with a liberal allowance 
for child nature, its natural tendency to activity, love of action and lack in such of all predetermined motive for action. This, followed on the part of the teacher by deliberated, but careful treatment based upon the best analysis of the needs of the case that he can bring to bear upon it will generally save the day for all concerned. This seems to be the best, the only method that will insure a fair degree of success in the use of physical and mental punishments in the schoolroom.

The Kinds of Punishments. The physical punishments practiced in the schoolroom lave been as varied as the inventive genius of the teacher could make them. If all of the various forms of physical punishments that have been devised and practiced upon school-children could be described, they would more than likely fill many ordinary volumes. While there are certain forms of punishment generally known to the school in the heyday of the practice, each teacher was a law unto himself and as a result there was no end to the methods adopted to inflict pain both to bring the erring one back to the paths of rectitude, and deter him and his companions from again leaving the straight and narrow path for the alluring call of the activity of childhood and youth into the highway and byway. In general we regard as punishments anything which wilfully applied to any one causes inconvenience, displeasure or pain, that is unwillingly born and that is intended as a deterrent from similar conduct in the future. In any community an individual is free to apply any form of punishments which the public sentiment of that community will permit. This is an uncertain and fluctuating element it is true, yet when one uses punitive systems, if he is to succeed with them his only hope of administering them is to have either the active support or passive acquiescence of the public sentiment of his immediate community. The kinds of punishment administered by the Swabian school master Haberle, mentioned above might be included here. To them might be added various forms of sitting and standing postures and even kneeling postures with or without extra means of increasing pain. The application of blows to the body by means of the hands 
and feet and other artificially improvised instruments, the assignment of various tasks in school or out and during, before or after school hours, these threc groups either alone or in combination will include most of the forms of physical punishments known to the school. Mental punishments also open a vast field to the teacher. These mostly depend for their strength on the social feelings of the individual, the emotions and desires that owe their existence to the fact of the group life. They too may undergo almost infinite variations.

a. The Reprimand. Out of this infinity of punishments that are thus possible and the myriad that are known to have been in vogue in the schoolroom we can only devote a brief word to a few which because of their importance are deemed worthy of consideration. The first one that will be treated is the reprimand. The reprimand is one of the commonest forms of punishment in use in the schoolroom to-day. Like all other punishments it has its good and its bad uses. Like others also its virtue lies in its being restricted to specific cases and in its being dealt out sparingly. Reprimand in the hand of an unskilled disciplinarian may sometimes take the form of a threat or scolding. At once it loses its power for good. Under any and all circumstances threats have been proved to be productive of but little good. Given out under strain of anger or excitment and amid the pressure of other duties they too often pass out of thought as soon as the occasion that called them forth has ceased to exist. When thus treated they put the teacher in a false light and put a premium upon bad conduct, by fostering the belief that there is little possibility of punishment following, when the conditions for the administering of it are unfavorable. The other faulty side of threats is that they invite transgression. The child is told not to do a certain thing which should be sufficient, but instead of stopping there and letting his past conduct prove what will follow he adds, that if obedience is not forthcoming such and such punishments will follow. This course is obverse to two primary pedagogical principles. In the first place the child knows if punishment is to follow just what it is going to be, can judge as to whether or not 
he is willing to suffer it, and put himself into the mental and physical attitude to receive it. Besides it gives his mates opportunity to tease and provoke him until his pride is reached with a new train of reactions, whereupon the pupil may determine upon some line of conduct that causes the infliction of the penalty to be devoid of disciplinary value, or makes its infliction difficult and hazardous or even impossible. In some cases it has caused the child to leave school or drawn the parents and school authorities into the affair. Upon some natures, too, threats only incite to action. Having been told what will happen the pupil sometimes thinks it his right to show all either that this particular thing will not happen, or that if it must and does happen he determines that both teacher and pupils shall see that he has no fear of any such conscquences, a dangerous evidence of false courage.

As for scolding it is never to be advised. It not only makes a mere prattler out of the teacher, but it is also discouraging and exasperating to the pupil. It awakens resentment in the pupil and causes him to lose both respect for the teacher and confidence in him. Upon gentle natures it has a peculiarly de-energizing effect. While upon stronger temperaments it falls like water on a duck's back. A few instances are on record, however, where a severe scolding on a high plane, not low vindictive name calling and fault finding has been productive of highly satisfactory results. This, though, is the exception and not the rule and the evil effects consequent in the wake of scolding still forbid its use to any extent in the schoolroom.

The reprimand itself when kept from turning into these two forms is a source of power in the hands of a skillful teacher, and is very effective in schoolroom management. Reprimands like all forms of punishments should be brief, and always kind. Their sole purpose is to serve as a deterrent and a reminder to both malefactor and school that the rules of the school are not to be broken and if broken "the way of the transgressor will be hard." Reprimands may be either public or private. Public reprimands are regarded by all from the very principle that underlies their effective- 
ness as more severe than private reprimands. Public reprimands while justifiable under certain conditions should be as rare as possible, for fear that they lose their sting and consequent disciplinary value. They are a power in school discipline and should never be abused. For when these have lost their effectiveness there is no adequate substitute for them, as it is a well known fact that usually a large majority of students prefer almost any kind and severity of punishment rather than a reprimand, especially a public one.

b. Detention and the Assignment of Tasks. Detention after school and the assignment of tasks either before, during or after school are methods of punishment very much in vogue. These, too, have their good and bad sides, the latter tending strongly to discount them rather than make them of any merit. The chief drawback to detention after school is that in general schoolrooms are not often fit either for pupils or teacher after school hours. Rooms are cold and ventilation as well as light is bad and cannot be remedied, ventilation, often because there is no heat to create a circulation of air, and light, because the sun is mostly too low in the horizon for its rays to possess much penetrative or light giving properties. Besides both teacher and pupil are in no fit physical condition to get the desired effects out of the punishment. More often the teacher who has much discipline to do during the day is so worn out that the punishment is oftentimes more severe upon the teacher than upon the pupil. Too often also in the moments of reflection after school the teacher repents and the pupil is dismissed long before the expiration of the time of detention originally announced. The pupil soon notices this fact and the use of detention after school as a means of punishment soon loses its efficiency for him and through his advertisement of it for the school. A good plan is never to let it be known how long the child is to be detained. Then the teacher is free to dismiss him at his will without thereby compromising himself. In general, though, long detentions after school hours are inadvisable under any circumstances. They often affect the outside duties of the pupils, under which circumstances the teacher comes in for an unfair amount of adverse 
criticism, too often, in the presence of the child. It is much more advisable for the teacher in such cases to visit the child's parents or guardian and to seek aid there. At times summary corporal punishment may be substituted for lengthy detentions with wholesome effects. Many school boards because of the abuse of this method of punishment by exasperated teachers and the continued complaint of parents against it have made explicit rules regulating the practice and limiting it otherwise. In general noon recess hours are inconvenient for detention both to pupil and teacher and are accordingly legislated against. In the evening there is a maximum limit established by many school boards.

The assignment of tasks as a means of punishment is not so common, the chief danger from them being the likelihood of the child associating the unpleasantness here developed in the performance of the task with the task itself and not as was intended with the wrong done. In which case a dislike for study, or for that particular study is fostered, the very thing that was not desired. The virtue of the method then will be seen to be limited chiefly to those cases where the task assigned is an unperformed school task. Even then it is best when it is a task in which the pupil is a poor student and the task to be done necessary for the further progress of the child in his advance work with the class. For the work of the school to be at its best, to be pleasurably, well and willingly done it ought, if possible, never be allowed to descend to the level of a distasteful task.

Corporal Punishment is the great bone of contention in the schoolroom discipline. There are ardent advocates of it and equally ardent opponents to it. Whatever may appear to have been said against it here is not intended to advocate its abolishment, but rather to bring about its restricted use in the schoolroom. It is a kind of punishment that is easily applied by all. Because of this it is quite likely to be abused in its use. It is only the abuses of it that we cry out against. Children are in the formative period. They exhibit many tendencies that are unsocial and even dangerous to the social equilibrium, many of their tendencies are anarchistic and even annihilistic, which if allowed to 
develop will bring untold misery and suffering upon humanity. These tendencies must be overcome at all hazards. In their incipiency they may be uprooted easily. But if left to grow to their full strength and maturity it may be necessary to destroy the individual in order to nullify the tendency. It would obviously be an abused system of punishment which hesitated for a moment to inflict severe corporal punishment rather than run the risk by a method of false kindness and misplaced sympathy to allow these tendencies to get firmly rooted in the "nature" of an individual. The "whys and wherefors" of corporal punishment as well as the conditions under which it should be inflicted together with its justification and dangers have already been given. These circumstances failing the resort to corporal punishment is justifiable. Every individual born recapitulates in brief the life history of the race. He comes into the world a type of all of the former savagery of his race, no matter how advanced the society may be into which he is born. All of his savage tendencies - and he has them galore - have to be curbed, controlled and either eradicated or directed. If he is to become a member of this advanced socicty all of his unsocial tendencies and instincts have to be removed at all costs. Any savage traits appearing and left to develop unchecked will tend to unsocialize him and take him back to the savage, de-civilize him. Children have little or no concrete knowledge of relations or of consequences. We who have such knowledge must regulate their conduct for them. Heredity is a biological principle. Biological change is slow; it comes only after long periods of time. To think then that the children of the cultured will all have natural tendencies to culture is evidently an error. At least, whatever tendencies they have in this direction, which are incidental, are subordinate to those of the tendencies of the race, which are fundamental. Personally the author favors a regulative and punitive system that is in harmony with real life. A child should early learn both in the home and the school that which he will meet in life. Not to the extent of ruining or destroying him but to the extent of saving him. Any pettyfogging home or school system of penalties that out 
of fear or kindness allows a child to grow up uncontrolled, ungoverned and unamenable to law is a disgrace to itself, and the school which does so has forfeited its justification for its existence and support and should be "recalled." The theory that education should be pleasant, interesting and the system to the child's liking is all very good and even desirable as an abstract ideal. But those who place the responsibility for attaining this ideal on the teacher, even, assuming, that all teachers are perfect in their profession, have no knowledge either of child nature or of human nature if they expect them to accomplish the desired ends without a rigid system of penalties. Children are worlds unto themselves and oftentimes more complicated in their action and reaction than teachers. Now when other means fail to beget certain kinds of responses physical stimuli must be applied to control and direct the action of one child toward another. While every child is not a direct offspring of his satanic majesty himself, he is also not the image of the babe Christ, but is more than likely somewhere between these extremes. Wherever he stands the teacher must take him, get acquainted with him and then make of him a being fit for society by imparting to him knowledge and instilling into him modes of conduct in the forms of physical and mental action and reaction. This child has both an intellect and a will. Both of which will have to be reckoned with in every form of caprice known to man and devil. Here lies the problem. To solve it will require both staff and rod.

c. Suspension and Expulsion. Both of these methods of punishment are to be the means of last resort. With children under the school age limit they are impossible because of the compulsory school law. Only when all other means of control have been exhausted and the best good of the school demands it should it be tried. It puts the child out of reach of the sphere and influence of the school and is only justifiable when either the school can do the pupil no more good or he is such a disturbing element in the school that he threatens the welfare of the school, or both. So serious is the question of suspension or expulsion that in most cases no teacher is allowed the free exercise of the power. Gener- 
ally it is only possible with the consent of the principal or superintendent, or both. This does not apply to older pupils who are presumed to have reached the age of responsibility and to know what the consequences of their acts will be. Even in these cases best good demands that every other appeal be made to a pupil before resorting to suspension or expulsion. Of the two expulsion is the more severe. It excludes a pupil from school for a school term generally, while suspension excludes him for any length of time less than such. Most cases of suspension range between the period of a week to a month. It has been argued that expulsion may be for any length that the school authorities may name. But it is generally conceded that its limit of enforcement is for one year.

Witnesses to Punishment. Experience has taught that the teacher who is responsible for the enforcement of a rule that is broken should inflict the punishment, if the best results in discipline are to be obtained and the teacher is to retain a high degree of efficiency in enforcing school laws. Many school boards and superintendents have rules that only the principal may inflict corporal punishments. These are without a doubt wise regulations and have their justification in the fact that in the public schools most of the teachers are women who because of their weak physical natures are incapable of successfully administering punishment to the older and stronger recalcitrant pupils, while the principals are generally men with sufficient physical strength to enforce the school regulations in all of the ordinary cases. Another reason for such regulations is that the principal is generally a more experienced disciplinarian and should know more means of effectively administering punishments. Again he does not experience the constant contact with the pupils that the teacher does. Not knowing him then there is a tendency for them to both fear and respect him. Another good point in favor of this method is that the principal is less likely to inflict punishment under provocation or anger, or be moved by personal feeling or malice. Too he will have the time to reason with the individual with- 
out prejudice or preconceived bias. Oftentimes, however, it becomes necessary for teachers to administer corporal punishment without calling in the principal. Iu such cases this should be done. It has a salutary effect upon the school and gives the teacher ordinarily increased power to control. For where the pupil is punished by the principal especially if the teacher is absent the pupil fecls that the teacher is not a party to the punishment and in fact knows but little of it and as a result he may feel free to commit fresh crimes, especially if he is of the temperament to be easily goaded by the taunts of his fellows.

Punishments before the whole school should be rare. Too much care cannot be exercised in the inflicting of public corporal punishment, if there is any sentiment in the community against it. Such sentiment exists to a more or less degree in almost every community. Wherever such a sentiment is pronounced either in the community or the home the pupils soon learn how to take advantage of it for their own benefit. It is surprising, too, in how many ways they can turn it to account. When they become witnesses to acts of corporal punishment they are quite apt innocently to get distorted and enlarged ideas of the intensity of the punishment inflicted and exaggerate it either with or without evil intent, to outsiders. In such cases it will be always advisable for the teacher to take special precautionary measures to see that no overt act of his shall give credence to such reports. Care may be exercised for example in the selection of instruments of punishment and in choosing the parts of the body for receiving the punishment. Sensitive or vital parts of the body should be avoided. Those instruments also that have ugly associations such as rawhides, various forms and sizes of whips, pointers and especially all forms of weapons that will break easily should be let alone. If teachers have reasons to fear unfair or unreasonable censure it is better in such cases to have a fellow teacher or some one else in authority and in sympathy with the work present as a witness if for no other reason than as a protective measure. Besides a fellow teacher, some other person in authority 
such as the principal, superintendent or even a member of the board or one of the commissioners who is friendly may be called in as a witness. Though also sometimes good may result by having parents come in and administer or assist in administering punishment the practice in general is to be condemned, as it weakens the teacher's control over the pupils and often invites the interference of parents where their interference is not only not desired but may be even dangerous.

But witnesses or no witnesses there are certain forms of corporal punishments that are not to be indulged in, though if forced to the defensive teachers must do whatever the situation demands. Punishments that descend to the plane of brutality are always to be condemned. Corporal punisments that disturb bodily functions or cause lasting injury or excessive and long enduring pain beyond the degree to correct and deter fall under this same black list, as do all indiscriminate uses of the hand on the body or limbs of the child. In this relation boxes on the ear as endangering the sense of hearing and slaps on the cheek or anywhere in the face, as dangerous to the nose and eyes, or mouth, as having the danger of disfiguration, all fall under the above as tabooed methods of punishment in the schoolroom. All forms of physical punishments that cause excessive strain or pain in the limbs or other parts of the body have been condemned by modern pedagogy as unhygienic and filled with invisible dangers physiologically. In all such cases, however, the critical situation is the teacher's and he must master it, if he is to hold his own and do his work. This first and last, but with it all at all times are to be associated the demands of the individual, the school, the community, the state and society. He is to give the situation the best, the noblest and the highest that is in him, but first and last he must be master, he must rule, direct, instruct, and teach, without any form of punishment if possible but with them if necessary.

\section{REFERENCE READING}

Compayre's "Psychology Applied to Education." Chap. XIV. O'Shea's "Social Development and Education." Chap. XV. 
Arnold's "School and Class Management." Chap. VI, Sect. 5, VII. Perry's "Management of a City School." Chaps. VIII, IX.

Dinsmore's "Teaching a District School." Chaps. X, VI.

Baldwin's "School Management and School Methods." Chap. XIV. Fitch's "Lectures on Teaching." Chaps. XV, IV.

White's "School Management." P. 190.

See also references to chapters on Discipline and Schoolroom Supervision. 


\section{CHAP'TER IX}

\section{INCENTIVES AND S'TIMULAN'TS IN EDUCATION}

Besides being both a reformative and a deterrent in forms of conduct, punishments are a stimulant to activity in education. At least it should be in the capacity of the former that punishments should function in the schoolroom routine, while other means that appeal to something higher in the subject than mere bodily pain or mental discomfort should serve as an exciting agent or stimulant to arouse interest and spur on the will so as to tide the pupil safely over the rough and unpleasant places in the school life. For, just as the normal body enjoys healthful exercise for a time, but after a brief period of activity requires also another period for rest, recuperation and a re-storing of the bodily energy used up in action, so does the mind after like periods of activity grow weary and require corresponding periods of rest and recuperation. In like mammer just as there are times in the history of bodily activity, when for the good of the organism, as well as for the good of other organisms like itself and dependent upon itself it is necessary for the body both to possess and at times employ means of producing activity when weary and even when almost exhausted, in order that the organism itself and other organisms related to and perhaps dependent upon it might exist, so in the case of the intellect it is necessary that there exist means, when it is tired and disposed to rest, of enforcing upon it activity at the cost of inconvenience, discomfort and even pain, in order that the best good or continued activity of the intellect itself or of other intellects dependent upon or elosely related to it might continue to exist and function.

In the case of the intellect, this source of enforcing activity when necessary to gain a distant or remote end, whether fully realized or not, is the will. When the individual can- 
not fully realize or appreciate an end in action because it is remote it responds but feebly to a will that compels also feebly. In such cases action must be engendered by those properly empowered with rights to arouse the will to action by stimulants, who do see and appreciate the value in the enconomy of life of these distant ends. This is the case in matters of education and it is upon this that the right is granted. In the minds of the pupils most of the ends of education are secondary and remote. As such they are but little appreciated by those who come under the jurisdiction of the school. Consequently those charged with responsibility for getting certain results in the school processes must either substitute temporary and immediate ends that can be readily appreciated or use various forms of stimulants to arouse the will to action where the ends themselves because remote fail to do so. The will may be aroused to action by stimulants working internally or externally. These stimulants are either natural or artificial. The natural stimulants to intellectual action are the same as the natural stimulants to any form of human action, and as a fact of knowledge are as old as the science of mind itself and has developed concomitantly with the development of the knowledge which that science has brought us. These natural stimulants are the emotions, motives and desires as aroused by things which by nature in and of themselves are stimulative to action. The knowledge of artificial stimulants unlike their counterparts, the natural stimulants, have developed chiefly along with the science of pedagogy. In actual practice it appears that the artificial stimulants though less lasting in their effects and the success they bring, are more in use and oftentimes more effective where used than the natural stimulants.

Artificial stimulants to intellectnal activity are generally grouped under the one head of rewards, but are more often considered under the more special heads of prizes, privileges and immunities. The chief reason for the effectiveness and practical value of prizes is that they are easily accessible and besides being something tangible that furnishes immediate pleasure to the body and mind are more concrete than 
privileges and immunities which are therefore less effective and have less of practical value in them. The appeal to these stimulants and corresponding dependence upon them for results in educative processes, have both a good and a bad side. The artificial stimulants as was said above are more commonly in use and more effective for immediate results though the natural stimulants are to be more preferred because their effects though more difficult to obtain are more lasting and far-1reaching when once they are obtained.

The Nature and Justification of Rewards. The custom of giving rewards in the forms of prizes, privileges and immunities is an intricate part of our social and political system of government as well as of that of our systems of education. Inasmuch, therefore, as the school is supposed to fit one for life in the world of action about him and inasmuch as educational institutions reflect both social and political institutions in the ends they seek to attain, not only will many of the practices of social and political institutions be found in the school but except in a few minor details in which the ideals of the school will be apart from that of the state and society, the practices of the former will be heartily approved and assiduously taught in the latter, for the perpetuation of which through instruction in it the school receives its first and primarily commissioned duty. This practice therefore receives general sanction and has become a commonplace if not indeed a necessity in our educational systems. 'The efforts of the school may be and indeed should be toward so restricting it as to keep it on a high plane and remove from it whatever of the unmoral it may have received in practice. The problem in education as already stated lies in the fact that its ends are remote and mostly abstract. The child with which the school deals is incapable of either conceiving or undertaking to attain these ends except in a vague and indefinite manner. The moment, therefore, the schoolwork becomes the least bit irksome and force either physical or mental is applied to urge the child on in his work the reason for it and the end it will serve in his life are called into question by him. The fact of his competency or incompetency to properly pass judgment upon it never 
becomes a part of the issue. When this time arrives, there must be something tangible in the form of ends presented by the school to satisfy this demand, or the whole system, of which this is a part, is condemned by the child as useless and becomes a process in life to be avoided as an obstruction to his wishes and desires, the necessity for which is generally to him inexplicable. This demand the school must satisfy. To this end it has created the system of rewards and punishments in order to hold the child while the intermediate processes leading to the more remote end are being successfully carried on. This is perhaps a most important reason for the presence in schoolwork of both forms of stimulants. Humanitarians and all moral workers with men find it difficult to get matured individuals to labor long for distant ends. If such is the case with the mature upon whom life's responsibilities fall with much increased intensity, how much more difficult will it be to attain these ends with children who have not yet felt or appreciated the intensity of life's responsibilities.

The purpose of rewards is to give incentive to action. Experience has shown that neither children nor grown ups will long pursue good for its own sake. Rewards, however, are only a temporary incentive to action. Herein lies their chief danger as well as the unfortunate need of their constant renewal and change to maintain their force as stimulants. However, they may be made into a system such that, if they are carefully administered, much of the demand for various punishments to aid in the attainments of the more distant ends of education may be done away with. Rewards receive their power from the fact that they awaken new and vivid emotions and desires and connect in a pleasurable manner achievement with the efforts of labor. Without stimulants experience has proven that there is no motive to effort: Remove from labor the motive and you rob it of its flavor. "Just as the object of punishment is to establish in the child's mind an association of ideas between the fault committed and suffering or privation; so the reward is intended to connect the idea of a duty accomplished with that of the pleasure which results from it," writes Compayre. 
Like all other school methods the use of rewards is capable of abuse and as such is to be most rigidly condemned. Like punishments also, their value rests in their use with tact and discretion. It has been found out that the receiving of rewards tends to create vanity in the recipient and jealousy upon the part of the other members of the school by developing in the school as a whole dangerous motives and desires. Too often, also in the continued off ering of rewards for work or conduct both pupils and teacher lose sight of the distant end of education in the receiving and awarding of rewards. The habit has very frequently been known to engender a false standard in the pupil. The pupils under such a system too often get to working for the reward instead of for the real end of educational effort, knowledge, skill and ability. This is often the case when rewards possess much intrinsic value. It has been found a good expedient at times in these matters to have all rewards get their chief value from their relation to the ends desired, rather than from any quality inherent in the object itself. In all that is said about the giving of rewards the fact must not be overlooked that care should be taken that the reward is placed fairly within the reach of all and each and every one should be encouraged to feel that he possesses equal chances for it, if he will do his work according to instruction and directions. Closely following this announcement and encouragement to compete, the conditions of awarding them should be so made as to really make the chances of all equal.

Prizes. In the giving of prizes there are two essential qualities that should always characterize the act. In the first place prizes should represent real, conscious and prolonged effort. If they fail to call forth this their basic end, that of stimulation to action, their effect is lost, whereupon they react to defeat their own end. The association of effort with the gaining of the prize is the only natural pleasure that is to be derived from its winning. In the second place prizes should represent real achievement, real progress made along the line of the endeavor. Though it is not always possible to do so, care should be taken that the thing 
achieved, the progress made, should not be lost sight of by the individual gaining it but it should become a permanent part of the child's mental and moral possessions. Too often these essentials are overlooked entirely or forced far into the background while details much less permanent and beneficial to the child are substituted. In the giving of prizes it is customary to use medals fittingly inscribed (and even without inscription) and books. Though there is in the act itself no essential need of restriction of the practice to these two classes of prizes. One of the things desired in giving prizes is that the prize shall be lasting. This is especially true of medals. The essential element of a prize other than its durability is that it shall afford intimate association with and relation to the acts which won it. Money is objectionable as a prize because of the tendency too often with it to becloud the real end, and the motive in awarding becomes an end in itself. Money may be and often is made into a medal and with the simple medal may be preserved as a relic of school days and early achievement and as such may be kept as a family heirloom. Books on the other hand are to be particularly recommended as prizes, because they gain their value from the knowledge they contain, the inspiration and ideals they foster, their freedom from all tendency to turn the mind of the recipient away from the real end for which the prize was originally awarded, their variety and the small expense attached to procuring them. Too, the giving of prizes must be sufficiently infrequent and the prizes of such a nature as to be always desired and worth putting forth the effort required to attain them.

The success of awarding prizes depends apart from the intrinsic characteristics just mentioned also upon the time, place and circumstances of their awarding. 'There is considerable danger for example in the public awarding of prizes. The visitors are too often unacquainted with that for which the prize was offered, what is meant to be gained by the teacher in offering them and what it is intended thereby to do for the pupils who are working for the prize. In the absence of this information fictitious ends are substituted for the real ones and the rewards themselves thereby 
gain secondary values that are often very dangerous to the welfare both of pupil and teacher. It is at the point where outsiders become interested in the nature of the prizes, their winning and awarding that the wrong spirit is likely to be instilled into the pupils and the effort to win the prize become at bottom the effort of one family to gain outward evidence of excellence and superiority over another family. At this point prize awarding in the school may engender the bitterest kind of feeling. It may then become an occasion when every act of the teacher, whether justly so or not, comes in for severe criticisms and antagonisms, which may result in the loss of position by the teacher or maybe the beginning of lasting animosity in the community. However, where prizes are for results where the assistance of outsiders is desired it is justifiable to award the prizes in their presence and even to let them know beforehand that presents will be awarded for such. This is particularly advisable for such as the family, friends or community residents who can aid in effecting a remedy for good attendance and punctuality, or, where the outsiders have control over the accomplishing of the desired end. Many authors advocate giving prizes for work which was done by the pupil without a knowledge that a reward was to follow the successful completion of a given kind or piece of work.

While at first sight this may not seem to be fair to all in that the pupil has not had a warning to prepare himself and be at his best, it is to be commended because it strikes at that which was fundamental in the end of giving rewards, namely, the general excellence of the pupil and constancy in maintaining effective work in the routine and class work of the room. What is desired in offering prizes. in the school is effective work and most surely those who work along steadily without any knowledge that they are to be especially rewarded for their work, but do it willingly and well at all times are to be encouraged. The fact of the matter is that this spirit is the very one desired and to be rewarded. This being the very attainment for which the prizes were originally offered, for which the act itself was thought out, introduced and continued and as such should 
by no means be overlooked or neglected. The whole school should be encouraged in every way to work without thought of other reward than the mere gaining of knowledge and the formation of good habits of thought and action. When, then, incidentally, rewards come in the steady and unselfish pursuit of the end of education it would be joyfully received and have a salutary effect upon the school. Results are always best when effort is put forth without the thought of any form of immediate or tangible reward. When this end cannot be gained without prize giving, then some other stimulant than prize giving is in order for things are wrong in such a school at bottom and the school needs a regeneration and reorganization.

Prize giving is sanctioned by good usage everywhere but must be kept on a high plane and never be so frequent, or of such nature or value as to encompass the fading into the background of the real end of education and all forms of school processes. In education prizes are means to ends and can never become anything else, if the real end of the school and its processes is to be kept constantly in view and finally attained.

Privileges. The granting of privileges is a common method of rewarding labor and achievement in the public schools. It may take the form of granting a partial holiday for the achievement of some particularly desirable but difficult piece of work, with an excursion into the woods when the season is appropriate and every impulse within us and all nature without bids us abandon the confinement of the school and enjoy the beautiful flowers and the healthful sunshine. It may take the form of bestowing the rights of the honor seat or the place of honor at the head of the class for the highest excellence in work in some one or several groups of subjects. In many schools, where there are private libraries, books are loaned to students who combine accuracy with speed, which they may read while the class as a whole is completing the exercise. Where special reading courses are outlined this time may well be given over to the reading of such works. In special libraries of current literature, where such magazines as the Youth's Companion, St. Nicholas or 
other hightone periodicals are maintained, access to these may be granted as special privileges. Where it has been found out that they can be loaned out for home use over night without bad effects upon the getting of lessons the reward might take this form of privilege with advantage. In this way also, a secondary end of education might be fostered, namely, that of creating a love for good literature and of affording a fit introduction to our best authors, for the sake of forming in the pupils desired traits of character and of giving them needed instruction and development along certain definite lines ordinarily considered, without the range of the activity of the schoolroom. Needless to say, to meet with success the books must be inviting in their content as well as cultural and instructive, if the desired end is to be attained and the spirit of work kept up to a high degree of efficiency. The next step in granting privileges is perhaps the bestowing of the rights of monitorships to pupils as a reward for meritorious conduct and excellence in work. In granting all forms of privileges discretion and care are necessary in order to see that they are not of too long duration to discourage those not permitted to share them nor to allow those enjoying them to become either careless in their duties as monitors or fall to a low standard in the performance either of the monitor duties or the schoolwork by the excellent completing of which the honors of monitorship came to them. The rights of monitorship should not run so long as to allow either the interest in its winning to lag, or the enjoyment of it to cease to be an object of desire. Their aim should be to maintain constant and wide awake effort. To induce renewed effort and maintain a wide awake desire privileges where convenient and where there is no other serious objection should be reappointed upon the new standing either weekly or monthly. Only under rare circumstances will it be found advisable to let privileges run for a longer time, if the end to be obtained thereby, is the arousing and maintaining of interest and increased activity on the part of the pupils in the work of the school.

Due perhaps to the long sway of the law of the survival of the fittest operative under the principle of selection, the 
intellect of man is particularly responsive to all forms of contest and competition. There are among men, by a nature inherited from the racial ancestry, temperaments which will exhaust themselves merely to appear to advantage among their fellows or seek places of so-called honor. Personal pride and love of approbation of their fellows are particularly strong stimulants to action for other natures. In granting privileges care should be exercised to see that weaker natured pupils, who are by temperament predisposed towards contests and competition do not orerdo themselves and wreck or ruin their lives by underdoing too great a strain. Serious shocks to educational progress and considerable adverse criticism of its methods are often brought about in the school by inaugurating a system of calling forth effort that is damaging to health and bodily or mental welfare. Education of no sort much less that comparatively small amount furnished by the school can for a moment be weighed against health. Consequently anything in its methods or practices which is clearly damaging to health is to be condemned. The moment contests or competitions whether they carry with them bestowing of rewards or not, are announced, most such natures are at once on the qui vive. In the suspense and strain of the contest itself these natures are keyed up to a high degree of tension. With some the tension becomes so great as to upset the physical functions producing thereby organic nervousness with all of its evils of dyspepsia, constipation and other related disorders or even a nervous breakdown. When such conditions result the practice is undoubtedly bad and wisdom as well as best good, advises that it be discontinued.

Immunities. Another practice common in school life to promote progress and induce work is the granting of immunities. In some forms this practice is quite common and seems to have almost universal sanction by the leading authoritics on pedagogics. In the granting of immunities the danger lies in the tendency to grant exemption from routine processes which often become tiresome and resultingly distasteful. Much of the work of the school and of life consists of routine and the education of the child in it and 
the cultivation in him of a taste for it or at least the removal from him of all antipathy toward it is one of the chief dutics of the schools. To extend, therefore, the granting of immunities to this phase of schoolwork would be, then, ostensibly detrimental to the main end of school training. Exemption from performing tasks that have no more than disciplinary value and which in no way materially affect the best good of the child or tend in any way to thwart the basic ends in education may and do receive common sanction. Tests and examinations are secondary means in education and from many sources are seriously questioned as to their practical value in educational processes. It is argued that they form no competent basis of judgment as to the work or ability of students, while they entail upon teacher and pupil much labor and loss of energy and time. The practice of granting immunitics from these is quite common. As they are supposed only to brighten up the pupils' memory, show the teacher wherein his teaching has been ineffective and with what pupils, and therefrom to justify his marking of a pupil in a particular manner, they may safely be considered as of secondary value in education. If tests and examinations are regarded as such it will be taken as proper to exempt pupils from them as a reward from work, especially since they are so laborious and are too often the source of serious worry on the part of many pupils. These statements, however, are not to be taken as an argument for omitting tests and examinations altogether from schoolroom work as a useless method whose results are either unnecessary or undesirable for the school processes. Nor are they to be conceived as in any way an argument against them. For while tests and examinations may have their bad sides and may have several evils that follow in their wake they undoubtedly are a great aid to the teacher in rendering judgments against the pupils and in estimating the progress they have made. But above all things they serve as a threatening spectre, a ghost that will not down, which when the category of stimulants is nearly exhausted still serves to quicken the mind to action and urge the lagging bodies on to the desired goal. 'The only thing is that too much store must not be 
laid upon their mute evidence nor must their frequence be allowed to exhaust or worry down the energy of the pupils. In the case of reviews, the author hardly believes that any experienced teacher, one who knows the practical knowledge gaining value of them and their power for giving understanding and strength to thought, would advise their being used for immunities. The review is such a necessary part of the recitation to all pupils and at all times can offer something new to the pupil if the teacher is wide awake and full of his subject that no end otherwise desired can safely be offered as a justification for exemption from them. It is during the review that real correlated knowledge is gotten by the pupil, when a connected chain is forged out of the whole subject matter and the new link or links given their positions in the chain according to their relation. To allow therefore, exemptions in this case would be to run the very risk of leaving the whole body of facts in the mind perhaps as a disorganized tangled mass which the mind could not lay hold of for use, not knowing them in their various relations nor how to use them in such.

The Natural Stimuli. The natural stimuli employed in the schoolroom to bring about educational activity on the part of the child are mostly abstract and distant in their effects. It is for this reason that the system of socalled artificial stimulants were found necessary in order to offer something to the ehild that was both concrete and immediate and as such would prove to be a force immediate in inducing active response. In the last analysis man is essentially and fundamentally a social being. All of his bodily functions and tendencies to action that are not purely biological in nature owe their origin and consequent development to this fact. Even those tendencies pronounced to be unsocial, which it is the aim of the schoolroom processes to either remove or curb and redirect, and which while their ultimate results are either harnful to social progress or even destruetive of the existence of the social group itself, are traceable back to an origin that lies deeply imbedded in the action made necessary by the contact and struggle incident to our existence as a member of a social group. Selfishness, the 
most unsocial of all human emotions, for example, was evidently called into existence by the struggle for existence between the ego and alter of society. If there were not in society that which by demanding the substances of life for itself endangered the existence of the ego, the ego could never have felt or developed a supply of egoistic motions to oppose the demands of these altruistic emotions. In other words there can be no contradistinction nor antithesis between the ego and the alter of the social group unless there is also a multiplicity of relations each with its own quota of needs. This requires in the natural order of things that more than one ego exist, which is the paramount fact of the world of endeavor and achievement. So that while there are unsocial tendencies that must be controlled or destroyed for the sake of society they owe their being to the existence of aggregate life. These the school must control and redirect and make of them stimuli for educational activity. But while the unsocial tendencies have their value as educational stimuli it is the social stimuli that the school can use to greatest effect to arouse the pupils to educational activity. Chief among these are love of approbation, love of commendation, desire for knowledge and efficiency and desire for good standing.

Loze of Approbation. One of the greatest controlling forces in society is the desire for approval. It is often and justifiably called, because of its greatness as a controlling force in the actions of men, the love of approbation. This is at bottom a fceling in the members of the social group, of a dependence upon their fellows. It has grown apace with the great division of mental and physical labor of recent times. Practically all of the controlling forces available to society, the state and the school that do not deprive of life or liberty owe their effectiveness to the power of this love of approbation in man. Even self-esteem is based upon a false or true judgment of the value of self to society and social activity. Whenever in society the state or the school an individual is found to whom the good opinion and resultingly the good will of his fellows does not appeal, there is but little left by means of which he may be controlled 
other than the depriving him of his liberty of action or of his life. There is no force that will reach him outside of physical force and that must be so inflicted as to keep him in constant fear of it, or else he must be placed where he has not the freedom of action to carry out his unsocial tendencics. All of the common forms of natural stimuli to educational activity whether of practical or theoretical utility in the school will when traced back to its origin be found to have grown out of this basic principle of love of approbation. Self is the original source of all action; to self as a center all action returns. The approbation of self by self and the approbation of self by others while interactive and co-dependent cover the whole category of incentives and stimuli to action. Desire for excellence in general and in schoolwork in particular, desire for praise and emulation, desire for knowledge and efficiency, also love of duty, love of right and love of honor, all are but forms of approbation, some purely approbation of others, some purely approbation of self, some still a mixture of the two. Self-esteem also is often advanced as a natural stimulus to action, but this too more exactly speaking is a form of self approbation. The desire for present and future good, and all forms of desire for personal welfare both physical and mental gain their force as incentives to action and labor both in the schoolroom and out, as much from the principle of approbation as from the biological principle of the struggle for existence. As a means to an end in educational activity it is probably second to this principle in its practical value, especially whenever the school processes are given a direct relation to it.

Good Standing. The desire for good standing though classed in the group of natural incentives to school work has seen such current application and been given such a form as to make it almost an artificial means for the attainment of education. It is one of the most common means now in use to obtain desired results in school work, and perhaps one of the largest. Too often both by children and parents grades are taken as evidence of excellence and become desired in place of it, the shadow becomes substituted for the sub- 
stance. The whole school becomes dominated by it until school processes are directed to that end and all activity on the part of the pupil has the attainment of a certain grade in view. When grades and marks represent true excellence and are real evidence of advancement and successful effort they bring real satisfaction to all and the effort which is thus called forth carries the pupils farther toward the goal in a way that is unquestionably beneficial. The desire for good standing offers a good opportunity, since the standard is an arbitrary one for the teachers to keep a high ideal before the pupils and consequently raise it as the pupils appear to attain it, care being always exercised not to overtax the youthful energies of the child. If students realize that the standard is high, they will work hard to attain it and take greater pleasure in it when attained, the essential being first that it be such as can be attained by all and the second that it be such as can be thoroughly understood by them. The demand for a full understanding of that for which one is striving has been the ground for much real antagonism to any system of marking that involves the use of figures, especially figures of two digits. This practice finds some grounds of defense in the higher grades, but in the lower grades especially the primary ones where the children are struggling with the simplest concepts of the relation of numbers in the arithmetical processes the use of figures of two digits can scarcely find justification. In the high schools and colleges where if any place figures of two or more digits can be used with a reasonable amount of understanding by all, agitation has caused reform and they use a simple system of symbols or figures of one place, but in the grades, especially the lower grades, where above all places figures should have been abandoned because confusing and as such ineffective as a stimulus for work, they are employed with great scruples. Symbols with their meaning and values well understood may be used with satisfaction, but words expressing quality of work are much more satisfactory. Of course neither words nor symbols are satisfactory where competitions on the standard of mere grades are in vogue as they do not permit of the accurate classification necessary. 
School systems that approve of or advocate the use of such a system must use the numbers with two digits and even three digits at times when competition is close. Competition has its bad side but it is only a means to an end and if it can be used in such a way as to make this end attainable and still preserve other ends equally desirable there is nothing to do in fairness but sanction it. It is a natural and universal principle and cannot be safely overlooked in school when the child meets it outside of the school and must continue to meet it throughout life. In giving marks, dissatisfaction either on the part of parent or pupil can often be remedied by having the pupils keep a record of their own. This, however entails considerable loss of time in comparison of grades between teacher and pupil. Because of the imperative demand for time for the other routine duties both for pupils and teacher this method cannot gain extensive use. A good substitute for it, if there seems for any reason to be general dissatisfaction with the marks, is to take a few moments once or twice and mark a few pupils in public and upon that basis show the monthly averages that are possible in various subjects under different qualities of recitations. Many pupils as we all know are sadly devoid of any proper conception of what havoc a failure here and there during a month's recitation will create in that month's averages. Daily marking for whatever purpose is an exhaustive burden on the teacher especially if the class or classes are large. It is a source of wasted energy that often tells seriously on the quality of teaching. Too, its demand in order to properly judge results is questionable. What the school aims at is regular, constant and faithful effort, not a spasmodic one called forth when some appreciable object is offered for a prize. By such methods of reward we reward only the superficial in effort and do even that in a purely mechanical way, while that which is fundamental in education and in life, persistent effort, is generally left unrewarded and oftentimes unnoticed.

Commendation. Another form in which the desire of approbation shows itself is the desire for commendation. Commendation is the outward sign of appreciation of either well 
directed effort or successful achievement and is taken by those who receive it as an evidence of merit. Though commendation is a strong stimulant to gain renewed effort it is also capable of producing much harm unless carefully used. To begin with commendation should never be given except for work done by the use of will power and the expenditure of time and effort or even with some personal sacrifice. To be effective as a stimulant commendation must not be dispensed too freely nor for work that has not decided merit in it. The value of it depends too upon the general respect and esteem in which the teacher is held by the pupils. Here is a case, too, where the teacher's standard soon tells. If he bestows commendation for a poor grade of work or work imperfectly done, the pupil soon adopts that as his standard and often forms as a result habits of carelessness and neglect that follow him through life. As was said about marks and grades, here too persistence at work even though not always successful should not be overlooked. Commendations are particularly prone to arouse vanity. It forms an appetite that is whetted by satisfaction. In addition to this, commendation is especially effective with little children. Their whole soul can be aroused to activity by it. Since, however, the aim in school is to bring about work without stimulation, commendation should be applied in such a manner as to become more rare as the pupils advance in years, and the attempt made to secure results without an appeal to it. Private commendation where successful is to be more preferred than public commendation. In the former case it is valued for itself and obtains its strength chiefly through the influence the teacher exercises upon the child. In the latter the effort solicits the play of a desire for advantage over other pupils or perhaps again serves to satisfy some spirit of revenge that conditions in and about the school may have engendered. When it arouses these feelings it has passed its stage of usefulness and the best good of the school demands that it be immediately discontinued. Too often commendation descends to the level of mere flattery unstintingly bestowed. When this happens it is full time to call a halt. Nothing is so demoralizing 
upon the work of a school as cheap flattery in the hands of an indiscreet and gullible teacher. When commendation takes the form of emulation which it may well do with older pupils it becomes more powerful if properly handled. The elements of self-esteem and desire for excellence give to it this increase of power as an incentive to action. Its virtue lies in the fact that coupled with the other elements there is generally present a definite ideal toward which the pupil is working. It carries witlı it generous and honorable ambition. When these forces can be brought to bear upon a pupil to produce effort and successful achievement he is well on the road to a life of usefulness and is under the control of forces that are generally guaranteed to take him safely through. The use of emulation has its dangers too, chief of which is the begetting of wrong standards and selfish ambitions, but in the hands of a high minded, exemplary teacher it may arouse a spirit for study and create ideals in it that have given to the world some of its greatest men of science, art and literature.

Desire for Knozoledge and Efficiency. The intellect we learn from psychology is one of the "organs" of the mind, (a phase of manifestation of mind). Its functioning produces knowledge. Like every other organ it is endowed with an innate desire for activity. This yearning for activity becomes in the mental life a craving for knowledge which it is claimed is a spontaneous and natural principle of the mind fundamental in all intelligent beings. Like all other functions both physical and mental, the functioning of the intellect is especially active in the early periods of life. Like all other functions when they are given full opportunity for exercise, the organism receives pleasure. Mental pleasures are distinguished from physical pleasures in being perhaps less intense, but more enduring. The satisfaction of the desire for knowledge is a continuous process that may continue during the normal period of life of a healthy body and mind. It is true that the desire for knowledge and truth is one of the most noble as well as most enduring and useful desires that arises in the soul of man and one that actuates the men of science to wear themselves away in the 
search for new truth. It is also true that knowledge alone without its root in the more fundamental desire for approbation and the kindred feelings of esteem and personal welfare which they bring, would be a minor stimulant to intellectual effort. Knowledge in itself did it not bring with it access to the material goods of the world, high position, consciousness of excellence among our fellows and secret power above others, would become an object of little or no desire. Even the mere joy of knowing as an abstract quality is an insignificant stimulant to action unless it is known to bring to the possessor certain advantages not possessed by other men. The cravings of the mind are strong and are a sufficient reason for calling forth intense intellectual activity and lead often to self-sacrificing efforts in study and especially in research, that the uninitiated novice can never appreciate. But let it be abstracted from all other relations in life and be left to stand for its own sake and the previously unquenchable fire soon sinks to dying embers and is extinquished for the very want of sufficient fuel to maintain zeal. When it comes down to a fundamental fact nothing in life and its relation exists in and for itself, neither as force nor as matter. Nothing has any value for its own unrelated sake, not even knowledge. In other words take away knowledge from its relation to human activities, its effectiveness and power in human affairs and make it of no earthly value except for knowledge and it can be of no use or value to man. "If salt has lost its savor wherewith shall it be salty?" If knowledge is of no value except for knowledge, of what use or value shall it be except for knowledge? No man could be induced to waste his time in the pursuit of something that is of no earthy value unless he were an abject fool. If he were proved not to be a fool then at once you would refuse to believe that he was doing something that was of no value to him or lis fellows. 'This, of course, is contrary to popular opinion, but is basic notwithstanding. If the possession of knowledge served no end in individual life other than to satisfy a demand for functional activity it would fluctuate with the rise and fall of bodily energy and would in its turn depend for its power upon lack of satiation. But this is 
not the case in practice, there, the desire generally so overruns the supply of the bodily energies that oftentimes exhaustion, sickness and breakdowns resulting in death occur. It is because of its universal relation and theoretical control of these relations that makes it truly the most desirable thing in the world and consequently causes the sacrifice of all else in the world to attain it, even health and sometimes life. Seen in this relation by only a few it becomes the wherewithal in life to the few. Whatever be the qualities of mind different from those of matter, mind cannot get too much food (knowledge) in its mental relations unless perhaps in those cases of morbid activity that are not normal but diseased states.

Because the desire for knowledge is natural and its satisfaction keen, the use of it as an incentive to the pursuit of knowledge must of necessity be of practical value. To this end the teacher should bend his every effort. Daily evidence of the practical value of knowledge may furnish a beginning. When this has become effective theoretical values of knowledge may be taken up. The gaining of knowledge, however, is not a pleasure, in fact it is impossible unless there is activity, sometimes intense activity, enforced to the point of bodily suffering. As an organ in the knowledge getting process the intellect must function. No doubt neither knowledge, nor any amount of activity of the faculty of knowledge on the part of the teacher, is knowing for the child. His own intellect must act for itself and knowledge is the result. To impart knowledge a teacher must arouse the intellect of the pupil to action. Anything other than this is a misnomer. We must work upon the desire for activity, arousing it to action either normally or abnormally, naturally or unnaturally and then keep it aroused and active by means of various stimulants until it functions appropriately for itself, when the only demand then is that the activity be directed along the proper channels and the material for the activity be supplied in such a manner and amid such conditions as to make the activity pleasurable. Everything else will be assured, natural mental activity can be entrusted to nature. 
As a matter of fact the intellect begins to function at the beginning of life. The desire is there naturally and since the whole environment furnishes material the intellectual activity is well on its way when the school age is reached. The trouble begins here because the school processes so interfere with the natural processes as often to clog or cram the intellectual machinery in such a way as to materially hinder its action or even stop its normal processes. Then it has the burden of reawakening activity by artificial processes which have all of the weaknesses and foibles of artifice against nature and the activity drags on amid theory and practice until the child either is finally gotten back into the right track or is ground out by the process an unfinished product to shift for himself in the more extensive world processes. In the complex life of to-day which is far from what we call nature, many unnatural things are necessary. This is true of school processes. Much of school routine is, and of necessity must be contrary to nature. In school nature and artifice (art) must mix. The danger lies in attempting with the young child in the lower grades to make the transition from nature too suddenly, so suddenly that we interrupt and destroy the methods of nature before the methods of art have gotten a working hold upon the child intellect. If this danger could be overcome all would be smooth sailing. At least, however, the teacher can advise himself well of the methods of nature and begin there and make gradual transition to the methods of art. This would make a revolution in many cases in methods and in still more cases, in results. Teaching to-day is too often false and artificial. As a result its efforts too often end in corresponding failure. Activity is a normal condition of life, when this is made possible by nature or by means as nearly like those of nature as is possible, or by methods of transition sufficiently gradual to enable a gradual transformation of nature. When this change in methods comes so suddenly as to check nature, the processes cease to bring natural pleasure strengthened by a consciousness of normal development added to a feeling of skill and power. These latter may then be made the source of secondary or derived pleas- 
ures in activity whereby the ends of education may be the more readily and casily served.

Love of Honor and Right. Love of honor and right are again both high forms of the basic principle of love of approbation. In fact they are stronger forms of it than those forms of it mentioned above. Of course, right doing has its own reward in the moral and intellectual world apart from the superficial reward which men accord it. The very fact of its being right in the generic sense of the word makes this a logical necessity. It is only because right doing has its own reward that it is designated right. Apart from this, right doing is rewarded by the fact that it is taken as an evidence of certain qualities of excellence, power, esteem and a successful pursuit of certain ideals common to civilized man, but which are attained in various degrees by different individuals, that make it a source of approbation primarily in others and secondarily in self. If a child can be brought face to face with the fruits of right conduct that accrue in the very nature of things, that would be the highest standard attainable. It is satisfactory, however, if he even be made to appreciate the values of right doing for the good of his fellows. As the appeal to the desire for approbation is one that is easily made and readily effective, its pedagogical value in the schoolroom is inestimable. Care must be taken always in this appeal, however, to see that the proper conception of right is present. Children in the home, on the street and in the school get sometimes not only crude and misleading conceptions of right, but even harmful conceptions of it. There are still others who have little or no conception of it at all. While the teacher must see daily evidences of the standards of right and wrong manifested by his pupils, in order to assure himself that all is as it should be, he should interest himself to find out wherein the standards are different from his and wherein wrong or low, and take pains to correct and elevate them. It is surprising to find out sometimes what low standards some pupils have, as well as, what high standards other pupils have. Especially are these facts more likely to come to the front in games and competitive contests than elsewhere, 
when the conflicting interests of self and others meet. These are sometimes more prominent in the games of boys than those of girls. The fact is the school child's code of morals is more often one of expediency and convenience than one of right, with self as the center from which all judgments emanate. The chief lessons necessary for pupils in right doing are to respect the rights of others. Because perhaps of the biological relations between egoism and life in the young, the interests of self seem to predominate and the young require careful instructions in their relations to others and their own rights in the premises. The duty of the school here is clear.

Closely interwoven with the question of the love of right is that one of the love of honor. The real value of this feeling as an instrument of control in the schoolroom and an incentive to perform the duties in the various forms of school routine and school exercises can hardly be overestimated. How universal and powerful the desire for honor is but little appreciated. Even in the most depraved, some sort of an idea and code of honor is present. The band of robbers and the den of thieves each has its individual code of honor. The code may not be one to which we would subscribe, but it suits their standard and all of the group generally own fealty to it. The first thing, then, for the school teacher to do is to see to it that the standard of honor among his pupils is proper and of reasonable elevation morally, not over the heads of the pupils, in which case it will have little practical value for them, but as high as possible for the greatest appreciation and best good of the pupils. If this is below his standard once he gets the pupils consent to it he can easily take steps to elevate it. Most pupils have a keen sense of honor. So keen is it that when it has been developed in the wrong direction it is often difficult for the teacher to control the situation. Many a teacher has experienced difficulty at some time in his work in getting pupils to "tell" on one another. But although "tattling" is always obnoxious to the true teacher and therefore to be discouraged there are times when it is necessary to know the truth in a given case. At this time no false sense of honor should be 
allowed to obstruct the course of justice in schoolroom discipline and punishment. The difference between tattling and giving desired information when asked for it directly if not fully appreciated can easily and readily be made clear. A high sense of honor with power to distinguish it in its desirable and undesirable form should always be encouraged and where absent every attempt should be made to arouse it. Let every pupil know what you think of his honor and what you think it ought to be. In whatever respect it is wanting it will probably be not found so long. The history of pedagogy teems with cases illustrating the efficacy of putting faith in pupils and of letting them know that you trust them. The general experience is that they respond generously. The love of honor always proves especially valuable in maintaining discipline and obtaining good government. In fact personal honor and integrity is the principle on which the practice of self-government in our various institutions of secondary education is based. It is of particular value in democratic forms of self-government, where each citizen is placed upon his merit and where the institutions of the state are dependent for their perpetuation upon the honor and loyalty of each citizen. Love of honor ought, therefore, be especially in schools of democratic countries. In the administration of the affairs of the school the love of honor of a pupil is sometimes put under considerable strain because at times it becomes necessary to appeal to a pupil for testimony against himself or his best friend. Here the love of honor is put to a severe test, but if it is fully appreciated and the pupil awake to his relations in the matter, the response to the appeal of honor will be satisfactorily forthcoming. By many, such a situation is based upon a false system of school government and is accordingly condemned. When such is necessary that justice might prevail, it is hardly deserving of a judgment of condemnation. The real fact in the matter is, that the child should be taught not only not to shield himself in the wrong, but also not even to shield his brother, sister or best friend. Let him know from the start that it is unmanly and damaging to character to do wrong but it is far worse once the wrong is done to attempt to shield one- 
self by treachery or falsehood. Wrong and punishment should be so associated in his mind that when he does the one intentionally the other must and will follow. If he comes to this attitude about himself there will be but little trouble in getting him to reach the same conclusion about his friend. To do wrong is to merit condemnation and punishment, but to commit one wrong and then attempt to cover this by another wrong is deserving of double condemnation and punishment. Besides the deception in covering up the wrong is more damaging to character than the committing of the act itself. 'These aids to love of honor might become very powerful. If, too, the teacher would carefully discriminate in punishments based on the willful intention of the pupil to commit wrong he will find out that an appeal to his honor for the truth will be much more readily effective.

These are a few of the incentives and stimulants in practice in the school to excite educational activity in the pupils, with relation to the fundamental spring of human action morally considered, namely, the love of approbation, also these taken in their relation to the method of applying them, and their effectiveness when applied in producing the desired ends in education.

REFERENCE READING

King's "Education for Social Efficiency." Chap. VIII.

White"s "School Management." P. 130. 


\section{CHAPTER $\mathrm{X}$}

\section{ROUTINE AND ACCESSORY DUTIES OF THE TEACHER}

There are certain routine and accessory duties which all teachers find it necessary to do in order to have their work attain any degrce of perfection and efficiency. Both experience and observation have gone to show that while these duties must never be allowed to descend to the level of mere mechanism, they must be performed constantly and seriously by every teacher if the work of the school is to be of lasting benefit both in a general and in a special sense. Of these the routine duties are more or less elaborately worked out and in general are practiced everywhere, the accessory duties cover a more recent field of activity for the teacher. Their limitations are not yet clearly defined but during their still early period of growth they have already shown that within their confines there are numberless ways that they may both augment and intensify the influence and work of the school. The best evidence that we can produce of the effectiveness and helpfulness of these accessory duties to the school, is the fact that everywhere their need is being preached and the wholesome good they are doing being advertised, all resulting in the rapid and almost phenomenal spread and organization of these forces for educational purposes. These accessory duties of the school teacher lie in the field of activity and cooperation with such movements as civic clubs, mothers clubs, neighborhood and community assemblies and agitating other movements and assemblages which look to human uplift and give aid to the constructive forces of education as controlled and directed by the school.

\section{ROUTINE DUTIES}

Opening Exercises. Not all, nor even the greater part of the routine duties of the school can be mentioned here to 
say nothing of discussing them. Indeed only a few of the more important can receive our attention and only enough will be said of these to show what the general nature of these routine dutics is and how their faithful performance affects the general welfare of the school and the working efficiency of the pupil. The first of these which will be dealt with, is the matter of holding opening exercises. To begin with opening exercises have been worked into the work of the day as a moment for "getting one's sclf together for the schoolday." Because of this there is never much time to be devoted to them. However, it has been made clearly evident that these opening exercises may be made the occasion for much opportune and helpful instruction in work not otherwise provided for in the school course and thereby become an elevating influence both on tcacher and pupil. Besides these, the opening exercises furnish a splendid opportunity for religious instruction. Religious instruction as such is sadly absent from many of the homes from which the school draws the majority of its pupils. In some homes there is outright indifference and even open opposition to the religious sentiments. In others it is merely neglected in the rush to meet other demands of life. But whatever may be the theoretical objections to religion on the part of any one, none can seriously or effectively deny that practically religion is a potent factor in controlling the actions and affairs of men. Chiefly because of the ignorance of the child, the crudeness of his knowledge and beliefs and the fact that he is psychically, mentally and morally in that historical stage of the race when religious beliefs held full sway and dominion over man, the child is particularly susceptible to the controlling influence of religious truths and religious sentiment. In the carly formative period, when the impressibility of the mind is great, it is highly essential that the foundation of religious zeal and devotion be implanted in the child whercupon may be built a strong mental and moral superstructure. Of course this country is a republic and because of its conception of human rights tolerates every form of religious sect and creed that there is, so long as its operation does not interfere with the proper adminis- 
tration of our civil and political institutions. This makes instruction in religion so far as the teaching of any creeds or dogmas is concerned impossible in the state system of schools which are maintained by the taxes levied upon and collected from all of the people alike irrespective of religious views and adherence to sects with their various creeds and dogmas. But it does not and should not prevent the conducting of devotional excrcises in all of our public schools where proper love for God, respect for his laws and faith in the teachings of Jesus can be carefully instilled into the minds of the children of the country. This is perhaps the primary reason for holding general exercises during the day for the children. In some sections of the country the general sentiment of the community is against the holding of devotional exercises in the school. So strong is this adverse sentiment in some sections that it has resulted in the enactment of laws against it. However, even with this done it can hardly be claimed as sufficient grounds for not having some form of general exercises at the time when the entire body of students and teachers can be together, even if local conditions and problems should demand the holding of these exercises at another hour of the day than at the opening hour, that is more convenient for all. If the holding of opening exercises were justified only on religious grounds, in these sections where sentiment or statutory enactment prevailed to prevent these, there would be little further need of opening exercises. But opening exercises or when this is impracticable or impossible later hours of general assemblage have other functions to serve almost equally important. There is much other good such general gatherings of teachers and pupils may do. In the first place there is the general socializing tone and influence of good fellowship which it exerts over all. If at that time deference and regard in seating is had for the respective grades of pupils, such gatherings may serve to quicken ambition and stimulate to wholesome activity all of the egoistic emotions and many of the altruistic emotions which react most directly upon the more general feeling of love of approbation. Again these gatherings may be made the occasion for various forms of special 
instruction not otherwise provided for in the course. In the higher grades where separation permits this may be extended to procuring outside talent for special instruction along a chosen line. Instruction in manners and morals may be profitably given at that time as well as instruction in the general rules and regulations governing conduct in and out of the building on and off the grounds and the method of their application and enforcement. The hour of the opening exercises may also be made the occasion of determining punctuality and attendance of pupils. Especially is this true where there is departmental work and no other general assembly room where the supervision of attendance may be had. From the viewpoint of discipline these assemblies for the opening exercises have further justification. They offer an opportunity for the students to come into contact with the governing power, the principal, for example who will generally preside at these meetings. They will also do good by bringing pupils into closer contact with the assisting teachers whom the pupils would perhaps not otherwise learn to know until years afterward, if at all. Where these opening exercises are held in the separate rooms the individual teacher can so enforce his personal magnetism as to make these gatherings a time of close communion and understanding, and, so interesting that they will become a time pleasantly anticipated by all, ushering in the day with a happy beginning. Under ordinary circumstances the general value of this kind of an exercise in relation to the other work of the school can hardly justify the use of more than from five to fifteen minutes of the school day for it. Nor would less than five minutes be of much profit for such an exercise. The mean average general in use for these opening excreises is ten minutes.

Length of School Hours. The questions of the dismissal of students and the length of time that they may safely be kept in school to insure the meeting of the greatest number of ends are without doubt next in importance. If not so, they are at least logically next in order, what is to be done with them while they are in school being treated of in other chapters. The dismissal of students is a matter to which 
much less time and attention is paid than to the opening exercises. All authors on pedagogy unite in advocating that the hours of the primary pupils be shorter than those of the older pupils. Where they all assemble together this necessitates their being dismissed before the higher grade pupils. Oftentimes however, if it is found necessary to dismiss the lower grades before the higher grades because the smaller children who desire often to play with the older ones sometimes get hurt or are "bullied," receiving rough handling that causes complaint from parents or guardians or from outsiders, merely passersby. Oftentimes, too, this same condition arises with different grades of the larger pupils. Once in a while it extends to different school buildings. Sometimes a demand is felt for a change in times of dismissal of a class or of a whole school because of differences arising from the merest trifle between pupils of different buildings. Especially is this the case when there are schools for separate races, or in congested districts where there are large foreign elements in the population. Such friction has been known to cause serious trouble even provoking the calling of the civil authorities. In such cases the expedient of having one school open and dismiss sufficiently earlier or later than the other in order to give all of the students of the one grade or building time to scatter or get home before the others are dismissed is of ten tried with success. Where they are all of one building but different grades the demand for making the school hours of the little folks shorter resulting in their being dismissed from school earlier generally solves the problem. At least, it permits those in authority easily to lay the blame for the happening upon the really guilty one. Other expedients where the troubles arise between the respective grades or pupils of other buildings such as having one set of pupils restricted to one side of the street, especially if of another building or district; or the expedient of having one set come and go from one corner and the other from the opposite corner have also been known to give satisfaction when tried. The school period is usually from nine to twelve and from two until four. This time being shortened from one half to an hour and a half for the primary grades, with 
recess periods corresponding to the grade. Some schools also have half day sessions while others begin earlier and hold later having one long, continuous session.

The Kecping of Grades and Marks. The question of keeping grades and marks has always been a cause of much discussion among school teachers and school authorities. The question is not so much that grades should not be kept, as it is how much keeping of grades is necessary to bring about the highest degree of efficiency in schoolwork, it being assumed that by using grading as a means of producing satisfaction in the mind of the child and creating in him renewed interest in and satisfaction with the work the quality of the work of the school is improved. Experience has taught that it is difficult for the teacher always to remember just what a given pupil deserves in a certain subject during the course of a month, especially if marks are given in numbers of two or more digits. When the marks used are symbols of one digit up to and including ten the case is less difficult. This represents a more general equality in marking, one that is more satisfactory and that will give more justice to all, that is much less laborious and which may be readily given at stated periods instead of during or immediately after each recitation. However, whatever system is used they should at all times be well understood by the pupils. Where rewards are given or the grading system is used as a means of stimulation and for the purpose of working upon the spirit of competition to more or less extent present in all pupils, in order to assure justice and satisfaction to all, a more exact system of grading is necessary. This is perhaps the basic justification of the system of numbers of two digits in keeping grades, and especially those of three digits which under this system of competition sometimes become necessary in order to decide " who is who" in cases of close competition. For mere promotion such an extensive and laborious system of keeping grades can hardly be justified, especially where the system is rational and not mechanical.

Of course, where the pupils are promoted purely upon the grades they make, with no reference to their general or even special ability, or without the question of whether or 
not they can do satisfactorily the work of the next grade, these elaborate systems of grade keeping may well be a necessity. But where the quality of the work done by a pupil during the whole year and his general efficiency in the work together with his ability to do the work of the next grade satisfactorily to himself and the teacher, are the prominent factors in the question of promotion, then, of course, the keeping of grades becomes secondary and is used merely to serve as a general guide to the more mature judgments of the teacher. When grades become the determining factor in all school promotions they become the sole goal for which the students strive and the means in education become substituted for the ends, while the ends are lost sight of entirely. Education then becomes a failure and its processes worthy of the severest condemnation. It is a fact, however, that for the sake of justice there must be some keeping of grades. Oftentimes where the teacher's judgment is to be trusted entirely, the nature and occasion of the mistakes and neglects of pupils serve to magnify them as evil, while on the other hand like causes serve to minimize them, in each of which cases injustice obviously is done. Again, with time the kind of recitation made by certain pupils is lost sight of under some circumstances, while those made by others are easily remembered, all without any evil intent on the part of the teacher. Further the grades made in a given subject immediately preceeding the time of recording marks may become the determining factor in the marks, while those more remote are forgotten, thus again doing injustice to all, to some by their getting the good out of the more recent recitation and failing to get the bad out of the more remote or vice versa. Thus we see that for the best good both of pupil and teacher an accurately kept system of grades is necessary; necessary to the pupil in order that he may feel sure that he is getting all that he is earning and also that he may know that he is being watched in his work from day to day; necessary to the teacher in order that he may be sure that he is dealing out justice alike and at the same time protecting himself from any unfair criticism. In all of this he will have at all times in his possession a very powerful means of stimulating the pupils 
to good work. However, when it comes to the mere question of promotion much of the mechanical method of employing grades to determine whether or not a pupil should be promoted as was said above, might be done away with in most cases with better results. Especially is this true when it comes to examinations. When an examination really covers generally the work gone over by the pupil it may be taken usually to represent the student's knowledge of the subject and his ability to master it as well as the quality of teaching he has received in it. But regard must always be had for other circumstances entering into it to determine the result which a careful teacher who knows his pupils can easily detect. Pupils of a nervous temperament need never be expected to do themselves credit in cases involving great nervous tension, as the very mention of examinations will probably exeite such natures and cause them "to go to pieces" and "forget all they ever knew" about the subject matter. Sickness or general debility will also enter in as factors contributing to determine results. In all such cases greater satisfaction will be found to result if due allowance is made for the pupil when the facts are evident.

One of the objections to the present extensive system in grading and the keeping of grades is its wear and tear upon the teacher by the amount of clerical work it entails upon him. This situation has to some extent been relieved by the use of printed forms supplied by the school authorities which only require filling in and signing by the teacher. But even with this there is still enormous work to be done upon the reports before it is time to fill in the blank report forms. There must be adding and dividing to obtain averages. This work must be correct. That is an absolute necessity. Now imagine a teacher with fifty pupils (many have a hundred or more), each having on an average six different subjects for marking. Add to this attendance, punctuality and deportment. There are fifty cards to be filled out and averaged up requiring six, eight, ten or more hours of work. If the time could be had for this work in anything like reasonable amounts this would not be so bad. But most of it has to be snatched up during the school days and evenings 
at home between times in amounts often of ten and fifteen minutes. The recording of the marks of the day will take up all of the spare time of a teacher. Now if for the sake of convenience weekly records are made the teacher will have practically all of his extra hours taken up. Fortunately most grade reports are made out by the month, which does help some. But still the strain is great, much too great for one already so heavily taxed as a teacher. In addition to these, there are the term or semester, and yearly reports, both the grade reports to parents and the grade and official reports to the school authorities, to be made out. Many a teacher has gone into the schoolroom, vigorous and strong, bright and cheerful but a few years of this grind has brought him to the stage of the proverbial anaemic, sallow in color and lifeless in action, a bundle of nerves and a magazine of abnormally stored energy, that wins for school teaching the name of the "drudge " profession and for the teacher the name "scold."

These reports are not without their purpose in the plan and process of education, but the question concerning them naturally is, is the purpose they serve sufficiently urgent and mandatory to warrant their preparation at such an enormous cost to the vitality and working ability of the teacher? The teacher who spends his out of school hours even into the night perspiring and fretting over " averages" and " reports" when he lies down to rest is too overwrought to soon go to sleep or when asleep to get much rest and recuperation out of it. Without this rest and recuperation from sleep and with a constant demand upon his energies in the schoolroom day after day he soon wears away under the grind and is in no way prepared for matters of discipline, punishment nor even for matters of instruction. The result is that the school work suffers and the school runs down while the teacher gradually becomes unfit for the proper performance of any part of his work. Besides this, the time for home study and home preparation of the lesson so necessary for successful teaching is taken up in this way and the more important duties of the schoolroom pay for it. Of course, the parents through reports learn just what their children are doing in 
the school in a way and the school authorities - the principal, superintendent, commissioner or board - also get some idea of attendance, enrollment work covered, etc., while the pupils on their side get some idea of their progress and may guess whether or not they are likely to pass. But many a parent signs the report without even looking at it and returns it; or he instructs some older brother or sister to do it, or he may even leave the report for the child himself to sign and return. Whereupon the whole aim of the teacher in doing and the school authority in having done, this enormous amount of work that has cost the teacher so much in time and effort being thus lightly cast aside without any material effect upon those for whom it was prepared, fails entirely. In many cases it is true, the report is carefully examined and the sending of a report means much both to parent and child. But the question is, does it pay to place such burdens upon the teacher at such cost to hin in health and working efficiency? Principals, superintendents and others in authority must have reports in order to have direct knowledge of the working of the system and be able to properly administer and direct it. In many cases taxes are assessed and appropriations made for the maintenance of the school, which funds are pro-rated out with the facts contained in some of the reports, demanded by the school authorities, as a basis. These reports then would seem to be necessary for the very existence of the school as it exists under our present system of administration. A fact that serves to some extent to compensate for this form of report making and clèrical work constitutes one form of its justification. So that, while much of this form of work entailed upon the teacher seems to be necessary, it is a fact that it induces upon him a serious and constant expenditure of energy so much needed for other work. It follows, therefore, that if for no other reason than for the sake of the schoolwork proper and the health of the teacher these duties ought to be reduced. The system of making reports should be reduced in the frequency of issuing reports and the system or marking so changed as to give some noticeable relief. If this change reduced the number of stimulants applicable 
to obtain good work others should be invented that will bring out desired results. These a resourceful teacher can readily invent, there being too many means already known to need mentioning here.

Another time problem with the teacher is the question of correcting exercises at home. Much of the work of the class is such that work leading up to it or arising from it must be done outside of school hours by the teacher. The demand for teaching in the schoolroom will not permit its correction there, and in general the duties of discipline and punishment in the form of detention after school together with the keeping of daily records of the recitation, attendance, punctuality, etc., make it impossible to correct it after school hours. The remaining alternative is to correct the work at home. This then becomes another tax to sap the teacher's strength and vitality and reduce still lower his energy remaining for the work of the schoolroom. Of course there is good in it and the work the next day can progress better if the grades and papers are ready for the pupil and he can learn of his mistakes and the manner of correcting them. Too, once work of this kind is taken home for correction, in order that the student may not get the idea that the teacher is lax or that that kind of work is not important and because of it grow indifferent to it, it is necessary that the marking of them be carried through and reported back as soon as possible to the pupil. Happy and fortunate is the teacher, therefore, who can reduce this kind of work that he cannot devise means to correct in the schoolroom, to a minimum without sacrificing the essential ends of the school processes. Both for his own best good and that of the school he should not be overtaxed by such kind of work. There is much virtue at times in having the pupils themselves correct their own exercises within the recitation period, each correcting the work of another and returning it, the teacher supervising closely and directing the whole. This, however, has its dangers and may at times lead to ill feeling between the students and sometimes to injustice, but a watchful teacher can readily detect all evil tendencies and check them before harm is done. Especially, if he never lets the work 
get entirely away from him and looks over the work freely either while it is being done or afterwards. To its credit it might be said that this practice will tend to give the pupils an insight into the methods of the teacher and at the same time will tend to bring the facts of the lesson before the pupil in a new light, thereby serving to make the facts more easily retained by the pupil.

About the drain of these routine duties outside of the school hours upon the teacher there is much to be said. While the keeping of grades is necessary for the proper estimation of the amount and quality of work each pupil does and figures more or less prominently in his promotion from one grade to another; while the correcting of work at home is to some extent necessary for the successful and proper administration of the system that regular reports be made to the principal, the superintendent and others in authority, in fact while it may be necessary for all of the little routine duties of the schoolroom to be done, it is equally necessary for the instructing work of the school and the discipline and punishment incident thereto that the burdens of the school work outside of school hours, upon the teacher be reduced to a minimum, and that minimum which must be done without further reduction should be facilitated in every way by the various mechanical devices available, in order that the teacher may have as much of an opportunity for study and preparation of his daily work and the husbanding of his strength for that general good nature, poise, sympathy and high degree of scholarship both in the specific knowledge of the lesson and the broader field of fact so necessary for good discipline, good control and successful instruction. If it is true that without this drudgery work little effective teaching is possible, it is equally true that with it there is so fearful a drain on the energies of the teacher that even when the work is reduced to a minimum by such available means as printed blank forms it still so taxes the teacher that his force as a factor in the schoolroom work is so weakened in time by them, until it is a question as to which should really be given precedence. Since the latter effects are not secondary for the schoolwork and primary for the liealth of the teacher and the proper 
education of the pupil, it is unquestionably better that if either one is to suffer that this mechanical work suffer if to no greater extent than by a reduction in quantity. Unfortunately there are no statistics either upon the health or mortality among teachers, but certain it is that these facts are potent in affecting both the health and mortality of teachers. Apart from this, a fact that is even more important to school authorities, the drudgery of schoolwork especially in this line of duties in conjunction with the matter of salary is the cause of making the profession of teaching only a stepping stone to other professions with a wholesale defection from it into them, a fact which is a source of great inconvenience and hindrance to the processes of education along all lines and in all grades of the work.

\section{I. ACCESSORY DUTIES}

Professional Courtesy Among Teachers. The subject of the accessory duties of the school has not received attention widely from the authors of textbooks on this subject. However this field is growing and more likely will be considered of an ever growing importance to the general success of the school. The subject of professional courtesy among teachers though it has always received much consideration both with tongue and pen, has seldom been considered a duty of the teacher, much less has it ever been considered in the light perhaps of an accessory duty of the teacher. Let it be said, however, that the spirit of professional courtesy among teachers is growing. But needless to say it will still stand considerable improvement. In medicine professional courtesy is at its height, among men of the professions. Lawyers also appear to maintain a high quality of professional courtesy among themselves. Members of the teaching profession have not, it seems, arrived at the same high point of courteous consideration from their fellows, although it is a contemporary profession with law and medicine. This charge of lack of professional courtesy may be borne out in truth by fact, or it may be that simply because the teaching profession is a circumscribed restricted and much "bossed" profession the agents here not having the same freedom in 
action and method nor finality in judgment that the other sister professions have, the fact of lack of professional courtesy among them may be only a semblance brought out by this restriction under which they are employed and work, while at bottom law and medicine, as professions may suffer as much from the lack of professional courtesy as does teaching. Too it might be charged that the teaching profession is overcrowded and competition is resultingly closer. But, whatever the causes, much of the ill-repute that has fallen upon the profession and much of the weakness and foibles of the "professors" have been heaped upon it by members of the profession themselves. The teaching profession is often degraded by incompetent material and often " purged " of competent material by the small salary paid for the amount of preparation and work demanded by it. But it must ever remain true that teaching is one of the highest and noblest if not the highest and noblest of the professions known and open to men for practice. We often hear poet, press and public extol the sacredness of the teaching profession, but few of us ever give to the matter consideration sufficiently serious to gain anything like the true appreciation of the real meaning of teaching to civilization and humanity. Teaching as carried on by the school of to-day is a highly developed method of systematized world progress. Without the processes of the school the world of tomorrow would be without material for its myriad activities and without competent leadership in its many crises and critical periods. With poor or meager processes the material for adrancing civilization becomes correspondingly poor and meager, and progress itself is endangered thereby. The responsibility resting upon the school is a serious one. The cause, therefore, which the school espouses is a lofty one. All the more merit attaches itself to the laborers because the work must be done with conparatively slight pay. With the exception of preaching, teaching is the most poorly paid of all the professions. Agitation has done much to increase the salary of the teachers, but much still remains to be done. All of these drawbacks should serve to unite the school teachers more closely and make them more loyal one to another. As a profession teach- 
ing will never come into its own until teachers show more courtesy and respect professionally one to another. The consciousness of a common but high calling, community of interest and labor together with a united and aggressive opposition always leading the attack and assailed on all sides, if the profession expects ever to attain its own, it must unite within its own ranks, develop professional faith and courtesy and meet the common enemy with a united front. For no profession is so constantly on the carpet for complaints and fault finding as school teaching is.

These words, however, must not be mistaken as a plea for "clannishness" among the teachers. This is not meant, nor is such even advisable. This would bring upon them renewed opprobrium and not undeservedly. What is meant by this is a plea for teachers to uphold one another in their methods and honest, sincere practices, lindly forbearance one with another, fellowship at all times and encouragement. Nothing is so good but that it has a soul of badness in it; nothing so bad but that it has a soul of goodness in it. Method by which one teacher succeeds will fail utterly in the hands of another and vice versa. Neither all of the good, all of liuman capacity for the performance of labor, nor all of the means with which to do, rests with a single individual or group of individuals. Considering these facts many a time a word of encouragement and support wisely spoken will be the cause of tiding a teacher over a serious difficulty. Teachers should cultivate high motives and high standards each for himself and expect the same for others, always judging the acts of each other by this standard set up for self. If teachers show that they have little or no respect for each other's worth they have no reason to expect the general public to do otherwise. Unfair criticism here is ruinous and very little criticism even though it may be just is damaging, to all. Patrons and pupils are both quick to perceive any evidence of depreciation of one teacher by another and generally equally quick to turn such a state of affairs to advantage. Many a case of severe punishment and discipline has been made necessary in the school room by some word or outward sign of criticism or disapproval of one teacher by another 
teacher in the presence of a pupil. While untold humiliation and even loss of position has fallen upon teachers through unkind and unfair criticism from their fellow workers. Principals suffer more personally from this lack of professional courtesy than the teachers do. It is distinctly human to feel that we can do something better than some one else, or that if another method which appealed to us, but not to the other fellow, had been followed, all would not only have been otherwise, but better. The point is, however much we may feel so, we should express it but little if ever and by all means it should be said nowhere, where it can possibly spread and in time affect the general influence of the individual for good. Teachers all owe it to themselves, to their fellow teachers, the pupils and the profession at large to cooperate loyally with those with whom they labor and at the same time to do all they can to improve the standard of the teaching profession. Miscellaneous criticism is bad at all times, but especially is it bad when it falls upon inexperienced or malicious ears, however well intending, honest or even deserving the criticism may have been.

Professional Organizations Among Teachers. A great movement that has served to increase the professional spirit among teachers is the formation of various forms of teachers' organizations, such as the 'Teachers' Associations, Institutes and Reading Circles, etc. Through these communion and fellowship, exchange of views and experiences, hearing of lectures and receiving of special instruction all tend to increase professional ability, raise professional pride and establish among teachers a community of feeling and interests made possible in no other way. Teachers' associations are being organized everywhere in state, county and city throughout the country. Patrons and school officials are seeing the need of them and are appreciating the good they do to such an extent that they are not only approving of and encouraging them but they are making attendance upon and membership in them compulsory, even in some cases going so far as to pay for the extra attendance upon them or to withhold salary for the session when the teachers do not attend. In many instances they also appropriate moncy for securing compes 
tent talent for proper instruction along various lines. Once in a while it is true sessions of these organizations descend to the level of mere political gatherings, where the struggle for office overshadows all else, but happily such sessions are the exceptions rather than the rule, thus not materially affecting the capacity of these organizations for good educationally and otherwise both to the teacher and the profession.

Home Visiting by the Teacher. The question of home visiting sometimes becomes a potent consideration with the school teacher. Many teachers have not much use for the method and we must confess that it does not always bring the results hoped for. At times it has even been known to make matters of discipline and work in the school more difficult than before. But even with that it is a practice commonly in vogue and has its good results. In the hands of a skillful teacher it has been known to help to tide over many a difficult situation. If it does not do anything else but give the teacher an insight into the home life and surrounding of the child and the nature and temperament of the parents, the instincts and tendencies which the child has inherited, thereby awakening in new channels the teacher's sympathy and widening his understanding as well as showing just how much cooperation the teacher may expect from the parents in managing the child it has more than paid for itself. In doing this much it will have put the teacher well on the way toward a full mastery of the situation. Very often it is found out that brutality exists in the home in which case kindness will probably bring a good side of the child to the front. Other parental peculiarities may be observed which may serve to throw some light on the nature and habits of the child. Very often, because there is no opportunity for home study or encouragement of it, home work from the pupil when not done can be understood and handled so as to win the child to more successful efforts. Again when there is no sympathy with the school and the influence of the parent is exercised to disinterest the child and have him stop school, counteracting forces can be set to work to win and hold him. If it is a matter of personal cleanliness a visit to the home will enable a tactful 
teacher to save the day with the pupil. If the home influences have produced any mental peculiarities in the pupil that are hard to manage, or if heredity has wrought badly, in eitler case such knowledge can enable the teacher to readjust his judgments and try out his problem in a new way with more hope of success. 'To obtain this information would more than may any teacher for a visit to the home of a pupil. 'That there is a large possibility of good in the practice has always been known and recognized. For it is a practice that has to more or less extent always been advocated by expericneed teachers, principals, superintendents, school authorities and writers upon the subject.

In visiting the homes of pupils there are still other good effects that recommend the practice favorably to the minds of most earnest and well intending teachers. Oftentimes for example physical defects appear in the child that make against him and which it is evident the parent has never noticel. $\Lambda$ visit in regard to them therefore will of ten become necessary. Furtler it often becomes advisable to visit parents and learn of the peculiarities of pupils, especially where such marked peculiarities cannot be learned from other teachers. Well disposed parents are often glad to note that teachers are sufficiently interested in the welfare of their children to visit them, especially if the teacher comes to make a good report instead of a bad one. Family pride, a perennial reason for putting spurs to children in school work is often aroused in this way. Then, too, the parent can "get to know" the teachers in this way, a fact that oftentimes proves to be a valuable asset in the teacher's behalf. It is never encouraging for parents to sec a teacher only when there is a complaint to be made. An introduction under such circumstances is always an unfortunate one, if not indeed, a bad one. And even in cases where there are bad reports to be made the sting of it may be removed by showing at the same tine what good there is in the jupil and contrasting it with the bad, using the whole as an argument why the bad should be eliminated and why the parent should assist in bringing this about. A hopeful tone is always beneficial, especially when accompanied by cheerfulness. Bad reports should not 
be made too often. Few parents are willing to admit that their child is wholly bad and hence incorrigible and to attempt to convince them of it is a difficult undertaking fraught with danger for the welfare of the teacher. If the home visit does not bring the desired results, the situation is up to the teacher and he must handle it in his own wisdom and at discretion. The teacher should always possess and show keen interest in lis work and that of his pupils and carry his enthusiasm into every home that he enters whether on a sad or a pleasant errand. This will not only beget both confidence and support in return but will awaken in the members of the home a kindly reciprocal interest in the success of the tacher. 'This responsive attitude in the home will improve steadily, also, if the teacher ean on such occasions be naturally practicat in his understanding of children and how to work with them. However, this matter of home visiting and seeking openly aid from the parent must not be carried too far. Parents prefer to feel that the teacher can manage the situation umaded by them. Such parents may regard such appeals as an evidence of weakness on the part of the teacher and beeme dissatisfied patrons instead of satisfied ones. Also many parents do not wish to be annoyed by the teacher about their child or children and the school processes. These parents have sent their children to school to get rid of them and they wish that you keep them and control and teach them without annoying them with the problems that arise in this process. Where these suggestions are considered and acted upon home visiting will be found to have virtues that those who have never practiced it can never imagine.

Arousing an Educational Spirit. Very of ten teachers go into a community to teach school and find the school interest dead, enrollinent small and habits of attendance bad. The cause of this upon investigation will be found out to be either lack of interest and financial support by the school authorities, or by bad practices either morally in administering the affairs of the school by those preceding, or by cultivated indifference to education and educational processes in the community for the various financial or social ends of certain individuals or groups of individuals. There are oftentimes 
accessory contributing causes which also require consideration. But, whatever be the causes these conditions when found existing, these require the immediate attention of the teacher, if he would succeed. If the fault appears to lie chiefly with the methods and indifference of the school authorities, there is the place to begin. Armed with the facts and the wishes of the patrons he can with ease tactfully approach them, state his case and endeavor to win their support to helpful measures. Most school authorities will respond cheerfully with all of the means at their disposal and when this is exhausted, they will of tentimes lend their moral support to any effort to gain aid in other ways if they see that the teacher is competent, enthusiastic and practical and that he is really capable of doing good.

If the fault lies with the patrons of the school, the place to begin is in the schoolroom. Strive first for better lessons, better attendance and greater interest. Impress the children with your ability and enthusiasm and let them advertise "the new teacher," the things he is doing and how he is doing them. When the children attending are won, follow this up by efforts on the outside. The parents are generally won with the children. But where not, visits among the influential laity and the seeking of their cooperation is advisable. Next the influence of the local ministry might with profit be solicited and a united effort made to arouse the educational interest of the community. At appointed times special sermons in the churches could be preached having been previously advertised and announced and every effort put forth to secure the presence of those elements of the community whom the movement is intended to reach and affect. The nature of these educational sermons may best be practical and of local concern. In addition to these, special work by the school pupils may be prepared for exhibition until there is a fitting amount on hand, of a quality to invite favorable comment and impression, whereupon at an entertainment given by the pupils of the school or during a regular session it night all be put on exhibition with much benefit to the school, serving to arouse the desired interest in the school and its work. The good effect of this kind of work on a community 
if successfully and creditably carried out can hardly be estimated. Much of the apathy and indifference of a community toward a school and its work is due to previous bad methods, bad management, inefficiency and consequent bad results, until the patrons have grown discouraged and felt perhaps that not only were most teachers bad or of no account, but that school itself was a useless luxury, that a community was just as well off without as with, and where their children did attend the sooner they were through it and through with it the better. The kind of method suggested above will serve materially to change this view for the better and the teacher will soon see that a new hope has been awakened in the patrons and a new interest created in the work of the school. This can be made the basis of gaining a larger attendance and of doing better work with much more ease in maintaining discipline and order. Many children who had abandoned school as something undesirable will be found returning and the teacher will see that he is doing effective work and has the sympathy and cooperation of the entire community, both patrons and school authorities. Of course, a large attendance does not make a good school, neither does it tend always to increase the working efficiency of the school, nor is it intended to convey that impression here. It is a fact, however, that all other things being equal, the larger the attendance upon a school, the greater is its power for good and the further does its influence extend.

In many counties in the various states throughout the country the funds obtainable for school purposes are not sufficient to run the school more than from three to six months. That this term is too short to be of any material good to the community is obvious. Where the movements suggested above have been instituted with success and the patrons and authorities see that the school is doing good they are generally willing to make individual contributions to extend the work. Cases are on record where by community rallies school terms have been raised from the minimum to six, eight or even nine months, all under the competent leadership of the teacher and through the faith which the teacher has created in others by the success of his methods, his gen- 
eral ability and his enthusiasm. To be sure such work ought not to fall on the teacher, but if conditions demand it and the need is upon the community, who more interested and who more competent than the teacher should be, can be expected to do it? If the teacher aims to render real and efficient service in a community he must do what his hands find to do and aim to do that well.

Neighborhood Meetings. A popular method of drawing the school nearer to the patron, carrying the patron nearer to the school and arousing in the patron greater interest in school work and its success is by means of periodically holding neighborhood meetings and community conferences. These have been particularly useful in the South where educational interest is at what we might say below par. In these neighborhood meetings and conferences questions of general community interests come up and methods of solving them are devised. In some of them instructions in specific methods of various kinds of work are offered, the audience being instructed in something of practical use in the home, school and daily walks of life. These meetings may and generally do take various forms to obtain certain ends locally desired. When they take the form of mothers' meetings they are of particular value to the school, as the mothers of any community are most closely connected with the problems of the school and can most readily and capably contribute to their solution. Many of the serious problems of the school arise among the indigent poor of the community. An avenue of approach to them could be found by the school if it could come in the form of charity that would supply to those in need the means of satisfying the immediate physical demands of the body for food, shelter, heat, etc. After this the influence of the school could be extended and the children of such families brought into the school. This done, thereafter, when in need, the things nccessary for life, health and school attendance could to a great extent be supplied through this source. Many a time the hardheartedness of the world toward the unfortunate and its indifference to their suffering is the cause of the presence of criminality and criminal tendency among the poor. If society would reach out its arms to 
the children in such cases, extend them charity and help and provide means of getting them into school and keeping them there, the crimes among the children of the poor would be greatly lessened. The school teacher if not actively a participant in these meetings and conferences should ally himself with them and keep them in touch with the needs and demands of this class of pupils and invite their help and cooperation in creating the means for then, whereby they can come within the sphere of influence of the school. There are also other problems of the school which these kinds of meetings could assist in solving. They can do much to have the salaries of the teachers raised, improve the school building, the school grounds, enlarge and improve the school equipment, extend the school term, increase the attendance, raise the curriculum and contribute in a general way to the extension of the influence of the school for good, and contribute materially to the solution of its varied and complex problems.

The Teacher's Value to the Community. From the above it is evident that the teacher who wishes will find a broad field of activity for the use of his capacities and energies. In the light of this, the teacher who can allow his school duties to begin with the opening exercises of the school day and to end with the closing hours of school in the afternoon is doing but little of the great work before him to earn his pay, however small it may be. That teacher whose sphere of influence is restricted within the four walls of the school house is a factor so insignificant in the affairs of men that he is more a burden to society than a benefit to it. The true teacher constitutes the leavening in the community that "leaveneth the whole." By his moral force, strength of character and model of conduct he should raise the community standards. Once he has worked himself well into the forward movements of the community, the standing thus gained may with ease be turned into a force to raise the standard of the school and intensify its power for good by instilling into the pupil a strong desire for higher things, higher and nobler ideals, of men and measures. Where, however, his work is of such nature or proportion that he cannot take the initiative 
in movements for community advancement he should consider it his duty to cooperate and work with others in all such movements and to give to all forms of social gatherings, civic meetings and general movements for social uplift, his spare time and surplus energies. Besides the consciousness therefrom of doing good in a community and therefore having its love, confidence and respect, his efforts will react upon the school enrollment, attendance and good conduct on the part of the pupils that will make the work of the school teacher much more pleasurable and which will raise materially the working efficiency of the school. It must not be expected that all of these numerous activities and interests of the teacher will be received by the community necessarily without opposition on the part of many. This will hardly be the case. Besides being wedded to old ways and habits of living and thinking from which they turn but slowly, many people look askance upon new-comers, especially if they are active and aggressive and seem to have an abundance of new ideas. Other spirits will antagonize him and his movements for mere personal reasons. Others still, will contend that he has enough to do to keep him busy in the school room, arguing that if he does that well he will have rendered the desired service to the community. The opposition may even carry their case to the school authorities. But this extreme will be rare. Despite any opposition of this kind, however, the teacher must push his movements forward in the interest of the community, securing himself at all times by keeping the work of the sehool on a high plane and allowing none of it to suffer by these outside activities. Opposition marks the path of all progress. To overcome it and still achieve is the effort of a truly great soul.

In his regular routine duties the teacher already has much to do. Indeed he of ten has too much to do. To add to these such accessory duties as are here outlined is to heap Ossa on Pelion. Again in many cases these movements may not meet with success, at least they may not meet with such success as was anticipated. It still remains true, however, that where these things can be and are done by the teacher, the school flourishes and humanity is benefited by his having been in the 
world. Men afraid of opposition and criticism never turn the world upside down by their " doughty deeds." Nor do those who are afraid to work and extend their energies and those who do not even risk their health for the uplift of their fellows ever amount to much in the world or make the world better by their having been in it. Men of the first type need to learn that it is only just adverse criticism that hurts or will perhaps undo one. Those of the second will do well to learn that " it is better to wear out than to rust out." The world is little in need of any individuals either of the first or second type. Power-capacity and energy-supply are meassured by work, action and work. World progress and human uplift are accomplished only by the severest forms of work.

\section{REFERENCE READING}

King's "Education for Efficiency." Chap. VI.

Arnold's "School and Class Management." Chap. IV, Sect. 4.

Perry's "Management of a City School." Chaps. III, V.

Colgrove's "The Teacher and the School." Chaps. V, X.

Dinsmore's "Teaching a Country School." Chap. II.

Pichard's "School Supervision." Chaps. X, XI.

Johonnot's "Principles and Practice of Teaching." Chap. XV. 


\section{CHAPTER XI}

\section{INSTRUMENTS OF PROGRESS IN THE SCHOOLROOM}

\section{The Courses of Study and the Daily Program}

I. Courses of Study. There are two factors above all others which have been found to facilitate the work in the schoolroom and to promote definiteness of progress in the educational processes. These are the courses of study and the daily program. So important has the question of courses of study been found to be that experience has taught that such matters cannot safely be entrusted entirely to the discretionary knowledge of the various teachers. As a result when teachers begin their work in the school they find their courses of study definitely outlined for them. When the teacher enters his schoolroom to begin the work of the year, there must always be something definite for him to do. He must know first of all just what he is to do, where he is to begin and how he is to proceed in order to get it done. The course of study is provided for this purpose. Lack of experience in teaching and lack of knowledge of the relative value of school processes, one or both, may contribute to produce the condition and the causes why so few teachers can be trusted to make out a proper course of study for any given grade or grades that they are to teach. Besides that a graded school to be successful must be well articulated; the work of each grade must represent a distinct part of the whole course and each part of it must fit into and coordinate with the whole. Furthermore, the work of the common school must fit into that of the high school, that of the high school into that of the college, and that of the college into that of the university, while each teacher must know what progress has been made by the teacher in the grades below 
her and she in her turn must know what is expected of her by the teacher or teachers in the grades above her. In schools where departmental work is carried on, the demand for a course of study becomes even more imperative.

Another problem that makes it necessary that there be a standard course of study not subject to individual whims is the question of promotion and transfer of students from one building to another or from one locality to another within the state and county or without their bounds. Whenever living circumstances make it necessary for a child's parents to move into a new community and put the child into school there, justice and a high degree of efficiency in the grading and the work of the school demand that the schools of the general system be so articulated in their courses of study that the work of the grade in the new community and that in the former community have sufficient in common to enable the child to enter the new school without serious handicap to his work or without loss of standing in the grade in which he was before moving to the new locality. The only way in which this end can be properly conserved is by there being a common course of study followed in general by all, so that all of the grades of the same class in the system may be doing practically the same kind of work as well as be making practically the same progress in that work during a stated period. Because of the independence of action by various city, county and state superintendents of education, a trait which will probably always characterize our educational work, because of our national ideal of personal liberty and freedom of individual action, the results along this line are not as uniform as would perhaps be desirable for this end. But it is progressing in this direction and in time will no doubt be much nearer perfection. Another fact in this connection is that the normal equilibrium in such matters is considerably disturbed by the agitation and reaction against the rote and groove as well as archaic education, brought to us from classical times. This reaction has introduced us into a period of transition from the form and rote education of the past to the substance and thought education of the present which when we have finished the transition will probably 
bring us again to a uniform and generally well articulated system. Imagine though, apart from the above, what a fearful lack of uniformity and system there would be if each teacher were allowed to use his individual judgment or perhaps better lack of judgment in such matters. It matters not, though, how uniform the course, or how well theoretically the work of the grades may articulate the one into the other, there will always be local conditions peculiar to each community, such as length of school term, number of teachers and their competency, together with the general health of the community and the various accidents incidental to all school administration, which will enter from time to time to throw the system out of gear and thereby by putting one behind the other break the uniformity so desirable and indeed so necessary.

The Justification of Courses of Study. Through many years of experimental work extending from the Grecian period down to to-day, the question of courses of study in the school has received attention and constantly undergone ehanges until to-day through knowledge gained through this experience and observation there is a very definite reason for the place assigned each subject in the course and the determination of the amount of time which it is to receive under various conditions of teaching facilities and the general purpose of education as judged by the educational ideals and standards of various countries, states, and cities and rural communities. It is obvious that the kind of political institutions in a country will determine the subjects to be taught in the sehools of that country as well as the relative amount of time each is to have in the course. The course of study will vary if only in its minor details; that for a mining section differing from that of an agricultural section, while that for a commercial center will vary from that for a manufacturing center, and so on. The same will be true of the course of study prepared for the privileged and leisure classes in contradistinction from those for the masses. In republics no form of education for the leisure or privileged classes in particular is supported by the state. This, of course, does not refer to institutions for technical or profes- 
sional education. These forms of education are offered quite generally in state schools.

Historical Development of Courses of Study. From our earliest historical knowledge of educational processes and schools we find that the matter of the course of study was quite definitely outlined and followed, whether the system was under the control of the church and ecclesiastical institutions or under the control of the state and the dominant political institutions. The age periods for primary education varied in different countries from five to eight years, but began in most countries at from six to seven. Intermediate education extended from the twelfth or fourteenth to the eighteenth or twentieth year, while the "higher education " began at about the age of twenty and on even as far as up to the thirty-fifth year. Courses of study in these three educational groups have been decidedly uniform. China, India, Judea and Egypt all had as the course of study in their primary educational work, reading, writing and arithmetic. Persia paid but little attention to any of these except among the leisure elass. To these three subjects training in ceremonial institutions (of the priesthood) and moral customs, Judea increased her course of study to include music (both vocal and instrumental) and added thereto elementary work in the industrial and mechanical arts.

The intermediate and advanced courses of study have remained very uniform and everywhere covered the entire field of knowledge, though only in the past century or so, because the activity to obtain a living took all of the time of men, did intermediate and higher education become accessible to others than the socially privileged, the ruling classes and those select few who enjoyed special political, professional, and ecclesiastical opportunities and maintained themselves in it by rigid caste rulings and regulations and a strong spirit of clannishness. Sparta's literary education was but little other than primary, her state ideal being to make warriors out of her citizens. Pythagoras, a prominent exponent of the Spartan ideal in his school, offered in the primary course of study, reading and writing, to which, a little later in that course, were added arithmetic. Still later appeared 
grammar, literature, geography and music, finally astronomy and mathematics being brought in. Aristotle advanced this course of study to include poetry, rhetoric, drawing and philosophy, with all of its known branches. In the Christian period immediately following, the training in the elementary branches included reading, writing and sometimes arithmetic, but still in the primary grade Latin and Greek were added, the full course including reading, writing, arithmetic, grammar, music, rhetoric, mathematics and philosophy.

Luther found out that the chief obstruction to the successful propagation of his ideas was general ignorance among the masses of the people. To overcome this he put forth the proposition that the state had the right to enforce compulsory education. Finding that the course of study then in use in the school was not of the kind to make the spread of his views and the influence of his work sufficiently efficient he proposed a new course of study which he himself had devised as a substitute for the prosaic one inherited from the classical times. It was composed of reading, writing, arithmetic, mathematics, bible, catechism, Latin, Greek, logic, rhetoric, history, natural science, music and gymnastics. In this course of study as proposed by Luther and introduced by him we notice several signs of the times and some advancement of human knowledge. The presence of "Bible study" and "Catechism study" is to be explained by the fact that Europe and especially Germany was in the throes of a fearful struggle for religious freedom. Natural science which we know now under the name of "nature study" was present in the course probably because of the new spirit for scientific methods and investigation that constituted a reaction against the atrophied and unproductive forms of studies at the head of which reactionary movement stood such men as Bacon. Music was there probably through its relation to the religious feeling and worship as it was in the Judean course of study, while the presence of gymnastics is probably a relic of the Spartan system and the practical need that was felt in the terrible degradation which the body had undergone by the asceticism of the church, which taught that the body polluted the spirit and construed religion to be bodily chastise- 
ment, privation and abnegation. History which had been notable for its absence from the previous lower courses was introduced by Luther to aid in his fight within the church and as first taught was almost entirely church history. Throughout, however, the course is markedly advanced. In the primary grades besides instruction in religion and morals there were taught music, reading, writing, arithmetic, bible, catechism, natural science and gymnastics. Latin was begun in the second year and Greek in the third year of the primary grade. This was quite a formidable course of study, especially when it is remembered that the method of learning them was by rote. Under such a regime the work must have been straining despite the presence of gymnastics to break the long tedious strain.

About this same time (1550) Sturm became head of the Gymnasium at Strassburg and introduced a course of study there that became a model for all of the more important schools of Europe for the next two hundred and fifty years and which is to-day still followed by many countries, particularly Germany, in their upper primary and throughout the secondary schools. His course of study was a Latin course of study. That is, Latin was made the basic subject with the right to alternate with it or substitute Greek for it in the higher grades. It ignored the mother tongue almost entirely, not only not teaching it, but also not allowing its use except in the explanation required by the difficulties of the text. Pupils were not even allowed to converse in the mother tongue on the way to and from the school. The first year course with Sturm consisted in the learning of the alphabet, reading and writing, and the learning of Latin declensions and conjugations with instruction in either the German or Latin catechism. All of the succeeding years of the course were marked only by an advance in the Latin instruction.

The English poet John Milton made the first decided step toward nationalism in courses of study. His efforts were bent toward the adoption of courses of study to the capacities of the pupils; an evident reaction against the course of study of Sturm. He decried strongly the method then in 
vogue of compelling students "to spend seven or eight years merely in scraping together so much miserable Latin and Greek as might be learned otherwise later, easily and delightfully in one year." He considered it a great fault of the system "to require verses and orations of immature students and to introduce them suddenly to the abstractions of logic and metaphysics."

Following Milton, Herbart made another determined effort to place the then used course of study on a rational basis. His labor's were spent in an effort to determine the order of subjects by their " progressive and logical connection," to arrange the course of study to correspond to the progressive unfolding of the mind. Let the subjects of the course grow in complexity as the child's mind grows in power to comprehend, and education will be easy, because natural, was his argument. He based his system upon mathematics for which course he provided a lengthy philosophical exposition by way of justification of it. Both Herbart and Herbert Spencer were markedly influenced in their writings by the reaction against the prosaic and theoretical education of the schools of their time which were run chiefly under the dominance of religious bodies and their religious zeal, which during those times were the paramount feelings controlling human action. Too, they were both materially influenced by the reactionary methods of the French Renaissance whose school principles were widely heralded. Spencer's efforts were bent in the direction both of the order of arrangement of subjects, their promincnce in the course and the amount of time they should receive in the schoolroom. Spencer would determine his course of study upon the relative value of studies in the living activities of a people and used as his basic principle that of " what knowledge is of most worth." This in turn was determined by one's standard of living. While this proposition of Spencer's was perhaps indefinite it was undoubtedly intended to break up the petrified customs of making courses of study according to the theories of a dead past and was intended to make the new courses of study thoroughly practical and utilitarian. Since the school cannot teach all branches of knowledge and since no one person can learn all that the 
school teaches it is imperative to know what is the relative value of the various branches of knowledge which the school attempts to teach. Spencer outlines the kinds of activities in life for which the school is supposed to prepare one on the basis of their contribution to the self maintenance of that individual. With this as a guide he formed his course of study. On a similar plane with Herbart he held that the course of study should correspond with the unfolding of the mind. The course of study according to him should proceed "from the simple to the complex, from the concrete to the abstract, from the empirical to the philosophical." It should carry the child in education through the same periods as those through which the race passed in its historical devclopment. That is, the course of study should first of all be composed of those subjects, a knowledge of which will cnable him properly to meet directly the problems of self-preservation. Next it should contain those subjects a knowledge of which will enable him (the pupil) properly to meet those problems which affect his access to the necessities of life and that therefore indirectly affect self-preservation. These subjects must be imbodied in all courses of study and these courses of study should be placed within the reach of all, because to all living beings are due the opportunities for obtaining (earning) a livelihood. When these problems are successfully met in society by its various individual members, then the courses of study may be extended to include those subjects which provide a knowledge for the rearing and disciplining of off spring. This accomplished the course of study may include those subjects which provide knowledge that will enable the maintenance of proper knowledge, that will enable the maintenance of proper social and political relations of the state. Finally, according to this scheme of Spencer's the course of study may include those subjects which enable the exercise of the finer miscellaneous activities which make up the leisure part of life, that part which is generally devoted to the gratification of the tastes and feelings, especially the feelings of the esthetic sense. As the child becomes secure in the possession of a knowledge of these various activities, he can advance in the courses of study until he has access to all that the 
school offers. Courses of study which administer to the means of self preservation both directly and indirectly are first and generally provided. Other more extended courses later as the demands on the clild rise beyond this level.

Unlike Herbart, Spencer makes science the basis of his course of study. To him the study of science was the road to human happiness; it ministers successfully to all human ills. Latin and Greek with him fall from their high position of honor and prominence in school courses of study on which they had been for so long a time enthroned, as do bible study and the study of the catechism. The humanities also lose their position of eminence. The old course of study was outlined for the rich and leisure class; it was impractical and non-utilitarian. In their stead Spencer would substitute a course of study admirably adapted to the needs of the masses. For this purpose he offered a course that was practical and highly utilitarian. The cultivation of the esthetic tastes and feelings is a privilege accorded only the rich and leisure class. But inasmuch as the leisure class does not constitute the main body upon which civilization rests, so ought not the education which is only for them make up the chief part of the current course of study. In this connection Spencer's stress upon physical education is also worthy of notice. He sounds a timely note of warning in this regard which has been and is being well heeded in our more modern courses of study.

To-day the courses of study in Germany as prescribed for the primary grades of the public schools intended for the use of the whole population (I refer here to the so-called "Volkschulen") consists of instruction in the catechism and bible history (chicfly ancedotes and biographies), reading, writing, arithmetic, geography, natural history, singing and gymnastics. The lower primary grades offer as their course of study: Catechism and bible history, reading, writing and arithmetic (numbers), natural history (nature study), singing and gymnastics. The courses of study in France for the primary grades call for instruction in moral and civic duties, reading, writing, arithmetic, grammar, literature, history, geography, natural science, designing, 
modeling, music, gymnastics, military for the boys and needle work for the girls.

From these facts, not only is it evident that the problem of courses of study is an old one, and that the present one has been reached after long years of experience and experimentation. But it is also clear that the courses of study are pretty uniform throughout all of the enlightened and advanced civilized countries. It is also a fact that they are instruments of such importance in the outcome of educational processes, that they cannot be safely entrusted to the whims of either ignorant or capricious persons or those given too much to fads in matters of education. After such a long period of trial it is safe to conclude in this matter of courses of study that each subject of the course has come to have its position in the course because of some specific demand in the life of the child which it is to supply and, because of this, that it cannot be dispensed with without impairing the child as a finished educational product. With the general purpose of education clearly defined and the kind of education that is most worth, the relative value of the subjects is readily found and where there must be a process of elimination invoked, the local or practical grounds may without serious harm enter and be plied as a shearer's blade to cut out those of less practical value. The question of selfpreservation and self-maintenance must and will always be paramount until the race advances to the point where there is abundant material goods well distributed throughout the masses. During this time the local and national ideals and needs will control the nature of the courses of study. Once the questions of self-preservation and self-maintenance are removed from the imnediate consideration then the courses of study may flower out into such forms as will cater most fully to the higher and more nearly theoretical ideals of the more capricious and fastidious rich and leisure class.

Courses of Study in America. America has not advancel in these matters perhaps quite as far as the countries of Europe, though since she has started along this line she has proceeded more rapidly than they have. Fifty years ago our courses of study consisted in the rural districts chiefly 
of reading, writing and arithmetic with some language (grammar) work and some geography (more nature study). The freedom of activity which is part of our national ideals has allowed those in authority to proceed according to their own wishes and as a result the courses of study as they have grown have become overcrowded with many unrelated subjects arranged in no definite order. The result is that in such cases the knowledge gotten, if such it may be called is disconnected and of little worth, the energy of the pupil being uselessly dissipated by being stretched over too large an area of subjects and subject matter. While it is true that the tendency in America is toward intension in educational processes, more than toward extension in them, which may be partly the cause of the status of things educational with us so far as courses of study are conccrned, yet it is a fact that studics need to be more concentrated. Where, because certain groups of subjects extend in parallel lines, concentration is impossible, the condition might be remedied to some extent at least by an appropriate combination of coordination and correlation. Herbart and Spencer, especially the former, both advocated courses of study based upon the principle of concentration aided by correlation and coordination. The earlier courses of study, as may have been observed, were based purely on the principle of correlation and coordination. The humanities (history, literature, etc.), the sciences both physical and biological (including the physiological) and the mathematical subjects constitute the correlated courses of study generally offered coordinately. These are usually everywhere introduced by the less coordinated and correlated subjects known as formal subjects, of which the chief are reading, writing, arithmetic (number work), nature study, grammar (language work), drawing and modeling. Primary knowledge, therefore, is formal knowledge and is necessary before any other form of knowledge is possible. A primary course of study because it is basic and primary is now and has always been practically the same in all countries. It is in the upper primary, intermediate, grammar and high school courses of study that this problem peculiar to America presents itself. Besides being 
reduced to a system of concentration, correlation and coordination the lower subjects should follow the psychological order (the Herbartian and Spencerian doctrine) while the higher subjects should follow the logical order. In the advanced graded work of the city schools the course of study is at its best and as such is on an a verage equal to that of the most advanced cities of the advanced countries of Europe. In the rural districts, however, our courses of study are behind those of the schools of such countries as are included in the preceding reference. However, lack of uniformity in courses of study is in a way evident everywhere both in this country and in Europe. In the French system of schools the courses of study are perhaps the best and most uniform known. These courses of study are strictly prescribed by the ministers of public instruction and rigid adherence to them is enforced by the department throughout the state by means of a very extensive system of deputies.

Experience has fully taught the need of having courses of study articulate well by grades and years. With this condition and those above fulfilled the teacher is relieved of much responsibility in things that while they are vital, they are cut and dried for him. All that is required of him is that he bend his energies in teaching the course of study that is outlined for lim. A prepared course of study will insure in the first place that the end of education as broadened by the experience of centuries will be achieved with some degree of definiteness and certainly that the work through the progressive steps will be harmonious and the efforts spent not lost by useless repetition, nor its effects spoiled by disconnection. It will provide that the work undertaken will proceed in harmony with the natural unfolding of the mind and be so uniform as to reduce the inconvenience and loss of time incidental to the transfer from locality to locality and state to state to a minimum.

II. The Daily Program. The next instrument of progress in the schoolroom that is of vital concern for the teacher is the daily program. Unlike the question of the course of study it is not so definitely determined by custom nor are the scientific regulations governing it as minute as those 
controlling the course of study. In its variation it is susceptible to local conditions, due in part to the nature of the program itself and in part to the fact that the teacher is not only allowed to make out his own daily program to suit his own convenience and the accommodations of his own room, but in most cases is required to do so. In this, one of the chief problems of the schoolroom is that of time. Everything must de done, done well and done in the least possible time that the results will justify. In other words the daily program aims to secure a maximum amount of school work with a minimum expenditure of energy and time. The amount of time available for the schoolroom processes is determined first of all by the length of the school term, while the length of the school year is determined in turn in most cases by legislative enactment. These aim, however, only at general restrictions and regulations within which limitations the local boards and county superintendents make rules to suit the immediate conditions of the schools and the various means on hand to maintain them.

In the Northeast, West, and the better schools of the South the school year ranges in length from thirty to forty weeks with a standing average between thirty-five and thirty-six weeks. In the rural sections of the North, East, West and especially of the South the year is generally shorter. In many of the counties and districts of the southern states, the school year either by lack of funds, or because of the rules and regulations of local authorities or both, is often restricted to as short a time as three calender months. Where not bound by other restrictions, the question of funds for longer maintenance of the scliool year is generally locally met by the patrons and the school year extended in this way. In some sections mostly agricultural, for the sake of making and harvesting the crops the school year already short is eut into two sections, one during the cold months between harrest time and the time of sowing, when agricultural pursuits are impossible, and the other in the hot months of the summer when the crops are planted and "laid by" and the laborers resting, waiting for the crops "to make." Both of these conditions materially affect the work of the 
school and react upon the school course as well as upon the daily program affecting both materially for the worse.

While the tendency in America is toward a longer school year and there is constant agitation leading to improvement in this line, the school year in America as it is in practice in our larger citics of the North and limited to few vacations is far in advance of that of the most advanced countries of Europe such as Germany, France and England.

The School Day. While the course of study is more directly affected by the length of the school year than the daily program, the daily program is determined chiefly by the course of study both as to the number of subjects which can be taught in the course of study, the order in which those subjects shall come in the school day and the amount of time which shall be given to each. It is customary in America to divide the school day in the public schools into two sessions, the one, the morning session runs from nine o'clock in the morning until twelve o'clock noon, and the other, the afternoon session running from two o'clock in the afternoon until four. In some of the rural schools the other inconveniences of the school are offset by extending the afternoon session from one o'clock until four. In many city high schools the session runs from nine o'clock in the morning to two or two-thirty with an intermission at the noon hour of from twenty minutes to a half hour. Many of the schools of the larger cities such as Baltimore, Philadelphia and Washington hold what is known as half-day sessions running from nine to twelve in the morning. At noon the pupils of the morning session are dismissed and a new set of pupils come to the afternoon session which begins at one o'clock and continues until four o'clock. In many colleges and universities the school work begins as early as eight o'clock or even seven o'clock and extends continuously throughout the day until five or even six o'clock in the evening, while a few cases are on record where recitations in them run until seven, eight, or even nine o'clock. In European countries the school day as a whole is generally longer than in America. In Germany for example a full day in the public schools is usually seven hours long, while 
in France it is sometimes seven hours long but more generally only six hours as in America. In England it sometimes is seven hours and in some sections six hours long. Both in Europe and America for various reasons justified by the nature of the case, first and second year primary pupils are generally dismissed from one-half hour to one hour earlier than the pupils of the higher grades, both in the morning and in the afternoon sessions, also giving to them longer and sometimes more frequent recess periods than are given to the higher grades thus cutting their day to five or eren four full hours in a school day. This early dismissal is justified first by the fact that the younger children suffer more mentally under confinement and restraint than the older ones and need for health, more opportunity for exercise in the open air to promote healthy and vigorous growth so necessary for the future well-being of the child physically, mentally and morally. The work of the primary grades is also light and of small amount and there is not such a noticeable demand in them for time. With the higher grades where there is such an extended course of study that the time devoted to each subject must be carefully determined beforehand and strictly adhered to during the day in order that all of the work of the day may be properly done with neglect of none of it, the economic use of time is imperative. Here school must be held to the last minute and recesses, intermissions and other exercises of a general nature must be reduced to extend over a minimum amount of time.

Recess in the morning is generally fifteen minutes for the higher classes and that in the afternoon is ten minutes. Oftentimes that of the lower classes is longer and they sometimes have more recess periods than are given to the upper grades. In the upper grades the sixth, seventh and eighth the great demand for time has often made those who feel only the pressure brought to bear upon them to get over a certain amount of work satisfactorily, advocate the removal of the afternoon recess entirely and the reduction of the morning recess to ten minutes. In many schools this is done. But the reactionary pedagogy with physiology 
and hygiene at its back is agitating not only for the longer recess in the morning and the restoration of the afternoon recess, but is proposing a rational method which would have the teacher study the needs of the pupil and give him the right to take whatever steps he finds necessary to revive and reinvigorate the school so as to bring the work up to a proper standard of efficiency and bring about a true economy of time. Sometimes the situation may require only a few gymnastics in the midst of plenty of fresh air. Then again it may require a brief recess period. It is a fact that when there is too much lethargy present in the body of students it is better to remove this lethargy at any cost in loss of time, rather than to hold school and drag on through the day's work. Such work would in results obtained be practically wasted. While the freedom to so control a situation arising in the school work may at times be abused and the purpose of the school to that extent be defeated, it still remains fundamentally true that the teacher should be given the right under individual discretion to so regulate the activities of the pupils as to keep the work of the school at all times up to a high degree of efficiency and the children always active and vigorous. This is the paramount purpose of recesses and intermissions. Sometimes this may be accomplished by the arrangement of subjects throughout the day. But the results from this are minor in their effects. Instead of recesses those who see the loss of time in dismissal and reopening during recesses and who wish to avoid the efforts necessary to get the students in order and back to work after recess advocate substituting gymnastic exercises in the schoolroom with a full circulation of air as a substitute for recesses. It is true that in this way the order of the school is disturbed to a minimum degree and the loss of time is reduced to its lowest, but the real proposition, the health of the child is not considered. This question of substituting constantly indoor gymnastics for play in the open air at first bid fair to solve many difficult problems attached to the question of recesses. But tests have soon shown that the substitute was a poor one as far as the vital functions of the body and the health of the pupil were concerned. It 
was soon evident that these received a benefit in the free and full bodily exercise in the open on the playgroud which no amount of indoor exercise could replace and leave the health of the pupil unimpaired. The real fact is, the experiments showed that gymnastics far from being recuperative in the same sense that play in the open air is, are a strain upon the child second only in waste to that entailed by such a heavy subject as mathematics, which is one of the subjects of greatest strain on the vital energies of the child.

The Course of Study and the Daily Program. While, as was shown above, the course of study is fixed along pretty definite lines, it was also seen that it is sufficiently elastic to be slightly varied to meet any urgent local demands in minor subjects. These minor subjects may be limited because of the school year, because of its being broken into a winter and a summer session, because the school day is short, because recesses, intermissions or general (opening) exercises reduce the amount of time available for the purpose of actual teaching. Minor subjects may be dispensed with easily according to the Spencerian doctrine of the relative value of subjects as determined by the national and local ideals of education and the social element which the school is immediately to serve. In manufacturing, agricultural and mining districts, as well as in other sections adapted to engage in plying certain other forms of activities, the courses of study should be sufficiently elastic to allow of minor changes to meet the local demands arising from its immediate economic or social conditions. For example, music might not be as essential in the course of study for rural communities as nature study and agriculture, while in a mining district the demand might turn to drawing, modeling and clay working, or in a manufacturing district again basic work in the physical sciences, physics and cliemistry might be required even in the lowest grades. Whereupon, upon the basis of relative value of subjects if it became necessary to cut or keep down the course of study the local demand along specific lines could be used as a basis. In larger cities where there is more wealth and a larger leisure class and consequently 
more education for culture, all subjects could be retained, the school year being continuous and of maximum length.

Form and Content Subjects. From the viewpoint of the relative value of subjects they are divided into two groups, form subjects and content subjects. The form subjects are such subjects as reading, writing, arithmetic, drawing, music, spelling, language, etc. The content subjects are such subjects as geography, nature study, science, agriculture, civics, history and literature. The form subjects one will readily see are more important in the lower grades and grow less in importance as we ascend the scale of the grades. A scientific course of study will show this, and the daily program will give prominence to the subjects on the same basis. In the tendency to overcrowd the courses of study of the American public schools alluded to above, there is a disposition to crowd those years that experience has shown should be given over to the study of form subjects with content subjects, thus neglecting the form subjects. But whatever justification such steps should receive on theoretical grounds, experience shows that content subjects can only be put into the earlier years of schoolwork at the expense of the form subjects. Form subjects are drill subjects, subjects for the gaining of the rudiments and the establishing of paths of motor discharge along various nerve tracts, for the formation of accurate and definite habits in education, the gaining of complete muscular coordination in physical processes and full control in mental processes. Besides, the mental energy of children is very limited comparatively speaking. Hence to dissipate their energies between form subjects and content subjects is to make the work in both ineffective if not really null and void.

Fatigue Agents. Given, then, the relative importance of form subjects and content subjects in the various educational periods the daily program should cater to each in the different age periods as represented by the grades, and subjects should be sacrificed on the basis of their relation to the form series and the content series. But this is not the only problem to be considered in the arrangement of a daily program. The next matter of importance is the ques- 
tion of the demand of the various subjects of the course of study upon the energies of the child, and the various amounts of child energy available during the daily school sessions for school work. Passing at this time the general effects of the school surroundings, the decorations of the room, its leating, lighting and ventilation and the general manner of the teacher upon the energies of the child, we come to those activities of the child immediately connected with the educational processes of the schoolroom in their relation to the energies of the child and their demands upon that energy. Careful study of the fatigue curve (better called the energy curve) of the child shows that it rises and falls throughout the day under normal conditions with rhythmic precision. There is a double loop of rhythm to the curve. It rises steadily in the morning from the opening of school until between nine and ten, generally between 9:30 and 9:45. It reaches its maximum height for the morning round about ten o'clock in the morning session. It falls rapidly until the recess period about ten-thirty in the morning. After the recess due to the invigoration received at that time in play in the open it rises more slowly and not as high as in the morning period before recess, reaching its maximum between eleven o'clock and eleven-fifteen, after which there is rapid fall until the noon intermission gives another longer period for rest and recuperation, and a recharging of the energy cells. In the afternoon session the energy curve rises as in the morning, reaches its full height more rapidly than in the morning and declines more rapidly generally sinking below the lowest level of the morning session. There is a break in the fall of the afternoon curve where there is an afternoon recess or the gymnastic exercises, though less pronounced, where the gymnastics are substituted for the open air play, when the curve rises again to a maximum quickly and slowly falls until the close of school.

The graphing of this curve shows some interesting facts. Neither in the morning session nor in the afternoon session, at the opening of the session, nor immediately after the recesses or gymnastic exercises is the rise of the curve greatest, but only after the muscles become well charged with it 
does the curve reach its maximum. The point of maximum height after each opportunity for recharging the cells is given, is not reached for some time after the discharge of the energy has commenced. In the morning when the supply of energy available is greatest the current of discharge is longest in reaching its maximum strength as the curve shows by attaining at that time its greatest height. 'There is a like fact evident in the afternoon session and after both the recess or recesses of the morning and afternoon sessions. What is more to be expected the curve is lowest at the close of school in the afternoon, and that as the cells discharge and the energy is used up, the process of discharge is gradually retarded as the energy curve shows by its gradual fall during the morning and afternoon but especially in that period of the afternoon session between recess and the close of school.

The Relative Fatigue Value of Form Subjects and Content Subjects. In this same connection it is perhaps unexpected but a fact that the primary subjects of the school course, the so-called form subjects are more taxing upon child energy than the higher subjects, the so-called content subjects. The reason for this probably lies in the fact that most of the form subjects involve the putting forth of considerable physical effort, sometimes in cases where muscular coordination and nerve control is poor they involve the putting forth of intense physical effort. This is seen in such instances where primary children write and draw with the whole body. In some rare and extreme cases the whole body of such pupils becomes rigid, the muscles contracted, mouth twisted, lips puckered and eyes squinted. That any exercise that thus draws energy from all muscles of the body and so intensely too will soon use up the store of energy in the energy-cells goes almost without saying. The same is true oftentimes in the cases of early vocalization and singing. Experiments along this line by investigators have proven that as energy users mathematics stand at the head of the list of subjects in the course of study, closely followed by writing, drawing, spelling, reading and gymnastics. Where the objects dealt with in drawing are colored, tests 
have shown that they produce less discharge from the energycells. Music, too, where it is singing of words especially if the tune is lively or the words cheery and not a mere drill in technical forms is less taxing, while nature study and geography are well toward the bottom of the list. Foreign languages probably because of their empty form and consequent lack of interest and extra demand for the exercise of will power stand at the bottom of the group. These facts all tend to show that the interest that one has in a subject has much to do with stimulating the energy cells to discharge their content, thereby making available for the work a greater amount of energy. It also shows that subjects that are not interesting create the greatest demand on the energy of the child. Hence these should not be forced upon the child mind for too long a period at a time, and hence in subjects in which there is special natural interest due to local or personal conditions, more can be done with less cost of energy than in these subjects in which there is not this natural interest. All of these facts about the cost of energy in performing the various duties of the schoolroom and the status of the bodily energy during different periods of the daily session will determine materially the arrangement of the subjects for recitation and the amount of time that each should have.

The Arrangement of Subjects. These facts while vital are merely incidental to the general points that are of interest here in connection with the making of the daily program. From the facts given above it is obvious that the best results will follow if we do not have two form subjects, especially if the time allotted to them be long, follow each other in succession in the program; if form subjects they would have shorter periods than content subjects. It is also clear that two short periods in different subjects will be less fatiguing than one long one in the same subject, other things related thereto being equal; that form subjects should be given, in the degree of their demand for energy, at those periods in the day when the energy curve is highest, according to their demand as energy users; that drill subjects should be of short duration and well dispersed throughout the daily program because of their power to increase the energy dis- 
charge; that the program for each session should open with light fatigue subjects in order to allow the process of energy discharge to get well under way, when those subjects which require more energy may follow at a time when the discharge of energy is sufficient to enable the pupil to handle them without undue fatigue. Speaking of the subjects in the course as heavy and light in a classification based on the amount of energy they use in preparation and recitation, the heavy subjects should be interspersed with the light ones and come preferably in the morning, while in these the light ones should appear in the program at the opening of the session, just after recess periods, and toward the close of the morning and afternoon sessions. The heavy subjects should appear more toward the middle of the time between the opening and recess and recess and noon in the morning session and at a like time in the afternoon session. In the case of two exercises involving mechanical movements such as drawing, writing, singing and oral concerted class recitations there should be inserted between them in the program some other subject to break and relieve the strain. It is also better that they not follow any form of special physical exercise, recess or intermission. Length of periods too should vary according to the "weight" of the subject, and this time should be short in the lower grades and lengthened gradually as the course ascends in the grades. Chadwick whose suggestions for recitation periods are the standard in America proposes in this instance that the pupils from 5 to 7 be given recitation of fifteen minutes; $\gamma$ to 10 twenty minutes; 10 to 12 , twenty-five minutes; 12 to 16 , thirty minutes. This is on the assumption that the time is available. It is believed also in the light of what has preceded that form subjects might in each of these cases where fatigue, the course of study, or daily program demands it, be allotted less time than the general scheme calls for. In high schools it is customary to give classes from 40 to 45 minutes. In colleges and universities the literary classes generally receive sixty minutes, rarely 120 minutes, while laboratory subjects extend over 160,180 or even to 240 minutes (4 hours). 
Daily Program in Ungraded Schools. In the ungraded schools of the rural districts, the graded schools of the congested city districts and those cities where only one session is held the problem of time is a serious one which must be solved as best the conditions will allow. Though for smaller children home study is condemned for physiological and pedagogical reasons the first move made to economize time is to do away as far as possible with the school study period and use the time thus gained for recitations. Another method employed to satisfy imperative demands for time is to alternate subjects. Still another is to estimate the relative value of the various subjects and cut down the recitation periods allotted them in the week's program, thus creating time for the other subjects. A method of last resort is to remove subjects from the daily routine entirely and give general instruction in them during the opening or general exereises when all of the pupils are present. Of all of these, alternation or the reduction of the number of recitations in a given subject per week is the least objectionable. For this purpose of alternation such subjects as drawing and modeling, writing and music, nature study and geography may be used without great loss to the pupil, inconvenience to the teacher or disruption of the program. Morals and manners where not taught in the general or opening exercises may be alternated with a gymnastic or recreation period. Where there are two or more elasses in a room some of the subjects such as spelling and writing and even drawing might be doubled up without serious loss or inconvenience.

This statement while based on acknowledged principles is only suggestive. The teacher will in most cases be compelled to depend on individual resources to master the situation, and much that could not be mentioned or even with safety be advised may sometimes have to be done. All that can be said is that as much of the standard systems and approved principles as is possible should be used in making out a daily program. Once one has been made out it should be strictly adhered to until conditions make it impossible to follow it. Whereupon a new one which can be followed 
should replace the old one. Daily programs facilitate the school work, make it definite, enable it to proceed without break and consequent loss of time, destroys all dangers of yielding to hobbies and favorite subjects and insures uniform and general education. It compels to a great extent the preparation of the work of the school for the next day at home and rounds out all of the work of the school processes into systematic whole.

No examples of a daily program are given here, because these vary so in every locality and condition that no great uniformity exists. Nor can they exist. Furthermore it is assumed that with a careful understanding of the principles given here and with the course of study for the graces in hand any teacher can provide himself with a daily program to meet the particular demands of his school.

\section{REFERENCE READING}

King's "Education for Social Efficiency." Chap. XI.

De Garmo's "Interest and Education." Chap. V.

Münsterberg's "Psychology and the Teacher." Chaps. XXV, XXVI.

Jones' "Teaching Children to Study." Chap. V.

Colgrove's "The Teacher and the School." Chaps. X, XI, XII.

De Garmo's "Principles of Secondary Education." Chaps. I, V.

Johonnot's "Principles and Practice of Teaching." Chaps. III, IV, V, VI, XIV. 


\section{CHAPTER XII}

\section{ACCESSORIES OF THE RECITATION}

Their Value. No matter connected with the school and its processes is as important as the work of the recitation. All of the functions of the school are secondary and accessory to it. It is the crowning glory, the climax of the educative process toward which all other activities tend. Whatever successes attend other phases of the schoolwork, however well directed efforts may be along other lines, if in the recitation there is lack of method, lack of system, lack of success, all else is practically in vain. Out of the recitation come the facts that make up chiefly the early store of knowledge with which the young enter upon life, out of the recitation come the order and association of facts that establish their relative values and give to them practical utility, out of the recitation comes that power of discrimination and skill in the use of the facts together with the confidence in one's ability to use them in harmony with the world's processes, which is the starting point of all of those forms of self-activity that lead to persistent endeavor and ultimately to achievement. Thus the theory and practice of education is justified by basic philosophy and evidences of a keen and thorough understanding of general principles, when it makes the recitation fundamental in all educational forms and educative processes.

The Preparation of the Teacher. Special preparation. is necessary for the proper performances of any and every kind of special work. The more highly professional and special the work the greater is the need for special preparation. In every field of human endeavor this is either tacitly assumed or overtly adnitted. And yet, despite this fact, in the teaching profession more than in any other, the novice and unprepared is inducted into places of authority, respon- 
sibility and direction. That the profession loses in standing and achievement as a result of such conditions must obviously be true. This loss in standing and achievement is felt by the profession in the withdrawal of public confidence and the continued low salary which the members of the profession everywhere receive. However, the recent agitation for better prepared teachers is reaping good fruit and is resulting gradually in the elevation of the rating of the teacher both in the community and throughout the state. It is also resulting in increasing the amounts available for salaries. The assessment of school taxes is increasing everywhere as are the number of sources from which school funds may be derived. Correspondingly, if the possession of higher grade certificates is to be taken as evidence the teachers everywhere are better prepared. In the twelve Southern States the percentage of teachers having first grade certificates has increased thirty-two percent during the past decade, those holding second grade certificates have increased nineteen percent, while those teachers holding third grade have decreased eleven percent. In many Northern States where the standing of the teachers as evidenced by the grade of certificate they held was already high, there is a corresponding improvement in intellectual qualifications.

Heart Training. Apart from this, generally speaking, the kind of preparation necessary for the teacher is of a twofold nature. Teachers need preparation of intellect and of feeling, that is, preparation of mind and of heart, if we may use language current in professional literature. Furthermore, the teacher needs the very highest preparation obtainable in each of these. It is ordinarily proposed both in theory and practice that the amount of intellectual preparation necessary for the teacher in the lower grades is small and that this demand increases in amount as the teaching ascends to the higher grade of pupils. From the viewpoint that the teacher must always keep a certain distance mentally ahead of the pupils in order to hold their respect, and blaze a path through the field of knowledge which the student may follow without fear or equivocation, and that it will make the teacher a mysterious savant with powers in awe of which 
the pupils must stand, this view is probably correct. But if we take the viewpoint that the earlier steps in the educational processes, being fundamental and the foundation upon which the superstructure of education is to be built, then they are paramount and consequently the sine qua non (the indispensable thing) of education. Add to this the fact that the mind and body of the young child is a tender plant susceptible to the influence of every force acting upon it and whose effects run through a long period of the child's activity and perhaps throughout his whole life, determining his abilities and capacities for organic activity and his share of human joys, then, we can see that it must require for the best good of the child even better preparation both in heart and mind for those teachers who are expeeted to supervise and direct the elementary educational processes of the child. That teacher needs the aid of the entire available field of human knowledge, if he would even hope for success. The complacent satisfaction of the young teacher as he enters upon his new dutics of teaching the young " shoots to shoot" entirely unconscious of the difficulty that lies before him or the responsibilities that devolve upon his shoulders in this new capacity is a magnificent example of blissful ignorance. For the mere dealing out of facts of knowledge or the directing of the muscular movements of the elementary school exercises, it requires but little knowledge on the part of the teacher, we must admit. But if the giving out of these facts and the directing of these movements are to be done with due regard to the physical, mental and moral best good of the child, it nust be clear to all that the knowledge of even the most learned is not always sufficient to guarantee that they will be done in accord with the demands of nature, the state and society, and resultingly in accord with the demands of the best good of the ehild.

It is an ancient maxim gleaned from the riclness of the experience of the centuries of experience through which society has passed which says "practice makes perfect." But nowhere is the truth of this saying more evident than in the processes of the schoolroom. Everywhere and in every field of labor there are things necessary for efficieney in work that 
can be learned only in practice. In school teaching it is only by meeting and solving the daily problems as they arise that the teacher becomes strong. Too often, teachers use the profession as a stepping stone to another profession. Individuals enter this profession and little suspecting the intricacies attached to it in operation fail or because of the unsuspected side to it, discovered by close contact with it, form a dislike for it and leave it for another profession. Others enter it deliberately to earn money to enter into other ficlds of activity or professions and at the intended times other things being favorable leave it for their chosen purpose. No profession suffers from this practice as does the teaching profession. The problem is partly created by women who enter the profession to carn a living until a fitting chance for marriage offers itself when they resign mostly at times to suit their own convenience leaving the school and the authorities to suffer and work off the difficulties thus created as best they can. This has become a serious matter with school authorities. Some have been forced by way of protection to make rather stringent regulations regarding the practice. In many cities as a result of this practice being carried to excess school boards have passed measures compelling teachers when elected to sign a contract and agree to fulfill the terms of the contract during the whole of that school year. In many cities also this has been a potent factor in admitting married women into the eligibility list of teachers thus crowding out the girls for whom sometimes strong pleas are made. The harm done by this practice of young unmarried women during a school year to the school, is often irremediable at least during that particular year, for the available material in mid-year is often poor. The lack of knowledge of the nature of the schoolwork done by the teacher who has resigned and the demand for a new learning of the pupils and the work so hinder the progress of the work where such a resignation and election have taken place that the work of that whole year is practically wasted, much to the loss and sometimes serious handicap of the child. Let this be repeated often in the course of a child's grade work and his education in the fundamentals of education 
will be to all intents and purposes ruined, especially inasmuch as a bad foundation in education will mean a bad educational superstructure. Some of our most brilliant characters and greatest statesmen have boasted of the fact that they have made use of the small salaries and abundant opportunity for experience of the lowly schoolroom as a stepping stone to the larger and more remunerative fields of labor and professions. This may be a credit to the men who boast of it, but the school certainly has paid dearly for this service it has rendered the nation in this capacity, many a child's future being blighted thereby. The statesman and professional man have reaped the reward, but the school and the school-child have paid the price. Again, unlike the lawyer and the doctor, the school teacher is generally not a finished product educationally. The teaching profession is composed to a great extent of individuals who have dropped off from school all along the line for various reasons. Some of them intended at the start only to go so far in school, then to begin teaching. The opportunity for this not presenting itself at the expected time, they have continued in school until the opportunity did present itself, when they quit school and began to teach. Still others quit school under various forms of pressure and drift into teaching as a possible means of earning a living, only later under the lack of renewed ambition to turn off into some other profession as a matter of choice from particular fitness, for pecuniary or other reasons more often personal than otherwise.

Another fruitful source of injury to the cause of the public school and education in general, is the disposition of those in authority to gratify their desire for personal power by catering to those who worship them by fawning or truckling, or who use the schoolroom as a means of "dispensing public patronage." Besides condemning vehemently such practices for their direct evil effect upon the community and the school and in some forms of "dragging them into politics" no honest manly aspiring school teacher who is properly prepared to do his work is going to tolerate such treatment, or risk his future by entering upon his life's work on a basis 
so fickle as momentary political preferment. Nothing too severe can be said of such a practice and any community in which such a method of administering the school exists, should rise up in its strength and break up such a system at once at whatever cost in money, time and labor. Politics and good schools are as fundamentally antithetical as are oil and water. The same is true of "favoritism" in selecting teachers and good schools. You may lash oil and water into a mulch wherein they may appear to have become mixed, but the moment the energetic process is over, each returns to its own and the mixture is no more. Whereupon all of the myriad evils of lack of cooperation and inefficiency wax and grow strong to the destruction of all possibilities for good in the system. Herein lies the danger from politics and favoritism in school affairs. When they come into school administration competency and fitness depart leaving the school in the possession of incompetency and its accompanying train of evils.

Professional Training. Apart from the general educational qualifications given above as a requisite for a teacher and those general personal qualifications mentioned elsewhere, such as enthusiasm, kindness, sympathy, esteem, love, tact, in dealing with pupils and mastery of subjects taught, for a teacher to be really proficient in his work he should also be well trained in the professional side of his work. For this latter purpose a working knowledge of history of education, where the nature of the problem of education as conceived by the world behind us is shown and the views and methods used by the men of such times in all of the countries of civilization in solving the problem is stated connectedly; of psychology, where the method of operation of the mind and its nature, growth and development, together with the relation of the chief faculties for effective schoolroom work are shown; of pedagogy, where the method of preparing the material to be taught and the best methods of presenting them to the pupils, the methods of maintaining proper discipline and control and of inflicting punishment during the work, of applying the rules of method to those of matter in order to effectively reach and impress mind. Besides these 
special phases books abound which amplify under the various heads of special treatment the particular parts of the more general subject of education. We have for example many books on punishments in school, school discipline, school management, general and special methods of the recitation and the philosophy of education. In addition to these there is also an abundance of current professional literature to which every teacher has access and of which he should gladly make constant and fitting avail. In order to increase the professional training of the teacher local teachers' meetings are held generally bi-weekly or monthly where persons competent to instruct are in charge, county institutes and state associations where under competent instruction by association and communication one with another, teachers may gain better and more practical knowledge as to expedients in schoolroom work and discipline. Besides these, much is being offered to teachers now in the form of summer normals, and summer schools, attendance upon which by the cooperation of the various local authorities is being made compulsory to an ever increasing extent. Further opportunity of personal advancement both along professional and general educational lines is offered by correspondence schools, for the efficiency of whose training one cannot always vouch but which are springing up everywhere. To these have been added still more recently university extension courses, reading circles (organized of tentimes under the advice if not directly under the direction and supervision of the superintendents), and many other forms of gatherings, where literature upon school matters is read and discussed, lectures upon special problems given and a general interest in matters pedagogical is aroused and fostered, of practice where under model conditions and an experienced eye the prospective teacher may get some experience. None of these methods, however, surpass in results the simple and perhaps somewhat antiquated method of home study. In the quict of his own chamber the enthusiastic, energetic, wide-awake teacher may gain as much of practical value as through many of the other methods of gaining knowledge and acquiring professional fitness mentioned here, combined. In regard to the demand 
for preparation of the teacher for his work Socrates, who in the work of pedagogy has rank second to none, said " what a man proposes to do that he should learn well before the doing is attempted." D. P. Page said in the same connection "Going to the class so full of the subject, that were the text-book annihilated, he could make another and better one - he will have no difficulty to secure attention." J. G. Fitch writes out of the depth of his experience that " a true teacher never thinks his education complete but is always seeking to add to his own knowledge. The moment any man ceases to be a systematic student, he ceases to be an effective teacher." Teaching is a living profession and no teacher who is not actively alive can hope to keep in the advance guard of teachers. Not only must he be fully and thoroughly conversant with the special field which he teaches but he must be acquainted with the general field of knowledge and by constant study keep abreast of the times in the advance of knowledge and the introduction of new methods. Not that he must be always in search for the " fad" in education nor the insecure facts of the speculator, but he should always keep up with the safe advance in the production of facts and the devising of methods. This represents culture and sober training.

Assigning the Lesson. The first step leading up to the recitation proper is the assignment of the lesson, generally referred to merely as the assigmment. This is a very important preliminary, for upon its effectiveness depends to a great extent the results obtained in the recitation itself. The assignment of a lesson assumes, to begin with, that the teacher is well acquainted with the needs and abilities of the pupils, just what he knows, what he can do, how much he can do well, on the one hand, and on the other, what difficulties the lesson itself presents that the pupil has not at his command the means of overcoming, and what peculiarities in statement, thought or method occur in it that might mislead the pupil and thereby cause misdirected effort and wasted time, which have as their ultimate end his discouragement. Being acquainted with all of this it also assumes that he will make due allowance for it and will take such steps, 
in the explanation of the assignment as will be in his judgment best suited to remove all such difficulties. Assignment is not intended to make the lesson so easy for the pupil that it will seem to him mere child's play to get it, all human beings enjoy those things best which are obtained at the greatest sacrifice in time and effort. Of this fact the pupil in the schoolroom is a splendid witness. However, it would obviously be out of the question to assign a lesson and expect the pupils to get it, when it presented difficulties that he neither knew how to overcome, or knowing this had not within his reach the means of overcoming them. After having overcome the difficulties of the lesson itself the next step in the assignment is to show the value of the lesson in the immediate process through which the child is going and connect it where possible to his past activities, inasmuch as all native interests are strongest and lie along the line of the things that are directly related to self and the welfare of self, either past, present or future. Once this has been shown him you have struck a naturally responsive cord whereby you can create in him interest in and desire for the subject matter of the lesson. In order for the teacher to be able fully to meet the aims of the lesson in the assignment, he must have carefully prepared it in all of its details, must have well perceived its general purpose in the course, its relation to the other subjects in the course both those preceding and those succeeding it. He must also know well the facts in the lesson, their relation to each other, to those facts which have preceded in former lessons and those which are to come in future lessons. Experience has taught that where natural interests are wanting the natural love of the young for stories and anecdotes and their inmediate response to them with the keenest interest, may be used as a means of arousing artificial interests. These anecdotes and stories may be fittingly connected with the facts of the text and appropriate queries advanced as to how such and such facts in the lesson have come to be, what becomes of the eharacters in the next lesson, or what happened in the previous lesson or lessons, ete. By referring the pupils to the text for answers to such queries we arouse their inter- 
est and send them in a state of expectant attention in search of explanations to the queries and answers to the questions, which, whether they establish a personal connection with the events of the text or not, are bound to lead them deep into the text, with the result that they will gain a full knowledge of its contents, their relation and application.

The Length of Lessons and Child Energy. The length of lessons assigned should bear a distinct relation to the age of the pupil, the time that he has to spend upon it, and the amount of bodily energy that he may use for getting it, without unduly robbing the growing body of such amounts of energy as are required for healthy activity and normal growth. Where there is departmental work teachers in their assignment should always make due allowance for the demands upon the pupils from other teachers. Children as we have seen, and especially the younger ones have limited amounts of mental energy, and though under the strain of powerful stimuli such as super-excitement, of love and fear, they may command more energy for use in getting an assignment either in school or out, it is better not to tax these energies too much. Whenever there is an excessive demand for this energy in mental activity the bodily organs suffer from the loss of it either by temporary impairment or permanent injury, such as atrophy of the special organs or in some such form as retardation in general organic development. Consequently in the assignment of the lesson it is necessary that it be not too long. The length of the lesson therefore will be determined very decidedly by such things as the age of the pupils in the class, the advancement of the class in the grades and in the particular subject, how long they have been studying the subject, what mastery of it they have already attained, what special fitness they may have for the preparation of it either in school or at home, or both, whether or not they will have opportunity for guidance and help from the teacher during the study period, how long the study period will be and what aids such as objects, maps, designs, drawings, and other illustrative material they will have access to for use in making clear the facts of the lesson and driving them home to the mind. These con- 
stitute quite a large number of details to be kept in mind in assigning a lesson, but, if they are given even momentary consideration, it will be seen that they are highly essential to the successful achievement of the real end of the assignment. Nothing is so discouraging to the young mind untrained in effective willing as to be called upon to perform continued labor, to put forth long continued effort, and to be constantly confronted by tasks whose length and difficulty make it impossible for him to successfully perform them. Lessons should be reasonable both in length and the number and kind of difficulties which they present. It is as discouraging for pupils to have lessons that cannot be mastered because unreasonably difficult, as it is to have such assigned as are unreasonably long. The fact is that the short difficult lesson if not capable of being mastered is really more discouraging to most minds than a long lesson that is " ungotten "merely because too long. The one situation begets a feeling of helplessness entirely wanting in the other where the consciousness exists that all that is required is a little more time. Though as far as knowledge getting and education are concerned the result in each case is generally the same, namely nil, association from their past experiences both in the mental and physical world has led most pupils to believe that short lessons and easy lessons are synonymous and that likewise long ones and difficult ones are synonymous. We have all seen the effect of this kind of youthful association, and witnessed the ineffectiveness of our efforts to prove that long lessons may be easy, easier even than shorter ones.

Clarifying the Assignment. Another grave problem of the assignment, especially if it is to be effective for good, is to make it understood by all of the class. Many a teacher has awakened, after lengthy efforts to make clear in the assignment the scope, difficulty and method of attack of the lesson, only to find sometimes that much of the class has failed to grasp the real and practical points of the assignment. The difficulty here is mostly one of attention on the part of the pupils. Pupils have their attention elsewhere when the lesson is being assigned. They are in disorder. Some are look- 
ing out of the windows or elsewhere, while others may even be looking directly at the teacher, but with thoughts miles away and never hear one word either of the amount of the work that is to be prepared or of the explanations that go to make up the preliminary and accessory steps of the assignment properly so-called. This latter form of misunderstanding is a problem of discipline and must be overcome, by all means.

Another form of misunderstanding is where the teacher in making the assignment uses one set of words and thinks she is using another, says one thing and thinks she is saying another, thereby giving the students the wrong idea or confusing them. This is a minor fault, however, and seldom happens, requiring only a little care on the part of the pupil and teacher to be entirely removed. For in most cases such words are not sufficiently in harmony to escape detection, nor is the sense of what is being said sufficiently obscure to prevent the proper word being supplied in thought thereby enabling the error to be seen and corrected at once.

Still another cause of misunderstanding of the assignment which applies also to the work of the recitation proper is that misunderstanding which arises from the teacher's vocabulary (use of words) being out of reach of the pupils. This is commonly called talking over the heads of the pupils. To assume that because pupils listen attentively and ask no questions they understand all that is said, has been proved again and again to be a serious mistake. It is surprising sometimes to learn what crude conceptions they form of what one says and how far off from the truth their conceptions are. In the first place the schoolroom should always be the place for very simple but correct English. But even this will be no guarantee that one is understood. This should be followed now and then by request from the members of the class for the meaning of a particular word, phrase or sentence used by the teacher which would show whether or not the pupil was taking in what was said and connecting it properly with the other facts in his mind related to the facts of this lesson.

Nor can the mere statement of the pupil himself that he understands what is being said be taken as gospel truth. 
For oftentimes he honestly thinks he both understands and is making proper application of what he hears or sees but in each is mistaken. The safe process for the teacher is to verify this by constant interrogation of the members of the class. One's vocabulary is made up of the words that he hears, and reads most. This is a potent argument against putting the young minds of the primary grades who are possessed of but meager vocabularies consisting mostly of nursery language in charge of highly and technically trained minds. The language of such teachers is mostly out of reach of these little minds. For they live and move, outside of the schoolroom, at least, in a different intellectual atmosphere from that of their pupils and in one where all they read. and hear is in this technical vocabulary. This technical vocabulary is often, unconsciously and without previous intention to acquire it, a part of such persons and flows spontaneously at all times, especially when the mind is directed intently toward the thought of the talk without regard for the language in which the thought is couched. When such teachers talk to their classes, if these happen to be young pupils, there is constant danger of their shooting over the heads of their pupils the bolts of knowledge which they would much prefer should have penetrated the minds of the pupils. Of course, with due practice and care simple words can always be used, but where one thinks naturally in a technical or philosophical vocabulary it is difficult to use an untechnical or an unphilosophical one and not sacrifice thereby the thought to the words. It is the same as when one speaks in a foreign language, having previously thought in the mother tongue and then translated it into the foreign tongue.

The thoughts, where such methods are necessary, become dead, prosaic and lose their power to charm and enthuse. I speak here only of this habit as innocently acquired. The other where big words are purposely sought for the sake of vaunting self and giving a false impression, though it is often met, is too belittling and unworthy to receive any consideration.

In the assignment the lesson should be discussed from beginning to end. In this discussion emphasis should be laid 
upon the points of likeness between the various facts of this and other lessons with their essential points of likeness and difference made clear. In every lesson there is generally some particular method of attack which will yield results better than another. Just what form of attack is best fitted for each particular lesson the teacher must determine. Much of the lesson, too, is fundamental, the rest merely explanatory to or descriptive of it. In the paragraph for example there is a main sentence around which the rest of the paragraph clusters. In the paragraph it is the topic sentence which is primary and around which all else clings as merely descriptive or explanatory. The proper assignment of the lesson will discover for the pupil that which is important in the paragraphs or topics of the lesson and bring them out clearly. The ability to separate the tares from the wheat in a lesson is more than half of the battle. A book does not contain all that is to be known of a subject and by the very necessity of the case cannot contain it. In order, therefore, to make his teaching as effective and broad as possible the teacher should aim to extend the facts of the book which at best can be only suggestive of the contents of that particular field of fact and thought, supplement them by adding those facts of the pupil's individual experience, which have a peculiar force and charm for him, and build upon these by references to other texts where the subject matter of the lesson may be reviewed. By this means a very strong stimulant to the activity of the child mind may be obtained in the interest aroused by various discreet forms of comments and queries in the adopted text, aided by suggestions as to the way the subject may be found treated in other texts. The mental principle that gives justification to this method is that the more forms and relations in which a fact is learned the more numerous and strong will be the associations formed, whereupon it will be retained better and have a greater working force in the individual mind.

Outlines in Teaching. A very effective method of teaching, one highly recominended in all sections and very generally employed, is the method of teaching by outlines. This is to be especially advocated where the teaching is sufficiently 
advanced as to be in those subjects classified as content subjects in contradistinction to form subjects. By the time the pupils have reached these subjects they are sufficiently advanced to recognize the relations of facts and understand the value of their association in educational processes. These outlines may be given at the beginning of a subject and may extend throughout the course if the teacher so desires. The outlines of the work may be given altogether at the beginning of the work, in parts as the work progresses when rational points of the subject have been reached or at the end of the year when the subject has been finished. Where there is sufficient time it may be constructed from day to day as the class progresses in the work. Where there are ostensible reasons against the giving of the outline at any of these times the best good of the class in that subject as judged by the teacher should be the guide. It can be readily understood how particular local conditions might materially affect the demand for and use of the outline in the work. This fact comes to the front with force in the matter of subjects that are continued through two or more years. Here it will be necessary, if the outline is used, for the teachers of the different grades to confer and agree upon the outline to be given and the amount that should be given out during each year of the work. The outline is especially of value in the review, where it is necessary that each part of the subject shall be seen and reviewed purely from its relations to the whole. Outlines should be prepared fresh each year with due regard for the advancement and peculiar fitness of each particular class. This will also give opportunity for any change in the subject matter, any advance or increase of the teacher's knowledge or change of method in teaching it. The outline itself may best be divided into two parts appropriate in content and length for the class consistent with their age, advancement in the study of the subject and general preparation for it.

Another of the special advantages of the outline apart from the knowledge of the whole which it makes possible, is, that it gives a logical division of the subject even down to topics and subtopics, when each part of it can be seen in its 
relations to the whole, one thing taken at a time without fear of its being conceived of as a separate whole without relation to the other parts, both those now past and those still to come. By being logical in division and treatment the subject will conform to the natural methods of the mind and consequently will be better and more quickly grasped and longer and more clearly retained by the pupil. Again, besides enabling the taking up of as small a part of the subject matter as the circumstances may demand the outline also permits the limiting of the length of the lesson with ease without undue sacrifice of the connection and the conception of the part in its relation to the whole. Success in teaching a subject means that there must be due precaution taken to see that a given lesson is mastered before the class takes up another. It means also that the assignment must not be too long even if the assignment must be reduced to the "one thing at a time and that done well" rule. Furthermore, it means that the various parts must never be allowed to lose their relation to the whole in the pupil's mind, and that every legitimate means available both natural and artificial must be taken, to remove all unnecessary and insurmountable difficulties, arouse interest and hold the attention of the pupils.

Teaching How to Study. While the process of teaching how to study is, as is the assignment of the lesson, a matter accessory to the hearing of the recitation, like the assignment it is really more important than the recitation as far as the getting of knowledge from the lesson is concerned. This fact is evident since the hearing of the recitation is only for the purpose of seeing how well the principles of the assignment and those of studying have been understood and how effectively they have been applied. In the crowded curriculum of the schools of to-day and the constant pressure from parents, superintendents and school authorities for tangible evidences of progress, the teacher who has not full self-possession, determination and a clear knowledge of that which is fundamental in school processes in contradistinction to that which is superficial, is often likely to desert the true educative processes for the false ones. Demanding results in a schoolroom without knowing how these results are ob- 
tained, low permanent they are, or how effective for life they will be, is a serious mistake and one which no well wisher of the school or of the pupils can safely afford to do. When those on the outside make this demand without knowing the evil it will entail upon the pupils, it becomes the duty of the teacher who does know this, to insist upon the righteousness of his method and to pursue the ends of the school work according to those methods which science assures him will bring about the best and most lasting results. Demand for subjects should never be allowed to take precedence over the demand for study hours, nor the amount of work which can be thoroughly and well done, neither with the teacher nor with the pupil. Study hours should be given to all pupils of whatever grade and should be well dispersed throughout the entire day and week. Not only study hours when the pupils may study undisturbed are necessary, but also study hours when they may study under the guidance and supervision of the teacher. Every daily program if it expects success to attend the efforts of the teacher should allow vacant periods for teacher and pupils, especially in the lower grades, where the habits of study are being formed and the pupils need help and guidance. For in the early stages of acquiring habits of study the pupils need the assistance and supervision of the teacher. As was seen above, the pupil either through inattention or other causes is likely at any time to miss the assignment of the lesson or when he does not miss it to misunderstand it. Unless discovered and remedied early this shortcoming will bring serious obstruction to the progress of the child in his work. But only conjoint study between teacher and pupil can detect this fact in time to bring about the best results for the pupil. Whenever there is a misunderstanding or miscarriage of the assignment undirected study is a harm whose effects may develop bad habits in the child that will follow him throughout his educational career and even on into the activities of life itself. Of course, just as it is bad application of principle to make the assignment so easy that the child will have nothing to do and thereby defeat the very purpose of assignment, so it is possible for the teacher in attempting to study with the 
child, to study for him and thereby give the child nothing to do to cultivate his mind and whet his appetite for study, thus robbing him of the true benefits of study, making him lazy and dependent and annulling the good effects of both the study period and the studying process, for the attainment of which the study period and its methods were originally initiated. However, it must not be understood that mere reading over of the lesson with a pupil is study properly so-called. There must be explanation, the explanation arising from thought-compelling questions, thought-compelling voids in the content of the lesson.

The first time the lesson is read over only the more prominent facts should be sought out. These should be explained and driven home to the mind. Subsequent readings should each add their quota of facts of secondary or tertiary importance until all that is desirable in a lesson is obtained. Like the words of the teacher but perhaps more prominently and frequently so, the words of the text are beyond the comprehension of the pupils. As a result he may oftentimes labor throughout the study period not getting his lesson not alone because he does not know how to get it, but also because he does not know why he does not know how. Another advantage of the study period is that during it the teacher can learn the methods of study used by the pupils and thereby discover wherein they are faulty and very often why in their application they bring failure. L. R. Fiske says in this regard that during the study period the teacher should find out not only "what has been learned" but also "how the student proceeds in gaining knowledge should be investigated and guidance offered" where necessary. Hinsdale writes "The teacher is to help the pupil to learn his lesson by explaining its language. He should not so much work for the pupil as with him. He should guide him not by directing him to go forward but by leading him forward." Prof. Frank McMurray in his "Method of the Recitation" says "wrong methods of study, involving much unnecessary friction, prevent enjoyment of school. This want of enjoyment results in much dawdling of time, a meager quantity of knowledge and a desire to quit school at the first oppor- 
tunity." The danger of misunderstanding and confusion from the language of the text books is particularly prominent where different text books are used in the same class, or where in attempting to supplement the work of the class, pupils are referred to other texts. While such a practice is undoubtedly a commendable one and is filled with magnificent possibilities of good, the teacher should be well acquainted with the texts suggested both in their thought content and word usage so that he will know that it will be easily understood and that it will not either by the facts it gives, the language which it uses to express these facts, or by the trend of the thought advanced, bring out in the pupil's mind contradiction or lead to confusion in the pupil's thought. These dangers if allowed to creep into the use of new or different text books will do more harm than the supplementary knowledge they contain will do good. "To make the text book a help " therefore, says Bain, " and not a hindrance demands the greatest delicacy; the sole consideration being that the pupil must be kept in one single line of thought and never be required to comprehend on the same point conflicting or varying statements."

Study Questions. In centering the attention of the pupils upon the main points of the lesson a system of questions have been worked out known as " study questions" which are very widely in use and which have received the sanction of most authorities on the subject of pedagogy. These study questions are ordinarily divided into two groups: "questions for facts" and "questions for thought." Questions for facts are of particular use and value in the lower grades where the thought power of the child is just beginning to unfold. As the thought power of the child grows and his development along this line is assured, there should be a corresponding substitution of the questions for thought for the questions for fact. The principal drawback to the method is when it remains composed entirely of questions for facts. These tend to chop the lesson up into a mass of ungraded elements and calls for facts without showing their natural relation to other facts. It also too often descends to the stage of mere mechanical parrotlike study period and recitation that 
are the ruination of independence in study, thought, recitations, knowledge and afterwards in the activities of life itself. Everybody who studies or has studied knows that very few of the facts of a given lesson, section or chapter are of equal importance. Any system of questions for attack and mastery of these facts that cannot or does not recognize and allow for this difference in importance must of necessity be faulty, allow of frequent error and entail much needless and profitless labor. Questions of fact in the study of the lesson tend very strongly in this direction. Because of the low status of the child mind they are perhaps necessary in the lower grades but should be abandoned as early as the development of the class intelligence will permit, if they are to do good and not harm.

Besides the fact that these questions produce self-activity and even thought on the part of the child, they give him something definite to do, and serve to awaken in him the spirit and desire for achievement, when answers to them are found. Too, since they are concrete, they have a native power to awaken and enliven interest, especially when the interest of a long and tedious lesson would lag. These questions should always be upon the main points of the paragraph or topics. Where there are subtopics or points of secondary importance questions should indicate their presence as well as their relation to the main points, and discussions should show their value in the lesson. All study questions are best put on the board and perhaps hidden from view by a map or other device until the class is ready for them in order to avoid the distraction which they will cause when exposed to view while other matters or recitations are before the class. This is on the assumption that all study questions are prepared beforehand by the teacher either at home before school or even during a study period of the pupils. If study questions are to do justice to the pupil and the lesson and give credit to the teacher, previous preparation of them is always necessary. Once prepared, convenience may demand at times that they be dictated to the pupils from the teacher's copy. Study questions become particularly effective if the class has been accustomed to outline work in 
the text. In such case the questions can be shown in their relation to the entire outline. In this manner gradually the questions for minor facts may be omitted and by referring to the outline and the main points as indicated by the questions, the pupils may easily detect all that is important in the lesson and just wherein they are important. As the child becomes experienced in the use of questions and outlines he can produce both for himself and work by them now and later when he will have reached the point of independence in the schoolroom and recitation processes. This should be the true aim of the teacher in all of his efforts with the pupil. Then he will be able to direct his own studies almost entirely independent of the teacher.

The Effect of Environmental Conditions on Study. Other things of importance that will contribute materially to the results of the study period in the school are the physical environment of the room, the physical and mental environment of the pupil and the condition of the tools (facts) with which he has to work. Anything which tends to increase the normal dissipation of energy will to that extent effect the capacity of the pupil for study. While all forms of physical defects produce a constant drain upon the bodily energies in the activity of the organs, the sense of sight is the chief source of drain in study, if defective. Bad light, bad ventilation, bad heating and other unfavorable conditions such as the accommodations of the body in the seat, all tend to dissipate the energy of the pupils and cause early fatigue in whatever form of activity body, mind or both, are engaged.

In this regard the effect of the use of hard pencil and bad paper in the case of written exercises is worthy of notice. Besides the serious temporary weakening and possible permanent impairment of the organs of sight by such a practice if continued, the immediate strain upon the eyes in reading faint writing is very exhausting and would soon dissipate the energies of the body and make suecessful study impossible. Soft lead pencil writing on good paper is much better on the eyes than that of hard pencils. But as far as the eyes are concerned, experiments have shown that material 
written in ink is the most satisfactory study material for the pupils. Of these black ink used on good paper gives best results, closely followed by writing in heavy blue ink. Study of this question of favorable working instruments and favorable working conditions has caused much attention also to be given to the matter of the quality of paper and the size of print used in text books. Not only are these of vital importance to the health of the pupil and to his eye sight, but they materially affect the study habits of the pupils. Pupils who must strain their eyes to make out the physical character on a page or must even put forth special effort to make them out clearly are placed at a disadvantage at the outset and are called upon constantly to put energy into the mere matter of distinguishing the characters which should go into the understanding of the facts of the lesson and the mastery of the thought elements contained in it. If both of these must go on during the study period the pupils soon become tired and exhausted long before the study period is over or the lesson is mastered. Those pupils who suffer from bad or defective eyes become exhausted even before the remainder of the class.

Home Study. It is this guidance and supervision of study so necessary to young minds which is made possible by the presence of the teacher which gives school study the advantage over home study. In most homes the requisite conditions of quiet together with a fitting place for study are generally wanting. Too, oftentimes the child is disturbed from his study by thoughtless parents, relatives or friends merely for service or convenience and less often as a means of discipline and punishment. Few parents know the real value of study to the child, while still fewer parents are able to aid their children in the processes of study. Of those few who are able to aid them only the most limited number know the methods best calculated to give the desired results in knowledge and in strength required for future self-direction. In the young from a physiological viewpoint there should be as little restriction upon the activity of the child outside of school hours as possible. For this reason lessons that will confine pupils or restrict their activity out of school to any 
great extent should not be given them. Besides that, in these younger ones more so than in the older pupils the habits of study need to be guided so that they may be properly performed and the child be given the proper start in his school work. Parents seldom have the time to give their children for studying with them, assuming that they know how to study with them properly. Again the material for illustration, suggestion and help available in the school room during the study period if it could be used skillfully at home by the parents, which is seldom the case, are not to be had generally there. So that for all of these reasons, namely, to secure the proper formation of habits of study, to have available the proper accessory illustrative material for study and the general supervision and direction of efforts in study within the time allowed for this supervision and direction, to be assured of some one charged with the responsibilty of seeing to its use and the general strain and restriction it puts upon the child activity outside of school hours, the assigning of lessons for home study is to be condemned especially in the lower grades and to be sanctioned even to a small degree only after children have advanced sufficiently in years and acquisition as to be practically selfdirective and at the same time have bodies sufficiently strong to stand the strain and confinement incident to home study.

\section{REFERENCE READING}

Bagley's " Educative Process." Chaps. XIX, XXI, XXII. DeGarmo's "Interest in Education." Chaps. XII, XIII. Morgan's "Psychology for Teachers." Chap. II.

White's "The Art of 'Teaching." Chap. IX.

Jones' "Teaching Children to Study." Chaps. VI, VII, VIII.

Colgrove's "The Teacher and the School." Chaps. XIX, XX, XXI.

See also references Chap). XIII - The Hearing of the Recitation. 


\section{CHAPTER XIII}

\section{THE HEARING OF THE RECITATION}

The Kinds of Recitations. There are two kinds of recitations, the written and the oral. Even the examination as conducted in the school serves as a form of the recitation. Both for the sake of time, which is a very important factor, as we have seen, in the routine processes of the schoolroon, and for the sake of the proper expression of ideas, which is paramount both in the routine processes of the schoolroom and in after life, the oral recitation is to be preferred in the classroom to the written. Another point in favor of the oral recitation is that it permits a free and ready exchange of ideas both between pupils and between pupils and teacher, as well as makes easy the correction of mistakes either in the understanding of the text or in the expression of the ideas gleaned from it.

Written recitations too, have their good points and are advisable at times both for the sake of variety, for the concentration it brings and the intensity it gives to the mental processes by combining in action the sense of seeing the sense of hearing and sometimes the muscular sense (in writing the exercise). Written exercises are best done on the black board where all may see the work and get the benefits, thus concentrated and intensified, of the criticism, correction of mistakes and other helpful suggestions. The written recitation also may serve as an exercise in writing. Such an end, however, with it should only be secondary, especially since writing is provided for by special arrangement in the daily program. Most of the consideration therefore, here will be given to the oral recitation. Where, however, the written recitation is meant, the reader will be able to understand it as such from the sense of the text, if no special mention is made of the fact. 
In the recitation the teacher may have the pupils recite individually or he may have the class as a whole recite in unison. The best and perhaps the only valid reasons for the class-union recitation is that it serves as a variety and breaks the monotony, saves the time of the class, both that which is lost in rising and sitting, in passing unanswered questions from one pupil to the other together with that time which is lost in the delay caused by the slow and timid pupils and the correction of such individual mistakes as are detected in the correct answers given by those members of the class who know the lesson. Psychologically the joint recitation tends to arouse the mind, stimulate it to action and thereby gain interest and hold the attention. However, while these points in favor of the class unison recitation are worthy of consideration, they make impossible some of the basic purposes in which the recitation originally was intended to serve the individuals of the class. So that as a continuous process of hearing the recitation the method is to be condemned. The recitation is for the purpose of individual as well as class work. Teachers hear lessons more to learn what the student does not know than to learn what he does know. The class unison method reduces the obtaining of this information to a minimum. Thus it is hardly possible in the class recitation, for example, to tell whether the assignment was properly understood and applied or whether the study period was effectively used by those pupils who do not know their lessons and who being aware of that fact may take advantage of the class recitation in unison to hide their faults and ignorance by either keeping their voices low, or by saying nothing and moving their lips in harmony with the class, while it is reciting. Furthermore class recitation permits inattention on the part of those members of the class who are inclined to inattention. Another very common and merited objection to it is that it disturbs the order of the room and of the whole building and prevents effective study by those classes in the room that have a study period, as well as of those in the building who happen to be studing at that time. Consequently it is rightly so that the class recitation should be little used, the chief time and 
stress of the recitation being devoted to the individual recitation.

The Individual Recitation. To begin with in the individual recitation the child should be taught to stand when called upon to recite. If sufficient effort is put into getting onto his feet it will help materially in having him put aside all distracting thoughts leaving him free to give his whole attention to the matter of the recitation. To have the pupil stand while reciting also tends to remove him from any evil influences of his environment; inasmuch as it generally puts him beyond the reach of his fellows, or his book, or both, thereby putting him entirely upon his own resources and compelling him to think for himself. Since, as is generally agreed, the attitude of the body reflects the attitude of the mind, it follows that slouchy, lazy, lounging attitudes of the body should not be tolerated in the recitation for fear they may beget a like attitude of mind.

Now comes the recitation question. Much has been said and written about the proper time of asking the questions of the recitation! Here, too, variety might be practiced to advantage. In fact stereotyped methods in any and all forms of school exercises are to be in general condemned. It will be found, in the recitation questions, to be productive of the best results, if the pupils are niade to stand before the questions are asked them. The advantages are obvious. In the first place this method arouses in the pupil expectant attention in which state of mind the pupil is more likely to summon all of his efforts and begin to think, running through in his mind all of the topics and study questions of the lesson. It is a fact, however, that this method in some minds will tend to confusion and the loss of the power to think, the longer the period of delay the greater the helplessness and confusion. In these cases, which will be due to individual temperaments it will be best to change the method so as to give the pupil a chance. During the moment of expectant attention as never before the child will appreciate the need of having previously mastered his lesson. The question coming then removes him entirely from his neighborhood environment and the last vestige of distraction elements be- 
ing forced out of him, temporarily at least, leaves him free to devote his whole thought power to the finding of the proper answer to the question. This method is very rigorous and highly disciplinary. By some it is condemned because under it the timid and easily excited pupils become confused in the interim between tho request to rise and propounding of the question, whereupon all knowledge either "vanishes into thin air" or loses its connection in their train of thought thus resulting in the giving of an incorrect answer. There is, to be sure some justification in this plea. However, the validity of the other method is not to be questioned on this account, nor its use abandoned. In general, it is undoubtedly the best method both for matters of the recitation and as a measure of discipline. Along with the matter of the appropriate method of asking them, it goes without saying that all questions should be clear, brief and contain but one central thought. Nothing is more confusing to any mind or more discouraging to pupils who have spent so much time and effort in preparing a lesson than to be confronted in the recitation with questions that are either untimely, indefinite, unclear or too long. Of course, from this it does not follow that questions should be mechanical, or, especially with the pupils of the higher grades, that they should be mere questions for facts, but rather questions for thought. Fact questions rather mechanize and stagnate the mental powers, while thought questions arouse the mind and stimulate it to healthy activity. When answered nothing less than a full answer to the question, such an one that will indicate fully that the pupil has both heard and understood the question in detail should with justice be accepted.

The method has been adopted in many schools of having the pupil so shape the answer that it will repeat the word and thought of the question. This method has its good qualities and may be practiced where preferred, though the method has been overdone and debased by many untactful and unresoureeful teachers. The only thing essential in answers as well as questions is that they should be full in their thought content as well as in their form content. The time long 
method of questioning given to the teaching profession by Socrates and bearing his name is still in use. It is still to be recommended to all, though it has its shortcomings, its force for effectiveness depending upon the teaching qualities of the teacher who handles it. The Socratic method gets its virtue in fact almost cntirely from the skill with which it is used. Its aim is to deprive the mind of its power by stripping it of its contents, show what little it contains and create in the mind a desire for that knowledge, which it does not contain and thereby excite to activity in an effort to acquire such knowledge. It stimulates the mind to think for itself. The method is to be condemned to the extent that it is not effective to present truth but only puts the mind in a position to receive truth, whereupon it must go off in search of it. It only draws out that which is in the mind. Present day methods however do not aim to stop there. They not only must create a conscious need for truth, but they must cither supply it or see to it that it is supplied. Its duty lies more in the latter field. To effectively apply the art of questioning requires more than a novice. To be effective questions must come from those who know the psychological laws of association and suggestion as well as the laws of mind in general. Equally must the questioner know the subject matter both in part and in its entirety, and the relation which the part bears to the whole. With this before him the purpose of the lesson, just what part in the whole the facts of to-day's lesson are to play, what particular gap in the student's mind is to be filled by them, can be readily brought out, and must be, if the purposes of the recitation are to be fulfilled.

The Order of Questioning. In what order these questions are to be asked is the problem which is now to be considered. One of my teachers in college in a class of about seventyfive used to enroll us on specially prepared recitation card forms. These were arranged alphabetically. Before he had gone many letters down the alphabet most of the class had caught on to his method and proceeded to prepare their lesson as the Professor's progress down the line of names seemed to indicate that their turn would come probably in the next 
day's run. Just about the time the class had become settled down to this method the Professor without a word of warning struck consternation into our midst one morning by shuffling the cards and making a new start. He went around the class several times that morning and had time to spare. The wisdom of the procedure needs little comment. The brighter and more honest members of the class soon found the safe road to good marks and ultimate promotion and followed it. In this connection there are many methods to follow in asking questions of a class in the recitation. They may be asked alphabetically, by the order of seating, the order of enrollment, their rank in the class, and other methods. But that is just where a grave fault lies. To attempt to follow any order for any length of time is unsafe for the best results. The most stupid and dull pupil soon learns such a method when employed by a teacher. In fact the more stupid and lazy pupils, if they do not detect such a method first, at least are among the first to avail themselves and prepare themselves and their lessons in such a manner as to profit by it. Experience, and it requires very little, shows that calling upon pupils to recite at random, is always productive of the best results. Then pupils can conscientiously prepare each lesson expecting that he will be called upon more or less times to do a fair part of the class reciting each day. Besides this the ability to propose questions opportunely for answers is effective in discipline and soon wins both the fear and respect of the pupils. The evil of ignoring the dull pupil in favor of the bright ones is a common one. Pupils should all be treated alike and given equal opportunity for reciting each day's lessons. They ought never be allowed to feel that they will in all probability not be called on again, or at least, not until the other members of the class have recited. When for example, for any reason disorder prevails in any section of the room giving out a question then and there to the pupil in disorder, or requiring him to take up the question where the other left off will serve to produce order, enforce attention and teach the child the need of always paying strict attention to the processes and progress of the recitation. The real fact is, 
the effect is wholesome, if pupils can be made to feel at all times that they may be called upon either to begin to recite, to complete the unfinished recitation of another or even to repeat such a recitation. When such methods being employed fail and the proper disciplinary measures follow once or twice it will be discovered that more attention will be devoted to the recitation by all members of the class and that it will take on new life and show marked change for good.

The Function of the Teacher in the Recitation. Teachers should never lose sight of their function in the recitation. To hear, correct, explain, extend and briefly supplement the expressed thoughts of the pupil is their whole duty. 'The recitation is not for the teacher, it is for the pupil. For the teacher to use it in telling what he knows of the lesson to the pupils is ostensibly out of order. Too, consequently, his language should be simple, brief and always to the point. To be a good listener is a trait whose quality is proverbial but nowhere is it more valuable than when properly exercised in the schoolroom by the teacher. To offer the missing thought or word whenever there is a pause in the flow of language of the child soon checks the flow entirely or sadly impairs it and tends to make of the otherwise industrious energetic pupil a lazy, lounging drone, always sufficiently awake to start off the recitation feeling assured that the ever ready teacher will finish whatever he starts out with. The real end of the hearing of the recitation is to test how well from the student's viewpoint the lesson has been assigned, how well studied, how well the principles of studying applied and how well the facts and thoughts of the lesson together with the words in which they are encouched have been understood. This can only be known by letting the child express his knowledge gained about the lesson in his own language, tell what he himself has gotten out of the lesson and tell it in his own language. It is a scrious mistake for the teacher to allow himself to feel that he can anticipate what the child is going to say. He can only know what is coming from the pupil when the pupil has finished with his recitation. The recitation should be exact, complete and as brief as a full statement of it will allow. Brevity, however, in the recita- 
tion, is secondary and will be acquired only by practice. Pupils should be taught to be definite in expression of their thought. No answer ending in "and something like that" should be tolerated. Such answers if allowed have a tendency soon to break down all disposition toward exactness and care in the preparation of the work for the recitation. Time may become very pressing at times, the demand for speed and advancement imperative, whereupon the desire to assist with a word or two will almost be uncontrollable. Surely, the teacher may reason, just a word here or there to help express an idea that is known cannot do much harm. But if indulged in, it marks the beginning of a habit to help on the part of the teacher and a habit to await the assistance of the teacher by the pupil, both of which habits easily grow and ruin the best capacity for work in each. I know it may seem to the teacher that since the pupil knows the lesson and knows how to express it in the main, that one word has failed him, the time of the class cannot be taken up in this waiting and hence it will not matter if I help him a little. This is a common and potent argument in such cases, but the best thing to do is for the teacher to guide and direct the work, leaving the actual doing of it for the pupils. This will be found best for the good of the pupil in every way. Reason, the art of reciting, the habits of study of the pupils as shown above and the work of the recitation for the pupil are soon ruined by this method. The start once made, it is easy to keep up the practice. Here a bad habit is hard indeed to break. Soon the pupil will be hearing the recitation instead of the teacher and the teacher will be reciting instead of listening to the pupils recite. Such teaching is the great burden of the profession to-day. Of course the teacher can tell the pupil and save time for other work. This much is granted. But what good will the pupil get out of it? How mueh independence of action, how much thought activity, how much knowledge, will the pupil get out of it? What is happening to the pupil all of this time? How is the judgment of the effects of the assignment to be gained by this method? How is that of the study period? How is the teacher to know whether or not the pupil 
understands the words of the text, whether or not he is growing in power of self-direction in his study, whether or not his power of expression is developing and whether or not he is acquiring facts of knowledge and power of thought in using them? All of these are primary in the methods of the recitation, yes in the method of the schoolroom and of the whole educative process of the school, if the child is to be aided at all by it in his preparation for activity in the broader field of life. As to how much talking the teacher may safely do in the recitation there is now and has ever been a serious problem. Of the two evils how much talking or how little, it is pretty hard to decide which is worse. It is perhaps better too little than too much, though both are bad. However, the former is the greater evil and the one that needs to be most inveighed against. In general it might also be said that the teacher should aim to make his efforts tell and do his talking in the assignment and during the study period, while the pupil should be allowed to make his efforts tell in the recitation. At appropriate moments the teacher may step in and support the child when he cannot help himself. But he must be well assured of this fact. Nor must the act be committed too often. The mere fact that time is pressing is no legitimate excuse for too much activity and talking on the part of the teacher during the hearing of the recitation. Indeed that is just why the time for hearing of the recitation is given to the school. To use it for the purpose of the recitation is not only legitimate but a necessity, for the rendition of proper and successful service to the public by the school and the teacher.

The Favorite Subject. Other dangers to the attainment of good results in the recitation are the favorite pupil and the favorite subject or subjects. The danger which the favorite subjects offer is of secondary importance in the conduct of the recitation. They should have been properly disposed of by the course of study and the daily program, if they were properly made out and are properly followed. The trouble with the favorite pupil and the favorite subject is that they are a part of our nature and owe their existence 
to the principle of individualism that runs through all animal life and if we are to accept the more sweeping opinion of the advanced scientists through both the vegetable and mineral kingdoms. That, therefore, we meet the problem of favorite pupils and subjects in the schoolroom need not surprise us in any way. Under this principle it will be natural to find both pupils and subjects that will interest some teachers more than others. This fact, however, because of the harm consequent in its practice in the schoolroom should not be allowed to enter and vitiate the work of the schoolroom. Very often favorite subjects have followed teachers all of the way through their school career and by reason of over attention to them they are especially proficient in them. The fact of its being a favorite subject is probably due to some special ability which they discovered they possessed in it. The opposite history is probably true of those subjects that are not favorite subjects. Where teachers find it necessary to handle the non-favorite subjects the very fact that they are inefficient in them should cause them not to neglect them either in the process of the assignment, the study period or the recitation. The fact should rather cause them by resolution and effort to strive to make their efforts with them especially detailed, careful and resultingly successful. Nor should they neglect those subjects in which they are more proficient and better prepared to handle in the processes of the assignment, the study period and the hearing of the recitation. The aim should rather be to carry them all along with due effort to the demands and best good of the individual pupil and the class as a whole.

The Favorite Pupil. The favorite pupil is a problem of a slightly different nature. To begin with he is everywhere present. We find him in all classes and subjects. Not that he is the special favorite of the teacher in bestowing his evidences of approval, or that he is picked out for all of the special privileges of the school, though these generally fall to his lot. In that case it is a matter of school discipline and government and not one of the conduct of the recitation. Here, it is that pupil who is particularly bright and apt in various ones or even in all of his subjects, who 
learns his lessons well, understands quickly the assignment, knows how to use the directions of the study period, who learns his lessons well and quickly and expresses himself clearly and fully and freely. This is the favorite pupil in the hearing of the recitation. How to handle him best for his own good and that of the class is the problem. When the recitation lags the teacher is inclined to use him to bridge over the gap, when a point in the lesson is not clear or incompletely brought out or only partially correct he is the one to be used as a means of getting the proper answer and thereby awaken a feeling of pride in the other less apt pupils of the class. This is especially true if there are patrons, friends or school officials present and the teacher wishes the class work to appear well. $\mathrm{He}$ is in the true sense the "whip" of the classroom recitation. Through him the teacher gets lessons recited and incidentally stimulates the other pupils to habits of study and the making of better recitations.

All teachers have had their favorite pupil in this sense. They would hardly be human if they did not. But to treat him this way is the beginning of evil. Teachers owe it to themselves, the pupil himself and the class not to give such a pupil too much time, attention and consideration, either on special or ordinary occasions. For once such a method is started it is but a short step from this to the habit of ignoring the less apt pupils and giving all attention to the few favorite pupils, adjusting all demands of work, all remarks, explanations and suggestions to them and their abilities rather than to the general intellectual aptness and capacity of the class as a whole. In which case we have a class of special pupils rather than a class of pupils of various abilities each, however, developed to some degree and advanced to some extent in the work of the class. The problem of the apt or favorite pupil has led to the tendency quite prevalent in many school systems, but which has a good and a bad side, of separating the bright and dull pupils and of making of them separate classes. The argument justifying this procedure is that the dull pupils are a hindrance to the bright ones and since the schoolroom puts a premium on self activity 
and individuality the proper thing to do is to put the brighter pupils together in a class where they can secure the greatest self-activity and put forth the greatest individual effort. The argument, it must be admitted, has some weight, but the fact remains that while the dull pupil may be a drawback in many ways to the bright pupil he is also of material advantage to him. His untiring effort is a good lesson in industry and his questions and mistakes together with their correction by the teacher, will undoubtedly expand the knowledge of any pupil, however bright or advanced he may be. Besides it is a fact that the most effective work in teaching is done by those teachers who realize that they have a mediocre class which must receive their very best efforts if they are to make fitting progress. Consciousness on the part of a teacher that a class does not need care and effort will generally make that teacher careless and a bright class will soon become a dull one.

The favorite pupil in the recitation comes in for particular consideration on certain occasions as has been said above. But though on such occasions the teacher may mean well by the practice, besides its being discouraging to the more faithful pupils and very often ruining the bright pupils by giving so much consideration and attention to them, the method is to be condemned because it does not represent in the pupil his ability to receive teaching, or, to use a coined word it does not represent his "teachableness." To this extent such a pupil is not a credit to the teacher nor does he represent the actual ability of the class or the fruits of the teacher's effort with the class. Again, it is not the doing of the easy work that makes the man strong nor the teaching of the naturally bright pupils that proves the teaching ability of the teacher. But, just as power and skill are shown in the ability with which the mechanic performs the difficult tasks, so teaching is evident only in getting good results out of mediocre students. The fact is that if any members of the class above all others need the attention and efforts of the teacher constantly in the recitation, it is the mediocre and lazy pupils. The bright ones will generally take care of themselves. 
Nor is the habit of teaching for the "average pupil," so often recommended, best. The efforts of the teacher should by all means be directed toward the individual pupil and the work arranged for his benefit and advancement. In actual practice there is no average pupil, but there are individual pupils. The recitation is for the whole class and the questions should be so shaped and the answers to them so given that all may profit by them. The same should hold true of all explanations, suggestions, references, explanations and facts added by the teacher. Questions should be passed around to all alike and all should be forced to take an active interest and part in the recitation. Questions should be asked and answers given in the ordinary tone of voice, but clear and distinct. Repetition should be avoided, the pupils being given to understand at the outset that they must give close attention and "catch" the question when it is first asked. The habit of repeating questions besides losing much valuable time that should be given to the recitation encourages the pupils in not giving attention. No ends acceptable to the basic principles of education can justify any other method of treating the pupils in the hearing of the recitation. The questions of the teacher in the first place should open the child's mind for the reception of the answers given and the facts should be so given as to satisfy the demand thus created. There have been innumerable methods devised for the successful hearing of the recitation. The teacher who is enthusiastic and aggressive will acquaint himself with the major portion of these through the study and reading of such professional literature as will point out to him the more common methods out of which he can select those that appeal to him as most practical for his own use. Teachers should be conversant with many methods so as to be able readily to vary methods, thus keeping up interest and stimulating memory. For the best results in the life and interest of the class and the conservation of time, speed in movements, in thinking and speaking are essential both in the asking and answering of questions in the recitation. Then, too, sloth and sluggishness here soon lead to a like state in the mind whereby the whole aim of the recitation 
is weakened if not entirely annulled. Looking to this end care should be taken that lesson assignments are not too long. Nothing is more detrimental to successful recitation processes than long lessons. The quick movements and quick answers require in their execution and utterance greater concentration of energy and more intense discharge of it. This will tend to exhaust more rapidly the available energy when the recitation lags and the effects having been weakened are neither strong nor permanent in the association they form nor the suggestion they arouse.

Copying and Cheating. Crime exists in the world not so much because men are bad by nature as because they are weak and selfish. Life as an active striving process is a bundle of desires. Desires crave satisfaction in the yearning of the soul which they beget, they disturb the mental, moral and physical equilibrium and impel to that form of conduct in which intelligence sees the possibility of gaining the object of desires and by its satisfaction of restoring the body again to a state of equilibrium. For this reason only such punitive systems are justified which either satisfy the desire legitimately, divert them into channels where legitimate satisfaction of the desire is possible or remove the desire entirely. Those desires which men cannot satisfy by their honest efforts they either curtail or satisfy by dishonest efforts. This is the philosophy of crime both in the young and in the old. The stronger the will power and the keener the intellect the less disposed is the individual to crime, for he can both see the effects in consequences of his crime and will thereby become stronger to control his action. Equally true is it that the more of his desires he can naturally and legitimately satisfy the less is their demand upon him for illegitimate satisfaction, namely for crime.

Now, the chief crime that the teacher has to deal with in the recitation is that of cheating and copying. Investigation shows that cheating is done by pupils who do not know their lessons and cannot answer the questions and do the work of the recitation without assistance from others. While the teacher should by all means possible strive to break up the practice of copying and cheating, he should also strive 
to find out the cause of it and remove it, remembering that until he can do this it is safer to have the pupils understand, that it is much better for them to get the help openly from him than to seck it secretly from others. The teacher can help in a way to open the avenues of self help for the pupil, for pupils do not know often of means of self help nor do they realize the dangers that lurk in their own methods of prompting one another and of giving to and of receiving aid from one another. The canse of the lack of knowledge of the pupil of the subject matter of the lesson either is laziness and lack of application, some form of physical weakness such as impediment of speech, or of mind such as slowness, timidity, bashfulness or lack of understanding of the words of the text, the assignment of the lesson or the proper use of the study period. If it happens to be laziness that has placed lim in the position of not having gotten lis lesson then a corrective means either punitive or disciplinary should be applied. However, it will not do for the teacher to conclude too hastily that it is due to laziness on the part of the pupil. Even when the cause has been found to be laziness oftentimes upon examination the methods of the teacher will be found to have been contributory to that laziness rather than to have detracted from it. Oftentimes again, various forms of physical defects hidden in the inner physical structure of the child may be a contributing cause, or some form of inherent weakness or secret malady may cooperate to sap the energy and vitality of the pupil, though the general bodily appearance and attitude of the child may be expected generally to betray such early, when present. Affections of the eye and the ears are particularly contributory to bad work in the school and especially in the recitation. Whenever careful observation of the pupils fails to disclose any of these shortcomings and the teacher still has reason to believe that they exist he should call in professional assistance on the one hand for the pupil and look carefully into himself to see if the trouble does not lie within himself. A little care in the technique of the assignment, a little special supervision during the study period and perhaps a revision of the study questions according to the prescribed principles 
together with the putting forth of special effort to draw the pupil out more fully during the hearing of the recitation, if it does not cure the trouble will at least point it out so definitely that the teacher can then more readily form and apply methods to overcome the fault. The use of objects and other illustrative material, such as maps, pictures, etc., since they possess natural powers of clarifying knowledge can often be employed in these cases to advantage.

Examinations and Reviews. Memory and retention depend largely upon the clearness, vividness and repetition of the original stimuli; whether they be mere sense disturbances, newly given perceptions or recently created coneeptions. The especial process of repetition known to the recitation is the review. The purpose of the review in the recitation is to recall and fasten in the mind the facts of former lessons, connect them together and bind them into a whole based upon definite relations. Inasmuch as the early impressions in the young are light and the paths of nervous discharge for various stimuli shallow and often but poorly formed they are easily removed and lost track of in the stress of responding and forming paths of discharge for the inroad of new stimuli unless they are retained and made permanent by renewed discharges by means of reviews. Too, the molecular combinations resulting from the ideas in the minds of the young as translation of the molecular motion started by the external stimuli along the paths of discharge are particularly unstable and unless they are made deeper and more stable by repetition soon under the tendency to break up and form new combinations lose their force of attraction and disintegrate. These are the physiological justifications of reviews. Pedagogically speaking, a part of each day's recitation period should be given over to the review in order to prepare the pupil's mind for the reception of the advance lesson and provide a fitting opportunity for connecting the facts of the new lesson with those of the past lessons. The further on the class is, the more general and more important the facts brought forward each day in the review become. The importance of reviews especially where outlines are not available is always to be noted and suf- 
ficient time in the program allowed for them. In reviews, however, only the thought and the most important thought at that can receive time and attention. The descriptive details that serve the purpose only of accentuating or making clear the facts need receive in review no more than passing consideration, even if that. Care must be taken in the review, however, that the pupils do not become weary or that the facts of the review lessons become common and thereby repulsive thus begetting indifference to them on the part of the pupils.

Reviews if allowed to affect pupils in this way are perhaps worse than no review at all, tending as it will to decrease the desire for knowledge and decrease the effort toward self activity. Child mind especially, tires very rapidly of that which has become familiar. It demands ever the new to excite interest, gain and hold the attention. This is particularly true where the reviews involve going over the pages of the text again and again. Carelessness in preparation, indifference to the work of the lesson and general discouragement are very prominent dangers to this kind of review. Of course, only chiefly the old facts can be brought out in the review, otherwise it would not be a review. To meet this demand in the young for something new, however, the old facts can be presented in new ways, illustrated by new material (intellectual), by the outline or other devices of the teacher and thus made pleasing, interesting and effective. In this way, too, variety can be introduced at any time whereby the facts of the text will not lose their spiciness and power to awaken interest and hold attention. Both reviews and examination show the teacher how well his work of outlining the text, making the assignment, directing the work of the study hour, providing the study question, asking the questions of the recitation and explaining and supplementing the thoughts of the pupils have been done, wherein he has failed, what is necessary to be repeated and what avoided in the future for improvement and permanence in the class work, the recitation. The advantage of examinations over reviews is gained by the fact that more time is given to them, they are written, represent more fully the 
detailed reflective and retentive powers of the individual pupil and afford opportunity for detailed study, by the teacher, of the good and bad side of his methods, besides bringing to the surface other little faults in spelling, writing general diction and misunderstanding both of the sense and words of teacher and text.

"The Aim of the Recitation." The usual methods of imparting knowledge are through books in the general sense of the term, by formal lectures, various forms of explanation, a proper use of questions, by direct observation, experiment or experience or by a combination of any two or more of these methods. The aim of the recitation in so much as it is the crowning point of the school process and in relation to which all other processes are merely secondary and contributory, is co-extensive with the aim of the school and that of the educative process itself. To attempt to enumerate and discuss all or even most of them here would carry the work far beyond its intended scope. The mention and brief discussion of a few of these, the most important, however, will not be amiss here. Generally speaking the aim of the school is to put into the possession of the child the known instruments of civilized man and to give him skill and power in their use. The immediate process by which more than any other it is sought to accomplish this end is the recitation. Consistent with this view the aim of the recitation first of all is to prepare the child's mind specifically to receive knowledge, to impart to it knowledge and to train him how to use and acquire knowledge independently for himself. Or, stated somewhat differently, the recitation aims to give new knowledge, to connect this new knowledge to old knowledge and thereby extend the latter, and to enable the application of knowledge to the practical affairs of life by furnishing a supply of good habits in physical and mental movements. One author states the ain of the recitation as being " to give knowledge in the arts; power in knowledge getting and knowledge using; knowledge of how to treat our bodies; how to treat our fellows, how to be mentally and physically happy; how to shape and attain ideals; how to reach truth." Another offers the following as the chief aim 
of the recitation; "to arouse class interest; to accomplish class work; to effect advance in work; to promote independent work; to secure power of expression; to exercise the mind." To these aims might be added the ones, to organize ideas and provide individuality in thought and action. Here is undoubtedly a variety of purposes for the recitation in its entirety to serve. It can hardly be doubted but that it does to a considerable extent serve these ends. Indeed it serves these, as has been said, and many others. However, the best that may be said for all of these aims is that they emphasize, if indeed emphasis be necessary, very decidedly, the great importance of the recitation and the very imperative need that it and all of its accessories conjointly and in detail be carefully administered if the work of the whole school is not to fail, and the time, energy and money of all who contribute either directly or indirectly both parent, child and citizen to the efforts to provide educational opportunity for the child and place him under the control of the best educational processes be not used in vain. Having considered the aim of the recitation we now pass to the steps of the recitation.

The Steps of the Recitation. Some authors give as the steps of the recitation preparation, presentation, analysis, abstraction and application. Others give preparation, presentation, association, comparison, generalization and practical application. Still others shorten or extend this list by addition to or omission from it. All of these steps have been foreshadowed in the previous discussions of the chapter on the "Accessories of the Recitation" and the earlier part of this chapter. They are more or less familiar to the whole educational world and also generally in use by it. They are more suggestive in use than mandatory. The essentials of them should be followed in every recitation, but to attempt to adhere too rigidly to them in practice would so mechanize the recitation as to reduce its effectiveness. The purpose of the first step, namely, the preparation both of the teacher's mind by the teacher becoming thoroughly conversant with the facts of the lesson, in their relations with the preceding and succeeding lessons and the 
mind of the pupil for the reception of the facts of the lesson, in order that he may easily and readily comprehend it, is to be gained by the refreshing of the teacher's mind with the nature and relation of the facts and that of the pupil with the facts learned in the past lessons, their connection with those to come and their relation to the entire subject as treated in the text and given in the outline. The unprepared teacher is like a ship at sea without a rudder, unable to make the shore, wandering helplessly about embarrassed by her helplessness yet unable to make progress in the lesson. A state of unpreparedness in the teacher before his class is wholly inexcusable and fraught with every evil misfortune common to the school. To attempt to sow the seeds of fact in the lesson in the unprepared soil of the child's mind is almost equally costly. The preparation of the child's mind however for the recitation is practically accomplished in the assignment, if the assignment were properly made. It depends for its force chiefly upon the laws of memory, oftentimes called the laws of association, suggestion or simularity, whereby in the mental processes like tends to recall like; contrast, whereby opposites tend to recall each other; contiguity whereby the perception of things related in time and space tend to recall each other in the mental processes, etc., etc. As was said above the preparation particularly in as far as it refers to the child's mind indicates what is in it and what is in the lesson, shows the relation of the two and indicates why and wherein the contents of the lesson will tend to some degree to satisfy this apparent need. The teacher's preparation besides making known to him all of these facts before the recitation, permits him to devise means of bringing out clearly and impressing forcibly these facts upon the minds of the pupils, both naturally and by the use of such artificial means as may be available in the equipment of the school.

Presentation. The matter of presentation applies here only to the presentation of the facts of the lesson to the pupils by the teacher. It is a matter of considerable importance. Logically it follows the preparation of the child's mind for the reception of the facts of the lesson. To be 
properly done therefore it is highly essential that the lesson be so presented as to show clearly to the pupil that the lesson does either wholly or in part fulfill the demand which the preparation showed existed in the chain of facts that goes to make up their knowledge. Just as the preparation of the student for the facts of the recitation come in the assignment so the presentation first appears in the study period. In the presentation all of the technique and general principles of the recitation, the relation of the whole to the part as well as the general laws of conception must be known and carefully followed. Brevity, elearness, force in statement of facts and the general fitness of the mind together with the meaning of the words of the teacher and of the text must be well understood. The next four steps of the recitation, namely, analysis, comparison, abstraction and generalization are truly steps in the recitation proper. Proper analysis assumes that the pupil has a thorough knowledge of the material of the lesson, its relation to that which is past and to some extent to that which is to come, also the proper disposition of the facts of the lesson in their natural relation with the facts of the past and the future lessons. Thus are natural causal ehains established in thought and the new properly assimilated connected with the old and stored away aceording to the fundamental laws of the operations of the mind. Knowledge, then, becomes in the true sense the possession of the mind.

Analysis is highly complex and can only be done when there is full mastery of the lesson. It is, therefore, a stage in mental progress whose attainment is worth the best efforts of any teacher. Comparison follows naturally as the result of analysis. For before analysis can be completed by the proper storing away of the facts of the recitation in their proper places, which are determined by the natural relation, each of the parts appearing in the analysis must be compared in order that the true relation existing between them ean be discovered and the new facts stored away on the basis of this discovered relation, where, when the particular mental process is initiated they return to conseious processes under the control of the laws of association, or, as 
they are commonly called, the laws of suggestion. Abstraction also may be regarded as a cotemporary process with analysis as well as an outgrowth from it. It is cooperative with comparison in that when the facts in their parts are compared those which fall together by natural internal relations are drawn off from the others and set up by themselves. Its special use is to lead to some general principle or law by the processes known to logic as induction. It may also be used as a process in leading to deductions. This process of abstraction enables the drawing apart and separation of the individual facts upon which their clear definite arrangement is based. Abstraction works oppositely by the process of deduction, whereby the separate facts of the lesson are subsumed under general principles or laws already learned and accepted. The principle of abstraction is also one of the highest powers of the mind and as such should receive the constant attention and efforts toward development by the teacher. Suggestive questions given to the pupils after the facts of the lesson have been mastered may lead to abstraction either by induction or deduction. This becomes particularly easy if the pupil is allowed to use his own language and discover the laws under guidance from the teacher. To be of value the pupil should be encouraged to discover the law for himself and not have it pointed out to him. This last process is what is sometimes called generalization.

The last step of the recitation - practical application of the facts of the recitation - is supposed to give the child practical working efficiency with the knowledge content of the lesson. In this step he is supposed to know the relative value of the facts of the lesson and be shown how to apply them in life. To bring about this most effectively the facts of the lesson must be applied to new examples, to other cases not coming without the restrictions of the lesson text. Especially is it necessary to establish a relation between the principles and the problems of daily life, whereby it may be observed by the pupil wherein the school may and does prepare one for the practical duties of life. Let this be done and the school will have achieved a great service for the pupil, the state and humanity. The lesson steps should beget in- 
dividuality in action and power of self assertiveness. Knowing the facts in their relations of the part to the whole and the part to the part, the pupil is capable the more easily of breaking them down and rearranging them for any mental process which he contemplates performing. He can gather new knowledge, assimilate it to the old, initiate and originate thoughts by recombination of the old and new into different or new relations, judge society and modify his acts according to the judgments of society. He can express himself with force, accuracy and speed, learn the truth, shape and direct his actions in life so as to attain his life's ideals.

As was said above, however, these steps cannot be followed mechanically with any hope of success. They must be modified, omitted and combined as the circumstances will demand. Above all there must be variety in the combination and use of the steps of the recitation. Nothing prosaic and mechanical in their use will bring satisfactory results. For here above all else variety is the spice of life and sameness or the absence of variety will destroy the living activity that alone insures results.

\section{REFERENCE READING}

King's "Education for Special Efficiency." Chap. XIV. Bagley's "The Educative Process." Chaps. XXI, XXII.

DeGarmo's "Interest in Education." Chaps. VIII, IX, X, XI, XII, XIII, XIV.

Greenwood's “Principles of Education.” Chaps. IV, V, VI.

Bolton's “Principles of Education." Chaps. XII, XVI.

Baldwin's "Psychology Applied to the Art of Teaching." Chap. XXVIII.

Compayre's "Psychology Applied to Education." Chap. X.

Rosenkranz's "Philosophy of Education." Chap. IX.

Morgan's "Psychology for Teachers." Chap. II.

Münsterberg's "Psychology and the Teacher." Chap. XIX.

White's "Art of Teaching." Chap. XII.

Arnold's "School and Class Management." Chap. III, Sect. V; Chap. V, Sect. VI; Chap. X, Sect. VI; Chap. VII, Sect. II.

King's "Social Aspects of Education." Chap. XIX.

Colgrove's "The Teacher and the School." Chaps. XVIII, XVII.

Bransons' "Page's Theory and Practice of Teaching." VII, VIII, IX.

Howland's "Practical Hints for Teachers." Chap. XVII. 


\section{CHAPTER XIV}

\section{PSYCHOLOGIC PROCESSES IN EDUCATION}

Since the teacher deals with the child mind endeavoring to train and develop it, if he hopes to have any success worthy of mention crown his efforts it is highly essential that he acquaint himself with the nature of the child mind, and most especially should he get acquainted with its laws and processes of action. For this end it is not neeessary that the teacher should know theoretical psychology nor even practical psychology in all of its details though the more knowledge he had with both of these the better would he be able to guide, direct and control the child in the various school processes. However, it goes without saying that if the child mind is understood in the general detail of its progressive unfolding, both the quality of work and the quantity of work during the various periods of life of which the child is capable can be known definitely and the processes of the sehoolroom including the daily program, the course of study, the assignment of the lesson and the hearing of the recitation all can be arranged so as to be more nearly in aecord with the natural processes of the mind. Mere casual observation has shown that under certain natural unrestricted conditions the child mind works long and with evident pleasure. It is chiefly, because of this fact, when he is introduced into the school processes and does not usually work long, diligently or with apparent pleasure, that the school has set out in the method of nature to bring into the schoolroom its knowledge of men in order that the ends of society may be achieved by nurture with at least equal if not more prolonged diligence and enduring pleasure than are to be found in the like processes of nature.

The sehool sought long and wide for the trouble until it 318 
happily found that the difficulty lay chiefly in the difference in method between nature in the world and nurture in the schools. Since, then, the school bends all of its efforts in teaching to the reduplicating of the methods of nature in the methods of nurture, it has led to and made imperative on the part of the teacher and those charged with the responsibility of administering the functions of the school a careful study of the laws of growth, development and action of the mind, that is, has led to the study of psychology. In view of this co-dependence of pedagogy and psychology a treatise upon the one would hardly be considered complete without at least a brief discussion and description of the more general operations of mind immediately concerned in the processes of teaching and instruction. We shall, therefore, divert at this point and include a brief discussion of the more general and essential mental processes concerned in the work of the school.

The Sensorium. The mental life clearly defined as such when analysed for its lowest and simplest components above the stage of hazy semiconsciousness, is found to begin in the form of an excitation. The stages of development then lead first to sensations and from these on they pass successively into perception, conception, imagination, judgment and reasoning, together with the accessory stages or concomitant states and principles evident in interest, attention, memory, repetition, acquisition, association, with feeling and willing as co-equal forms of these mental activities. The intellectual value of excitation and sensation depends upon the nervous structure of the body which in its component parts make up the physical fabric of the senses. Collectively considered, this physical nerve-fabric constitutes what students of psychology commonly call the sensorium. This term is intended to include all of the various special senses of the body, whether they be accepted as the five senses known to physiology for some several centuries - sight, hearing, tasting, smelling and touch,- - or whether they be accepted as these plus the three or more added and pretty generally recognized to-day as valid, namely, the sense of weight, pressure, temperature and muscular tension (muscular action) or 
whether even they be extended so as to include all of the theoretical and speculative senses as proposed by some of the more recent authorities.

These senses are located, especially in various parts of the body, or generally diffused either on the external surfaces or permeate the various tissues and bony framework. They are connected with the intellectual center, the brain by the nerves of the body to which they owe their entire efficiency of action. These nerves are the routes of travel and means of communication between the world within the body (the thought-world) and the world without (the material world). Upon their proper functioning depends the entire mental content and working efficiency of the individual. All knowledge of whatever sort is built up either directly or indirectly out of the material furnished by the stimulation of the senses being carried to the brain by molecular motion in the nerves. The physical condition of the child upon entering school and during the school processes, the general capacity of his sense apparatus for receiving, transmitting and responding to stimuli must be of a high order if the school and the teacher are to succeed in their efforts with and upon him. They are of paramount importance so far as the schoolroom and its intellectual processes are concerned.

The great number and form of defects both natural and accidental with which a child may be afflicted and thereby be reduced to a lower degree of mental efficiency are too numerous to receive even mention here. But they do exist and do materially affect the standing of such pupils in the classroom work. The practice generally in vogue in countries advanced in educational theory and practice, such as Germany and France and being at present introduced into the more advanced American schools, of having attendant physicians either constantly or periodically visiting the schools and examining the pupils in their work, is a step to be highly conmended in connection with the matter of physical defects and efficiency in schoolroom work. Oftentimes these defects though seriously hampering the work of the pupils are of such a nature that they successfully for long periods escape detection by the unprofessional eye, 
leaving the pupil to drag on wearily through his work unable to do the work satisfactorily, despaired of by his parents and often abused and mistreated by both parents and teacher and held in low regard by his schoolmates, merely because his afflictions are not known and the suffering and inconvenience as well as loss of mental and physical energy they entail upon him, are unappreciated. It is also known that there are pupils of high nervous tension whose peripheral sense apparatus and nervous system respond to the slightest stimulation on the one hand, and pupils of low nervous tension on the other hand whose peripheral sense apparatus and nervous system respond only to strong stimulation. Between these extremes are to be found pupils ranging up and down the scale from one limit to the other. Discases of various natures contribute to intensify or lessen the degree of nervous tension. Foods and feeding, sleep and methods, places and time of slecping and other general habits of health all add to or detract from the general nervous tension of the system.

Also as was stated above the physical comfort of the child in the schoolroom as affected by the lighting, heating, ventilating and seating, all have their due effect upon the nervous tension of the child, dissipate more or less his nervous energy and reduce his working efficiency. For these conditions the teacher should always be on the lookout. Knowledge of the home, of the sleeping and feeding of a pupil, of the degree of the general nervous tension of his body will all aid in giving the teacher the understanding of his various inabilities in the school processes and help him in devising means of reaching the pupil. Students of low nervous temperament will respond less readily to the stimuli of the recitation, and the molecular motion involved in the grouping of molecules to form ideas in such will be less intense, and the paths of discharge will less deeply impress the molecular arrangement of brain cells, thus making them less permanent in their combination, causing the facts they represent in thought to be retained neither so long nor so clearly. Thus memory will be bad, conceptions unclear and not permanent. On the other hand the opposite will be true of those of high 
nervous tension and with those of few physical defects or entirely free from them.

The Important Senses in the Educative Processes. Those senses with which we are mostly concerned in educational processes are those of seeing and hearing and in the lower classes where object teaching is a prominent part of the exercises and drills that of touching. Of these three the sense of hearing is perhaps the most inportant in the lower grades, where the pupils are dependent on the instructions and guidance of the teacher for their learning. As they grow older and more independent and proficient in the school exercises and pass from form subjects to content subjects they are more dependent upon the sense of sight. The sense of sceing is perhaps rightly regarded as primary genctically as well as fundamentally in all sense of activity. Too, it might be claimed that pupils learn even in their elementary work more by seeing than by hearing, it might even be satisfactorily proved that they do. But what is meant here is that although they may see more and indeed more that is valuable in the educative processes, it cannot become fully available nor to any great degree available except under the guidance and direction of the teacher, who must depend for his imparting of knowledge and explanation necessary to its understanding upon the sense of hearing for his efforts reaching the brain and acting as stimuli to the mental processes. The demand for and use of the sense of touch in teaching is of comparative recent creation. It will gain more and more in use in education as object teaching comes into increased use in teaching.

Interest and Attention. The process of perception and conception do not require detailed discussion here inasmuch as all that is necessary to be said about them can with equal ease and convenience be brought under the heads of interest and attention, memory and imagination, a knowledge of which, because of their direct influence upon the results of the teacher's efforts is of primary importance to all who would have any degree of success in educational work crown their efforts. Interest and attention are absolutely in= dispensable in the work of the school. Attention is neces= 
sary in all forms of intellectual life, but interest is necessary for attention. There is no way to make progress, or succeed in the schoolroom without them. Though it is a fact that interest and attention are both aspects of one mental fact, namely, acquisition. Of the two, however, interest is by far the more important in educational matters. The fact is, attention is impossible as a continuous act without interest. Will may, to be sure, direct the mind to some object or person, or the performance of some act and it can do this for an indefinite number of times. But we are referring to the direct continued activity of the mind and as far as it is concerned the will cannot control or influence the prolonging of its activity. The efforts of the will begin and end with directing the mind. Unless the mind once it is directed to some object (end) is held there by some power inherent in the object, that is, unless some interest in the object is aroused in the mind by that object when the mind is directed to it which holds it and stimulates it to action, there is and can never be by the very nature of the case any conscions act of knowing as such. Fortunately for us all in this state of affairs the matter of interests is to a great extent looked after by nature, though in education the interests of nature must of ten be supplanted or aided by those of nurture (artifice). There are then two kinds of interests, the native and the acquired interests. Of the two, for civilized man, the acquired are perhaps the more important. Especially is this true in the case of those minds who believe that nature is imperfect, that art by surpassing nature improves upon it and that advancement is from the imperfect to the perfect, from nature to God. The native interests are primary and form the substratum, the stock in trade upon which the business of the acquired interests is aroused and developed. Just as the race has passed in its life history from the native interests to the acquired interests (if we are to accept IIacckel's law of phylogenesis) so the individual passes in his own life history from the native interests to the acquired interests. Just as in the early racial experience native interests were primary and ruled mental processes, so in the early individual experience native interests control mental activity, 
so also in the history of the race and individual, acquired interests rule even at times to the complete exclusion of native interests. The younger the child the more will his mental activity be due to native interests while the older the person the more do acquired interests govern his mental conduct. The native interests upon which as a foundation in education the teacher aims to build are the interests in movement, in novelty, in color, in living things and later on in life, in sex matters and finally in human affairs. When the child comes to the teacher his native interests are already pretty well determined for him, both by his family and individual experiences, those that are prenatal as well as those that are post natal. Every individual has his own native interests stamped into his psychical being when he is born, either in actuality or in a state of potentiality. These are determined by his ancestral experiences now become structural and transmissible by heredity. To these interests are added throughout life those interests created for him by his own individual experiences. These are constant within certain limits for all human beings. Beyond these limits they vary infinitely.

Here is the problem of the teacher to find out what are these variable quantities (interests) in each pupil and use them as a basis for his instruction. He must, of course, judge them when found, cultivate the good, divert those that are capable of becoming good and root out those that have too much of the evil in them to be of service in the classroom work. Since the end of civilization is often against nature many things which tend to civilize man will have no direct interest for the child. The burden for the teacher here is to connect the uninteresting to that which is by nature interesting until some interest is cultivated in it. In this the principle of association is the key that opens the door to the soul of the child. Objects not interesting in themselves may become interesting through association with objects that already have in them intrinsic interests either native or acquired. Apart from those native things of interest to us all, we possess an interest in things which experience has proved give us pleasure. This is probably because of the close and fundamental association of objects of pleasure 
with the maintenance of life. "Pleasure promotes and expands life, pain contracts and annuls life." Herbert Spencer wrote "Every laugh extends life, every tear shortens it." We are directly interested in, and our interests may be aroused by objects of bodily welfare, objects of familiarity in person or place, objects that have been related to us in the past or that we know are to be related to us in the future (providing we can be made to see and feel in some degree the extent to which they will affect us and the result that this relation will have upon us). We are also naturally and artificially interested in objects that contribute to our intellectual growth.

Here is a whole category of means of arousing interest in the pupils in the classroom work and of holding their attention for varying periods of time. A teacher acquainted with them has endless means at his command to arouse interest and hold the attention of his pupil. All children, even the dullest drones, have living interests in school and its processes as well as outside of the school and its processes. If the teacher will persistently seek them and bring them to bear in the work of the school he will see new effects wrought as if by a magic wand. Special attention is called to that group of interests centered in objects of intellectual growth. Children can all be interested to more or less extent in things they know and can do well. To what extent they sow this interest and the length of the period during which it is maintained will depend upon the way in which the teacher handles the pupil and the subject matter. This interest may be used by the teacher until others are found and then they all may be combined according to the ability and enthusiasm of the teacher and made the powerful instrument in education that they are intended to be.

Attention. As to the kinds of attention, in common vernacular we speak of close attention, absorbed attention and rapt attention. From another viewpoint these may be regarded as the degrees of attention. In scientific circles, especially in professional literature on the subject we are accustomed to the terms voluntary and involuntary attention, to which it is deemed necessary for the nature of the 
treatment here to add expectant attention. Attention may vary in extent, intent, duration, range and degree. The question of the number of things to which the mind can attend at one time arises at this point. But we pass the discussion as irwelevant here and delegate the determination of it to the field of psychology. As far as the art of teaching is concerned experience has taught that in dealing with child mind in connection with the facts of the lesson it is at least safest and best if not essential that we treat the mind with the assumption that it cannot successfully attend to more than one thing at a time. The distraction of referring or perhaps better recurring constantly from one line of thought to another together with the amount of energy thus steadily used, soon tells upon the gencral vitality of the cliild by using up very rapidly all of his available supply of energy. Not only has experience in the schoolroom thus solved the problem but it has also proved that only by constantly recurring to the same thing from day to day by way of repetition as in review can the child be gotten to retain the most essential facts of the lesson. Pedagogy has for a long time been convinced also that not only must the young mind not work for too long a spell at a time, too intensively nor too extensively, but that the range in study must be strictly limited to one thing at a time and indeed in most cases to only one phase of that subject at a time. Mental energy varies in intensity in direct proportion to its extensity, even as does physical energy. Again attention requires a large amount of energy and is conditioned by that preexisting already in the mind, one's expectations and one's needs in the premises.

Furthermore, much of the limited energy in the child available for the work of the recitation is used in those processes not directly mental but merely physical such as in the nerve processes involved in the action of the visual, auditory tactile and other senses before the actual mental processes dependent upon this (the sense material) are really started. The motor processes and adjustment incident in moving about the schoolroom for the various exercises and those incident in bringing the various sense organs directly into contact 
with the stimuli, also tend to exhaust the child's energy. These latter are evident particularly in such movements as the turning or inclining of the head " to catch a sound," of the eye to see an object, and of the hands to touch objects. Poor light, objects that are distant or that by their color absorb too much light, noises that are distracting, teachers' voices that are too loud or too low, all contribute in this way to the useless dissipation of the child's energy. It is a well conceded fact that physiologically the giving of continued attention is attended at times by severe muscular tension, especially where the act is new or difficult and when this form of the strain is absent the excitation is brought into its own by severe inhibition of other forms of excitation striving to gain expression in the present state of consciousness. Tests having the warrant of highly developed scientific methods in the laboratory and outside have proved beyond a question of reasonable doubt that physiologically under the strain of fatigue, disease and over stimulation such as nervous excitement or cortical center excitement and a superfluous flow of blood either to or from the brain, the power of attention is reduced and mental activity either is reduced thereby or else is made practically impossible. The other senses also use up some of the child's energy in their activity but as these are the senses particularly active in the educative processes, these only are mentioned here.

The justification in the demand that the energy of the child be conserved is easily seen. The physical environment must offer the maximum comfort, the manner of the teacher must be such as to promote the greatest mental ease, the physical movements of the child must be reduced to a minimum in their demands upon the energy of the child and the daily tasks of the schoolroom should not be so long as to produce strain or so-called restlessness in order that the conservation of the child's energy may continue at a maximum. In the fact that attention is conditioned by preexisting ideas, expectations and needs the justification of the form and nature of the assignment, the study period and the recitation, and most especially of the first and last is clearly evident. 
The first step in the educative process is to see what is the mental content of the child, both when he enters school and at the beginning of each recitation and in review. This done the logical place of beginning has been found. Too often in the passing of pupils from one grade and teacher to another grade and teacher, the teacher assumes that certain work has been done and at once proceeds to build upon this as found for his part of the educational structure to be built up out of the mind of the child, without seeking to find out exactly how much of, and how well the educational foundation and superstructure has been laid down at the time when the pupil was turned over into his hands. The new ideas to be of practical utility must be well connected with the ideas pre-existing in the child's mind. This being done the child can be led readily up the road of knowledge that he has thus far traveled and shown where he stands at the present recitation period and made to await with pleasure and anticipation the next step, having at the same time been shown his immediate needs and to what extent the facts of this lesson will contribute to the supplying of these needs. Attention by concentrating and directing energy makes impressions otherwise shallow, deep and paths of discharge otherwise impervious to more feeble discharges permanent and easily accessible, thereby increasing the conscious intensity, the completeness and the definiteness of the sensation by focusing it. Change, newness, novelty, surprise, curiosity, contrast, strangeness, familiarity and oftentimes discipline all contribute to the conscious intensity of the discharge of mental energy, the completeness and definiteness of the sensation or its consequent image. In fact these are the constant attendants upon attention. Psychically attention is to a high degree in older and almost entirely in the younger dependent upon the question of likes and dislikes. This is an important fact for the teacher to get acquainted with early in his educational work. The effect of the pleasure-pain economy is too near upon the young racially and the young individually to permit his very distant removal from its infiuence. This makes the proposition of 
pleasurable tasks for the school child, especially in the lower grades, paramount.

Voluntary, Inzoluntary and Expectant Attention. One or two authors attempt to name and justify another kind of attention namely that of indifferent or non-voluntary attention in addition to the three given above. Allowing for this discussion that such a form of attention exists, though the settlement of it belongs to the field of psychology, its pedagogical value is too small to justify its discussion here. The aim of all educative processes is to attain in the child the state of involuntary attention, hence the prime importance of the teacher's knowing the physiological and psychological phases of attention, the attendants of attention both physical and physiological and the part they play in the success of the daily routine of the school. There are from the pedagogical viewpoint two serious objections to voluntary attention. One is that the will power necessary to maintain it is usually not well developed in the child and not a great advance is made along this line even by the time the child is ready to leave the public schools as a finished product. In the second place, all that will power can do, even assuming now that it be sufficiently developed, is to direct and redirect the mind to a given thing, fact or eircumstance. Once this is done will has done its best. From that point on the mind if it works at all must operate entirely under the control of its predominating interests. It might be added incidentally that because of this very fact, it is seriously questioned by many authorities as to whether or not as a process of mind, voluntary attention can really exist. Sure it is however, that involuntary attention secured by allied powerful interests in the teacher, the schoolroom and its work is the goal desired and for which the educational forces are expending their efforts as the most important thing that the school can accomplish in pushing its work. Knowledge and existence are so closely allied in the natural order of things that whatever is a surprise is always somewhat of a shock to the organism. 'This shock may be a pleasant surprise or an unpleasant surprise. The educative process is normally filled with pleasant surprise. 
Expectant Attention. The anticipation of pleasure is one of the greatest joys of the human soul. It is upon this that the principle of expectant attention rests. The child's mind is prepared for what is going to happen. The mind is put into the state most appropriate for its reception, at the appointed time the expected comes forth and is received by the waiting. This is the supreme test, the supreme moment of teaching. In the hand of the skillful and enthusiastic teacher it is of almost unlinited value and power in the schoolroom processes. It should be sought after by the teacher and developed in the child from the very beginning of the school life until the close.

A high form of expectant attention is evident in the athletic and play contests about the school. Here the contestants in their respective positions each determined to do his best and to take every fair advantage of his opponent, and each keyed up to the highest pitch of nervous tension awaits the judge's voice, the discharge of the referee's pistol or the blow of his whistle to set into play every bit of energy pent up in the body. That nervous discharges of energy in this way and under these circumstances are strong and force paths of discharge that are deep and lasting goes without saying. Questions asked and answered under such circumstances of strain and tension are both definite and lasting in their effects. It has proved in practice to be a very effective form of attention for the teacher in the work of the recitation, but like every other good thing must not be worked overtime. Nor must the tension excited be too great, if the best results are to be gained without having their accompanying evils on hand to plague one.

Memory. On the one hand physiologically memory represents the paths of discharge in the plastic matter become permanent by constant discharge along the same route. On the other hand it represents also the groups of brain cells formed under the control of molecular force set in action by nerve disturbances in various parts of the body and made more or less permanent by persistent relations incited directly through renewed stimulations from the same or connected 
paths of discharge. Memory is strongest in the young because of the plasticity of the young brain and the larger amount of available energy and the impressibility of the nerve and brain substance so pliant in the child and yet unformed into stable relations and molecular groups. It is at its best in the early part of the day because of the larger amount of energy in the body available for the bodily and mental functions which serves at that time to intensify the amount discharged and the force of it. Memory also varies according to the time that has elapsed since the recording of the discharge among the molecules of the brain and higher centers and is determined chiefly by the time that has clapsed since the impression and the degree of the completeness and distinctness of the image formed. Loss of memory may come with disease, with weariness or with age, or it may be produced by the continued or excessive use of intoxicants and certain highly exciting drugs, or by direct injury to the brain. Not only does memory vary through the successive age periods, but it varies greatly in different individuals. We speak often of the naturally dull boy and of his counterpart the naturally bright boy. Above, attention was called to the fact that both by abnormal and normal condition some organisms are constantly in a state of high nervous tension and others are correspondingly in a state of low nervous tension. In the one of low nervous tension impression and memory will be slow, but the paths of discharge once formed will be more lasting, while in the case of those of high tension the impressions and memory will be rapidly gained and the paths of discharge rapidly formed but mostly will tend to be less lasting. But where they are both rapid and of sufficient force to be lasting the resulting mental state is pleasing. However, such cases of combination are comparatively rare. Usually those in whose structure paths of discharge are readily formed have these paths destroyed with equal facility. Though quick to gain knowledge they are just as quick to forget it. Those who remember with fulness and exactness and learn equally quickly are raru and by no means to be reckoned with as the commonplace. Also in some subjects teachers may get either 
large members of a class, or even whole classes whose memory is above the average and with whom good results are attainable with comparatively little effort.

A Good Memory. Evidences of a good memory may be seen in aptitude in application, firm hold on that which is learned and a consistent readiness in recall. Of all sense material that which is obtained through the activity of the visual sense is most easily recalled and next to this the material furnished by the auditory sense. After these the order in which the other senses are grouped as to the fulness of the material they furnish is given differently by different authors. Ordinarily, however, touch is generally next in importance. However poor a memory the child may possess it may be improved. The chief method to develop memory in the schoolroom is by exercises in acquisition and practice in recalling either of which may be varied in any number of ways.

Pedagogically, there are several facts about memory that concern us here. First there is the fact that the degree of perfection of memory is decidedly affected by the time that has elapsed since the activity of the mind involved had been present and by the degree of completeness and distinctness of the image originally formed during this activity. Here is the psychological justification of constant reviews, briefly daily, and more extended at longer intervals. It will be necessary that all class explanations and introductory work be completely and distinctly outlined. Hasty work soon begets its own condemnation, while work that is unclear or incomplete is also to be seriously condemned. Make haste slowly will apply in the work of the recitation equally well with the work of life. The justification of object teaching and the value of maps, charts and other visible forms of demonstration, including written work at the board and seat, all are invaluable because the images they form in and the impressions they make on the mind are more lasting; memory of them endures longest. The fact that fatigue is a prominent cause in the weakening of memory and memory work sounds a word of warning from a viewpoint about prolonging the school work, the assignment, the recitation and 
the study period unduly. Teachers should study the general impressibility of pupils, whereupon the easily impressible and those more slow of impression each can receive his due consideration and attention. The readily impressible is the apt student. It is the slowly impressible to whom the attention of the teacher must be chiefly given. They should be made the standard of work in so far as a regulative standard is followed.

The Kinds of Memory. Here as in the kinds of attention there is a variety of groups of classification. However, the one which is adopted here as of most use to the nature of this treatment is that of logical memory, mechanical memory and verbal memory. Of these three the logical memory is the most valuable to the intellectual processes. The mechanical stands next, while the lowest in the series is the verbal memory. The first of these, the logical memory gets and retains the sense of the thing learned, and to be remembered; the mechanical gets all without any successful attempt at distinguishing the important from the unimportant in ideas; while the verbal memory merely gets the words without any regard for the thought either as important or unimportant. Historically the progress of the race and the individual is from the rerbal memory to the logical memory. The struggle of the teacher is to get the pupils from the verbal memory to the logical even more rapidly than they would go by natural processes. The mechanical memory marks an intermediate step. Here where students do learn well they do not grasp or cannot grasp the important from the unimportant in the lesson. Here the assignment of the lesson can be of much help. It should aim to remove much of this difificulty, especially where outlines are in possession of the pupils. Whatever of the difficulty the assignment fails to remove, the explanations of the words of the text and the giving of carefully prepared study questions will more than likely dispose of. Too much care and watchfulness cannot be exercised on the part of the teacher to overcome verbal and mechanical memory in the pupils. These pupils if crowded in their work especially will often commit passage after passage of a given lesson without any 
adequate conception whatsoever of its thought content, both that in the thought content which is important and that which is unimportant. So adroit are such pupils that they have been known to recite their lessons clearly and often apparently thoughtfully until some careful questioning of the teacher or some slip of the pupil in the series broke the chain, thereby disclosing the fault. The confusion that may now be brought out will soon show that the pupil has no understanding of the thought but is dependent entirely upon the words. If the missing word is supplied, at once the repeating of the series begins and is carricd on to the end without difficulty, showing just where the trouble is.

A good method of testing for verbal memory is by giving appropriate questions on the sense of the text and requiring the pupils to find explicit answers to them. Requiring recitations in the child's own words is also helpful, as is the request to define words and explain the meaning of various passages of the text. For convenience along this line text books are generally divided into appropriate parts which are adapted to the principles of memory. Each of these divisions as has been said has its important sentence and its unimportant. These divisions are usually the topic, the paragraph, the verse, the page or the chapter. Because the topic is most generally the division used and studied the important sentence in the paragraph or topic is called the topic sentence. 'The topic or one or more topics usually constitute the assignment. Here the child learns the order of topics and the discussion of each and is prepared to go through the whole, once the machine (of thought) is started. These pupils are generally all lost for a beginning unless the question is couched in the words of the book or is such as to suggest to him the dirct words of the book. Hence originality in questioning is a practical method of reducing verbal and mechanical memory and particularly verbal memory.

Memory Devices. In aiding memory, especially logical memory an ingenious teacher can make many devices. Little rules that indicate in some way the run of the series are quite common, 'These in the lower grades the teacher may 
devise, while later the pupils themselves should be shown the value of such practice and taught to form their own little methods of remembering. One of these chief recommendations of logical memory is that it can be reduced to such a system, while the fact that verbal and mechanical memory cannot be so reduced will serve to discredit them as thoughit getting and thought retaining methods. While I write, the little verse for remembering the number of days in the various months of the year which is quite common comes to me. I give it here for the mere stiggestion of the method.

"Thirty days hath September, April, June and November, All the rest have thirty-one, except the second month alone,

Which has only twenty-eight in fine, until leap year gives it twentynine."

In music the use of the word B-E-A-D to denote the flats of the staff as they succeed each other in the scale up to four, and of the word f-a-c-e to denote the sharps corresponding are well known and commonly in practice. Many teachers practice this systen with more or less success. The fact is, so well recognized is the merit of this system that it has been adopted by the school and named the "system" or "law of mnemonics." Even in practical life experience has shown that couplets and words often form chains of connection in series that by the power of suggestion enable us to recall the thing desired in the series. 'This principle of memory has succeeded in tiding men and women of the world through important crises by their using this power of suggestion to recall that which they wished.

The Laws of Memory. There are several practical rules of memory known as "laws of memory" which while they are only suggestive are of considerable value to the teaching profession. They emphasize in a new way much of that which is given in a different way earlier in this same discussion.

1. The Law of Repetition. Repeat often the things you wish the pupils to remember.

2. The Law of Use. Strengthen the memory by constant use. 
3. The Law of Interest. Connect the things you wish the pupil to remember with those things in which he has native or acquired interests, for he will remember better those things in which his individual interests lie.

4. The Law of Attention. Attend well to the things you wish the pupils to remember.

5. The Law of Understanding. Have the child get a clear and full understanding of the things you wish him to remember.

6. The Law of Association.

1. By Contrast.

2. By Contiguity.

3. By Similarity.

4. By Sign and thing signified.

5. By Cause and effect.

6. By the whole and the part.

Entangle the things you wish the pupils to remember in a net of as many logical associations as possible.

Speaking of memory, its development and practical value to the teacher, William James says: "Of two men with the same outward experience, the one who thinks over his experiences most and weaves them into the most systematic relations with each other will be the one with the best memory." Improvement (in memory) is due to the way in which the things in question are woven into associations with each in the mind. From a pedagogical view point these laws of memory speak for themselves. They need only be applied for the teacher to see their efficacy in getting results.

Imagination. The laws of association might with equal justification have come under the head of memory and many authors treat them under this head. For personal reasons, however, I wish to follow other leads and consider them under the subject of imagination. Imagination works upon the material furnished through the senses and is to that extent identical with memory. But unlike memory besides reproducing the sense material it may use it by analysing and recombining it according to laws inherent in itself. Thus 
there are two kinds of imagination often called respectively the reproductive and constructive imagination. Some authors adapt a parallel division, namely, representative and creative imagination. There are other systems of division such as the scientific, artistic and ethical imagination and the associative, penctrative and contemplative imagination. For these, however, there is no demand here. Hence for uniformity it is better to employ here the classical division of the imagination into the representative or reproductive and creative imagination. It is the creative imagination that is the goal of education. To the activity of this faculty the world owes its progress in both material and theoretical civilization. Creative imagination creates by recombining the old images or parts of images into new forms. Its value lies in the fact that things being understood in the relation of the part to the whole and vice versa enable not only successful disintegration of the whole into its component parts, but also its reassemblage into a new whole made out of constituent parts of this whole either alone or in combination with the parts of other disintegrated thought wholes. Besides the native "psychophysical disposition" to revive the past "inherent" in the mind, creative imagination depends for its force and material on certain conditions of reproduction such as depth of impression of the original image, quantity of sense material, interest excited and the resulting closeness of attention, power of the suggesting image and the frequency of the occurrence of the stimulation for the original impression.

While it is seen by the foregoing that the mind has a native tendency to form images, teachers may greatly augment this power by seeing to it that the facts of the lesson are "driven completely home," that where possible the facts of the lesson are supplemented by much illustrative work both with objects, maps and board work. The fact in this is that the more the senses are aroused by the presentation through the same senses or different senses the deeper and more lasting become the paths of discharge formed by them and the more there is in the thought content to be disintegrated, analyzed and created into new mental forms. 
Some things also are by nature more suggestive than others by having stronger or more numerous connections. When these are employed the images formed are more enduring and more perfect. The stimuli that may be used to arouse image formation are either psychical, physical or physiological. Chief among the psychical stimuli are the so-called after sensations which cause us to hear long after the real audible sound has died away, such as when picces of music keep ringing in our ears or certain visible experiences are constantly before the eyes long after the actual experiences are past. In this way people and objects, places and events will suddenly return to one after years have elapsed since the original sense impression was experienced. Flow of blood into or from various parts of the body both in health and disease causes image formation. The dreams eaused by a full stomach are current examples of this. The delirium tremens and hallucination of the drunkard are probably greatly augmented by the over rapid cell destruction in the bodily metabolism induced by the alcohol. Likewise the various forms of mania evident in fevers are due to the rapid cell destruction and presence in the body as a foreign substance stimulating certain forms of nervous and cortical center action.

Imagination Subjects. Many subjects in the course of study are very appropriate for developing the power of imagination. Stories are the most commonly used subjects for cultivating the imagination. They may be either told or read and the children may be made to reproduce them or expand them as they see fit. Child imagination is particularly apt with these. Poetry is particularly appropriate for child imagination as is nature study, geography, music and drawing. History should head this list because of its relation to and dependence upon stories. More recently with the spread of physical education games have been included in the courses and have become a fruitful source for developing the imagination. This form of mental exereise has the extra virtue of being more assuredly pleasing than some of the other subjects suggested.

The Lares of Association. More important than the sub- 
jects that are particularly appropriate for the development of the imagination are the laws by which the images are recalled for the processes of analysis and recombination. These are the laws of association. The first three of these laws are given us by Aristotle. They are the laws of simularity, contrast and contiguity. To these Hobbes and Hume added the laws of means and ends, cause and effect, sign and thing signified and objects and their qualities. From the law of similarity it is learned that there is a strong tendency of the mind when one image is presented to it of recalling an image or images closely resembling the one presented. By the law of contiguity things closely associated in time and space and experienced in this association generally retain in the mental life a like closeness of association, the one serving as a means always of recalling the other and doing so not by will but by the very nature of this association in the past experience of the individual. The like is true in the relation of things opposite in their nature as experienced, also of things experienced in the relation of means to ends, of causes to effects, etc.

The value of association in the schoolroom is in using material and questions that are closely connected with the child's experience in and out of school and of connecting these with the facts of the lesson. They thus become a part of the child's real life and respond to the train of thought that may be set in motion by the teacher's questions. Imagination is not so much for use in the work of the schoolroom as to be developed there for use in after life of the pupil. Howerer, both in the assignment, the study period and the recitation the facts of the lesson may be thoroughly grasped through the proper formation of images, where other means fail. Images being for use in the absence of the direct object are fainter and less vivid than the objects themselves. This makes it necessary that the original impression be full and clear. To this end therefore all of the efforts of the teacher should be directed. Judgments and the combination of judgments (reasoning) depend to a great extent for their validity in the correctness of the image formed. Judgments cannot be depended upon where the images upon which they 
are based were either incomplete originally or have by long disuse and non-renewal lost their caste of detail.

This is a brief survey of psychology as it is directly related to teaching. Much more might have been added and more detail included in that which was given but the scope of the work forbade the undertaking of either.

\section{REFERENCE READING}

"Attention and Interest" by Arnold, the wholc work but especially Chapters IX and $\mathrm{X}$.

Compayre's "The Intellectual and Moral Development of the Child." Chaps. VI. VII, VIII.

Kay's "Memory, What It Is and How to Improve It." Chaps. V, VII, VIII, IX.

Taylor"s "The Study of the Child." Chap. XVI.

Dexter \& Garlick's "Psychology in the Schoolroom." Chaps. III, VIII, IX.

Colvin's "The Learning Process." Chaps. VII, VIII, XI, XII, XVII, XIX.

Morgan's "Psychology for Teachers." Chap. III.

Baldwin's "Psychology Applied to Art of Teaching." Chaps. VIII, X. Horne's "Psychological Principles of Education." Chaps. X, XI. Bolton's "Principles of Education." Chaps. XVIII, XIX.

Münsterberg's "Psychology and the Teacher," XVI, XVII, XVIII, XIX. 


\section{CHAPTER XV}

\section{SUBSIDIARY PHASES OF EDUCATION}

\section{Habits - Morals - Manners - Religion - Patriotism}

Under the head "Subsidiary Phases of Education" are included the subjects habits, morals, manners, religion and patriotism. By the use of the term subsidiary education it is not intended to convey the idea that these forms of education are unimportant, but merely that they have run so prominently through the discussion of the other phases of educational processes that there is but little left of a special nature to be said about them in addition. Hence from the viewpoint of extended special treatment they are regarded as subsidiary. From another viewpoint these phases of education are subsidiary for the school in that it is not necessary to delegate this work to the school as such, but it is customary, and properly so, to leave much, if not all of such education, to the home, the church and to some extent to the state. These have been and should still continue to do such work more and more effectually than the school. The nature of the development of habits, of morals, of manners and in general of patriotism is such that the school cannot get the results desirable on the scale desirable without very close cooperation of the other educational agencies as it can in the educational processes pure and simple. Then, too, the code of a system of subsidiary educational processes is not well determined and because of the breadth of the field and the freedom allowed for the play of individuality of views, cannot be as well determined as the work that is formally educational. So prevalent is the recognition of individual rights in these premises that it is the general custom everywhere to give way to and respect individual caprice in these matters of education on the argument that responsibility here is mostly individual and not aggregate as are 
also results. At present, however, the trend is everywhere toward more supervision and direction of these forms of education. This is due chiefly to the view coming into prominence that after all these things are as much for the aggregate welfare as for the individual welfare. As this view grows in strength the attention of those charged with the responsibility of the school education will be turned in this direction and there will, as a result, be more direct study given to these phases of education in the regular course of study and daily program until they will become as prominent in the school processes and as thoroughly developed, understood and systematically regulated and graded as any of the purely literary or intellectual work of the school. The tendency at present is strongly in this direction both in thought and action and much already has been done in recent years.

I. Habit. Fundamentally habit is closely akin to instinct. In fact historically it is the precursor of instinct. Through centuries of practice by successive generations of organism habits of action so modify organic structure as to become the physical basis of the various instructive actions. Habits therefore represent individual experience, while instincts represent the cumulative effects of racial experience. While habits are by some called aequired instincts it seems from the above relation more nearly the fact to say that instincts are acquired habits that have been retained and practiced by the successive members of family and race until they have modified the structure or become manifest in tendencies inherent in structure. Habits may arise by the conscious or unconscious response of the organism to the various influences of the enviromment of the conditions created by the environmental forces. They have both a physiological and psychological side to them. Pysiologically a habit is a pathway of discharge formed in the nerve substance by which certain molccular disturbances in the form of motion find their way to the brain and along which similar disturbances tend ever afterwards to escape. New or acquired habits according to this would simply be a new pathway formed in the nerve substance of the body along which incoming cur- 
rents started by disturbances in some part of the body would tend to become permanent as a line of least resistance for motion along which all future motion aroused by sinilar disturbances would tend to escape. From the same viewpoint the overcoming of a habit would be either the modifying of old paths of discharge and the formation of new ones or the entire removal of old ones with or without the formation of new ones in place of the old. The nervous system of the animal world was in the simplest form biologists tell us, a crude "device to connect sense organs with muscles," thereby enabling the discharge of movements in response to various stimuli in the environment. "Nothing that we do remains unrecorded by this system." It stores up the modifications of every act and its stimulus. The modification of structure resulting tend to preserve themselves and provide for similar discharges of motion in the future.

In every form of living structure there are inherent certain latent capacities and tendencies to action. By inducing these capacities and tendencies to issue in action we form the basis of habit. By focalizing the attention of the mind upon these actions and repeating them there are formed what are called habits. In life we owe all system in work and all forms of organization to habit, either directly through present actions, or indirectly through the structure inherited by the activity of the race in its life history. The chief value of habits both in life and in the schoolroom is that they contribute to an increase of speed and accuracy in action and diminish fatigue in labor. It also gives one new methods of approach in certain activities and for others a necessary knowledge. Without habit the mind could never get beyond the immediate action of the moment. The paths of discharge in the case of habit become lines of little or no resistence and when formed serve as a channel into which the mind can turn much of its work. The cerebral center is the seat of conscious action, the cerebellic center is that of unconscious or perhaps better that of partially conscious action. Actions which at first are highly conscious and require the entire force of the cerebral center to carry them to successful issue as the paths of discharge for them 
become formed may be delegated to the cerebellic center, thus leaving the cerebral center free for other forms of action. Thus by constantly making various forms of action habits we can obtain freedom of time and effort for the performance of other activities. This process may be extended without limit each time extending the range of habitual actions until we have at our command an indefinite number of habits of action now become a part of our organic structure permanently recorded in the nervous system as one's individual possessions for the emergencies of life, leaving the mind still free to pursue any form of conscious action on an equal footing with the rest of the world. Thus it is that habits diminish feeling and increase activity. While we bring a few hereditary reflex and automatic forms of action into life with us, the clief part of our habitual activities are formed and recorded in our organic structure by repetition under the control and direction of the will. Human freedom of action consists in the power of the mind to initiate organic action under the excitation of various stimuli to discontinue such action, to modify it or to remove either the exciting agent or the part or parts of the organism affected.

No new habits can be formed unless the will is invoked to arrest or modify old forms of muscular activity or initiate new forms. If one refuses by will to begin the performance of an act or to continue its performance a habit of action as a positive state is impossible. This is the history of habit both in the forming and in the unforming. Thus it is evident that will and habit go hand in hand. While, however, will may be invoked to form positive habits the failure to exercise will may just as definitely lead to the formation of habits of action that a very strenuous exercise of will may be required to unform and sometimes habits so formed require such suffering that the organism cannot successfully withstand the strain. All will, however, depends upon habitual muscular coordination. Since habits once formed exclude the formation of other habits it is essential that the proper habits be formed at the beginning. Both good and bad habits go through the same processes in formation and are recorded with like degrees of permanence in the nerve 
structure of the organism. Likewise both often involve serious shocks to the nervous system in order to be changed. It takes just as serious efforts to acquire a bad habit as a good one. Besides there is a triple loss of time and energy in the formation of bad habits to say nothing of the other manifold evils that follow in their wake. First of all bad habits must be formed and they go through the same process of formation as good ones do. Then they must be unformed. After they have been successfully unformed the good ones which might have been formed at first may now be formed in their places. Besides all of this it is much more difficult to unform an old habit than to form a new one, for so difficult is the unforming of some old habits that in accomplishing it the entire organism is sometimes undone. The longer the paths of discharge have been formed, the more persistent they become and resultingly the more dificult it is to remove them. That is to say the older a habit the harder it is to break one's self of it. It is an associated fact also that while the young acquire habits readily it is also comparatively easy for them to get rid of them, while with the older, the more matured, more slowly are habits formed and they are also more difficult and slow in yielding to efforts to remove them. In childhood the period of maximum plasticity and impressibility is the time not only to form habits, nor even to form good habits, but to form the best habits.

Kinds of Habits. With habits as with other forms of school and mental processes there are various classes or kinds given according to the author and his viewpoint. The classic division of habits is into the groups of native and acquired habits. This division is genetic and is the prevailing system of division. William James gives us practical, emotional, and intellectual habits. However, there is another classification that appeals to us here. This is the classification into physical, mental, moral and religious habits.

Nothing is more valuable, nothing contributes more to one's health, happiness and success in life than a set of good physical habits. Regularity and moderation in sleeping and eating, together with a good physical environment for the body enables the bodily energies to be raised to a max- 
imum degree of efficiency. The time comes in the life of every individual, when, if he would succeed he must have at his command for immediate use an extra supply of energy. If this is wanting and his body fails him he breaks down, or is unable to meet the demand of the moment and either is lost or fails in his efforts at achievement. Given a long life, normal strength and activity, most men of ambition get well onto the attainment of their life's ideals. Premature death superinduced by bad physical habits has robbed humanity of many of its most able and brilliant men long before they had contributed a small fraction of their energy and ability to human progress. The old Latin proverb, "Sana mens sano corpore" (a sound mind in a sound body) was not spoken amiss. The sum total of human happiness has been found to be decidedly affected by the sum total of human habits. Suicides and murders are often traceable to ill health and degenerate bodies obtained through bad physical habits. All forms of violent passions, irritability, melancholy, many spells of sickness and diseases are directly attributable to bad physical habits.

Moral habits in the sense of social conduct - our conduct toward our fellows - are the source of much pain and discomfort in society. Habits of moral action are woefully lacking in even many so-called highly civilized countries and highly educated people. Among men actions are mostly egocentric. That is to say the actions of men cluster about themselves. They emanate from self and return to self. Closely associated with moral habits are religious habits. Very little is done in the schools of this country either in religious education or the formation of religious habits. The state and the school leave such matters to the home and the church, while the home seems inclined to place its share of the burden on the church. The church has little direct cocrcive power to assiduously bring about the formation of religious habits. The custom of the church threatening the evil doers in the world with hell fire and vivid picturing of heavenly bliss as a reward for certain kinds of conduct have in many instances enabled the church to bring about the formation of good religious habits among its communi- 
cants, such as the regular attendance upon its services, the contribution of a "tithe" of their earnings to its support and the refraining from certain forms of action which it holds to be not for the good of the individual and mankind. However, good religious habits contribute equally with other kinds of habits to human happiness on earth besides having the distinct merit of holding out a ray of hope for suffering humanity in the presence of the great beyond to which all men come in their thoughts and which without this ray of light life itself for many would be miscrable and the passage out of life into the hereafter would be fraught with trembling fear and terrible foreboding.

The school is concerned chiefly with intellectual habits. William James says, "All our life so far as it has definite form is but a mass of habits - systematically organized for our weal and woe and bearing us irresistibly toward our destiny whatever the latter may be." These habits it is the business of education to cultivate if good, modify and redirect if they be capable of becoming good, or remove if bad, substituting for those removed such new habits as will promote the greatest degree of organic living and working efficiency and raise to a maximum degree the capacity of the individual for happiness and complete living. In producing desired habits the teacher can employ the principle of association or suggestion mentioned above to good advantage. In the school process if those things which belong together are put together, naturally, and if those things which belong apart are kept apart and thus drilled into the mind, the process of thus associating or separating them in thought will become in time a fixed habit, the value of which to the pupil's mental life will be for all purposes of education almost inestimable. Good habits can be fostered by a proper system of reward, and bad habits discouraged by a proper system of punishments - the good adhibited, the bad inhibited. All of the routine processes of the schoolroom may in this way be reduced to habit. Correct sitting and standing postures, grace and ease in movements and carriage, neatness in personal appearance, accuracy and thoroughness in school work, cheerfulness, good disposition and general pleasantness in 
manners are all a matter of habit with the formation of which the school can do much. Especially should the teacher concern himself with habits in work and posture. Slowness in sitting and standing indicate a corresponding trait in cliaracter, while lack of neatness in dress and personal appearance besides being manifestations of character will follow throughout life and by bad presentation handicap one even from the very beginning in life. In every form of life these kinds of habits once formed follow one throughout life for weal or woe. Consequently no effort put forth in early life to insure the formation of a series of good habits in the young in these things can be counted as effort misdirected. The cheerful smile even in trial and pain is always welcome. "Laugh and the world laughs with you, weep and you weep alone" is true both in theory and practice. No one wishes to meet the person who is always complaining and thereby is always miserable. He is shunned by all alike. Much of the ails of humanity is imaginery, much of our thought along these lines is merely habit, habits that it were better for us all had they never been formed.

We will now attempt the application of this discussion of habit to the field of education. A moment ago it was said that all system and organization owes its strength to habit. It is a fact habit does leave the mind free for conscious intelligent action along other lines. But it is also true that habit reduces conscious intelligent action, that is, the tendency of habit is to reduce the organism to a mechanism. Carried to this extent habit becomes an evil instead of a good. Again in all natures there is a strong reaction against the formation of habits of action. The argument being that will and initiative, self-assertive action, suffer thereby. Since the tendency of the age in matters educational is in this direction, this complaint is to be expected. The complaint, however, should be taken as a timely warning and the teacher who is wise will heed it. School routine even in the form of habit that makes the child an automaton and negatives his will is more than uscless. It is an evil.

II. Morals. Education for efficiency as well as for complete living must develop along all lines, that is, must fit 
a man for all of the forms of social activity and social contact. The best men in society, the ones who make the world better by being in it, are not so often those who have acquired the greatest knowledge of facts and truths, and the greatest skill in the use of the instruments of civilization and progress, as they are those who have the disposition and the strength of will (character) to regulate their conduct to the best interests of their fellows. They may know less of the duties and responsibilities of civic and social life, they may know less of facts of knowledge and underlying truths, they may have less skill in using the instruments of civilization, but such persons will be found to do more actual work, to render more enduring service to humanity than any other group of the social body. The end of moral education is the formation of character, - the training of the will to do that which the intellect shows to be the best for all. Moral education in general takes on two forms. In the one it becomes the training in the habits of living, the social usages as practiced by members of the social group one toward the other. This latter we generally call manners. The former form of education generally develops in two directions. In the one form it looks to the conduct of one toward himself and in the other it looks toward his conduct to others. In general the training in conduct towards self is neglected for the training in conduct towards others. But if anything is to be given more consideration, the proper conduct toward self should receive precedence over that toward others. Further, moral education too often takes the form of the abstract and impractical instead of the concrete and practical, whereupon we are led to look over the small and simple things at hand in life for the more profound that is often remote and difficult of attainment. There is just as much immorality and wrong in robbing one's body of rest, food and exercise as there is in stealing a neighbor's purse. It is just as immoral to overwork and abuse the stomach and vital organs as to mistreat one's fellows and overwork and underfeed and underpay them. The fact is, the former is more directly followed by retributive justice than the latter. Yet how many moral lessons impress these facts upon the minds of the young? 
On the contrary the child is taught the seriousness of the former almost to the total neglect of the latter. These relics of the asceticism and self-abnegation that marked papal supremacy in the Middle Ages and which was broken by the heyday of renascent humanism still have their traces in human conduct. The sickness, disease and human suffering that this indifference to self and self-welfare has caused mankind is almost beyond conception. The school can and should do much to remove this condition. Physiology and hygiene are especially fitted for the development of a moral sense and moral ideas looking to the care of self in conformity to the demands of the physiological laws of health and activity. The kinds of food, the amounts and the hours of rest and cxercise are all subjects that teachers may develop in the school to much practical profit even though the control of such things in practice is not left to the discretion of the teacher nor to the wishes or intelligence of the child, but is regulated by those in authority in the home, where similar kinds of intrusion are often seriously resented. Results therefore will be best where the home is advanced in thoughts and methods and teacher can have the thoughtful and sympathetic cooperation of the home in these efforts.

The other form of moral training - that which endeavors to regulate our conduct towards others - receives considerable attention from the teacher and is reduced to somewhat of a system in the school processes. But it too is to quite an extent an heirloom of the Middle Ages. However, perhaps for this very reason this code is pretty generally in use. It seems to have gotten its hold in the school when the church dominated both the school and the state. This code of conduct involves chicfly our conduct toward others. Its aim is to regulate action between man and man. Most moral teaching of this kind, however, is laid down in theory and abstract principle. It is the duty of the teacher to make them practical by teaching them by means of concrete illustration. For just as the facts of knowledge are best grasped by object lessons so the facts of conduct are most clearly taught by the use of concrete example. Just as also right thoughts are aroused by the presentation 
of those exciting agents calculated to awaken them, so right feeling in conduct is obtained by the presentation of such objects as will occasion the arising in consciousness of the desired mental images. Many have contended that moral judgments are innate in the mind. But whether this be true or not it is a fact that once there they require development if they are to become of any practical service. Capable judgment in moral matters is only reached comparatively late in the stages of moral progress just as is the case in mental judgment. While material for moral instruction in the school may be drawn from almost any source, literature, maxims and proverbs including fairy tales, parables, legends, fables, allegories and the daily occurrences in and about the school, all may by a skillful teacher be made fit material for moral instruction.

In right conduct we deal with what we call the moral sense, more commonly known as the conscience. This must first be awakened by the conditions of the living environment. Then it must be fed on the proper material and the nascent ideas developed into clear moral ideas along with the power to form full and complex moral judgments. In no form of instruction is the example of the teacher so necessary as in moral instruction. Here is one case where pupils learn to do by seeing things done as well as by doing. The abstract precepts of right and wrong conduct will avail much in controlling the acts of children, but where the child has the high standard of moral conduct in the teacher and in many in parents the appeal to him will always be much more effective. Children are to a great extent hero worshippers and imitators and they observe us and copy our actions and words when we are least conscious of it. There are few graded courses in morals in use in schools to-day. But whether such are available for teachers or not, both superintendents, principals and teachers in the graded schools can formulate plans for most instructions that will be progressive in form and scope and that are adapted to the ascending grades. In the school the child first meets his fellows on an equal footing. Here first fully the ego of one child crosses that of another and either takes up with or antagonizes the ego of 
the other. The right of one against another at once arises and must be considered separately and in conjunction with the rights of the aggregate. The growing child will have to modify many tendencies and get rid of others that up to this time he has been allowed to cultivate undisturbedly. In the process of this new experience and its changes upon his habits of thought and action the teacher can exercise great influence and drive home many valuable lessons in duties, rights, and responsibilities. The first lessons in importance in moral teaching in the school is probably that of obedience. Obedience at least to some extent has already been begun in the home, but generally only begins to be effective when enforced in the school. Next we come to property rights, to freedom of individual action, closely followed by honor, courage, self-control and truthfulness. All of these and many more are highly essential to the success of the child not only in the school, but also in after life. If these be well learned here in the period of high impressibility the child has with him an asset in conduct that will off set many other possible shortcomings.

Prominent among our conduct toward others stands our conduct to animals. Animals in their needs and activities appeal to the gentler emotions of man chiefly because of their dependence, also because of the services they render to man. To a few proper conduct toward them appeals also as mere matter of justice in the abstract. Primitive man whose status in each generation is represented by the ehild is unrestrained in brutality and marked by the lack of the higher feelings of sympathy and kindness. The ehief method of arousing the higher feeling toward the helpless and to prevent the venting of anger and violent passion upon them is through the appreciation of pain felt by self whether that pain comes from others or from the suffering subject. Fear of pain is undoubtedly a general means of cnforcing a restraint on human action. In the young curiosity is a ruling incentive to beget action and young children who have little idea of pain and suffering will inflict any amount of torture and pain upon animals without having any conception of what they are doing. In the absence of any outward check 
upon such actions the school through its teacher and teaching must impose an inward check. Talks upon the nature of animal life and the suffering they undergo, their service to mankind, their place in the economy of nature and the similarity between their lires and ours all will tend to create in the young the proper moral feeling toward animals. Children who in their youth when the dormant sympathies can be easily and properly directed are taught the needs of animals and shown how they both appreciate kindness and of tentimcs show their appreciation by reciprocation will learn lasting lessons of kindness to animals. For children to have various animals as pets is one way in which to promote kindly feeling in children for animals and another is by a proper series of talks and illustrations in the schoolroom of their habitat and methods of living, and rearing young with illustrations of whatever signs they show of mental life. To these efforts may be added with good effect the organization in the schools of societies for the prevention of cruelty to animals with perhaps pledge cards and other emblems of associations. Where occasion presents itself these school organizations may be made affiliated organizations with civic organizations of this lind. Much is being done in state, city and town for the better treatment of animals. These forces, however, are inconsiderable when compared to the force that the teacher and the school may become if proper forms of moral education be instituted in the school and if these be constantly and systematically taught throughout the school period.

Besides this in a general way everything within the school has a moral aspect that may be put to good use by the teacher in raising the moral tone of the school. The various movements of the school may be done with precision, promptness, regularity; during them the body may be held erect and the head up as well as obedience enforced, all of which tends to put the child in a position of advanced relation with his fellows that in itself is highly moralizing. $\mathrm{By}$ instilling habits of industry, neatness and accuracy and of application to work the school does much for many of its numbers. It is surprising how few children learn concen- 
trated and continued effort in the home. What this shortcoming or indisposition to pursue work for long periods of time means to organized capital and industry and to enforced idleness suffering and crime to the child in after life every one knows. It is left then for the school to teach children to work for longer or shorter periods of time even though it cost the putting forth of will power and the using up of much surplus bodily energy. Of course, care must be taken that health and growth be not impaired by such routine system, but the work of the school ought to be carefully mapped out with due regard for the health and growth of the pupils, and then its lcarning by all insisted upon by the stimulation of will and ambition.

No place, however, affords the opportunity for moral instruction like the playgrounds. Here the pure minded and the evil minded child come into familiar and close contact. The child of the slums meets and contaminates the mind of the child from the most cultured homes. Obscenity and profanity are rampant, also a host of minor evils. All of these the teacher must see, know, correct and overcome. The child is never at limself better than when on the playground. To begin with, activity is a demand for his proper growth and development. His moral weaknesses and misconceptions crop out there as nowhere else. His abilities and capacities are there free for the fullest expression as are the stimuli for exciting them to activity. Here the child may be observed exactly as he is. Aside from the fact that play gives the child new concepts of self in his relation to others it also gives the teacher interesting material as well as an opportunity for driving home moral lessons in conduct and feeling for others, that arise nowhere in the school life. While there are many arguments advanced against the recess period, the playground and their supervision by the teacher together with his constant commingling on the playground with the pupil, this is one argument and a very strong one why the teacher should at all times even at sacrifice to himself be present with the pupils on the playground. Sex commingling in the schools may be made the means of much valuable moral teaching. There is a wholesome moral effect 
both upon boys and girls where the two are allowed to commingle frecly in the school. Besides social pride which shows itself early in such schools, boys become gentler and more refined, while girls lose much of their prudishness and early sentimentality, when accustomed to the refined association of morally good boys. The locality of the school also contributes much to its moral tone. School buildings should be located in the better sections of the town and where there is the least amount of social pollution, for the children to be exposed to in their daily journeys to and from the school if the best is to be attained morally with the child.

III. Religion. On the one side morals run off into manners on the other side into religion. Religious education is forbidden in American public schools by legislative enactment. Not that the religious training is not essential, but that it is not considered the duty of the state to look after the religious education of the child, but that that responsibility by tacit consent, and rightly, falls upon the church. One of the chief reasons why all of the teaching and discussion of the bible is forbidden in the public schools is that it leads to wrangling over minor matters of doctrine which are matters for the sects to discuss and determine rather than for the school. Besides religious zeal and devotion are rather personal matters into which it is argued one should go rather by personal choice than by training and compulsion. It is a fact, however, that if the school aims in its efforts at the production of a well rounded complete man, to neglect such an important side of him as his religious side would be a serious oversight and mistake, for which the state and society pay a heavy penalty. Religious training is too important a factor in the progress and welfare of humanity to be neglected and when the chureh cither neglects it or the state finds that its results are not as far-reaching as it desires it to be, the state should take the necessary steps to fill the gap in training. Education as fostered by the state is compulsory and religion is a matter of personal choice. But even with this religion could be offered by the school and still be optional. If the state undertook religious education it could use compulsion in regard to it if deemed best and 
thereby get results which the church has not succeeded in getting in religious training. In a way religious education is a safeguard to the state the same as is intellectual education. Religious training and thought act as a check upon violent and fractious natures in a way that neither the state nor society could successfully do. It is but practical foresight on the part of the state, therefore, to provide that this restraint upon human action shall not be lost. The school in particular and the state less directly, both, owe their maintenance, perpetuation and present situation to the fostering care of the church and religion, when the unwarranted and sudden attacks of barbarians and savage hordes ignorant of the value of either institution assailed them and threatened them with immediate destruction. For the state to neglect religion now, when it has come into its own looks like gross ingratitude to say the least. American civilization is feeling sadly the need of the restraint of religious training in thought and action. The church and its work are baserl upon voluntary action, and, while it has done and is doing a great work for humanity even in this way it can hardly be expected from what was said above to accomplish what the state accomplishes in education. All civilized states have accepted and rigidly enforced the Lutheran idea of compulsory attendance upon the public schools, why can they not accept the other great doctrine of Luther and make bible study one of the subjects of the public school course of study? The plea that the church and the home can both look after the religious education is not a sufficient one. The church and the home can and do look after socalled intellectual education. But it was found out that whether they could or not they did not get the best results. So it is to some considerable extent with religious education. It is thus fair to both to say that they do what they can in this regard which is much, but not all that is necessary. The home has other distinctive functions which make this function secondary, while the church passes much of its function in educational matters on to its adjunct, the Sunday School, which it has created within its ranks and attempted to foster and support. And yet what a woeful lack 
is there here. The work is often poorly graded, if at all, the pupils badly classified, text books scarce and language not well adapted to the young mind of the child and the teachers untrained both in the subject matter of the text and the principles of teaching. The attendance upon the Sunday School, though various artificial means are taken to stimulate and leep it up, being non-compulsory, is irregular and consequently only a few of those amenable by age obtain even such education as is offered. There is little or no system of preparation or study of the lesson or of the recitation, while the time devoted to them is short, generally about thirty minutes, to say nothing of the lack of room, meager equipment and the general excitement and interruption amidst which the work is done. It is no wonder under such circumstances that religious education as fostered by the church is poor and that society, state and church alike suffer as a result.

There is without a doubt some justification of the attitude against the teaching of religion and the bible in schools, but this can and is only valid when it comes to sects and sectarian doctrine and religious views. Religion and the bible both can be shorn of these and introduced into the schools. Many countries of continental Europe have done this, notably Germany. Here, thanks to the influence of Luther religion is a prominent part of the German public school curriculum. It is true that it is optional with parents as to whether their children shall attend these exercises or not, but the education is offered under the guidance and control of the state to all who wish to attend upon them. Nor is the permission to keep children away from such subjects left entirely to the caprice of the parents, but those who desire to do such must get official permission from the state authorities, which is only granted after the parent has signed a rigid code of relinquishments, which few consent to do. The education given under the head of religion is graded and consists of bible instruction and instruction in sacred history and literature. Of course, there is justification in the jealousy with which Americans as a people guard their religious rights and freedom, when one thinks of and allows for 
what they have suffered to gain and retain them. But religion throws a halo of security around our social, political and civil institutions that we cannot well do without. Already contamination is creeping into our social structure and we should take hold before our civilization becomes rotten at the core and slowly eats out the heart of our institutions and government. Religious education can be taught in the public schools without endangering religious liberty and it should be. Moral education has its good quality and is effective within its range, but morality and religion while they have much in common have some things in difference. That is, religion is something apart from morality and this something morality can never supply until it becomes religion. Mankind has not yet reached that stage, if it ever will, where it can rule out of its life all conceptions of God, his works and his restraint upon human action and still vouchsafe to civilization the safety of its social, civil and political institutions. Religious education should be a fixed part of our public school curriculum. For by its being taught there much of stability and endurance of education will be saved for society and the state.

IV. Manners. Like instruction in religion, instruction in manners has been chiefly delegated to the home. It is only recently that it has found a place in the common school curriculum, though even to date that place is an insignificant one. Manners should be a prominent form of public education. Second to intellectual training and a very close second at that stands training in manners. However, though it may be just because of the custom one and all are in the habit of forming estimates of people by their manners. Very good manners because of the paths they open to the sex possessing them are cultivated by the really low and degraded. That does not reflect upon good manners but merely goes to show how valuable an adjunct good manners are to those who would be well judged and given a chance in the aff airs of life. If the school hopes to give the child that which is valuable in personal presentation to society it cannot negelect training in manners. Manners generally take on two forms. Either they become politeness with all that 
the word implies or they run off into etiquette as used in its broad sense. Etiquette in principle is an outgrowth or perhaps better a corollary to politeness which goes into more detail. Both politeness and etiquette may degenerate into mere form entirely devoid of all spirit. Etiquette has been more often reduced to mere tawdry conventionality which has become so empty as to cast a shadow of refiection upon true etiquette. In its teaching the school must carefully distinguish between the two, decrying the one and upholding the other. Etiquette is generally a form of conduct that is of much value for self and self-welfare as for others and the welfare of others. Politeness is entirely for the comfort and welfare of others. It is the altruism that has grown upon us with civilization and marks the progress of society from a barbaric horde to an enlightened community. Politeness is really the truest form of altruism, especially if it comes from the heart, as it is one of the most unselfish forms of conduct civilization possesses. America is in this respect to quite an extent a country of little social form and conventionality. We are, however, proud of this trait and are known throughout the world for their brusqueness of manner and curt indifference to social usage. It is the American idea of democratic liberty. And, while no true American would change the national ideal, there is some danger that the practice is condemnable as it may be and oftentimes is, overdone. While democratic ideas resent the restraint of excessive conventionality, there are certain simple forms that are necessary if there is to be permanence to what claims American civilization may make to culture. In Europe the American is forcibly impressed with the good manners in old and young and their exceeding politeness to all alike both to stranger and friend. This is particularly noticeable in Germany where lessons in manners constitute much of the school and home training of children and it is everywhere regarded as an evidence of culture and standing. The familiar "Howdy," "Hello!" and "Hello there!" of America without bend of body, nod of head or lift of hat form a remarkable contrast to the very formal and effective "Bon matin," "Bon jour," and "Guten Morgen," and 
"Guten Tag" of the French and German of all classes accompanied by a bend of body, bow of head and lift of hat. So far has this formal usage in manners extended that men lift their hats to men as well as to women in most places of continental Europe, this lift being not merely the raising of the hat but the removing of it to arm's length from the head. All greetings also are with full bows. The girls do the courtesy familiar to all Southerners as the "Curtsie," while the boys mostly give the greeting from the position of military salute. Of course, instructions in manners may go too far and a little of it goes a long ways with Americans, but in avoiding Scylla we must beware of Charybdis. Either extreme is dangerous. False manners are a bane to society, but simple good usage that represents the true feeling of one is an asset for individual or social group.

What particular social forms should be taught in the schools is not generally definitely outlined, nor are they taught in the same number and ways in the different schools. In general we should only do those things which express our appreciation and sympathy for the presence and welfare of others. 'These expressions should be particularly for the lowly and the helpless in general, and for others, out of respect and gratitude, but never to curry favor. Too often good manners both in young and old are turned to this degraded and degrading end. In the home where the welfare of each is closely interwoven with that of the other, courtesy and consideration are of the utmost importance. Next to the home those of the school come in for consideration. After these follow our general contact with our fellows in a social and business way. In the school, children should be taught how, when and to whom to raise the hat and what forms of greeting stand for in the social relation. In the nicetics and delicacies of such forms the school can have little interest. They are for the culture and refinement as well as conventionality of a society in which the school for itself especially in a democratic country can have little concern and to which it is not intended that the school should cater. There is upon one and all, however, constant demand for respect and sympathy for others who are sick or 
afflicted and in need of help everywhere in life. Giving seats, position or way to the aged, to our parents and older brothers, sisters and friends are all practices that help to lessen human woe and suffering and which give to children a self-appreciation and presence as well as regard from others that are valuable throughout life. Treatment of strangers, guests, hosts and hostesses and conduct in parlor and hall can be outlined and handled in a general way in the school, as well as the conduct at the table and on the street. The gencral suggestion being that the child be taught in these matters to put the consideration and welfare of others before self. Children, since they come in contact with new people daily, should be taught early how to receive and acknowledge introductions and how to remedy social and practical oversights and mistakes by an apology or a kindly and sympathetic "Excuse me, please." How and when to say "thanks" or "thank you" is another lesson that the child should learn early. Too of ten children take the acts of others toward them too indifferently and as a matter of fact. Children little know how much of the world order revolves around them and perhaps it is well so. But when their interests are looked after by parents, relative, friend, acquaintance or even stranger with patient toil and care and often serious sacrifice, certainly the child ought to be taught that system of usage whereby he will see and appreciate this help given him and know how and be disposed to show by these signs that he appreciated the effort put forth in his behalf, and know that such should be because these things have been furnished or made possible for him by the sacrifice of another individual or group of individuals. Instruction in manners is to be condemned when it attempts to make a "fop" or "dandy" out of a child or waste time trying to instruct him in fastidious usages. But the school can serve the state and society well by giving wholesome instruction in the simple matters of conduct that are demanded in the daily life of the child in the home, on the street, in public and in private, to old and young and to inferior and superior.

V. Patriotism. Patriotism is pride, whether it be of fam- 
ily, home, town, state, country or nationality, not pride merely expressed in so many words, but pride that will when necessary bring sacrifice and suffering even unto death that the object of pride may endure. Patriotism has done much for the world and saved the day on many a battle field. But this is not the only form and use of patriotism, though it is the one mostly heralded abroad. Much also has been done under the name of patriotism that has degraded its otherwise ethereal conception. The general definition of patriotism runs in this strain: Patriotism is devotion to one's country ; "Love of country," "a willingness to sacrifice for one's country," etc. These definitions all strike at the fundamental in patriotism. It is the feeling that places the welfare of the object for which the feeling is manifest above that of all other objects even self and is especially used in reference to one's native land. As taught in the schools patriotism should teach not only the strength and virtue of country but also its weaknesses and foibles. Then the child can grow up with joy in the one and a determination to correct and remedy the other. Too often, love of country or patriotism begins and ends with the foreign foe. But in every country there are often domestic foes that are more dangerous to the country than any foreign foe ever could be. To be effective lessons in patriotism should go hand in hand with lessons in government. In this country, for example, the principles of democracy as well as its snares and pitfalls should be known intimately to all of its eitizens. They then provoke serious consideration along with whatever we see to boast of. Democracies have their weak side as well as their strong side. So also have monarchies both limited and absolute. The school can and should show the child that which is sane and wholesome in government and civil life in general and the duties of the child in respect to it, both in peace and in war. The elective franchise is the guardian of our political and civil institutions. Upon its proper use depends the permanence and perpetuation of our country as a political unit. There is as much need for the proper use of the ballot as of the musket. Democracies are governed by parties. But parties and partisan measures are never 
of superior importance to one's country. Patriotism and partisanism go hand in hand as long as partisanism has the perpetuation of good government and civil institutions in the country at heart and not that of the party, or the furtherance of the selfish ends of the men who sometimes head the party. It is just as unpatriotic to aid and abet graft and corruption in government as to betray one's country to an external foe, just as unpatriotic to sell one's vote at the polls as to betray one's country for money. We are passing now through an era of corruption in government that, if the nation is to survive must be rooted out. The ballot is either misused or unused by a large part of the citizenship. If this crisis, for crisis it is, is to be safely met the ballot is the instrument with which it is to be met. Patriotism if properly taught in the schoolroom can do much to this end, not by talking or teaching politics but by talking and teaching honesty in purpose, respect for law and a love for its rigid and impartial enforcement and the need of voting for measures and men rather than for mere party. Many there are of the citizenship who would willingly give their lives to repel a foreign foe, but who would not give the good will of a friend or acquaintance selfishly interested in party advancement for the sake of good govermment.

Means of Teaching Patriotism. The nation and especially the school can do much toward cultivating a proper spirit of patriotism by acquainting the child with the nature and duties of all public officials and their restrictions by and subserviency to, the law, to the state and the nation. They will then know what they have a right to expect of them and how to demand and to obtain these rights. To this may be added the methods of observing the anniversary of great events or achievements in national life. For example, we celebrate the "Declaration of Independence" at which time orators speak of and teachers instruct in the meaning and value of that day to Americans. To this we add the celebration of the birthday of our national heroes and statesmen, when the children are taught the virtues and achievements that made these men great. From the events and characters of national repute we turn to those of local 
report. The semblance of the national flag and what respect of and love for it means, along with its history of origin and consequent existence, dwelling especially upon it as a symbol of national honor, integrity and respect. These may be accompanied or supplemented by flag drills and other exercises with fiag and bunting in flag colors to visibly associate the symbol with that for which it stands. In all such ways the school may teach patriotism to its pupils. However, lessons in patriotism would not be complete without the singing of our so-called national and patriotic songs. These patriotic hymns generally owe their origin to circumstances with which in most cases the song itself teems. Our " Battle Hymn of the Republic," " Marching Through Georgia" and "The Star Spangled Banner" all partake of the fiery spirit of the war times that gave them their birth. They seem to be used chiefly to arouse this side of civic nature and patriotism. For this purpose also Germany uses her "Die Wacht an Rhein," France her "I.a Marseillaise" and we our "America." Though, America not originating under similar circumstances, partakes of a slightly different spirit. The learning and singing of these hymns will arouse the soul of the pupil in the same way that it does the older citizens. In connection with this also just what these national hymms have meant to the nation in the past and what they will mean in the future should be shown by the teacher, the part that the rising generation must play in maintaining this meaning in the future and their connection with men and events should be carefully established in the child's mind. American patriotic celebrations do not seem to partake of such deep sentiment as patriotic celcbrations on the continent of Europe. Of course they do, but the nature of the depths in their expression is the difference of the emotionalism of the two peoples. America seems to be too busy in the things of the present and money making to feel the emotions of these people under the same circumstances. Besides the school preparation in Germany, for example, to which weeks and weeks of preparation and drill in song and march and the use of the flag is different. The old too, for such occasions gather in large assembly halls 
and listen to the speeches of orators upon the greatness of country and government. This forms a strong contrast to our fourth of July celebration in most parts of this country, where the day means a lot of fuss and noise with danger to life and little of the import of the day to our national life. The form has lost its substance. The Fourth of July is "firecracker day" to most of "young America" and hardly that to most of "old America." Seeley closes his discussion on Patriotism by this passage: "If patriotism is to be fostered in our land, it must come through the great body of teachers in our public schools. It must come early to the school children for the great mass of children leave school before they reach their teens. It will never be taught in the highest and best sense, if not taught by the teachers of the public schools who reach this vast body of children. Therefore as they lore God, and home, and country, and as they pray, and hope and labor for the glory of our great country and its noble institutions I summon the teacher to his greatest work."

The school is the greatest organized educational force known to civilization. Not only in the direct phase of education, that of getting facts and learning truth about the world, life and activity, but the school is great in these phases of education which we have designated here as the subsidiary phases of education. These forms of education are more strictly education for life, for complete living. In these subsidiary phases of education the school serves more the state, the church, the home and socicty while in the other it serves more directly the individual. Here the moral standard of the country, here her social and political institutions if they are to be maintained and purified are formed and fostcred, here the value of the ballot and its use must be lcarned as well as the nature and essence of democratic institutions. If the school stands by her colors here and does her work well, all is well, if she fail in this, she fails in all and for her all is lost. For in the nature of her scrvice the school is unique and no force in civilization has yet been found to take her place. 


\section{REFERENCE READING}

Taylor's "The Study of the Child." Chaps. XVIII, XIX, XX, XXI. Dexter and Garlick's "Psychology in the Schoolroom." Chap. XXII. Colvin's "The Learning Process." Chaps. III, IV.

Compayre's "Psychology Applied to Education." Chap. XI.

Horne"s "Psychological Principles of Education." Chaps. XXVI, XXIX, XXX, XXXI, XXXII, XXXIII, XXXIV.

Bolton's "Principles of Education." Chap. XXVII.

Rosenkranz's "Philosophy of Education." Chaps. II, XIV, XV, XVI, XVII.

Muinsterberg's "Psychology and the Teacher." Chap. XX.

Froebel's “Education of Man." Pages 60, 61.

Adler's "Moral Instruction of Children." Chap. V. 


\section{CHAP'TER XVI}

\section{PLAY, PLAYGROUNDS, ATHLETICS}

Play is the original form of animal activity, so much is this so that play has now become an instinctive and prominent trait of all of the higher forms of animal life. The greater the vitality and power of locomotion, the stronger is the instinct of play present in the organism. Play is natural; it is nature's method of getting exercise and exercise is a basic requirement in animals for health and growth. It was Lamarck who revived the old Grecian biological principle known as "The Law of Use" and wrote, "use strengthens, disuse impairs and abuse (misuse) destroys." It was, it may be assumed implicitly intended that this use was to take place in the open air, though the law would still be valid without meeting this condition. At any rate to produce the best results use, exercise or play must be performed in the open air and sunshine. Tests have proved that so vital is the need of sunshine for growing and living organisms and so thoroughgoing is this need in nature that all forms of plant life have acquired the power through its ages of strugggle for existence of extending its growth in any and all directions in order to reach the life and growth giving element, the sunshine. Plants left without it soon die, while animals have been known to becone inert, helpless, unformed masses of flesh without developed bony tissue, incapable of locomotion, when denied the full and free access to sunshine and fresh air. Physiology has in detail told how the chemical (actinic) actions of the sun's rays accelerate the production of red corpuscles (haemoglobin) and also of the white corpuscles (leucocytes), the former of which administer to the upbuilding processes of the body (cell formation), while the latter administers to the process of resistance of the organism to attacks from various de- 
structive elements in the environment. In other words red corpuscles enable growth and white corpuscles enable resistance to the ravages of disease. Fresh air contains oxygen. Oxygen is necessary for the animal processes in which the organic cells appropriate and perform that recomposition of matter known as combustion by which the heat of the body is generated and the food substances reduced to their elements and made assimilable by the various tissues of the body. But apart from these physical and chemical properties of air and sunlight, there are psycho-physical effects in play that are equal, if not superior to, the influence of play. In the first place it brings about effective muscular coordination and quick response to stimuli. In its higher forms it demands accurate and deliberate thinking under a degree of nervous tension calculated to upset the best mental poise and balance. It often requires self-restraining, when the tendency to self-expression is greatest. In the young, play is especially to be commended for its aid to muscular coordination. The inability of the young to properly direct the motions of their bodies and limbs and to produce rapid and energetic motion is characteristic of all of them. If, then, play did nothing else but this, it would have served a large need in animal life and motor economy. Especially is this effect valuable in such young as are by nature sluggish in bodily morements and dullards in mental processes. Play is by nature pleasurable. Biologically this would probably be explained as due to the fact that play tends to the prolongation of life through the extension of all living activities, for according to the pleasure-pain economy in nature that which is pleasurable tends to promote life and its activities, while that which is painful tends to demote life and its activities. In other words it seems that there is in nature an inherent demand for voluntary exereise. Growing organisms have a surplus of energy which must be gotten rid of in order that the organs may be free to create more energy, the creation of which is life, health and strength to it. Unless this energy is used up it clogs the system, enervates the organs and reduces their action. This may become so serious as to bring on disease and even death, for the crea- 
tion of this energy involves destruction of cells and the filling of the body with waste matter, while the dissipation of it involves the removal of all effete matter and the building up of new and better cell substances.

Demands for Recess and Playgrounds. Because of the evils of disorder and the disruption in the school program many educators have been led to advocate the abolishment of the recess period from the daily program and offer for it a substitute in the form of calisthenics and gymnastics. But the recess is the chief means that the school adopts for offering opportunities for play to the child. From a third to a half of the child's waking hours are spent in the schoolroom. To attempt to use up this much of the child's waking hours without provision for play in the open air is dangerous to the liealth of the child. 'Tis true that the work and discipline of the school seem to some extent to justify this attitude and that economy of time and energy seem to make it imperative. But is not the first demand upon all living organisms life and health? From this viewpoint indoor calesthenics and gymnastics are a poor substitute for free play in the open air, especially since it has been shown wherein indoor exercise fails to satisfy the demands of health because of the lack here of the direct effect of the sun's rays which play such an important part in the formation of the blood corpuscles, even granting that under the circumstances air for the schoolroom can be obtained of the same healthful properties as that in the open, a proposition which in itself is to be seriously questioned. Art has succeeded in many instances in improving upon nature, but this is one instance where there would be everything except improvement. For according to Jacob Riis, "To play in the sunlight is a child's right and it is not to be cheated out of it. And when it is cheated out of it it is not the child but the community that is robbed of that beside which all its wealth is but tinsel and trash. For men, not money make a country great, and joyless children do not make good men." Ages of experience has made this sentiment the embodiment of all progressive national and educational ideals. Thus play is not a luxury of the school to be cast aside when necessities 
are in demand, but it is a necessary form of self-expression even though it be primitive. It is like many other natural processes only capable of its best when it springs from the soul spontaneously and involuntarily: To direct attention to it in detail voluntarily is to rob it of its chief joy and source of good. To attempt consciously to make play pleasurable and center the mind upon the effort is to rob it of the very element that gives it its chief value.

The chief source of opposition to play is the sentiment come down to us from the middle ages a relic of religious ascetism, which belittled the body and all bodily functions and advocated its neglect and even abuse. The reaction against this kind of practical philosophy is growing stronger every day. To-day the tendency everywhere is to recognize and even to magnify the body and bodily functions. Spencer has shown in detail how the strain of each generation has become greater and the demand for larger earnings more imperious until the lack of spare hours for recreation (play) has not only so weakened each generation that its capacity for the enjoyment of life is lessened, but that it leaves them so depleted mentally and physically that their off spring come into life less prepared for its strain and its demands, especially when the preponderance of evidence seems to indicate that those demands will be greater upon the later generation than it was upon the earlier. Investigation has shown that overwork, improper food, lack of rest and bodily exercise in the open air and sunlight makes an opening for the successful attack of every form of disease, and that bad housing, improper air and sunlight is the cause of nearly all the epidemics and contagions. So that just as a grocer's bill by most of us would be more willingly paid than a doctor's bill, so a playground should be more willingly furnished to the young and old than a sanitarium for tuberculosis and consumption. Statistics go to show also that there is a relation between crime committed by individuals and the amount of access they have to playgrounds and opportunity for play. Having discovered this the "International Prison Congress" recommended as a preventive and reducer of crime "vast additions to playgrounds as the surest preven- 
tion of juvenile mischief and crime and as affording young people places where they may learn to bear defeat with courage and success with modesty." Along the same line Governor John A. Johnson wrote "He (the boy) must have enough of recreation and pleasure to keep the vinegar out of his nature and no man has the right to deny his children that."

The playground and games both for young and old furnish an opportunity for the players and those observing the play to learn the various weaknesses in human nature, both morally, mentally and physically as nothing else will. Passions such as would never crop out elsewhere will appear in the vicissitudes of the playgrounds, selfishness, vanity, dishonesty, disregard for individual rights and for law with a desire for order all show themselves in ways that occasions elsewhere do not often serve to bring to the surface. Opposite traits and qualities also come out on the playground, some good and some bad which a whole lifetime otherwise might not bring to the front. From the viewpoint of the state and society the playing of games is a wonderful schooling for the child, for he cannot play then without learning subordination and respect for law and order even if only the laws of the games and the order necessary for its successful continuance. Here, too, he learns the first full effects of unprejudiced as well as unrestrained disapproval of his fellows for the transgression of law and the disturbance of order. For every game has its laws by which each player must abide and methods according to which he plays. Indeed, as Gulick has well said "The play life of a people indicates more than anything else its vitality, morals, intelligence and fitness to live." Not only " the resisting power of the body can be kept at its best only where there is simple bodily exercise in the open air, but the good nature and cheerful temperament of the child is maintained thereby." Another good side of play is that there is no process in the school that is more democratic. On the playground plebeian and patrician, rich and poor alike meet side by side. It is a test of birth, but not of birth rated upon social standing and privilege, but upon the physical and intellectual stand- 
ing of the family. Neither do dollars and cents nor even formal education as mere book knowledge, and culture as superiority in fine usage and contact win the day. The son of the plebeian is here on equal footing with the son of the "best bloods." Each is given an equal chance with the other and the son of the patrician soon learns here that there are other virtues of value to his fellows and society besides those which in the experience of the home he has been led to believe rest in himslf and those of his kind. The playing of games on this basis of equality and merit has taught him a new lesson in life. Here play is a natural equalizer, socializer and denationalizer. It makes common blood of all and temporarily at least unites all in one common interest. Herein lies the virtue of play. This is the good that the school can do in fostering and supervising play and furnishing playgrounds and opportunitics for play. The good that the school can do socicty, the state and the pupil by offering training and experience in play is obvious.

Play Versus Schoolwork. In the chapter on "The Daily Program " it was shown that play had a decided effect upon the work of a school. Of course, it was found out also that play to some extent disorganized and broke down the government and discipline of the school and broke into the work of the day to some extent. But besides being minor this effect was negative. Some very essential effects, however, were found. It was found out, for example, that the bodily morements in the open air accompanied by a new form of mental process though at times intense purged the system of many physical impurities that tended to clog it and tax unnecessarily the vital organs in their functions, thereby producing sluggishness and fatigue; that it increased the vital function and by increasing the processes of deoxidation used up much of the food products collecting in the various parts of the digestive tract where energy was generated and stored away. As a result of these fruits of free bodily exercise in the open air and sunlight shortly after the recess periods the available bodily energy for school work was seen to rise markedly second only to that found present immediately succeeding the opening of school in the morning. 
Observation has also shown that the activity of play relieves especially healthy highly energized temperaments of surplus energy. Surplus energy must be gotten rid of and if it is not worked off in one way it will manifest itself in another. Such children must be allowed more freedom than others. An occasional run in the schoolyard or a new form of school exercise will serve to quiet such a one. But some form of expression he must have. The pressure from within is too great for him to repress. With some children relief from this pressure is imperative for good work out of them. Indeed teachers may at times find necessary, in dealing with a class of such pupils, to interrupt a regular exercise and have gymnastics, a brief moment of indoor or outdoor recess to relieve the general tension. An experiment of this kind will generally immediately show not only a new amount of working energy but also a new working spirit in the child. This condition is found to be more aggravated on some days than others. Too, it is of ten noticeable that such conditions are more frequent and serious in the children from the poorer districts where the tendency to more unregulated diet of coarse and highly energizing foods in unlimited quantities prevails. There is a generally prevailing opinion created through long years of observation that the pupils who excel in play also excel in schoolwork. This point is of value here not only because it shows that those who have energy for play also have like energy for work, but also because it shows that the same mental powers, muscular coordination and nervous control that are available on the playground are available in the schoolroom and that which is of equal or even greater importance, that the skill and increased control gained in the play of games is spontaneously applied in the exercises and work of the school. In the same way play contributes to individual and collective success of the social and civic body. Not only is the skill and muscular control gained there available in after life along with the powers of concentration, endurance and the arousing of new and allied interests, but the experience of inferiority and superiority to our fellows and the recognition of the great variety of abilities in various of his playmates gives him greater re- 
spect for them while at the same time teaching him just where he does excel, wherein he does not and also how he may improve himself. Too, associations and friendships sometimes started through incidents, associations and circumstances of play often become permanent and bring much joy and comfort to each of the persons thus related throughout his life time. He also learns the lesson of cooperation and united action, and experiences keenly the appreciation of his play-fellows where he contributes his full share to the success and pleasures of the game as well as receives their disapproval where either because incapable or negligent he fails to contribute lis share to the success and the pleasure of the game. For play not only brings to the surface in the child many native capacities but it also often shows one's various inherent weaknesses. On the playground also children learn valuable lessons in ethics. Not the theoretical ethics of the academy and the school, but the ethics of everyday life. All games have, for example, their prescribed rules of conduct and their prescribed penalties for non-performance or attempted breach in the rules of the game for the sake of unfair advantage in the performance of the various parts of the play. These nust all be adhered to and rigidly enforced. One of the chief characteristics of childhood is painful simplicity and frankness. The mistakes made or wrongs committed in the game are denounced by them with ruthless indifference to the amount of pain inflicted upon the unfortunate guilty ones. The fact is, in such matters children too often prove to be devoid of the consciousness of pain as it affects others. It is only later in life that they learn to smooth over ruffled moods, heal wounds with hurt-balm or condone mistakes and wrongs with sweet words and soothing manners. Then, too, say what we may, all children have their crude sense of justice and their own crude code of morals by which they judge and condemn mercilessly. In this system as administered by them, those of their number who have various unsocial tendencies or who practice unfair methods in play soon learn the sting of popular disapproval. In the games of play each learns his own rights and duties and whether he wishes to be or not is dele- 
gated his rights and forced to perform his duties by the opinion and conduct of others. While it is a commonplace psychology that a weak body means a weak will and weak willing along with a general impairment of mental faculties no allowance is made for this in this child code of morals. But although all of these complex effects are going on at the same time in child play it is done almost unconsciously and the whole soul life of the child finds unrestrained expression in play thereby. No one can look upon a group of children intently at play, a secthing running, jumping, laughing, shouting, conglomerate mass and not see that there is a divinity lurking behind it all, that play is as natural as life itself to the young and as necessary to their growth and development as food and drink.

But with all of this there is much of evil in play and much of potent good in it which if left uncontrolled or undirected may be wasted or may even be turned into evil and do harm. The teacher should give constant attention to the play and the children at play, if anything like the best results are to obtain. Among children there are the fractious, selfish and even unsocial individuals who will prove harmful to the other members of the group and to the playing of the game itself. Sometimes it will be best to let him run abreast of the concentrated opinion of his fellows, at other times this may be dangerous for the group welfare, whereupon a strong arm from the outside must interfere. This strong arm in the play about the school must be the teacher who should always be at hand to see that as far as possible the right thing is done at the right time and that the innocent unoffending and often the weak are not abused or outraged by the willful and selfish strong. In schools where children of various ages and sizes play together it is often necessary to restrict the older ones in their play in order to protect the younger and weaker. Oftentimes also unexpected freaks in play crop out and new and dangerous games may be introduced on the playgrounds and serious harm done in the playing of them either to the innocent child looking on or to those playing the game if the teacher be not on hand then and there to stop the play or modify it so as 
to rob it of its dangerous phase. New pupils from other towns and schools often bring with them vices and currupt practices, profanity and vulgarity that is highly contaminating, if not discovered early and rooted out with a strong hand. This the teacher can only do by his constant presence and watchful care. In all of this, however, it is not intended that the teacher should attempt to officiate and interfere with the children at play. Play is at its best from the viewpoint of health for the child and self expression in play most natural and sincere when the playing is undirected and unrestricted by outside authority, that is, play is best when it is spontaneous. The less of a conscious or externally controlled element there is in play the better will be the results accruing therefrom to the pupil. The teacher can even with advantage indulge at times with the children in their play, having a care always that he loses nothing thereby of respect or high regard either because of his ignorance of the game or inability to perform well that which he attempts, that the indulgence be not so frequent as to cost him his dignity or the act to lose by commonness its pleasure. Play is democratic as we have said. It is for all of the pupils. Oftentimes in play there are those bolder or more selfish natures who would crowd others more timid and less competent out of their places and parts in the play and usurp it for themselves. On the other hand there are those bashful selfconscious pupils who hesitate and are even inclined to refuse to take part in the game for fear that they may not be wanted or that they may not be able to do as well as some other, because of which they may laugh at them or otherwise hurt their feelings. Then, there are the restless and impatient pupils who fret and chafe under the delay in teaching the others the fine points of the game or play which they themselves have been even more slow to comprehend, but which they now know well, simply because they have had the opportunities of playing the game and learning it before. For all of these conditions, the teacher's presence on the playground is necessary and his tactful guidance and direction should give to all an equal opportunity to learn the various games played on the play- 
ground and to exercise this knowledge on an equal footing with every other pupil.

Play and Discipline. There is still another side of play that concerns the teacher deeply. Play can be and should be made to have a decided effect upon the discipline of the school. It should reduce discipline in the school to a minimum. Comparatively few, if any children are bad at heart and the conception of them that would make them so is fundamentally wrong and bound to lead to serious trouble, if not actual failure in the discipline and government of the school. It is the combination of conditions of health and environmental circumstances in play that combine to make play helpful in school government and discipline. For it is under the restraint and repression of the schoolroom that results in fretting, chafing, and restlessness which lead to misconduct and afterwards often to resentment, when unproportionate or unfair punishment due to hastiness or misunderstanding on the part of the teacher is meted out, that most of the trouble in the schoolroom begins. Healthy children are brimful of energy. This energy is being constantly added to throughout the normal waking hours and will increase to the "explosion point" unless care is taken to use it up. This energy makes child-life very expressive and repression of this tendency to expression very painful. Play, in the first place, gives full opportunity for normal expression and dissipation of this energy. In the second place play rests the organs from their tension and reinvigorates the body, thereby accelerating the vital functions, enabling the body to purge itself of impurities, improve the blood and cnable a new set to of all the bodily organs to their respective functions. The teacher who fails to see this demand for activity in the young is in serious danger of error of judgment and resulting mistreatment of them. Schools, of course, nust be orderly and children must be obedient. But when a child's whole physical and mental life is pressing out of him through eyes, tongue, finger tips, body and limbs, restrictions are useless unless they be simply directive, not repressive. At such times the tendency to action is too strong to be successfully suppressed without the applica- 
tion of dangerously strong measures. It can be better modified and redirected into other channels of expression. This condition it will be found will prevail particularly under such circumstances as bright days, patron's day, show day, etc. On such occasions longer recesses or considerable abridgment of method and exercise is about as good a way to overcome the threatening difficulty as can be found. All exercises that are animating and full of action are under such circumstances to be especially recommended. By this means mucl of the energy that would otherwise go to plan out and execute mischief may be dissipated. What this fails to use up the longer recess periods at such times will care for. Children who have become dull and indifferent because their systems are surcharged with energy and so clogged with effete and foreign matter that the lagging blood fails to remove it, spontaneously awaken on the playground and after having gotten rid of the congested bodily state, return to the schoolroom awakened and ready for the schoolwork. So that the playground by using up surplus energy makes possible an casy control and ready direction of the remaining energy into the desired channels of activity.

Playground. All of this exploitation of the good traits of play and its value to the school child and the school work has been done under the assumption that there is a suitable place provided by the school authorities on which the child may romp and play and give full expression to his physical and mental nature. This assumption is not without grounds. Few public schools to-day, both those for boys and those for girls are without some space provided as playgrounds for the school children. Too, there are very few school authorities who have not come to learn the value of playgrounds for the health, discipline and working efficiency of the pupils. And if the present general agitation for proper and adequate playgrounds for the young continues it will not be long before the pressure brought to bear will cause sufficient funds for the purpose to be put into the proper channels to provide these grounds. Not only schools but cities too, catching the spirit of the times and appreciating its effect in making good citizens are providing playgrounds 
for the children where they may gather in the cities removed from the centers of vice, dust and grime, and find healthy, wholesome play and joyful occupation, so that Satan may not find less innocent occupation for them. There are today in every state, societics which have branch locals in every city of any consequence whose sole purpose it is to see that proper playground facilities are provided for the children of the town. Playgrounds are primarily for play and not for ornament. This fact is generally appreciated for boys, but too often it is forgotten for girls. Girls' playgrounds of ten are chiefly ornamental, so much so that in most cases there is little room for free play for fear harm may come to the oftentimes expensive ornamentation. Most girls' playgrounds are thus reduced almost entirely to highly ornamental parks and promenades. Here the fault is committed, however much it is meet that the esthetic sense of girls be cultivated, of allowing the means to an end to usurp the rights and privileges of the end itself. And as a result instead of girls being given an opportunity for free and full expression of physical and mental states in play they are constrained to quietude and hampered activity, they, who of all children, should be given freedom of activity. There is at present, however, a tendency arising to give to the girl increased access to her own in this sphere with equal opportunity for self-activity, self-expression and freedom of mental and bodily development and freedom in all forms of athletics.

Plays for Schoolroom and Playground. While the number of plays that may be indulged in in the schoolroom and on the playground is large, here again as in all other phases of the schoolwork, just what games will be possible in the schoolroom and on the playgrounds and what success will attend their playing will depend almost entirely upon the ingenuity, tact, resourcefulness and general disciplinary ability of the teacher. The age of the pupils and the general advantages afforded by the schoolroom and the playground in facilities for a variety of plays and games will also come in for some consideration as to their ultimate effects.

In the schoolroom the bean bag games (bean bag target, 
passing the bean bag, dropping the bean bag, and other miscellaneous bean bag games such as line throwing, dropping the bag, circle throwing, catching bags, and tag with the beanbag) can be readily played and ordinarily the whole school can take part in the game. If this is impossible, the school may be divided into groups and the groups may play in relays, the off-groups forming the crowd of onlookers while the other group is playing. Marches, too, form a large part of inside play. There is the game of soldiers in which the whole school may join, the officers being chosen either by the teacher or the school, or by the school assisted and directed by the teacher, or the teacher may choose them on a basis of merit in schoolwork, announcement to this end having been previously made. Of all the marches the fancy marches headed by the so-called "Grand March" closely followed by the various folk dances. Next to marches from the viewpoint of the number who can take part come charades and magic music. Black board relay exercises may be indulged in in any form of school exercises both for the purpose of arousing interest and enthusiasm and for the mere health value as play. Quoits also make a good indoor game the pegs for the rings being immovably set in movable boards. There-are quite a number of intellectual and guessing games that are adopted to indoor use which may be used to further the school work especially arithmetic, geography, history and literature, as well as serve to satisfy the interest of play and resultingly the health of the pupil. Some of the principal intellectual games are "Packed My Grandfather's 'Trunk," "Buzz," "Simon Says," "Prince of Paris" and many others that partake of the nature of competition, such as "Spelling Down" and "Pronouncing Down." These last two may be extended to cover "Reading Down," "Reciting Down" and almost any other form of school exercise. Close to the intellectual games are the guessing games which are also of a semi-intellectual nature and by special effort and ingenuity on the part of the teacher may be made almost wholly so. Some of the more common guessing ganes are "Kingdom," "Bird, Beast and Foul," "Omnibus" and "The Ship Sails." Where desirable all of these games may 
be varied to suit the occasion and modified so as to cover any kind of class work which the teacher wishes to take up) in games. There is little if any lesson content such as cannot be made the subject of a guessing game and many form subjects also may be thus used.

While most of the games named above under the head of games for indoor play may be played outside with equal ease, there are besides these special games which because of the room they require, the amount of violent activity and the size and hardness of the instruments used in playing them are especially adapted to play out of doors and in fact can only be safely indulged in there. Strictly indoor games are chiefly for girls and small children and when taken outside, especially, are restricted to these. In consideration of these and any other games for indoors in comparison with outdoor games it will be well for the teacher to remember the disadvantages of indoor games of any and all kinds and the fact that free and undirected (not uncontrolled, but spontaneous) play produces the best results both on mind and body. It is granted, as a matter of fact that it will be advantageous at times, if for no other reason than because of a lack of time to have indoor games. When these take the form of play the results are better for healtin, invigoration and schoolwork, than when they are mere exercises such as calisthenics and gymnastics. Besides, where there are even covered grounds for exercise it will be found necessary under some weather conditions to have whatever exercise is given pupils indoors under the proper conditions of protection from cold, rain and snow.

Of the strictly outdoor games none are more common than the various ball games. "America's National Sport," bascball, stands at the head of these, though the danger to other children running around the school grounds in their own individual forms of play, the size of the grounds, the danger to window lights in the school building and neighboring houses together with various risks and inconveniences make it hardly a practical game in most school playgrounds, especially in larger cities. Besides baseball there are other ball games that may be played in the open air. Among 
them and in the order of their popularity and numbers of individuals who indulge in them, are, football (which in some places is under the ban) basket ball, volley ball, hard ball, racket ball, cricket, captain ball, dodge ball, long ball, pass ball, school ball, bounce ball, association ball (a form of football which in some schools has replaced football), "Ante over," lay ball, cross ball and many others too numerous to mention. Next to ball games on the American playground are the tag games held as strictly such. Among these we have cross-tag, prisoner's base, king's land, chain tag, wood tag, poison tag, slıadow tag, robber's tag, wet and dry land tag, pom-pom-pullaway, blacktown, Chinese wall, forfeit tag and school tag.

Tag games are appropriate for school play because of the fact that they are very simple, offer a moderate amount of activity, and afford an opportunity for many to indulge in play at one time without any great inconvenience and selfrestraint. As a general thing, however, tag games cannot well be indulged in by both boys and girls unless they are small boys and girls. The older boys are generally too swift of foot and rough for girls and small boys. This argument though, loses some of its force, because with some consideration it might be raised against most of the outdoor games and many of the indoor games. Leap frog, foot-anda-half, jump-for-down, imitation, advancing statues, fox and geese, hawk and elickens, ducks on a rock, are good games quite similar to tag games, but which are restricted mostly to smaller groups, the first three being especially adapted to older boys while the others are more appropriate for the smaller boys or with mixed groups of both small boys and girls. Marbles such as line lagging, ring lagging, purgatory, bull's ring, eye dropping are other favorite quiet games with boys and some girls. The question of "playing for keeps" in the game of marbles has brought a moral phase into the playing of the game under the supervision of the school which has caused it to be forbidden in many instances. This method of playing being aetually gambling, a habit which the school can hardly afford to foster even if it be only in play. 
Racing games such as dashes, relays (single and combined), hurdles, obstacle-races, potato race, egg race, sackrace and wheelbarrow race are good sports which one could hardly with correctness call games. They are, however, where not overtaxing (a very prominent danger) a pleasure to all. Ordinarily, races generally are over distances of from forty to two hundred yards, though they may be over even longer distances. Where not too violent no game is more exhilarating than is racing and few, if any, lave the generally tonic effect on all muscles and internal organs that racing has upon them. These plays are mentioned only as a few of the many forms of play exercises known to the school. The fact is the games known and available for use in the schoolroom and on the school playground are so numerous as not even to allow one to even enumerate them all in a treatise of this kind. These that have been mentioned are presumed to be worthy of consideration because they are simple and require but little apparatus except perhaps such as each teacher or pupil can easily furnish for himself. The list given here could be and is intended only as an outline which may be extended or modified by the teacher to suit his local schoolroom and playground conditions. Since the agitation for physical education has spread and the subject of play has been studied in its relation to human health, happiness, schoolwork, good citizenship, strong manhood, general living and working efficiency and vagrancy and crime there have sprung up everywhere playground associations, schools which teach play and the management and manipulation of playground apparatus. Along with this school authorities have fitted out playgrounds where many new forms of play may be enjoyed. Some schools even have gymnasiums whereby the amount of varied playing is increased many times over.

Athletics. Athletics reduced almost to a formal system of play, games and contests have taken the place of directed and controlled play. Athletics as thus organized constitute the chief fault, if fault it may be called, of the American system of play. Athletics having in mind competitive contests look more to the training and skill of a chosen few 
rather than to the healthful play and training of the pupils as a whole. It produces a few magnificent specimens of physical manhood capable of great feats in power and endurance but neglects the masses of the pupils almost entirely. It also aims to pick those already advanced in skill and power and in the given games thus omitting another large portion of the school body. It has as a basis group rivalry in contradistinction to individual rivalry which play aims to develop. The group to be benefited by athletics may be one class or grade, but it is more often one school as pitted against another in a contest. Athletics undoubtedly bring out individual and school traits and good qualities that never could be realized otherwise. But it is a criticism upon it that since it neglects the masses for the favored few in its training and development it has in many cases assumed too important a role in the work of the school. Too often it has been forgotten that athletics constitute a means of education and that, too, a prominent secondary means, and is not in educational work an end in itself. Athletics has in most if not all of the larger institutions assumed enormous proportions. So much so that its good for education has at times been seriously called into question. The long training season, the training table, the special quarters and the expenditure of large sums of money for paraphernalia, equipment and grounds are some of the more dangerous sides of athletics at their worst. In addition they turn the ideals of life into a light frivolous channel and make play an end in life instead of a means to an end. Athletics are also patronized and followed by a wild and dissolute element of loafers and idlers who seek acquaintance and friendship with the players mostly for monetary advantages which oftentimes, however, leads to seducing the players and leading them off from the sober paths of living, into the unwholesome and corrupt paths. Still atlletics are not to be condemned or abandoned, but the rather freed from its bad practices. They satisfy from one viewpoint, it is justly claimed, the primitive instinct of combat and racial enmity in man and represent a refined tone of heroism and hero worship. It is also probable that the natural instinct in man to struggle 
for superiority and survival is prominent in the emotion that causes him to foster and encourage athletic contests. But whether this be true or not certain it is that the pleasure men take in athletics is deep seated if not fundamental in their natures. Equally certain is it that the present football game, for example, when at its worst was a gratifying substitute for the battles and fisticuffs resulting in loss of limb and often of life that used to result when rival factions of the same or rival schools met whether by previous arrangement or by accident. It will also not be denied that athletic contests, if kept on a high plane of honesty, fair play and chivalry, all of which can be accomplished under good management, will improve both the individual and the group, morally. Valuable lessons in the evils of lying and cheating may be had all through the game, while lessons in cooperation and self subordination are presented also throughout the game. It is up to the management at all times to insist upon everything connected with athletics being open and "on the square." Where confidence, good will and ability go hand in hand an athletic contest is a source of much joy, whether it be the desire for evidence of skill, strength or eren warfare, whose satisfaction creates the joy. Disposition to rebel, to use profane language, to be brutal, even to bet, all will appear here and must be mastered. But with all of the good that athletics may do both for the individual and the school, it must never be forgotten that they are secondary to the school and its work. The schoolwork comes first and athletics afterwards. No kind of schoolwork should be materially neglected for athleicics. Children soon become turned from the work of the school to the work of the playground of the school. For the school therefore to lend any considerable aid to this natural tendency inherent in all growing, moving things, would be dangerous to its welfare and ultimate success. Many an otherwise promising young man and boy has had his schoolwork and future life ruined by injudicious indulgence in athletic activity. Whoever may be concerned, no plea of school pride, or athletic enthusiasm should be allowed to come between the pupil and his schoolwork, even if he has to give up athletics entirely. Another 
pregnant evil in athletics is the partisan spirit it develops. While school pride and patriotism all have their value and place they should not be allowed to over-ride the nobler elements of the contesting spirit. No better rule can be laid down than the golden rule, "Do unto others as you would that they should do unto you." The desire to win should never crowd out of one the desire to be fair, honest and manly. Victory in a contest is worth much, but it is not everything nor is it worth everything. A mind that will consent to stoop to means unfair or foul in an athletic contest can with sufficient pressure be brought to consent to the same in other affairs of life. The onlooking crowd is oftentimes responsible for sucl an attitude in the players, but it is the duty of the management to rule out all such attempts at unfairness and cheating, even if it costs the forfeiture loss or even breaking up of the game. The management may not be able at all times to control the crowd that comes to see an athletic contest, nor perhaps even the presence of vicious and criminal elements in the crowd, but it can and should by every means possible show to all contestants that it believes in and will enforce high standards in its contests, vouchsafing honesty and fair play rigorously to home and visiting team alike.

While athletics are for the relatively few, they require more playground and equipment than the ordinary games that are played on the school grounds. To a great extent in our educational system athletics appear in the high school, colleges and universities as a successor to play in the public schools, while the athletic field takes the place of the playground. Just as most of the public schools have to more or less extent adequate playgrounds and where they are not provided at present are being constantly added to the building equipment, so the high schools, colleges and universities are mostly provided with an adequate athletic field and where such is not present they are being rapidly supplied. In the grades of the public schools, however, even though in many cases much prominence is given to athletics and athletic contests, especially in football, baseball and basket ball, grounds for these games are less often main- 
tained for the contests and places of preparation and of holding the contests are generally to be had only elsewhere than on the grounds. This is practically true in the case even of the larger towns and cities, where the ground space is high and the public mind has not been brought around to the point where it is willing to consent to the outlay of the funds necessary to furnish these grounds and equipment. Besides the question of money there are also many other potent reasons why the public school should not put itself in the position of fostering too strongly the athletic spirit. In the first place the mind of the young is too unstable and too much inclined by nature to fly off and remain off from the work of the school. And in the second place the public contest because of the high degree of impressibility of youth, would probably have more lasting effect upon them for evil. Aside from these athletics seem to be more for the classes than for the masses. They are inclined to be aristocratic while play is democratic. They require more equipment, more special training and more money to maintain them, reaching in their turn only the few with its benefits. From the viewpoint of the school they require a special training and a degree of skill that could hardly be demanded of the ordinary. Again they are mostly for boys and leave the girls out of their sphere of good almost entirely. 'Tis true that teachers must be taught to play games and should learn to play as many different games as possible so as to be able at all times to entertain their pupils and make and kcep them contented and happy, but for the opportunities of the public school and the purposes which plays and games are to serve, they should receive the preference over athletics, at least in the public schools. Teachers who are deficient in their knowledge of games may now extend their knowledge of them by all of the ordinary methods available for the extension of knowledge in other fields. School journals are now taking up the question of games for the schoolroom and the school playground and most normal schools and teachers' colleges offer special courses both in the regular session and the summer session in teaching, directing and supervising play in the school and on the playground. Of one or more 
of these sources most teachers so desiring can avail themselves. Nor should a teacher deficient in these lines belittle the effect of his deficiency upon the school and its work. "All work and no play makes Jack a dull boy" is an old but true saying. Nowhere is its effects seen more clearly than in the work of the school. How the energy curve rises gradually after the school has had a period of play in the open air was shown elsewhere. This speaks for itself, and any one suficiently interested can carry these experiments further and learn for himself the effects of play upon the health, vitality and working efficiency of a school. The school therefore owes it to itself to foster play and devote a reasonable amount of its time, energy and equipment to the developing of the spirit of play in the children, if for no other reason than that the work of the school itself can be carried on to better purpose and more permanent results by this method. Fostering of play then by the school is not only a duty, it is a necessity and is closely related to the maintenance and growth of the school and the success of its efforts.

\section{REFERENCE READING}

Taylor's "The Study of the Child." Chap. XIX. Harris" "Psychologic Foundations of Education." Chap. XXXV. Compayre's "Psyehology Applied to Education." Chap. II. Rosenlianz's "Philosophy of Education." Part I, Chap. III. Frocbel's "Fducation of Man." Pages $29,30,49,97$.

Froebel's "Educational Laws." Chap. V.

Blow's "Educational Issues in the Kindergarten." Chap. VI. 


\section{BIBLIOGRAPHY}

The works on Education are so numerous that it would be very difficult and also unnecessary to give more than a cursory list of references in a work of such limited scope as this. The aim has been to limit the references to the smaller texts, many of which almost any one of limited means and literary taste can afford to buy and have on the shelves of their private libraries. In the profession of teaching nothing is so essential as a wide awake well read person in literature especially fitted for and adapted to the profession. Too, the time when a teacher can hope for success when wholly dependent for his capability upon the art as learned by the methods used by his teachers and unscientifically applied by himself is long past. The only hope that promises the least bit of a chance for successs to-day is that learned professionally in training supplemented by extensive reading of professional literature both practical and theoretical and applied by experiment to the everyday conditions of the schoolroom. It is with this view in mind that a bibliography of this kind is presented and it is most sincerely hoped that those who consult the works eited will find in it some literature that will throw helpful light upon the problems which confront them daily in handling their classes, in their efforts to do effective work, in unfolding truth, imparting facts of knowledge and forming habits which will form a character in the citizenship and give a skill in the use of the instruments of civilization, that will guarantee to the state and society industry, thrift and economy on the part of their product, thus enabling each to contribute his share to world peace and contentment.

Hinsdale's " Art of Study."

Smith's "Systematic Methodology."

Gordy's "A Broader Elementary Education."

Münsterberg's "Psychology and Life." 
'Tucker's "Education."

Griggs' "Moral Education."

Rorve's "Physical Nature of the Child."

Beard's "Education."

Henderson's "Education and the Larger Life."

Wagner"s "The Simple Life."

Brigg"s "School, College and Character."

Dalton's "Social Phases in Education."

Eliot's " Edueational Reform."

Roark's "Liconomy in Education."

Taylor's "Class Management and Diseipline."

O'Shea's "Dynamic Factors in Education."

Thorndike's "Principles of Teaching."

Angell's "Psychology."

James' "Psychology."

James" "Talks to Teachers."

Snedden's "Educational Readjustment."

Gillette"s "Vocational Education."

Power's "Educational Meaning of Manual Arts and Industry."

Snedden's "Problems of Vocational Education."

James' "The Will to Believe."

Hall's "The Content of a Child's Mind on Entering School."

Dewey's "The School and the Child."

Findlay's "The Principles of Class Teaching."

Gould's "The Children's Book of Moral Lessons."

O'Shea's "Education as Adjustment."

Sedgwick's “On Stimulus."

Winch's "Notes on German Schools."

Foote's “Weariness." Nineteenth Century, Sept., 1893.

MacDougali, R., "Fatigue." Psychological Review, 1899.

MacDougall, W., “Fatigue." British Association Reports, 1908.

Winch's "Psychology and Philosophy of Play."

Monroe's "History of Education."

Allport's "Tests for Defective Vision in School Children." Educational Review, 1897, New York.

Barn's "The Arid Atmosphere of Our Homes in Winter."

Belling"s "Ventilation and Heating."

Brigg's "Modern School Building."

Carpenter's "The Heating and Ventilating of Buildings."

Duke's "Health at School Considered in Its Mental, Moral and Physical Aspects."

Fritz's "Play as a Factor in Development."

Lukens' "The School Fatigue Question in Germany."

Mosher's "The Habitual Postures of School Children." Educational Revieu", 1897, New York.

Sumner's "Folkways."

Taylor's "The Problems of Conduct."

Thomas" "Relation of Sex to Primitive Social Control in Sex and Society."

Kidd's "Savage Childhood."

Palmer's "The Nature of Goodness (Punishment) Child Attitude."

Fichte's "The Science of Rights."

Sumner's "What Social Classes Owe to Each Other. What Shall the Public Schools Teach?" Vol. V. 
Kern's "Among Country Schools."

Scott's "Social Education."

Shaw's "School Hygiene."

Porter"s "The Physical Basis of Precocity and Dullness." Acad. of Sci., St. Louis, 1893.

Sanford's "Relative Legibility of the Small Letters of the Alphabet." American Journal of Psy., Vol. I, No. 3, 1888.

Scudder. In School Document. No. 9, 1892, Boston, Mass. "I Lateral Curvature of the Spine as Caused by the Seating of School Children."

Adler's "Moral Instruction of Children."

Compayre's "Intellectual and Moral Development of the Child."

Malleson's "Early Training of Children."

Payne's "Contributions to the Science of Education."

Spencer's "Education."

Bain's "Education as a Science (Punishment)."

Stanley Hall's "Youth."

Stanley Hall's "Adolescence."

Fichte's "Teaching."

Edgeworth's "Practical Education."

Wilke's "The Place of the Story in Early Education."

Judd's "Studies of Childhood."

Fitch's "Iectures on Teaching." Chaps. V, VI, "questioning in teaching."

Adam's "Primer on Teaching." Chap. VII, "questioning in teaching." Compayre's "Psychology Applied to Education."

Keating's "Suggestions in Education."

Martineau's "Household Education."

Locke's "Thoughts on Education" (Punishment).

Groos' "The Play of Animals."

Groos" "The Play of Man."

Bryant's "Educational Ends" (obstinacy and self will) 21 .

McCunn's "The Making of Character."

Gugan, "Education and Heredity (habit)."

Compayre's "Pioneers of Education." Chap. V, Spencer (natural punishment).

Minsterberg's "Psychology and the Teacher" (Punishment). Chap. XI.

Sully's “ Teachers' Handhooks of Psychology."

Huxley's "Science and Education."

Rosenikranz's "Philosophy of Education."

Reins' "Outlines of Pedagogics."

Herbart's "Introduction to the General Principles of the Science of Education."

Sully's "Outlines of Psychology."

Hill's "Elements of Psychology."

Preyer's "Infant Mind."

Lange's "Apperception."

Wiltsie's "Place of the Story in Early Education."

Howland's "Practical Hints to Teachers."

Prince's "Methods in German Schools."

Arnold's "Way Marks for Teachers."

Janet's "Elements of Morals."

Robinson's "Principles and Practices of Morality." 
Hyde's "Practical Ethics."

Adler's " Moral Instruction of Children."

Ped. Sem. Vol. I, "Moral Education and Will Training."

Preyer's "The Senses and the Will."

King's "Personal and Ideal Elements in Education."

King's "Psychology of Child Development."

Harris' "Psychologic Foundations of Education."

Thompson's "Brain and Personality."

Randeubusch's "Christianity and the Social Crisis."

Randenbusch"s "Christianizing the Social Order."

Hall's "Social Meaning of Modern Religious Movements."

McFarland's "Spiritual Culture and Social Service."

Gill and Pinchot's "The Country Church."

Carlton's "The Industrial Situation."

Wells' "A Social Survey for Rural Communities."

Ward's "The Social Creed of the Churches."

Ethical and Religions Significance of the State (Dealey in 1912).

Publication of the Baptist Department of Social Service and Brotherhood.

Patten's "The Social Basis of Religion."

'Taylor's "Religion in Social Action."

Ellwood's "Sociology in its Psychological Aspects."

King's "Education for Efficiency."

Drummond's "Introduction to Child Study."

'Tompkins' "The Philosophy of School Management."

Le Bonn's "The Crowd."

Butler"s "The Meaning of Education."

Kirkpatrick's "The Fundamentals of Child Study."

Adamson's "The Practice of Instruction."

Allen's "The Origin and Function of Habits in Certain Aspects of Educational Progress." Publication by Department of Psy. and Ed. University of Colorado. 


\section{INDEX}

Adjustment, 30-36.

1. Capacity for, 30.

2. Civil, 36.

3. Dangers of, 35 .

4. Economic, 35.

5. Mental, 31.

6. Moral, 33.

7. Physical, 31.

8. Religious, 34 .

9. Social, 36.

Air, humidity of, in schoolroom, 117.

motion of, 115.

America, courses of study in, 257 . national ideals of, 53 .

American civilization, 356.

American system, demands of, 167.

American education, results in, 17.

Approbation, desire for, 155.

Aristotle, 17. courses of study of, 252 .

laws of association by, 339 .

Arrangements of subjects, 268 .

Art in education, 20 .

Athletics, 61. moral value of, 385 .

Attention, kinds of, 325.

Average pupil, 307.

Bad boy, the, 153.

Bain, on education, 290.

Bryan, definition of education by, 14.

Calisthenics, 61, 62.

Chadwick, 269.

Chautauquas, 98.

Cheating and copying, 308.

Child energy, 281.

Children, motive in, 142.

Chinese education, 54 .

Chinese, national ideals, 54 .

Christian associations, 75,76 .

Criminal tendencies in school, 34.

Church attendance, reasons for, 94 .

Church education, 50, 89.
Class education, 53.

Coal stoves, heating by, 118 .

Commendation, the giving of, 214 .

Community meetings, 124 .

Confucius, 40.

Contagious diseases, 121.

Courses of study, purpose of, 248 . justification of, 250 .

historical development of, 251. and the daily program, 264 . value of, 259 .

Courtesy, professional, lack of, 235 .

Cultural education, 79 .

Daily program, aim of, 260 . difficulty of, 270 .

Demands in American education, 16.

Demands for physical education, 63.

Desks, 111.

Deoxidation in pupils, 131.

Disease, bacteria, 102. contagious, 146.

Discipline and government, 149.

Dismissal of students, 226 .

Dogmatic education, separation of, 92 .

Duty of parents, 83 .

Education, aim of, 20, 39, 41, 42 . as an art, 19.

by contact, 52 .

broad and narrow, 14.

definition of, 13, 14 .

limit of, 48 .

U. S. Commissioner of, 126.

Education and environment, 15.

Education and history, 26, 27.

Education and pedagogy, 26 .

Education and psychology, 25 .

Education, psychological aspect of, 24 .

physiological aspect of, 24 .

Educational opportunity, sources of, 49 . 
Educational spirit, method of arousing, 242.

Ego and alter, the, 210.

England, national ideals of, 53.

Esthetic education, aim of, 71 .

Esthetic education, opportunity for, 72 .

Exercises, opening, value of, 225 .

Facts, questions for, 290 .

Factors of education, 81.

Fatigue agents, 265 .

Fire drills, 109.

Fiske, L. R., 289.

Fitch, J. F., 279.

Form and content subjects, 265.

France, national ideals of, 54 .

Franchise, elective, use of, 362 .

Games, Indoor, 381. outdoor, 381.

German, courses of study in, 256 . national ideals, 53.

Gilbert, definition of education, by, 13.

Giving of marks, dissatisfaction from, 213 .

Government and discipline, 149.

Glass surface for lighting, 119.

Gymnastics for girls, 64, 65 .

Gymnastics, value of in school, 59, 60,62 .

Gulick, on play, 371.

Haberle, punishments by, 175, 187.

Habits, kinds of, 349, 345 .

Hamilton, definition of education by, 13.

Hauser on education, 40.

Heart training, 273.

Helvetius on education, 40.

Henry, George, on education, 40.

Herbart on education, 254,257 .

Heredity, 192.

Hensinger desk, the, 113.

Hobbes, laws of association by, 339.

Home education, 83.

Home visiting, value of, 239 .

Honor, love of, 221. standards of, 219, 220 .

Hume, laws of association by, 339 .

Illiteracy, 77.
Imagination, kinds of, 323. stimuli for, 338 . subjects appropriate for, 338 .

Imitation, stage of, 88.

Immunities, the granting of, 207 .

Individual limitations of, 48, 49.

Industrial schools, 65 .

Inertia of mind, 43.

Intellectual education, 55 .

Interest, kinds of, 323.

Instruction, definition of, 23.

James, William, definition of education by, 13 .

on education, $336,345,347$.

Jews, national ideals of, 54 .

Johnson, Governor John A., on play, 371.

Kasper, on education, 40.

Keeping of grades, value of, 288 . objection to, 230 .

Kerr, definition of education by, 13.

Knowledge, desire for, 217 . sources of, 17.

Kotelman, on education, 144 .

Laboulaye, definition of education by, 13.

Lamarck, law of use, by, 64, 367 .

Lesson, assignment of, 279.

Light, direction of, 119 .

Locke, John, on education, 38.

Luther, courses of study by, 252 . doctrine of education, 35 .

Luxfer prism, lighting by, 119 .

Manual training, 66.

Massachusetts, laws of, 114 .

McMurray, Prof. Frank, on education, 289.

Mechanism in schoolroom, 133.

Memory, device of, 335 . kinds of, 333.

methods for testing, 334 .

laws of, 335 .

loss of, 331.

Methods in education, 21, 24.

Middle Ages, papal supremacy in, 350.

Mills, James, definition of education, by, 13. 
Mills, J. S., definition of education by, 13.

Milton, Joln, on education, 253.

Mind and body, 25 .

Monitors, selection of, $13 \%$.

Monitorships, rights to, 206.

Moral education, need of, 69, 70.

Moral education, 55 .

National Education Association, work of, 126.

Neighborhood meetings, value of, 244.

Page, D. P., on education, 279.

Patriotism, definition of, 362 .

Pedagogy, definition of, 26 .

Periods, length of, 269.

Physical education, 58.

Physiological education, 56.

Play, supervision of, 375 .

Playgrounds, purpose, 379.

Playing games, kinds of, 380 .

Playing room, 105.

Plato, definition of education by, 13. on education, 17.

Politeness, 359.

Practical education, 78.

Prejudice, 46.

Primitive man, 352.

Professional organization, 238.

Professional training, 277.

Psychology, aim of, 25. knowledge of, essential, 26. physiological, 57.

Prizes, the giving of, 203.

Punishments, definition of, 187. justification, 157, 183. methods of inflicting, 174 . purpose of, 177 . value of, 183.

Rauber, on education, 40 .

Recess, time and value of, 262, 14.5 .

Recitation, accessories of, 313. aims of, 312. steps of, 315 . questions of, 296 .

Reciprocal cooperation, 85, 91 .

Religious education, aim of, 73 .

Relative fatigue value of subjects, 267.
Repetition in education, 17.

Restricted mind and body, 43.

Reviews, justification of, 310 .

Rewards, purpose of, 201 .

Riis, Jacob, on play, 369 .

Room, temperature of, 116 .

Rosenkranz, definition of education by, 178.

Rousseau, theory of punishments by, 178 .

Routine duties, 223 .

Ruediger, definition of education by, 13.

Science in education, 20 .

School aims, 87.

School buildings, 107.

School day, length of, 261.

School grounds, 102.

School hour, length of, 261.

School year, length of, 260 .

Scolding, 189.

Scope of work, 90 .

Scudder, definition of education by, 13 .

Seating, reasons for, 139.

Seifey on patriotism, 365 .

Self-activity, inhibition of, 134.

Self-esteem, 210.

Sex association in school, 355 .

Simon, definition of education by, 13.

Smith, Adam, on education, 40.

Social education, 98.

Social evolution, historical evidence of, 92 .

Socrates on education, $2 \pi 9$.

on method, 227, 299.

Special development, 60 .

Spencer, Herbert, courses of study by, 254, 257 .

theory of punishments by, 178 .

State education, 50, 52, 96, 97

Sturm, on education, 253.

Successful education, 22.

Sun as a disinfectant, 107.

Sunday schools, attendance on, 356.

Superstition, 45.

Supervision, aids to, 130 .

Sympathy, 142.

Teacher, preparation of, 272. appointment of, 164 . 
Teacher, unpreparedness of, 163. Unruly pupil, the, 140. value to community, 24.5 . vocabularies of, 283.

Teaching, definition of, 23.

Terms, use of, 22 .

Theory and practise in education, 17 .

Time and energy, conservation of, 126.

Thought, question for, 290, 298.

Toilets, problem of, 123.

Tradition, 44.

Training, definition of, 23.

Vocational education, $67,68$.

Ward, Leslie, on education, 38, 41. Whewell, definition of education by, 13.

Woodward, definition of education by, 13.

Xavier, Father, on education, 40. 
. 




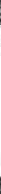

(4)

H.

(1)

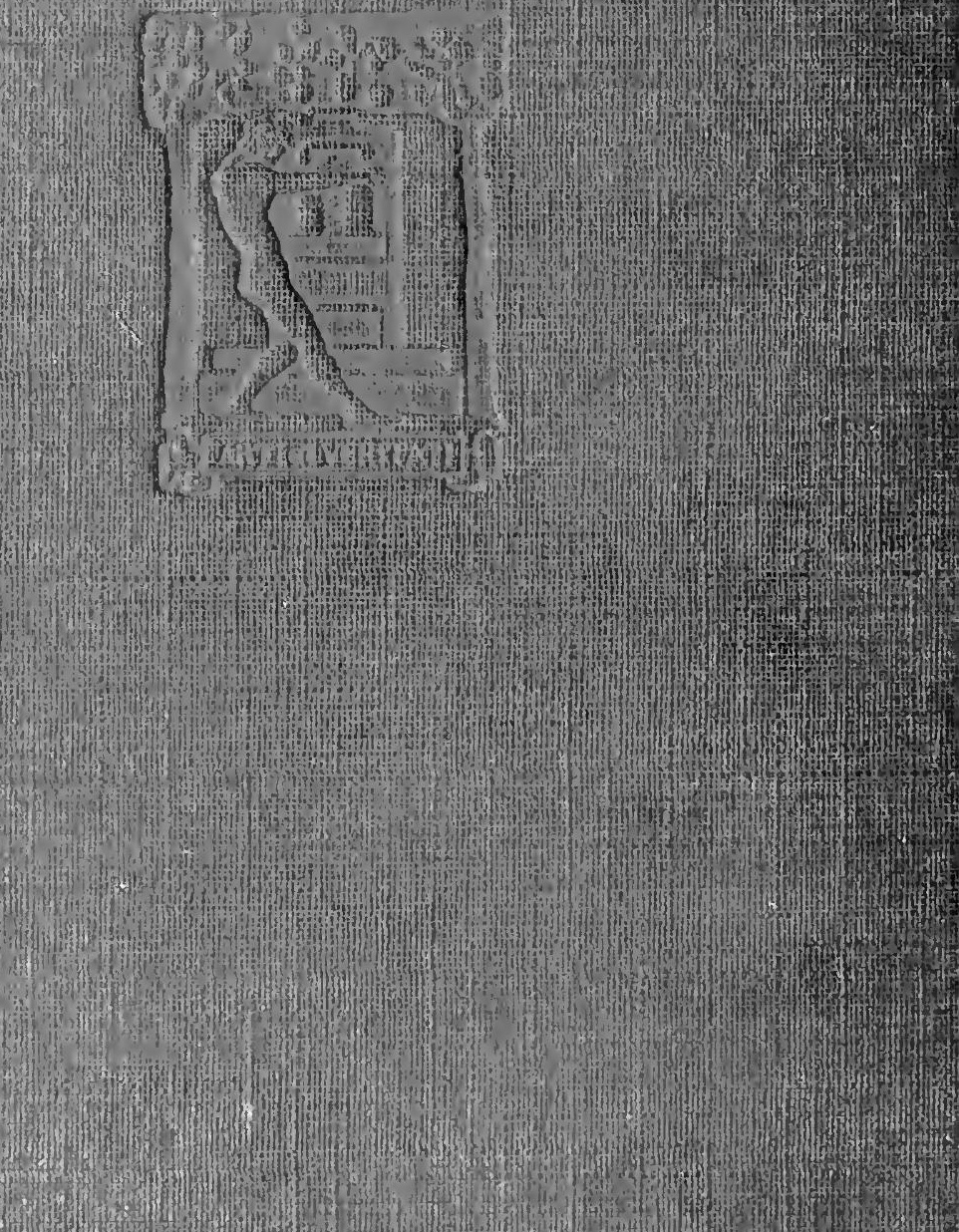

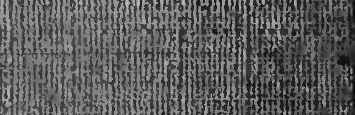

